\title{
Effect of Pre-treatment using Ultrasound and Hydrogen Peroxide on Digestion of Waste Activated Sludge in an Anaerobic Membrane Bioreactor
}

\author{
by \\ Priyanka Dilip Joshi
}

\author{
A thesis \\ presented to the University of Waterloo \\ in fulfillment of the \\ thesis requirement for the degree of \\ Master of Applied Science \\ in \\ Civil Engineering
}

Waterloo, Ontario, Canada, 2014

(C) Priyanka Dilip Joshi 2014 


\section{Author's Declaration}

I hereby declare that I am the sole author of this thesis. This is a true copy of the thesis, including any required final revisions, as accepted by my examiners. I understand that my thesis may be made electronically available to the public. 


\begin{abstract}
The rate of anaerobic digestion (AD) often depends on the rate-limiting hydrolysis step that makes organics available to microorganisms. To achieve efficient conversion of particulates to soluble materials and finally methane, the biomass in the digester must be provided with optimal operational conditions that will allow for biomass retention and substrate metabolism. Two approaches were employed in this study to improve the ultimate biodegradability of waste activated sludge (WAS) - Pre-treatment (PT) and operation using an Anaerobic Membrane Bioreactor (AnMBR).
\end{abstract}

PT of WAS is one way of speeding up hydrolysis. It has been proposed that PT leads to the lysis of cells, which in turn causes the release and solubilisation, and thus availability of intracellular matter to microorganisms for microbial growth and metabolic activities. This study compared the effect of thermal, sonication, and sonication + hydrogen peroxide PT on chemical oxygen demand (COD) solubilisation of WAS. Based on the soluble COD (SCOD) release, it was concluded that combined chemi-sonic treatment resulted in better WAS degradation rather than individual ultrasonic pre-treatment and thermal PT. The highest solubilisation rate was observed at a chemi-sonic PT of $50 \mathrm{gH}_{2} \mathrm{O}_{2} / \mathrm{kgTS}$ and sonication duration of 60 minutes. At this PT, a COD solubilisation of $40 \%$ was observed which was significantly different than PT involving only sonication and no pre-treatment $(0.88 \%)$ at $95 \%$ confidence. Therefore a peroxide-sonic PT was chosen to treat WAS in this study as it was expected to result in the greatest improvement in WAS biodegradability.

In addition to PT, biodegradability of WAS can also be improved by coupling PT with an AnMBR. AnMBRs prevent biomass washout by decoupling the solids retention time (SRT) from the hydraulic retention time (HRT). Thus, a long SRT can be used to provide sufficient duration for biological activities without increasing the volume of the reactor. In this study, a $4.5 \mathrm{~L}$ AnMBR with an HRT and SRT of 3 and 20 days, respectively was used to treat raw and PT WAS. In order to compare the biodegradability of PT and raw WAS, the AnMBR was operated in three phases. Phase 1 was operated with raw WAS, Phase 2 was operated with WAS pretreated with $50 \mathrm{gH}_{2} \mathrm{O}_{2} / \mathrm{kgTS}$ and 20 minutes ultrasound (US), and Phase 3 was operated with WAS pre-treated with $50 \mathrm{gH}_{2} \mathrm{O}_{2} / \mathrm{kgTS}$ and 60 minutes US. The anaerobic biodegradability of WAS following a combination of ultrasonic pre-treatment and $\mathrm{H}_{2} \mathrm{O}_{2}$ addition was significantly improved, with Phase 3 resulting in the greatest improvement. The COD destruction for phases 1,2 , and 3 were $49 \%, 58 \%$, and $63 \%$, respectively whereas the volatile suspended solids (VSS) destruction for phases 1, 2, and 3 were 46\%, 71\%, and 77\% respectively. Organic Nitrogen (Org$\mathrm{N}$ ) destruction increased from $44 \%$ to $52 \%$ for phases 1 and 2 respectively. A further increase of $18 \%$ in Org-N destruction was observed in phase 3. This improvement in biodegradability of WAS was attributed to the high solubilisations of COD, VSS, and ON and conversion of nonbiodegradable materials to biodegradable fractions.

In order to determine the effect of PT of WAS on membrane performance, the transmembrane pressure (TMP) and fouling rate were monitored throughout the operation of the AnMBR. Negligible variation in membrane performance was observed over all three phases. At a constant low flux of 2.75 litres $/ \mathrm{m}^{2} /$ hour (LMH), the TMP and the fouling rate remained low over the course of operation. In order to maintain the performance of the membrane, maintenance cleaning with $50 \mathrm{ml}$ of $2 \mathrm{~g} / \mathrm{L}$ critic acid solution followed by $50 \mathrm{ml}$ of $0.2 \mathrm{~g} / \mathrm{L}$ 
sodium hypochlorite was performed three times a week. In addition, a gas sparing rate of 2 $\mathrm{L} /$ minute and a permeation cycle of 10 minutes with 8 minutes of operation followed by 2 minutes of relaxation was employed. During phase 2 of this study, a new membrane was installed due to a faulty gas sparging pump. A slight decrease of TMP was observed with the installation of the new membrane; however the decrease was minimal. In addition critical flux for phases 2 and 3 were determined to be in the range of 6 to $12 \mathrm{LMH}$.

In conclusion, the incorporation of $\mathrm{H}_{2} \mathrm{O}_{2}$-US PT with AD could allow treatment plants to substantially reduce the mass flow of solids and organics and thus result in a decrease in requirements for downstream sludge processing. With sufficient maintenance, steady operation could be achieved for a hollow fibre AnMBR with a total solids concentration range of 20-25 $\mathrm{g} / \mathrm{L}$, an HRT of 3 days, and an SRT of 20 days. It was found that PT could be successfully integrated with AnMBR to substantially reduce the HRT required for digestion when compared to conventional designs. 


\section{Acknowledgements}

Many people have played a role in supporting and guiding me through this degree.

Firstly, I would like to thank Dr. Wayne Parker for his guidance and expertise, without which I wouldn't have been able to complete this degree. I am extremely grateful to him for taking the time out of his busy schedule, meeting with me every time I needed his help, and promptly replying to all my e-mails. I consider myself very lucky to have worked with such a knowledgeable and respectable person.

I am also grateful to GE Wastewater for supplying equipment for this study and to Martha Dagnew and Kyle Walder at the Wastewater Technology Centre (WTC) for being patient with me and answering my questions while I was acquainting myself with all the equipment and processes.

I would also like to extend my gratefulness and thanks to my fellow lab mates Mohammed Galib, Hyeongu Yu, Yaohuan Gao, Hou Yu, and Qiaosi Deng for sharing the lab space and equipment with me and assisting me in lab work. I am also thankful to Mark Merlau, Mark Sobon, Tom Sullivan and Terry Ridgeway for their assistance in trips to the WWTP and WTC and troubleshooting lab equipment. I am appreciative of Gillian Staples Burger and Peiman Kianmehr for replying to my e-mails promptly and answering my questions on lab equipment and procedures.

Last but not least, I am deeply grateful to my family and friends for their support and love. Their words of encouragement kept me going through tough times and my study. 


\section{Table of Contents}

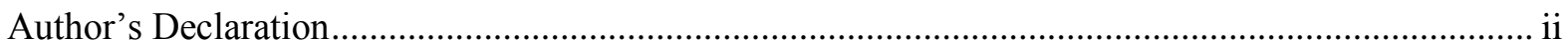

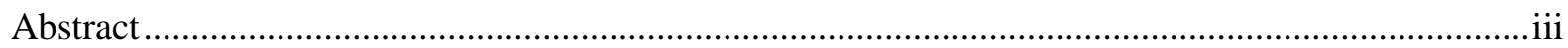

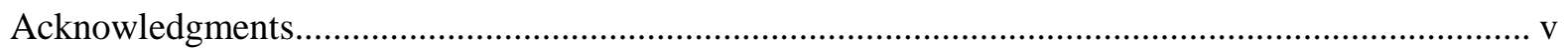

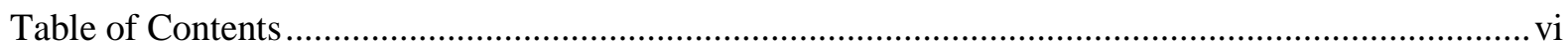

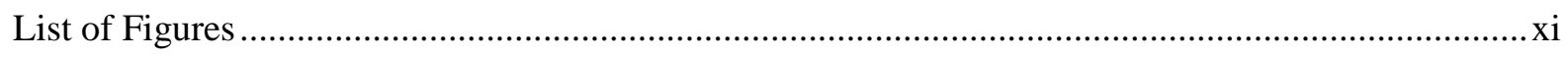

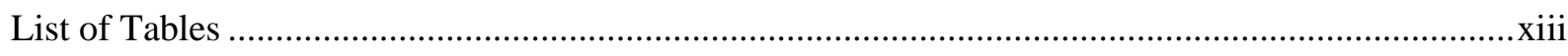

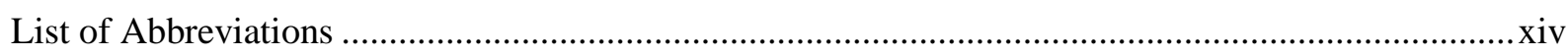

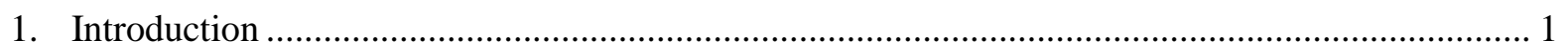

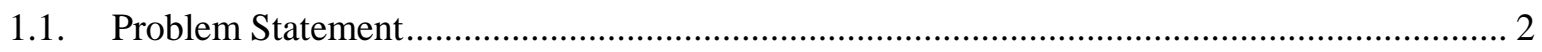

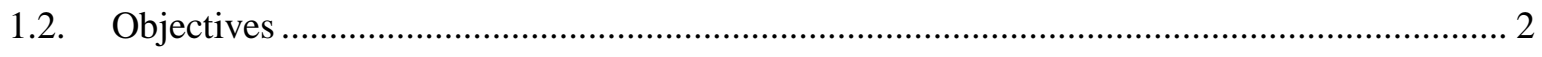

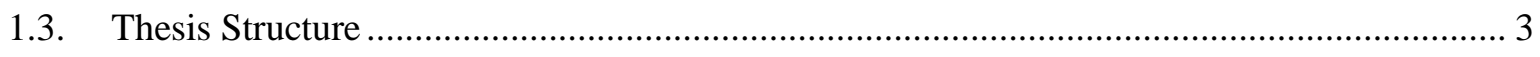

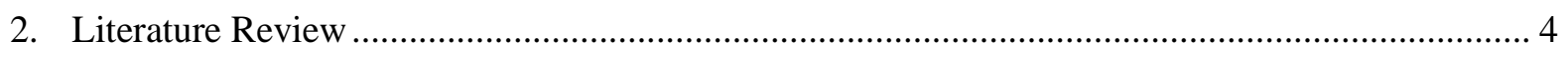

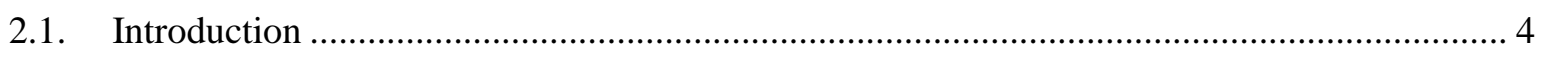

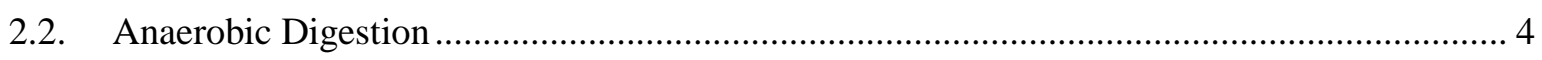

2.3. Anaerobic Biological Treatment Process .................................................................... 5

2.4. Anaerobic Membrane Bioreactor .................................................................................... 7

2.5. Anaerobic Digestion of High Solids Waste using AnMBRs ............................................. 7

2.6. Membrane Performance of AnMBR systems treating High Solids Waste ........................... 12

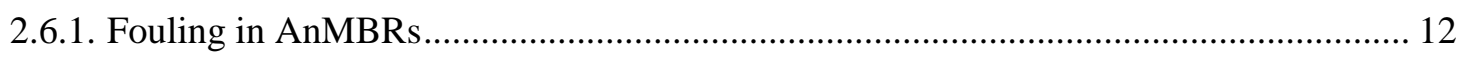

2.6.2. Conceptual Model of Fouling Mechanisms ........................................................... 12

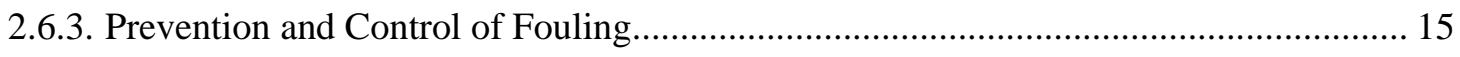

2.6.4. Studies on Membrane Performance of AnMBR systems treating High Solids Waste .. 16 


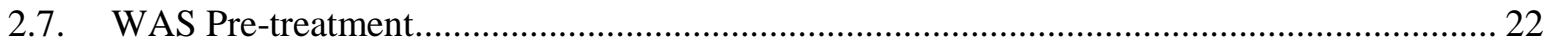

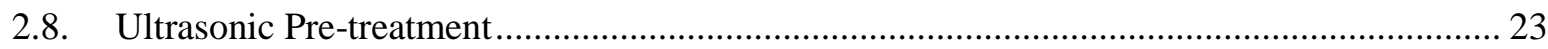

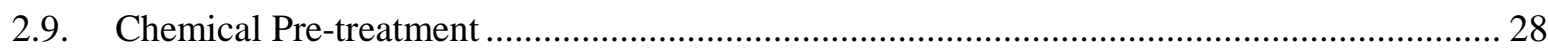

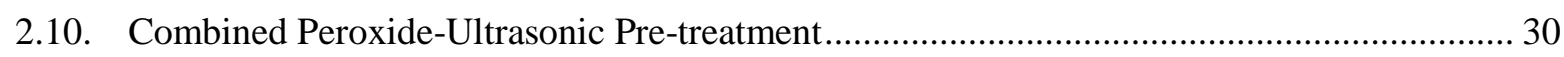

2.11. Integration of Pre-treatment and AnMBRs.................................................................. 32

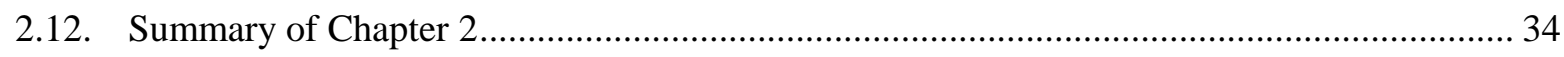

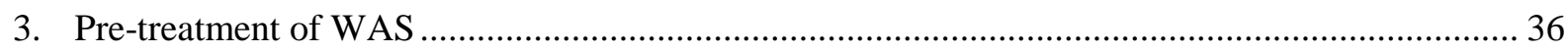

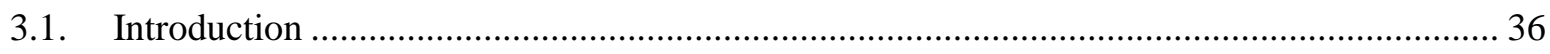

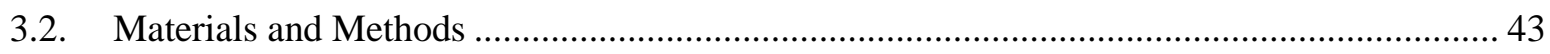

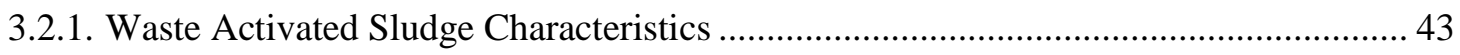

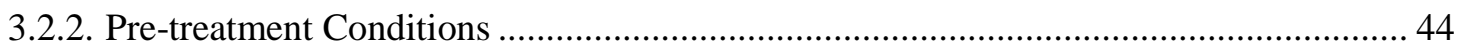

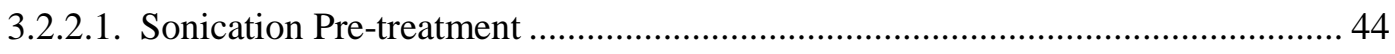

3.2.2.2. Pre-treatment using Hydrogen Peroxide/Ultrasound ....................................... 45

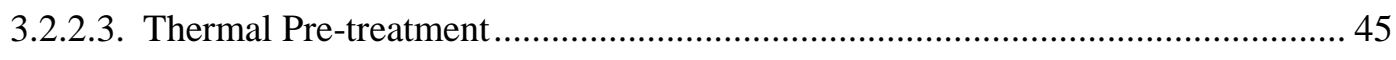

3.2.3. Anaerobic Membrane Bioreactor Digestion Operations ........................................... 47

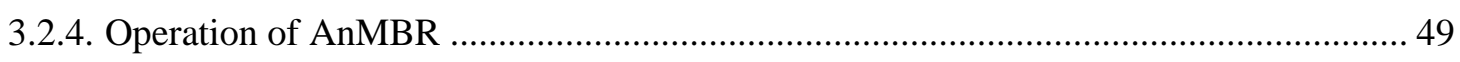

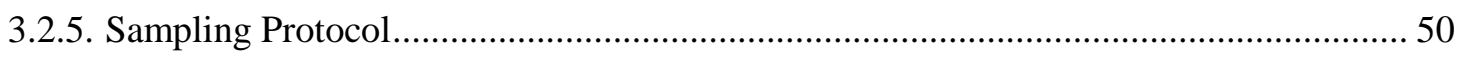

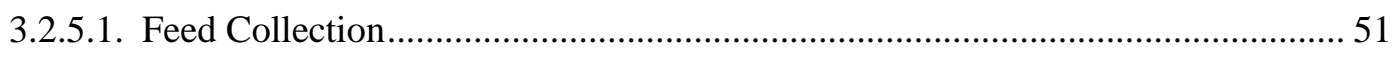

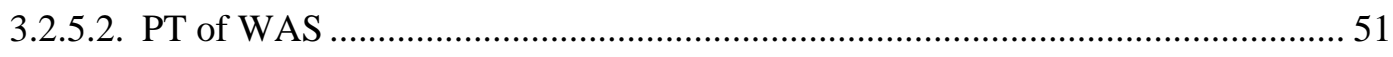

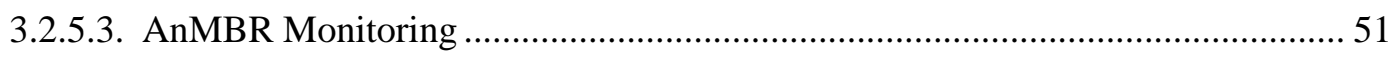

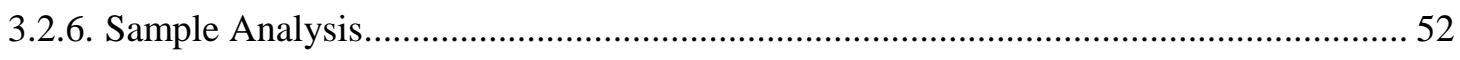

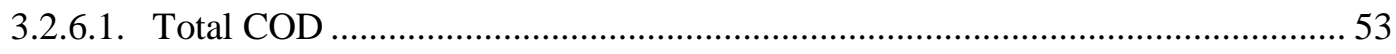

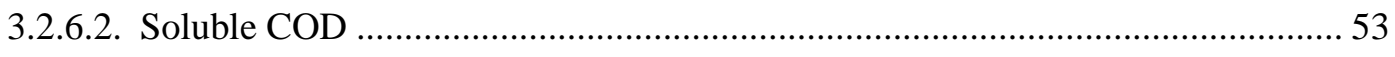

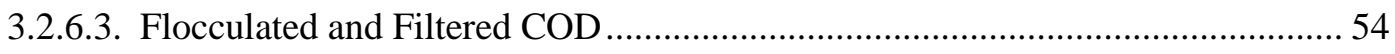

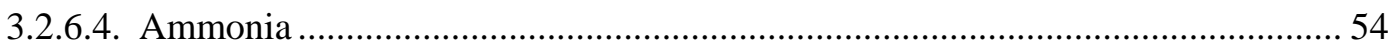

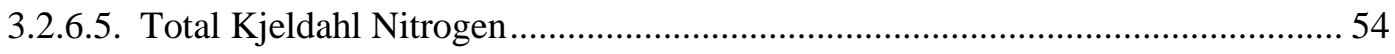




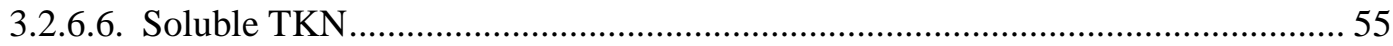

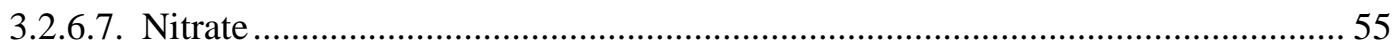

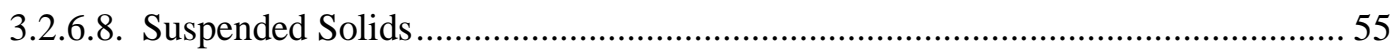

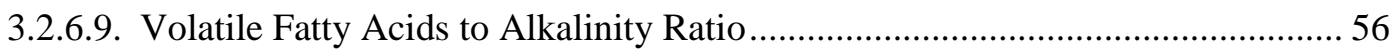

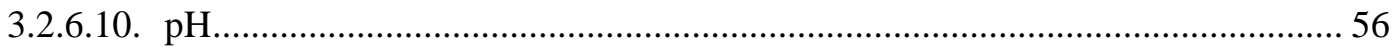

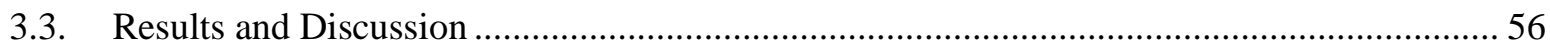

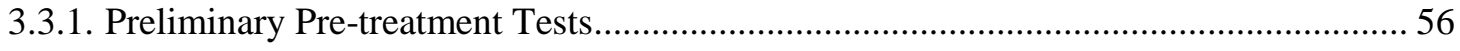

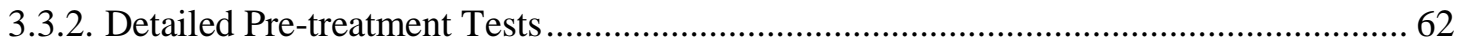

3.3.2.1. Impact of Peroxide-Sonic PT on Physio-chemical Characteristics of WAS ....... 62

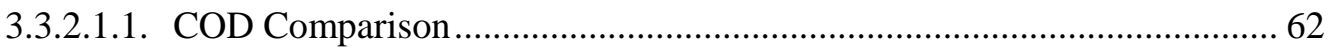

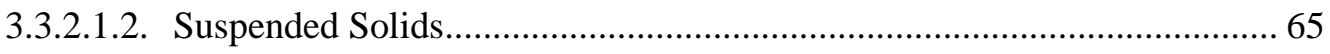

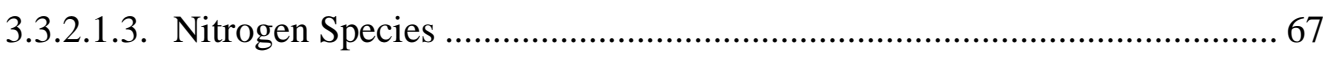

3.3.3. Anaerobic Membrane Bioreactor Operation ............................................................ 71

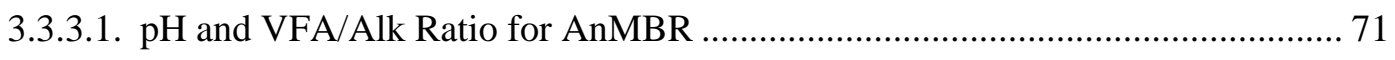

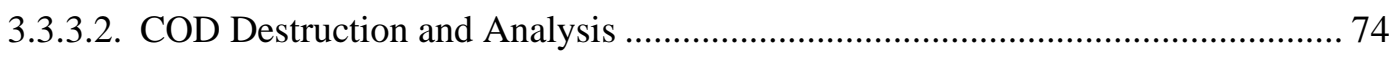

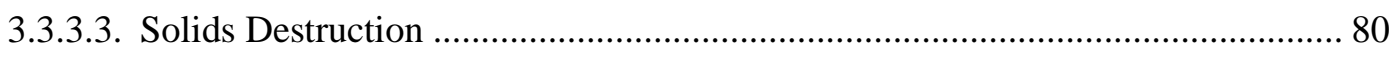

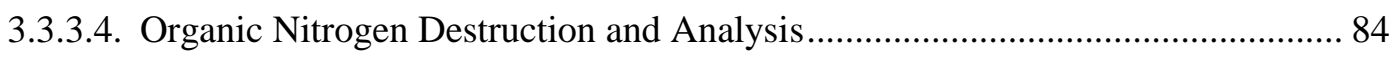

3.3.3.5. COD Decay Tests - Estimation of Biodegradable COD .................................. 91

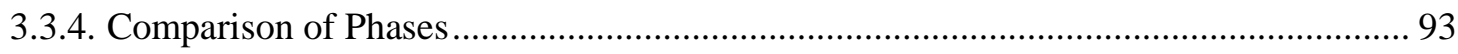

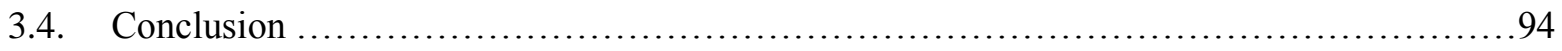

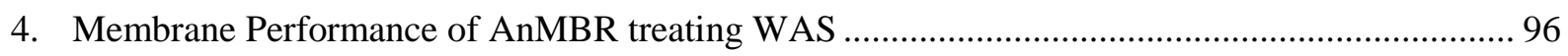

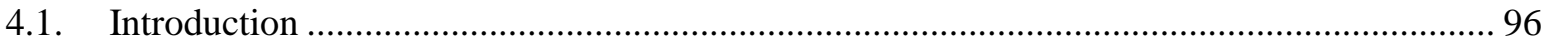

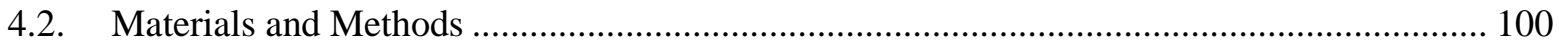

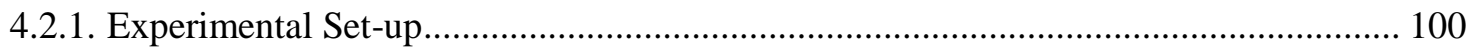

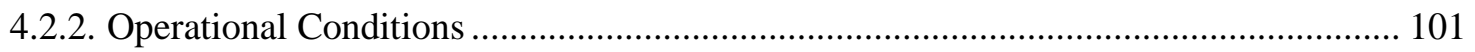

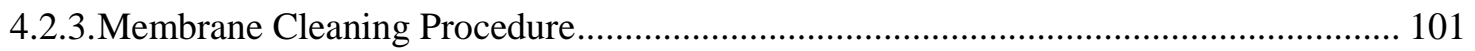




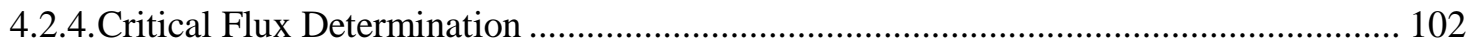

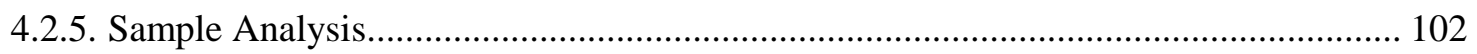

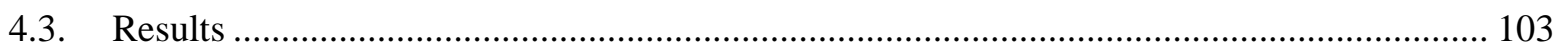

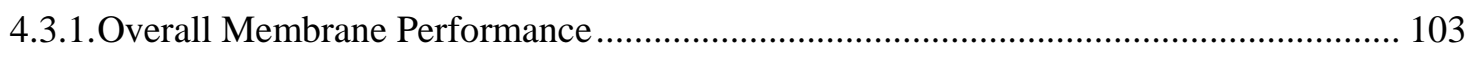

4.3.2. Impact of Solids Fractions on Membrane Performance ............................................ 107

4.3.3. Impact of COD Fractions on Membrane Performance ............................................. 108

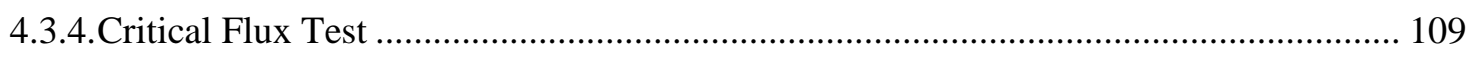

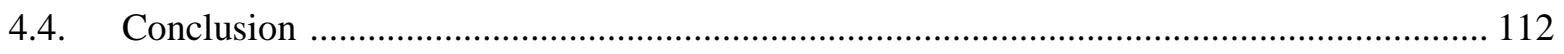

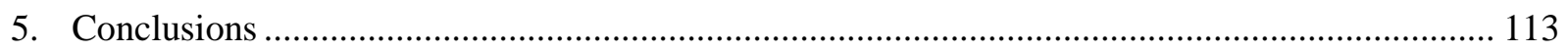

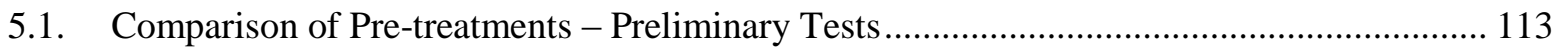

5.2. Comparison of the 20 and 60 minutes US AOP - Detailed Tests ..................................... 114

5.2.1. Physico-chemical Comparison of the 20 and 60 minutes US AOP ........................... 114

5.2.2. Biodegradability Comparison of the 20 and 60 minutes US AOP ............................. 115

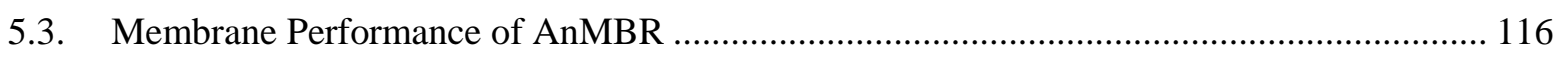

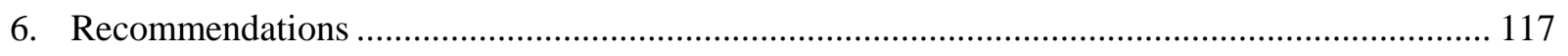

6.1. Pre-treatment and AnMBR Biodegradation Operations ................................................ 117

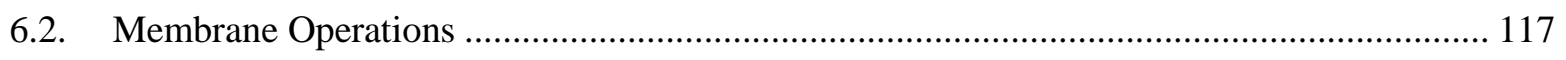

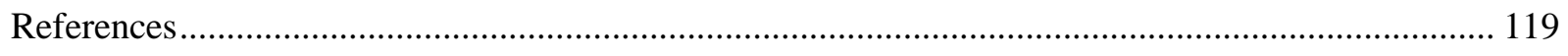

Appendix A: Physio-Chemical, Biodegradation and Membrane Operations Data............................ 133

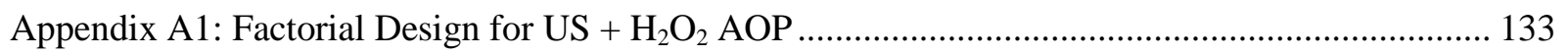

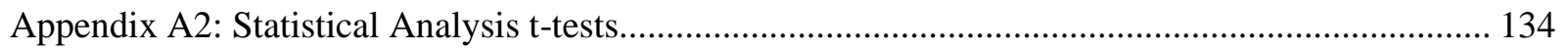

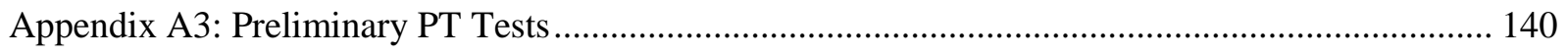

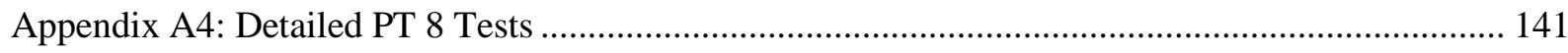

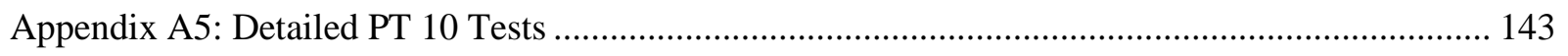

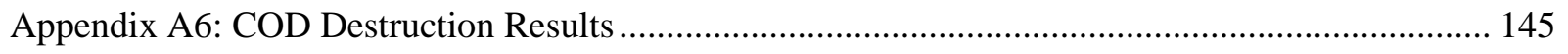

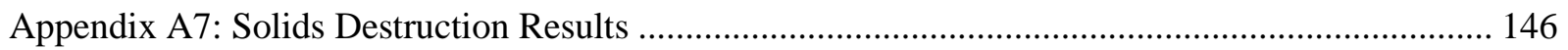




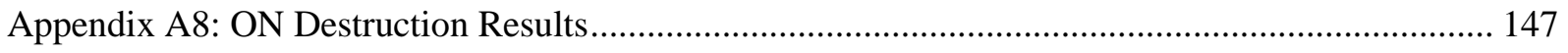

Appendix A9: COD Decay Tests for Phase 2 and Phase 3 .......................................................... 148

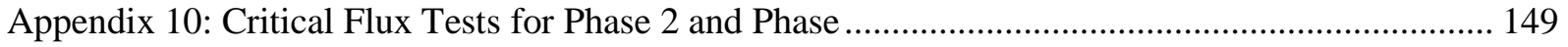




\section{List of Figures}

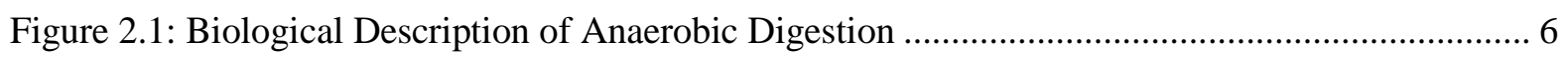

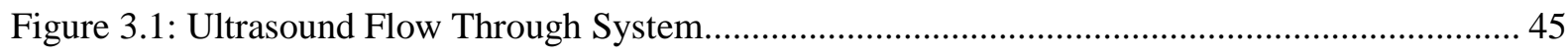

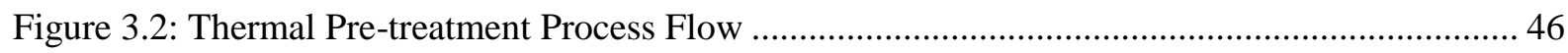

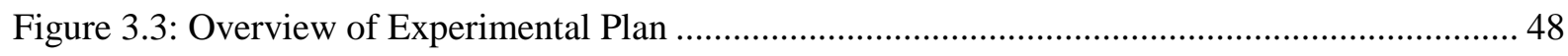

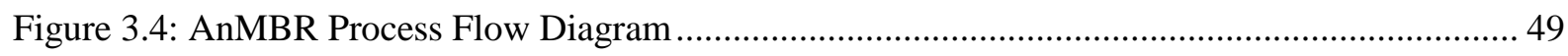

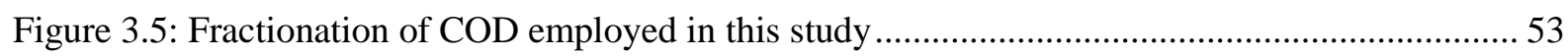

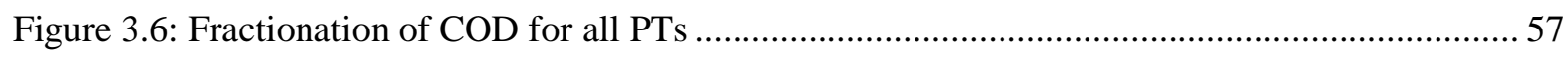

Figure 3.7: Average COD Concentration in Raw and Pre-treated Samples ..................................... 63

Figure 3.8: Suspended Solids Concentration for Detailed AOP Testing ........................................... 66

Figure 3.9: Nitrogen Species Concentration in Raw and Pre-treated WAS...................................... 67

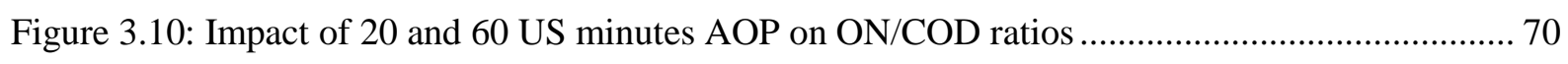

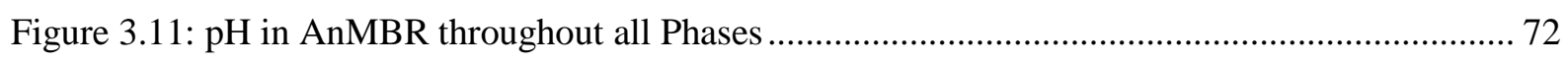

Figure 3.12: VFA/Alk in AnMBR throughout all Phases.............................................................. 74

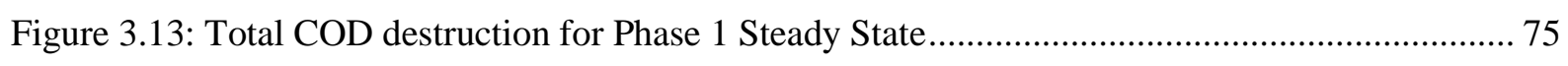

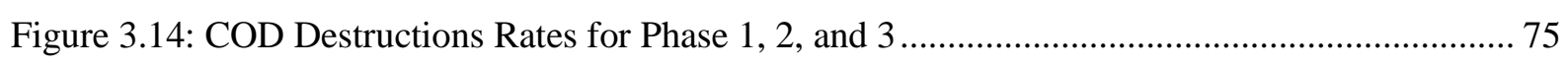

Figure 3.15: Average COD Concentrations in Phase 1, 2, and 3 AnMBR WAS ............................... 77

Figure 3.16: Cumulative Mass Balance of COD species through PT and AD ….............................. 79

Figure 3.17: Average Permeate ffCOD concentrations for all Phases ............................................. 80

Figure 3.18: Total VSS destruction for Phase 1 Steady State ......................................................... 81

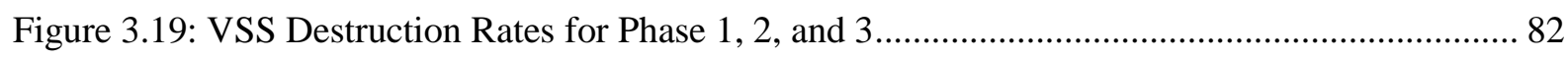

Figure 3.20: Average SS Concentrations in Phase 1, 2, and 3 AnMBR WAS ................................... 84

Figure 3.21: Total ON destruction for Phase 1 Steady State ....................................................... 85

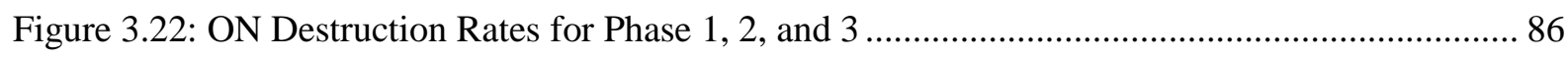

Figure 3.23: Average Nitrogen Concentrations in Phase 1, 2, and 3 AnMBR WAS ........................ 88

Figure 3.24: Cumulative TKN Mass Balance in Phase 1, 2, and 3 ............................................... 90 
Figure 3.25: Average Ammonia Concentrations in Phase 1, 2, and 3 Permeate 90

Figure 3.25: COD Decay Results for Phase 2 and Phase 3 3....................................................... 93

Figure 3.26: Total COD, VSS, and ON Destruction Rates for all Phases ....................................... 94

Figure 4.1: Overall Membrane Performance of Digested Sludge.................................................... 105

Figure 4.2: Fouling Rate Observed Throughout Membrane Operation ............................................. 107

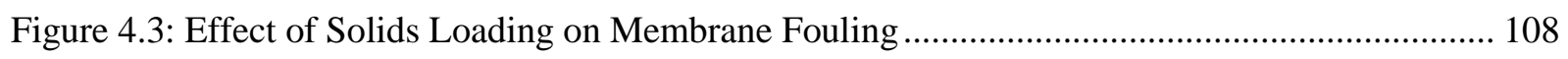

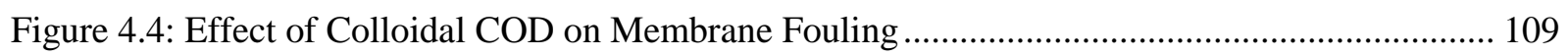

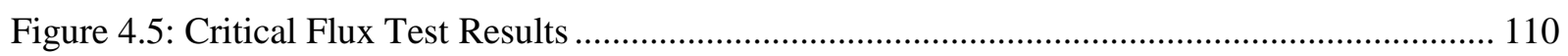

Figure 4.6: Critical Flux Range for Phase 2 and Phase 3 ........................................................... 111

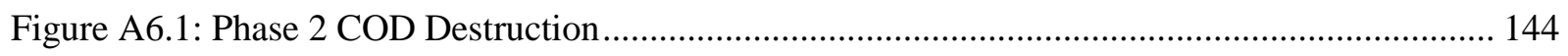

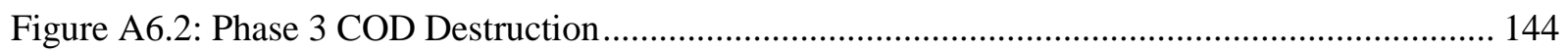

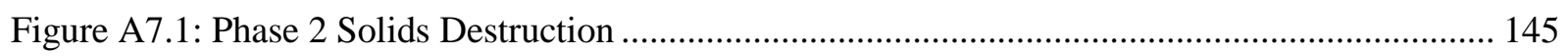

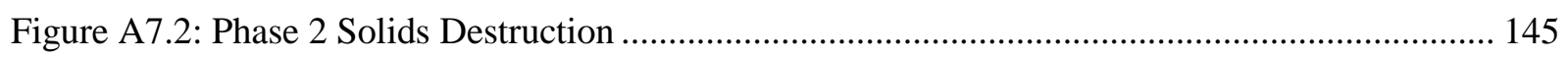

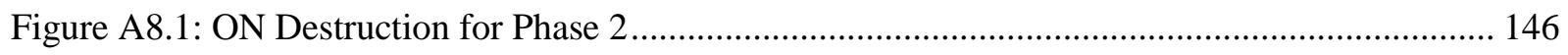

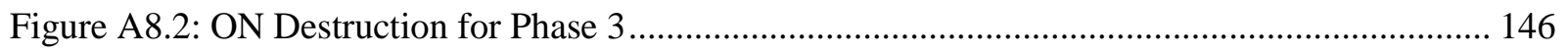




\section{List of Tables}

Table 2.1: Advantages and Disadvantages of Anaerobic Digestion ................................................. 5

Table 2.2: Biological Performance of AnMBRs treating High Solids Streams ................................. 11

Table 2.3: Classical Membrane Fouling Models ....................................................................... 14

Table 2.4: Membrane Performance of AnMBRs treating High Solids Streams ................................. 21

Table 2.5: Summary of Literature on Sonication Effects on WAS ................................................. 27

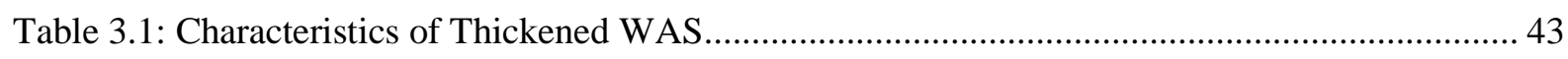

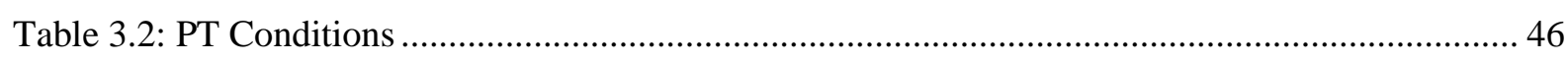

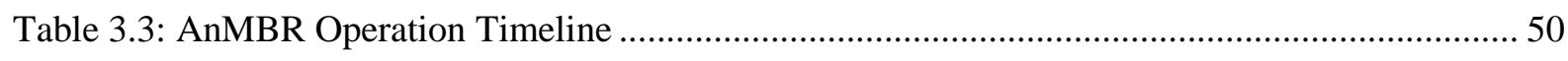

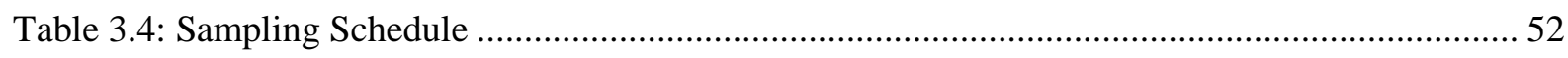

Table 4.1: Steady State Operational Conditions Relevant for Membrane Performance...................... 101

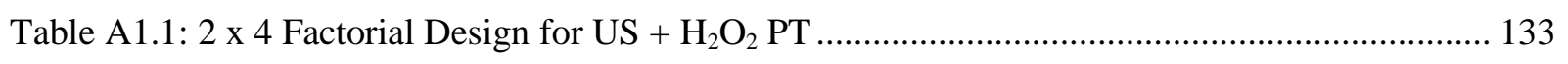

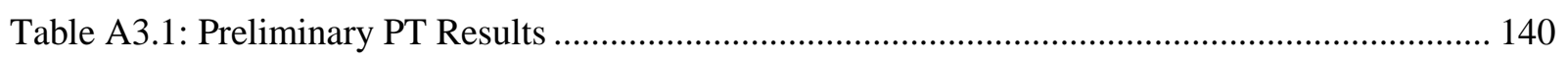

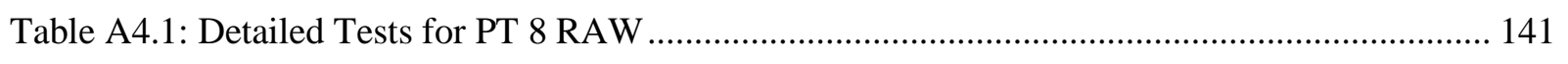

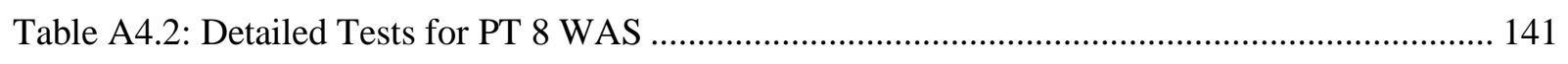

Table A4.3: Detailed Solids Tests for PT 8 WAS ................................................................... 142

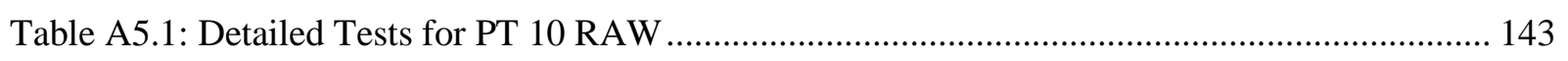

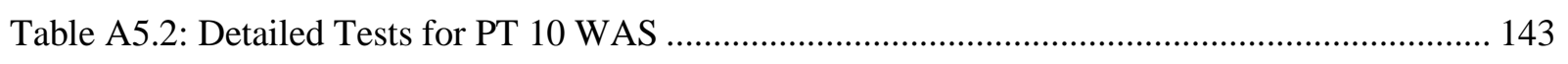

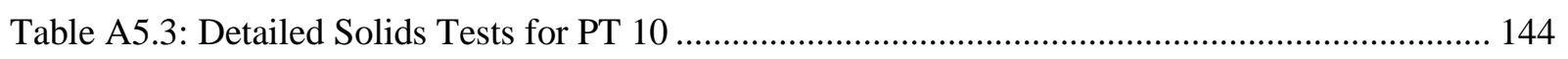

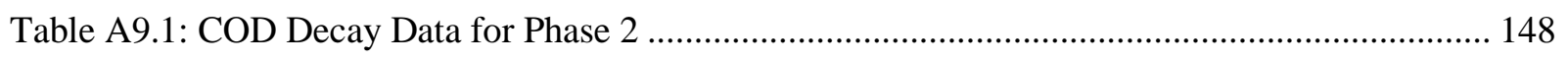

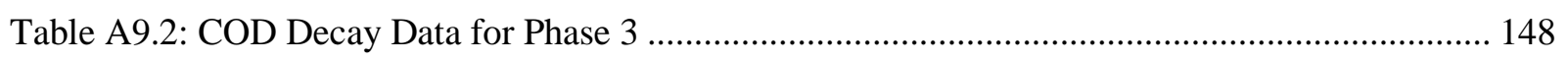

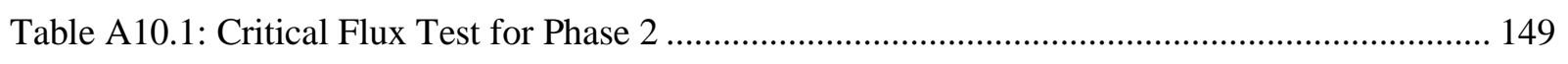

Table A10.2: Critical Flux Test for Phase 3 ........................................................................... 149 


\section{List of Abbreviations}

AD: Anaerobic Digestion

AOT: Advanced Oxidation Treatment

AOP: Advance Oxidation Process

AnMBR: Anaerobic Membrane Bioreactor

cCOD: Colloidal Chemical Oxygen Demand

COD: Chemical Oxygen Demand

CSTR: Continuous Stirred-Tank Reactor

DS: Dry Solids

EPS: Extracellular Polymeric Substances

ffCOD: Flocculated and Filtered COD

FSS: Fixed Suspended Solids

GC: Gas Chromatograph

HRT: Hydraulic Residence Time

ISS: Inert Suspended Solids

LMH: Litre/meter square/hour

MBR: Membrane Bioreactor

MLSS: Mixed Liquor Suspended Solids

MF: Microfiltration

MW: Microwave

OLR: Organic Loading Rate

ON: Organic Nitrogen

P: Permeate

PAN: Polyacrylonitrile

pCOD: Particulate Chemical Oxygen Demand

PDVF: Polyvinylidene Flouride 
PE: Polyethylene

PES: Polyethersulfone

PSF: Polusulfone

P1: Phase 1

P2: Phase 2

P3: Phase 3

PS: Primary Sludge

PT: Pre-treatment

PVDF: Polyvinylidene fluoride

SMP: Soluble Microbial Products

sON: Soluble Organic Nitrogen

SCOD: Soluble Chemical Oxygen Demand

SCOD/TCOD: Solubilisation Ratio

SRT: Solids Residence Time

SS: Suspended Solids

sTKN: Soluble Total Kjeldahl Nitrogen

TCD: Thermal Conductivity Detector

TKN: Total Kjeldahl Nitrogen

TMP: Transmembrane Pressure

tON: Total Organic Nitrogen

TWAS: Thickened Waste Activated Sludge

TS: Total Solids

TSS: Total Suspended Solids

UASB: Upflow Anaerobic Sludge Blanket

UF: Ultrafiltration

US: Ultrasound 
VFA/Alk: Volatile Acids to Alkalinity Ratio

VS: Volatile Solids

VSS: Volatile Suspended Solids

W: Waste

WAS: Waste Activated Sludge

WW: Waste Water

WWTP: Waste Water Treatment Plant 


\section{Chapter 1: Introduction}

\subsection{Problem Statement}

Typically, there are two types of sludge that are generated at wastewater treatment plants (WWTPs) - Primary (PS) and Waste Activated Sludge (WAS). Primary sludge is a product of the sedimentation of raw wastewaters while the activated sludge process is responsible for producing large quantities of waste activated sludge (WAS). A popular means of treating excess sludge is to stabilize the sludge by anaerobic digestion (AD). AD reduces the organic content and pathogenic population of WAS while producing methane as a renewable by-product. This process accomplishes stabilisation of sludge in 4 stages: Hydrolysis, Acidogenesis, Acetogenesis, and Methanogenesis. It has been established that the rate of hydrolysis is often the rate limiting step (Bougrier et al., 2006). In order to accommodate this slow process, anaerobic digesters need to be operated at long solid retention times (SRT), which results in an increase in reactor volumes due to an increase in the hydraulic retention time (HRT). Several approaches have been introduced to improve the rate of hydrolysis, which may result in a decrease in reactor volumes and associated costs.

Pre-treatment (PT) of sludge has been found to be one way of increasing the rate of hydrolysis (Shahriari et al., 2011). Pre-treatment causes the lysis of cells, thus making organics and nutrients readily available for microbial growth and metabolic activities. A wide range of WAS pre-treatments such as thermal (Bougrier et al., 2006; Climent et al., 2007; Bravo et al., 2011; and Burger, 2012), chemical such as peroxidation (Grönroos et al., 2004; Dewil et al., 2007; Eskicioglu et al., 2008; and Song et al., 2012), and mechanical such as sonication (Salsabil et al., 2009; Yan et al., 2010; Kim et al., 2010; Braguglia et al., 2011; and Yaqci et al., 2011) have been proven to be effective in pre-treating sludge. 
Another method to enhance the process of anaerobic digestion is to incorporate a membrane into the design of the digester. With an anaerobic membrane bioreactor (AnMBR), the solids retention time (SRT) can be decoupled from the hydraulic residence time (HRT), thus allowing operation at higher loadings and producing digested sludge with higher solids concentrations while occupying less space in the WWTP. Although AnMBRs appear to provide considerable advantages over conventional digesters when bioreactor performance is considered, a potential challenge is the fouling of membranes due to the accumulation of microorganisms, colloids, solutes, and cell debris in or on membrane surfaces (Meng el al., 2009). Thus identification of foulants and fouling mechanisms and incorporation of fouling minimization techniques are required for successful AnMBR operation.

Although AnMBRs may increase the rate of organics destruction the improvement in extent of biodegradation may be limited by the maximum biodegradability of the feed sludge. The integration of PT with AnMBRs may provide a solution by increasing the ultimate biodegradability of WAS. With a significant amount of particulates broken down due to PT, a high sludge age and the use of membranes to prevent biomass washout may result in an enhanced destruction of compounds.

This study evaluated a combined PT-AnMBR system to improve the ultimate biodegradability of WAS. Thermal, ultrasound (US), and peroxide/US treatments were initially compared to determine the preferred method to enhance the biodegradability of the WAS used in this study. Once the preferred PT was determined, it was evaluated in tandem with AD in a submerged hollow fibre AnMBR to allow for a longer SRT while keeping the HRT at a minimum duration. 


\subsection{Objectives}

The objectives of this research were to:

- Assess the impact of thermal, sonication, and sonication-peroxide pre-treatments on the physico-chemical properties of WAS.

- Examine the biological performance (COD, solids, and organic nitrogen destruction) of a low pressure and low shear velocity hollow fibre anaerobic membrane bioreactor in combination with pre-treatment.

- Examine the membrane performance (fouling, impact of colloids and inerts concentration, flux and transmembrane pressure) of a low pressure and low shear velocity hollow fibre anaerobic membrane bioreactor in combination with pre-treatment.

\subsection{Thesis Structure}

This thesis is organized into 6 chapters and 10 appendices. Chapter 1 provides a short introduction to current WAS stabilization processes, WAS pre-treatment procedures, advantages and limitations of AnMBRs and outlines the objectives of the study. Chapter 2 summarizes the literature on previous studies relevant to this study including those that evaluated the effect of PT on high solids waste streams, digestion of high solids waste streams via AnMBRs and the effect of high solids waste streams on membrane fouling. Chapter 3 presents the methodology employed and the results of testing that evaluated the effect of PT on the physico-chemical properties of WAS and the biological performance of a combined PT-AnMBR system. Chapter 4 presents the methodology employed and the results obtained in a study of the membrane performance of the AnMBR when treating raw and pre-treated WAS. Chapter 5 presents the significant conclusions of this study while Chapter 6 provides recommendations for future work. 


\section{Chapter 2: Literature Review}

\subsection{Introduction}

Typically, there are two types of sludge that are generated at wastewater treatment plants (WWTPs) - Primary (PS) and Waste Activated Sludge (WAS). Primary sludge is a product of the sedimentation of raw wastewaters while WAS is a product of biological processes such as the activated sludge process. With growing populations the amount of sludge to be treated at WWTPs is increasing. This poses a challenge to WWTP owners and operators since the costs associated with sludge processing may be as high as $50 \%$ of the total cost of wastewater treatment (Zhang et al., 2007). In this study, sludge stabilization by anaerobic digestion was evaluated.

\subsection{Anaerobic Digestion:}

Anaerobic digestion (AD) is a common sludge stabilization method employed in wastewater treatment plants that not only converts the organic matter into a renewable source of energy i.e. biogas, but also decreases the amount of solids while destroying a majority of the pathogens in the sludge (Abelleira et al., 2012). This complex biochemical process employs several groups of facultative and anaerobic microorganisms that work together to achieve stabilization and treatment of sludge in the absence of oxygen. The advantages and disadvantages of AD are summarized in Table 2.1. 
Table 2.1: Advantages and Disadvantages of Anaerobic Digestion

\begin{tabular}{|c|c|}
\hline Advantages & Disadvantages \\
\hline $\begin{array}{l}\text { No oxygen required- lower energy } \\
\text { required than aerobic digestion } \\
\text { digestion - decrease in sludge } \\
\text { processing and disposal costs } \\
\text { - Methane produced as a by-product - } \\
\text { renewable source of energy } \\
\text { High organic loading possible } \\
\text { Low nutrient requirements than aerobic } \\
\text { digestion }\end{array}$ & $\begin{array}{l}\text { - Slower process than aerobic digestion - } \\
\text { low growth rate of microorganisms } \\
\text { digestion } \\
\text { - More sensitive to toxins than aerobic } \\
\text { - } \text { Man aerobic digestion } \\
\text { - } \text { Produces odours }\end{array}$ \\
\hline
\end{tabular}

Source: Maier et al., 2008 and Metcalf and Eddy, 2003

\subsection{Anaerobic Biological Treatment Process:}

Anaerobic processes decompose organic matter in 4 stages: Hydrolysis, acidogenesis, acetogenesis, and methanogenesis. In hydrolysis, complex molecules such as insoluble organic matter and high molecular weight compounds are broken down into soluble monomers such as amino acids, sugars, and fatty acids by a variety of hydrolytic bacteria. Since this is a relatively slow process, it is typically the rate limiting step in anaerobic digestion of waste activated sludge (Bougrier et al., 2006). Hydrolysis is followed by acidogenesis that converts monomers into organic acids, alcohols, ketones, carbon-dioxide, and hydrogen by fermentative acidogenic bacteria. Acidogenesis is followed by acetogenesis that involves the conversion of acids and 
alcohols to acetate, carbon dioxide, and hydrogen by acetogenic bacteria. Slower growing methanogens then finally convert acetate, carbon-dioxide, and hydrogen into methane (Rittmann and McCarty, 2000). There are two classes of methanogens that are responsible for producing methane namely: acetoclastic and hydrogen oxidizing methanogens. Acetoclastic methanogens split acetic acid into methane and carbon dioxide while hydrogen oxidizing bacteria use hydrogen as an electron donor and carbon dioxide as an electron acceptor to produce methane (Appels et al., 2008). Figure 2.1 presents a simplified schematic of the anaerobic process as proposed by Gujer and Zehnder, (1983).

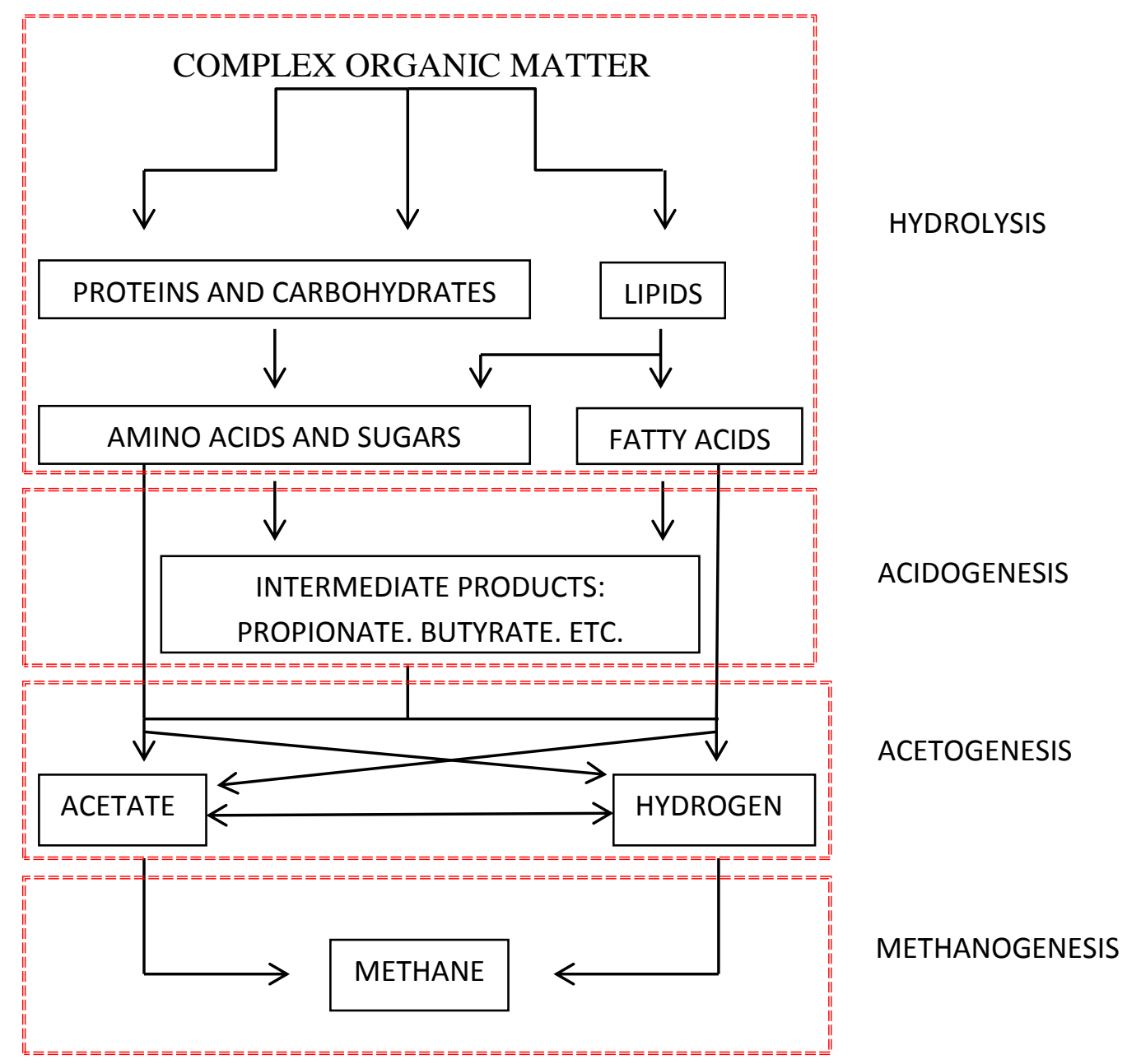

Figure 2.1: Biological Description of Anaerobic Digestion (Gujer and Zehnder, 1983) 


\subsection{Anaerobic Membrane Bioreactors}

As stated earlier, hydrolysis is often the rate limiting step in anaerobic digestion (Bougrier et al., 2006). In addition, due to the slow growth rates of methanogens, conventional anaerobic digesters need to be operated at long residence times (Dagnew, 2010). One major drawback of operating digesters at long residence times is that the volume of the reactors are large, which in turn increases the costs associated with the construction and maintenance of the digester. Collectively, these factors act to increase the cost of conventional digestion.

One way to enhance the process of anaerobic digestion is to incorporate a membrane into the design of the digester (Pickel, 2010). With an anaerobic membrane bioreactor (AnMBR), the solids retention time (SRT) can be decoupled from the hydraulic residence time (HRT), thus resulting in the ability to treat high loadings and sludge with high solids concentrations and slowly biodegradable compounds while occupying less space in the WWTP. The membrane is able to retain the biomass and microorganisms in the digester also resulting in a waste effluent with high solids concentration. Moreover, the permeate that is collected as a result of the membrane installation is solids-free (Lew et al., 2009). Due to all these advantages, AnMBRs are gaining popularity in the waste water industry.

\subsection{Anaerobic Digestion of High Solids Waste using AnMBRs}

Table 2.2 presents a cross-section of research that has been conducted to evaluate treatment of high solids streams using AnMBRs. As it can be seen in the table, AnMBRs have been operated under a variety of different conditions. Conventional anaerobic digesters are usually operated at a minimum HRT and SRT of 15 days for sludges (Metcalf and Eddy, 2003). The AnMBR literature has made use of HRTs that have ranged from 1.2 to 30 days (Fuchs et al., 
2003 and Takashima et al., 1991). However, when compared to the corresponding decoupled SRTs (range of 20 days to 365 days), it can be seen that the HRT values were considerably lower than the SRT, thus demonstrating a low reactor volume (Kim and Jung, 2007 and Ghyoot and Verstraete, 1997). Comparatively, long SRTs indicate that longer durations may be required to accomplish significant hydrolysis of high solids streams.

Some studies have evaluated the influence of SRT on chemical oxygen demand (COD) and volatile suspended solids (VSS) destruction rates. For instance, Dagnew, (2010) investigated the effect of SRT on the performance of a submerged AnMBR treating WAS and found that as the SRT was increased from 15 to 30 days, the VSS and COD destruction rates increased from $36 \pm 1.5 \%$ to $48.6 \pm 3.1 \%$ and from $40.6 \pm 1.8 \%$ to $50.8 \pm 3.8 \%$, respectively. Trzcinski and Stuckey, (2010) also investigated the effect of SRT on COD removal rates of a submerged AnMBR treating municipal solid waste leachate and found that as SRT increased from 30 to 300 days, the fraction of removed COD also increased. It was seen that as the SRT increases, microorganisms are able to hydrolyze particulates and high molecular weight molecules into smaller and soluble substances more effectively. Hence, microorganisms are able to degrade COD and VSS more effectively. Most of the studies discussed in Table 2.2 reported that decoupling SRT-HRT in AnMBRs kept the volume of the reactor low while accomplishing significant digestion of the high solids streams as shown by the high destructions.

Another operational parameter that is commonly reported in the operation of anaerobic reactors is the organic loading rate (OLR). Puchajda and Oleszkiewicz, (2008) have shown that increasing the loading rate can enhance anaerobic digestion. However, in order to ensure successful anaerobic digestion, conventional digesters are usually operated at high SRTs (and thus HRTs), which may result in low OLRs. This was confirmed by Verstraete and Vandevivere 
(1999) found that conventional anaerobic digesters are usually operated at low OLRs of $<1$ $\mathrm{kgCOD} / \mathrm{m}^{3} / \mathrm{d}$. On the other hand, due to the decoupling SRT-HRT characteristic of AnMBRs, these systems are expected to be able to handle high OLRs. The applied OLR for AnMBRs was higher than $1 \mathrm{~kg} \mathrm{COD} / \mathrm{m}^{3} / \mathrm{d}$ in the studies listed in Table 2.2, and in some cases higher than $10 \mathrm{~kg} \mathrm{COD} / \mathrm{m}^{3} / \mathrm{d}$, demonstrating the capacity of AnMBRs to handle high loadings (Fuchs et al., 2003 and Trzcinski and Stuckey, 2009).

However, despite the potential improvement in sustainability, using high loadings may negatively affect the AnMBR process. This is because high OLRs may require high cross flow velocities or sparging rates and more cleaning to prevent fouling of the membrane. Some studies have reported a decline in digester performance at high OLRs (Brockmann and Seyfried, 1997; Hernandez et al., 2002; and Padmasiri et al., 2007). This deterioration in performance was attributed to a decline in microbial activity as a result of high shear rates and physical interruption of the syntrophic interaction of acetogenic and methanogenic organisms (Brockmann and Seyfried, 1997 and Hernandez et al., 2002). Therefore, shear rates that are adequate enough to accomplish scouring of membranes and do not affect the biological activity of microorganisms should be employed.

Temperature is another factor that affects the activity of microorganisms. It should be noted that most of the studies reported in this review evaluated mesophilic reactors, with the exception of the study of Kang et al., (2002), where the AnMBR was operated at a thermophilic temperature of $55^{\circ} \mathrm{C}$. This shows that a broad range of temperatures can be employed in AnMBRs. From a biological point of view, microbial growth and decay rates have been reported to be linearly related to temperature (Dereli et al., 2012). The higher decay rate of thermophilic bacteria may lead to the formation of small particles such as extracellular polymeric substances 
(EPS), decay products or cell debris (Dereli et al., 2012). The existence of such particles within the reactor may have a negative effect on the filtration properties of the membrane, a concern that will be addressed in Section 2.5.

In some cases, similar removal efficiencies have been reported with thermophilic and mesophilic AnMBRs. For instance, Kang et al., (2002) reported a 99\% COD removal efficiency at $55^{\circ} \mathrm{C}$, while Fuchs et al., (2003) observed a 90-96\% removal efficiency by operating the reactor at only $30^{\circ} \mathrm{C}$. However, both studies employed AnMBRs to treat different waste streams under different operational conditions. Kang et al., (2002) operated the AnMBR at an HRT of 13 days and OLR of $2.95 \mathrm{~kg} \mathrm{COD} / \mathrm{m}^{3} / \mathrm{d}$ to treat an alcohol fermentation plant WW with an MLSS concentration of 2-2.5 g/L, while Fuchs et al., (2003) used an HRT of 1.2 days and OLR of 4.83$16.75 \mathrm{~kg} \mathrm{COD} / \mathrm{m}^{3} / \mathrm{d}$ to treat $22 \mathrm{gMLSS} / \mathrm{L}$ chicken slaughter WW. Despite having a higher MLSS concentration and OLR, Kang et al., (2002) achieved a high removal rate, which was comparable to Fuchs et al., (2003). Therefore, in order to minimize costs of heating, one may operate AnMBRs at mesophilic temperatures and acquire high removal efficiencies that one would observe at thermophilic temperatures.

In summary, the literature reveals that AnMBRs can be operated over a broad range of conditions; however the removal efficiency that can be maintained is a function of sludge characteristics, shear rate, and operational conditions. On the basis of the reviewed literature, the test apparatus employed in this study was designed to operate at a low HRT, a comparatively higher SRT, an OLR > $1 \mathrm{kgCOD} / \mathrm{m}^{3} / \mathrm{d}$ and a mesophilic temperature. This combination of operational conditions was chosen to accomplish a high removal rate while maintaining the costs at a minimum. 
Table 2.2: Biological Performance of AnMBRs treating High Solids Streams

\begin{tabular}{|c|c|c|c|c|c|c|c|c|c|c|c|}
\hline Type of Feed & $\begin{array}{l}\text { Type of } \\
\text { Reactor }\end{array}$ & $\begin{array}{c}\mathbf{T} \\
\left({ }^{\mathbf{o}} \mathbf{C}\right)\end{array}$ & $\begin{array}{l}\text { Volume } \\
\text { (L) }\end{array}$ & $\begin{array}{c}\text { HRT } \\
\text { (days) }\end{array}$ & $\begin{array}{c}\text { SRT } \\
\text { (days) }\end{array}$ & $\begin{array}{c}\text { MLSS } \\
(\mathrm{g} / \mathrm{L})\end{array}$ & $\begin{array}{c}\text { OLR } \\
\left(\mathrm{kgCOD} / \mathrm{m}^{3}-\mathrm{d}\right)\end{array}$ & $\begin{array}{l}\text { Feed } \\
\text { COD } \\
(\mathrm{g} / \mathrm{L})\end{array}$ & $\begin{array}{c}\text { Feed } \\
\text { TS } \\
(\mathrm{g} / \mathrm{L})\end{array}$ & $\begin{array}{c}\text { COD } \\
\text { Removal } \\
\text { Efficiency } \\
(\%) \\
\end{array}$ & Reference \\
\hline WAS & CSTR & 35 & 5 & 30 & 100 & - & - & - & 20.7 & 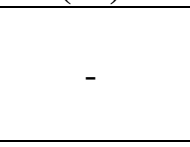 & $\begin{array}{l}\text { Takashima } \\
\text { el al., } \\
(1991) \\
\end{array}$ \\
\hline PS & UASB & 35 & 120 & 20 & $\begin{array}{c}\text { No } \\
\text { wasting }\end{array}$ & 50 & 2.01 & 40.2 & 44.4 & $\begin{array}{c}54 \\
25-59^{b}\end{array}$ & $\begin{array}{c}\text { Ghyoot and } \\
\text { Verstraete, } \\
\text { (1997) }\end{array}$ \\
\hline $\begin{array}{c}\text { Alcohol } \\
\text { Fermentation } \\
\text { Plant WW }\end{array}$ & CSTR & 55 & 5 & 13 & - & $2-2.5$ & 2.95 & 38.4 & - & 99 & $\begin{array}{l}\text { Kang et al., } \\
\text { (2002) }\end{array}$ \\
\hline $\begin{array}{l}\text { Chicken } \\
\text { Slaughter } \\
\text { WW }\end{array}$ & CSTR & 30 & 7 & 1.2 & - & 22 & $4.83-16.75$ & $\begin{array}{l}5.8- \\
20.1\end{array}$ & $\begin{array}{l}2.4- \\
4.7\end{array}$ & $90-96$ & $\begin{array}{l}\text { Fuchs et al., } \\
\text { (2003) }\end{array}$ \\
\hline WAS & CSTR & 35 & 100 & 2 & 20 & $18-55$ & - & $7^{\mathrm{a}}$ & $\begin{array}{l}5.0- \\
30.0\end{array}$ & - & $\begin{array}{l}\text { Kim and } \\
\text { Jung, } \\
(2007) \\
\end{array}$ \\
\hline $\begin{array}{l}\text { Municipal } \\
\text { Solid Waste }\end{array}$ & CSTR & 35 & 3 & $\begin{array}{l}1.6- \\
2.3\end{array}$ & - & - & $2.5-11.3$ & $\begin{array}{l}4.0- \\
26.0\end{array}$ & 30 & $>90$ & $\begin{array}{l}\text { Trzcinski } \\
\text { and } \\
\text { Stuckey, } \\
(2009) \\
\end{array}$ \\
\hline WAS & - & 35 & 570 & 7,15 & 15,30 & $\begin{array}{l}17.2- \\
28.3\end{array}$ & $0.73-3.14$ & $\begin{array}{l}17.4- \\
21.3\end{array}$ & $\begin{array}{l}15.9- \\
18.3\end{array}$ & $40.6-50.8$ & $\begin{array}{c}\text { Dagnew, } \\
2010\end{array}$ \\
\hline
\end{tabular}

${ }^{\mathrm{a}}$ Soluble COD , ${ }^{\mathrm{b}}$ VSS Removal Efficiency 


\subsection{Membrane Performance of AnMBR systems treating High Solids Waste}

\subsubsection{Fouling in AnMBR}

Although AnMBRs appear to provide considerable advantages over conventional digesters when bioreactor performance is considered, a potential challenge is the fouling of membranes due to the accumulation of microorganisms, colloids, solutes, and cell debris in or on membrane surfaces (Meng el al., 2009). Fouling is an unavoidable drawback of using a membrane as it affects the long term stability and performance of the membrane. Inefficient operation of membranes due to fouling will require elevated energy costs and may require frequent replacement of membranes, which in turn increases costs (Dereli et al., 2012).

In order to study fouling it is desirable to have metrics that can be used to quantify its extent. Two indicators of fouling have been reported in literature. It has been described in terms of either an increase in transmembrane pressure (TMP) (at constant flux) or a decrease in flux (at constant TMP) (Hong et al., 2002). Most studies on membrane fouling have used a constant flux approach rather than a constant TMP approach (Choi, 2003). Defrance and Jaffrin, (1999) confirmed that it is preferable to operate the membrane at a constant flux rather than at a constant TMP. Hence, the AnMBR in this study was operated in a constant flux mode.

\subsubsection{Conceptual Model of Fouling Mechanisms}

Conceptual models of fouling mechanisms can be used to identify fouling mechanisms and to predict the flux decline over time. There are four classical mechanisms that can be used to define fouling, which are summarized in Table 2.3 (Hwang and Lin, 2002 and Jaffrin et al., 1997). 
- Complete pore blocking, in which particles of a larger diameter than the pore constrict the pore entrance and increase filtration resistance.

- Intermediate pore blocking follows the same approach as complete blocking, but involves settling of particles on the existing particles blocking the pores.

- Standard pore blocking, which assumes that particles accumulate on the pore walls, thus causing the volume of the pores to decrease.

- Cake formation, which involves accumulation of particles on the membrane surface, thus resulting in a cake layer.

Conceptual models are aimed to accomplish characterization of fouling mechanisms. Prediction of fouling mechanisms, as a result of these models, can help prevent and analyze flux decline effectively. The literature presents models that describe these fouling mechanisms individually and in combination with each other (Hermia, 1982; Field et al., 1995; Bowen et al., 1995; Ho and Zydney, 2006; and Charfi et al., 2012). Most of these studies have adapted the models described by Hermia, (1982), which are summarized in Table 2.3. All the expressions in Table 2.3 are based on a mathematical model (Equation 2.1), which was presented by Hermia, (1982) and the flux decline expression (Equation 2.2). The constant $m$ depends on the fouling mechanism involved in the process and can be found in Table 2.3, along with the definitions of other parameters.

$$
\begin{gathered}
\frac{d^{2} t}{d V^{2}}=k\left(\frac{d t}{d V}\right)^{m} \\
\frac{d J}{d t}=-k J(A J)^{2-m}
\end{gathered}
$$


Table 2.3: Classical Membrane Fouling Models

(Adapted and Modified from Hermia, 1982; Bowen et al., 1995; and Charfi et al., 2012)

\begin{tabular}{|c|c|c|}
\hline Description & Fouling Mechanism & Flux Expression \\
\hline & $\begin{array}{l}\text { Complete Pore Blocking } \\
\qquad(\mathrm{m}=2)\end{array}$ & $\begin{array}{c}\mathrm{J}=\mathrm{J}_{0} \exp \left(-K_{c b} \mathrm{t}\right) \\
\mathrm{K}_{\mathrm{cb}}=\mathrm{k} \\
\mathrm{K}_{\mathrm{cb}}=\mathrm{J}_{0} / \rho_{\mathrm{s}} \mathrm{h}\end{array}$ \\
\hline & $\begin{array}{l}\text { Intermediate Pore Blocking } \\
\qquad(\mathrm{m}=1)\end{array}$ & $\begin{array}{c}\mathrm{J}=\frac{\mathrm{J}_{0}}{\mathrm{~K}_{\mathrm{ib}} \mathrm{J}_{0} \mathrm{t}+1} \\
\mathrm{k}_{\mathrm{ib}}=\mathrm{kA} \\
\mathrm{K}_{\mathrm{ib}}=\mathrm{C} / \rho_{\mathrm{s}} \mathrm{h}\end{array}$ \\
\hline & $\begin{array}{l}\text { Standard Pore Blocking } \\
\qquad(\mathrm{m}=3 / 2)\end{array}$ & $\begin{array}{c}\mathrm{J}=\frac{4 \mathrm{~J}_{0}}{\left(\mathrm{~K}_{\mathrm{pc}} \mathrm{J}_{0}^{1 / 2} \mathrm{t}+1\right)^{2}} \\
\mathrm{~K}_{\mathrm{pc}}=\mathrm{kA}^{1 / 2} \\
\mathrm{~K}_{\mathrm{pc}}=\frac{2 \mathrm{CJ_{0 }}{ }^{\frac{1}{2}}}{\mathrm{e} \rho_{\mathrm{s}}}\end{array}$ \\
\hline & $\begin{array}{l}\text { Cake Formation } \\
\qquad(\mathrm{m}=0)\end{array}$ & $\begin{array}{c}\mathrm{J}=\frac{\mathrm{J}_{0}}{\left(2 \mathrm{~K}_{\mathrm{cf}} \mathrm{J}_{0}{ }^{2} \mathrm{t}+1\right)^{1 / 2}} \\
\mathrm{~K}_{\mathrm{cf}}=\mathrm{kA}^{2} \\
\mathrm{~K}_{\mathrm{cf}}=\frac{\alpha C \mu_{\mathrm{p}}}{\Delta \mathrm{P} \rho_{\mathrm{s}}}\end{array}$ \\
\hline
\end{tabular}

Where $\mathbf{J}$ is the permeate flux $\left(\mathrm{m} \cdot \mathrm{s}^{-1}\right), \mathrm{J}_{0}$ is the initial flux at $\mathrm{t}=0\left(\mathrm{~m} \cdot \mathrm{s}^{-1}\right), \mathrm{t}$ is the time $(\mathrm{s}), \mathrm{A}$ is the membrane surface $\left(\mathrm{m}^{2}\right), \mathrm{C}$ is the suspended solids concentration $\left(\mathrm{g} . \mathrm{L}^{-1}\right)$, e is the active layer thickness (m), $\mathrm{h}$ is the deposit height $(\mathrm{m}), \mathrm{K}_{\mathrm{cf}}$ is the cake formation parameter $\left(\mathrm{s} \cdot \mathrm{m}^{-2}\right), \mathrm{K}_{\mathrm{pc}}$ is the pore constriction parameter $\left(\mathrm{s}^{-1 / 2}\right), \mathrm{K}_{\mathrm{ib}}$ is the intermediate blocking parameter $\left(\mathrm{m}^{-1}\right), \mathrm{K}_{\mathrm{cb}}$ is the complete blocking parameter $\left(\mathrm{s}^{-1}\right), \mathrm{k}$ is the kinetics parameter constant (unitless), $\alpha$ is the specific cake resistance $\left(\mathrm{m}_{\mathrm{kg}}{ }^{-1}\right), \mu_{\mathrm{p}}$ is the permeate viscosity $(\mathrm{Pa} . \mathrm{s})$, and $\rho_{\mathrm{s}}$ is the sludge density $\left(\mathrm{kg} \cdot \mathrm{m}^{-3}\right)$. 


\subsubsection{Prevention and Control of Fouling}

In order to determine the optimal operational flux of a system and control fouling, a critical flux test is often performed. The critical flux is defined as the flux below which minimal fouling takes place. The method of determining critical flux was introduced by Field et al., (1995) and this method was employed in this study. A critical flux test involves increasing the permeate flux in fixed increments for constant time periods and monitoring the TMP at each flux. A plot of this data reveals a linear relation between the TMP and flux within the sub-critical flux range and an exponential relation beyond the critical flux range. This exponential increase between the two parameters indicates rapid accumulation of foulants.

Operating the membrane below the critical flux has been reported to result in minimal fouling (Jeison and van Lier, 2006a). Fouling could still take place when operating under the critical flux; however the rate of fouling is lower below the critical flux (Fan et al., 2006). Thus, AnMBRs should be operated under the critical flux to minimize fouling.

Fouling can also be minimized by incorporating a relaxation period within the permeation cycle of the membrane. A relaxed mode of operation involves a cyclic interruption of filtration by releasing the pressure and allowing the accumulated materials on the membrane surface to be removed by scouring (Dagnew, 2010). Integration of relaxation in the permeating cycle has been proven to be effective in controlling anaerobic membrane fouling (Jude, 2006). For instance, Dagnew et al., (2012) compared the performance of a tubular membrane with continuous constant permeation for 30 minutes at a flux of 30 litres per $\mathrm{m}^{2}$ per hour (LMH) with a membrane incorporating a 5 minutes permeation followed by a 1 minute of relaxation cycle. They observed that relaxation extended the operation of the membrane by limiting the maximum 
TMP to 30 kilopascals (kPa). However, in continuous operation, the TMP increased almost linearly to about $80 \mathrm{kPa}$, thus demonstrating increased fouling of the membrane. Therefore, in an attempt to minimize fouling, the membrane in this study was operated at a relaxed operation rather than a continuous operation.

A wide range of relaxation and permeation cycles have been used in the past. Pickel, (2010) achieved a constant flux of $14 \mathrm{LMH}$ and a TMP of $0.079 \mathrm{kPa}$ with no cleaning by incorporating a 20 minute permeation followed by 5 hours and 40 minutes of relaxation cycle during a hollow fibre AnMBR filtration of WAS. On the other hand, Hulse et al., (2009) observed a flux of 4.6-11.8 LMH and a TMP of 1-1.74 $\mathrm{kPa}$ with cleaning at the end of operation by using a 9 minutes permeation and 1 minute relaxation cycle during a flat sheet AnMBR filtration of potato solid wastewater. The duration of the relaxation period depends on the characteristics of the stream being treated, operational conditions such as flux, and the cleaning frequency. For instance, a more concentrated stream and a higher operational flux with no cleaning employed may require longer durations of relaxation, as seen with Pickel, (2010). A few studies have achieved successful operation of the membrane by incorporating relaxation periods as low as 1 minute with 5 minutes of permeation (Dagnew et al., 2012). This study will investigate the effect of incorporating a relaxation cycle of 2 minutes with 8 minutes of permeation on the behaviour of a hollow fibre membrane treating WAS.

\subsubsection{Studies on Membrane Performance of AnMBR Systems Treating High Solids Waste}

Table 2.4 summarizes the membrane operating conditions that have been reported in previous AnMBR studies. From Table 2.4 it can be seen that AnMBRs have been operated over a broad range of fluxes when treating high solids streams. The range spans from that reported by 
Saddoud and Sayadi, (2007) (less than 3 LMH) when treating slaughterhouse WW at an MLSS concentration less than $10 \mathrm{~g} / \mathrm{L}$ to that of Pierkiel and Lanting, (2005) (146 and 66.7-83 LMH) when treating a combination of PS and WAS with an MLSS of 5 and $20 \mathrm{~g} / \mathrm{L}$. The relatively low flux reported by Saddoud and Sayadi, (2007) was accomplished with one cleaning cycle after 81 days of operation while Pierkiel and Lanting, (2005) performed daily and monthly cleaning cycles to maintain higher fluxes.

Although Saddoud and Sayadi, (2007) operated the AnMBR at a lower MLSS than Pierkiel and Lanting, (2005), they observed a flux decline from 20 to < 3 LMH after start-up. The low flux observed by Saddoud and Sayadi, (2007) was attributed to pore plugging and cake formation during filtration, which could have been prevented or controlled by performing regular maintenance cleaning. Thus, in order to maintain membrane performance, maintenance cleaning of the membrane may have to be performed in a timely fashion.

High MLSS concentrations do not necessarily translate to a need for frequent cleaning. For instance, Padmasiri et al., (2007) operated a side stream AnMBR with MLSS concentrations of 27 and $49 \mathrm{~g} / \mathrm{L}$ to treat swine manure with no cleaning employed during its operation. The long term performance of the membrane was attributed to the use of high cross-flow velocities that prevented deposition of foulants on or in the membrane. However, they also reported a decline in the biological activity of the micro-organisms due to the high velocities (Section 2.4).

It has been proposed that extremely high shear rates may result in irreversible fouling of the membrane. If the cross flow velocity or gas sparging rate is too high, this may lead to the disintegration of biological flocs, thus resulting in finer colloids and extracellular polymeric substances (EPS) and eventually severe fouling (Chang et al., 2002). Thus, a balance must be 
maintained between the shear velocity, membrane filtration, frequency of cleaning, and the biological performance of the reactor.

It has been reported that biomass concentration can significantly affect membrane performance. As it can be seen from Table 2.4, previous AnMBR studies have been conducted at MLSS concentrations ranging from 1.8 to 55 g/L (Pillay et al., 1994 and Kim and Jung, 2007). Jeison and van Lier, (2006b) studied the effect of biomass concentration on the critical flux in a mesophilic AnMBR, and concluded that an increase in biomass concentration from 20 to $40 \mathrm{~g} / \mathrm{L}$ led to a decrease in critical flux from 21 to 9 LMH. Zhang et al., (2007) also reported a similar observation. Hence, an increase in MLSS concentration reduces the flux range below which minimal fouling occurs. These reductions in flux are most likely due to the formation of a cake layer on the membrane surface, thus fouling the membrane and decreasing the resistance of the membrane.

The impact of membrane type and material of construction on flux has been the subject of previous studies. Ghyoot and Verstraete, (1997) compared the operation of a ceramic microfiltration (MF) membrane with a polymer ultrafiltration (UF) membrane for PS treatment and reported that the ceramic membrane maintained an operational flux of 200-250 LMH and a TMP of $200 \mathrm{kPa}$ while the flux and TMP for the polymer membrane was $25 \mathrm{LMH}$ and $375 \mathrm{kPa}$, respectively. In other words, the polymeric membrane displayed higher resistance to filter a suspension with similar solids concentration than a ceramic membrane. Although inorganic membranes such as those made of ceramics offer greater chemical, thermal and hydraulic resistances, they are not usually preferred as they are not very cost effective (Judd et al., 2004). For instance, Ghyoot and Verstraete, (1997) estimated the cost of the ceramic MF membrane to 
be almost twice the cost of the polymer UF membrane. In order to minimize costs, this study made use of an AnMBR with a polymeric membrane to accomplish permeate filtration.

Operation of membranes at higher fluxes has been reported to cause more fouling of membranes when compared to lower fluxes. For instance, Lew et al., (2008) investigated the relationship between flux and the fouling rate of a hollow fibre, MF membrane in an AnMBR. In this study, fouling rate was defined as an increase in TMP over time. It was found that an increase in the flux from 3.75 to $11.25 \mathrm{LMH}$ resulted in an increase of the fouling rate from 0.99 to $2.56 \%$. This may be explained by the increase in the rate of mass transfer of sludge particles towards the membrane surface due to an increase in flux, which led to an increased fouling rate.

Operating temperature has also been found to influence the flux and fouling rate of a membrane. Membranes have been operated under thermophilic as well as mesophilic conditions (Kang et al., 2002). Increasing the temperature has been reported to result in a reduced sludge viscosity which in turn, may increase the operating flux and improve the filtration performance of the membrane (Dereli et al., 2012). Jeison and van Lier (2006b) observed a higher critical flux range of 16-23 LMH in a thermophilic AnMBR treating sludge when compared to a mesophilic reactor, which had a critical flux range of 5-21 LMH. However, long term operation of the thermophilic reactor resulted in a decreased flux of 2-3 times that of the mesophilic AnMBR and irreversible fouling. As mentioned earlier, an increase in temperature can lead to an increase in microbial activity, thus resulting in increased EPS concentrations and smaller flocs. Finer sludge particles such as colloids may result in the formation of a compact and denser cake, which decreases the reversibility of flux loss in membranes, thus resulting in irreversible fouling (Jeison and van Lier, 2007). 
In summary, the literature reveals that AnMBRs can be operated over a broad range of conditions; however the flux that can be maintained is a function of sludge characteristics, shear rate, and cleaning frequency. On the basis of the reviewed literature, the test apparatus employed in this study was designed to operate with a hollow fiber membrane, an MLSS concentration of 20-25 g/L, a cleaning frequency of 3 times a week, gas sparging to generate shear, a relaxed mode of operation, and an operating flux that was below the critical flux. This design was developed to minimize the likelihood of excessive fouling in the experiments. 
Table 2.4: Membrane Performance of AnMBRs treating High Solids Streams

\begin{tabular}{|c|c|c|c|c|c|c|c|c|c|c|}
\hline Type of Feed & $\begin{array}{l}\text { Type of } \\
\text { Reactor }\end{array}$ & $\begin{array}{c}\text { Temperature } \\
\left({ }^{\circ} \mathbf{C}\right)\end{array}$ & Module & $\begin{array}{l}\text { Membrane } \\
\text { Material }\end{array}$ & $\begin{array}{l}\text { Pore } \\
\text { Size }\end{array}$ & $\begin{array}{c}\text { Surface } \\
\text { Area } \\
\left(\mathbf{m}^{2}\right) \\
\end{array}$ & $\begin{array}{l}\text { TMP } \\
(\mathbf{k P a})\end{array}$ & $\begin{array}{c}\text { Flux } \\
\text { (LMH) }\end{array}$ & $\begin{array}{c}\text { MLSS } \\
(\mathrm{g} / \mathrm{L})\end{array}$ & Reference \\
\hline PS & CSTR & 35 & Tubular & Woven Fibre & - & - & 200 & 50 & 1.8 & $\begin{array}{l}\text { Pillay et al., } \\
\text { (1994) }\end{array}$ \\
\hline PS & UASB & 35 & Tubular & $\begin{array}{l}\text { Ceramic, } \\
\text { Polymer }\end{array}$ & $0.1 \mu \mathrm{m}$ & 0.05 & $\begin{array}{l}200 \\
375\end{array}$ & $\begin{array}{l}200- \\
205, \\
25\end{array}$ & 50 & $\begin{array}{l}\text { Ghyoot and } \\
\text { Verstraete, } \\
\text { (1997) }\end{array}$ \\
\hline $\begin{array}{c}\text { Alcohol } \\
\text { Fermentation } \\
\text { Plant WW }\end{array}$ & CSTR & 55 & - & $\begin{array}{l}\text { Hydrophobic } \\
\text { PPE, Zirconia } \\
\text { Inorganic }\end{array}$ & $\begin{array}{l}0.2 \mathrm{~m} \\
0.14 \mathrm{~m}\end{array}$ & $\begin{array}{l}0.0129 \\
0.0113\end{array}$ & - & - & $2-2.5$ & $\begin{array}{l}\text { Kang et al., } \\
\text { (2002) }\end{array}$ \\
\hline PS and WAS & CSTR & 35 & $\begin{array}{l}\text { Tubular, } \\
\text { plate and } \\
\text { frame }\end{array}$ & $\begin{array}{c}\text { Titanium } \\
\text { dioxide/stainless } \\
\text { steel, polymeric } \\
\text { teflon } \\
\end{array}$ & $\begin{array}{l}0.1 \\
0.05 \\
\mu \mathrm{m}\end{array}$ & $1.4,1.6$ & $\begin{array}{l}480- \\
550 \\
345\end{array}$ & $\begin{array}{c}146 \\
66.7-83\end{array}$ & $\begin{array}{c}10,5- \\
20\end{array}$ & $\begin{array}{c}\text { Pierkiel and } \\
\text { Lanting, (2005) }\end{array}$ \\
\hline WAS & CSTR & 35 & Tubular & Stainless Steel & $1 \mu \mathrm{m}$ & - & - & - & $18-55$ & $\begin{array}{l}\text { Kim and Jung, } \\
\quad(2007)\end{array}$ \\
\hline $\begin{array}{c}\text { Slaughterhouse } \\
\text { WW }\end{array}$ & CSTR & 37 & - & - & $\begin{array}{l}100000 \\
\mathrm{Da}\end{array}$ & 1 & - & $<3$ & $<10$ & $\begin{array}{c}\text { Saddoud and } \\
\text { Sayadi, (2007) }\end{array}$ \\
\hline Swine Manure & CSTR & 37 & Tubular & $\begin{array}{l}\text { Polyether } \\
\text { Sulfone }\end{array}$ & $\begin{array}{c}20000 \\
\mathrm{Da}\end{array}$ & 0.0377 & $20-70$ & $5.0-10.0$ & 27,49 & $\begin{array}{l}\text { Padmasiri et al., } \\
\text { (2007) }\end{array}$ \\
\hline $\begin{array}{l}\text { High Solids } \\
\text { WW }\end{array}$ & CSTR & 30 & Tubular & PSF Membrane & - & - & - & $<4$ & 40 & $\begin{array}{l}\text { Jeison et al., } \\
\text { (2008) }\end{array}$ \\
\hline WAS & - & 35 & Tubular & PVDF & $\begin{array}{l}0.02 \\
\mu \mathrm{m}\end{array}$ & 0.2 & 30 & $\begin{array}{l}29.2- \\
34.5\end{array}$ & 19.8 & Dagnew, (2010) \\
\hline
\end{tabular}




\subsection{WAS Pre-treatment}

The performance of anaerobic digestion of WAS is often determined by the rate-limiting hydrolysis step that makes organics available to microorganisms (Bougrier et al., 2006). Pretreatment (PT) of sludge has been found to be one way of increasing the rate of hydrolysis (Shahriari et al., 2011). Pre-treatment can lead to the lysis of cells, which in turn causes the release, and thus availability of intracellular matter to the microorganisms (Bougrier et al., 2005). Hence, pre-treatment solubilises organics that are present in the form of suspended solids or adsorbed on their surface. Solubilisation of particulate matter has been found to cause changes in the physical and chemical properties of the sludge (such as suspended solids and chemical oxygen demand), thus making it readily available for microbial growth and metabolic activities (Pham et al., 2007). Since pre-treatment increases the rate of digestion, this may allow a treatment plant to reduce the retention time in digesters thereby making operation more economically favourable (Bougrier et al., 2005).

There are a variety of pre-treatments that can be used prior to anaerobic digestion. They include mechanical technologies such as sonication, thermal technologies and chemical treatments such as peroxidation (Bougrier et al., 2006b). Due to the large quantities of chemical that are needed and thus high associated costs, individual PT of WAS with peroxide is not widely used. Furthermore, the cost of disintegrating sludge by chemical treatment tends to be more expensive than mechanical PT (Ruiz-Hernando et al., 2013). Therefore, to date, sonication or thermal PTs have been preferred over peroxidation of WAS.

Some studies have suggested that ultrasonic (US) treatment may be more effective in improving the biodegradability of WAS than thermal PT. For instance, Sahinkaya and Sevimli, (2013) observed that treatment at $1.0 \mathrm{~W} / \mathrm{ml}$ of US density for 1 minute resulted in a $6.3 \%$ 
increase in biogas production with respect to the control, while thermal PT at $80^{\circ} \mathrm{C}$ for one hour resulted in a 3.5\% increase in biogas production compared to the control. In addition, Wang et al., (1995) showed that the order of pre-treatment efficiency in terms of improvement in methane generation after pre-treatment was ultrasonic lysis followed by thermal pre-treatment by autoclave followed by thermal pre-treatment by hot water, and lastly freezing. Therefore sonication has proved to be more effective in improving the characteristics of WAS than thermal or peroxide PT.

\subsection{Ultrasonic Pre-treatment:}

The term ultrasound refers to a sound wave propagating at a frequency higher than the audible hearing range of human beings ( $>20 \mathrm{kHz}$ ) (Kianmehr, 2010). When an ultrasound wave travels through a media such as water, it generates numerous cavitation bubbles in the water (Suslick 1988). Continuous oscillation of the wave causes the local pressure to drop below the evaporating pressure, which in turn causes these microscopic bubbles to explode (Wandzel et al., 2011). This abrupt and intense collapse of such a large number of bubbles produces strong mechanical shear forces that can disintegrate bacterial cells, cells walls, and membranes (Khanal et al., 2007). The disruption of bacterial cells results in the release of intracellular organic substances and solubilisation of particulate organic matter (Takatani et al., 1981). It has been hypothesized that fragmentation of organics due to sonication aids the rate-limiting hydrolysis reaction in anaerobic digestion and hence can in turn be reflected by increased methane generation and reduced sludge volume (Show et al., 2007).

Sonication has been reported to be a promising and effective pre-treatment method for sludge and has been widely researched in laboratory, pilot and recently even in full scale (Tiehm et al., 1997; Chu et al., 2001; Onyeche et al., 2002; Grönroos et al., 2004; Foladori et al., 2006; 
Bougrier et al., 2006; Nickel and Neis, 2007; Pham et al., 2007; Zhang et al., 2007, Zhang et al., 2008; Salsabil et al., 2009; Yan et al., 2010; Kim et al., 2010; Braguglia et al., 2011; and Yaqci et al., 2011). Table 2.5 provides a summary of some literature involving sonication including sonication characteristics, solubilisation extent, solids reduction, and biodegradability of WAS, all factors that are important to this study.

Most of the existing literature assessed the effect of sonication on WAS by monitoring the soluble chemical oxygen demand (SCOD) release or solubilisation ratio. The solubilisation ratio is defined as the fraction of total chemical oxygen demand (COD) that is soluble. Past research has demonstrated that a linear relationship exists between sonication duration and solubilisation ratio or SCOD concentration. For instance, Chu et al., (2001) concluded that as the treatment time was increased from 20 to 120 minutes, the fraction of SCOD/TCOD increased from 3 to $20 \%$. In another study, Kim et al., (2010) observed an increased solubilisation from 8 to $50 \%$, when the the energy supply was increased from 3750 to $45000 \mathrm{~kJ} / \mathrm{kgTS}$. Similarly, Zhang et al., (2007) noticed an SCOD increase of about $3000 \mathrm{mg}$ COD/L after increasing the sonication duration from 0 to 30 minutes. In another study, Yaqci et al., (2011), reported a 36\% SCOD increase after increasing the sonication duration from 0 to 30 minutes, thus verifying the linear relationship between sonication duration and SCOD concentration. Thus, most studies suggest that increasing the sonication duration increases the solubilisation ratio.

Analogous to COD solubilisation, sonication has also been reported to result in increased solids solubilisation with an increase in sonication duration. For instance, Zhang et al., (2007) observed a decrease in TSS concentrations of up to $24 \%$ when the sonication duration increased from 0 to 30 minutes, thus demonstrating that sonication solubilizes suspended matter. Salsabil et al., (2009) also observed a linear relationship between TSS and VSS solubilisation and 
treatment duration, with a maximum TSS and VSS reduction of 23.3 and $29.7 \%$ at a duration of 4 hours. In another study, Bougrier et al., (2006) pre-treated WAS samples of $20 \mathrm{~g} / \mathrm{L}$ TSS at specific energies of $6250 \mathrm{~kJ} / \mathrm{kg}$ TS and $9350 \mathrm{~kJ} / \mathrm{kg}$ TS. It was found that the VSS/TSS ratio decreased from 78 to $73 \%$ with the energy supplied indicating preferential solubilisation of organics. Sonication only slightly affected the inert solids, i.e. less than $10 \%$ of the inert solids were solubilized. Thus, sonication significantly affected the organic solids but not the inert fraction.

Although sonication results in the transfer of materials from the particulate phase into the soluble phase, no studies discussed in Section 2.5 observed significant reductions in total COD. In other words, no significant destruction of organic matter took place. Thus, sonication did not diminish the available resource for methane generation.

In addition to solids and COD solubilisation while conserving TCOD, sonication has also led to improvements in the biodegradability of WAS. The extent of solubilisation of COD fractions has been used to assess the impact of pre-treatment on the biodegradability of WAS (Kianmehr, 2010). For instance, Grönroos et al., 2004 studied the effect of sonication duration on SCOD increase and methane production from WAS. They noticed that as they increased the sonication duration from 0 to 10 minutes, the SCOD concentration and methane production increased from 620 to $4200 \mathrm{mg} \mathrm{SCOD} / \mathrm{L}$ and from 3.22 to $8.09 \mathrm{~m}^{3} \mathrm{CH}_{4} / \mathrm{kg}$ SCOD consumed in sample, respectively. In another study, Braguglia et al., (2008) observed that an increase in SCOD concentration was accompanied by an increase in VSS destruction from 2 to $5 \%$ and biogas volume from 26 to $29 \%$ via AD when the sonication duration was increased from 2 to 4 minutes. Similarly, Nickel and Neis, (2007) also observed a biogas volume increase of $16 \%$ and a VSS destruction increase of $40 \%$ after increasing the sonication intensity from 5 to $18 \mathrm{~W} / \mathrm{cm}^{2}$. 
Therefore, PT can result in an increase in the extent of destruction by making soluble matter more readily available to microorganisms.

As previously discussed, sonication of WAS results in the release of material from the particulate phase to the soluble phase. A considerable fraction of organic materials in WAS comprises of extra cellular polymeric substances (EPS) (Liu and Fang, 2002). It has been hypothesized that sonication of WAS results in the solubilisation of EPS, which results in smaller and finer particles such as colloids (Kianmehr, 2010). Some studies have reported an increase in colloidal COD (cCOD) with sonication. For this study, cCOD represents the fraction of COD that can pass through a $1.5 \mu \mathrm{m}$ filter but not through a $0.45 \mu \mathrm{m}$ filter. In one study, Musser, (2010) observed an increase in cCOD/TCOD fraction from 15 to $50 \%$ after increasing the ultrasound dose from 2 to $12 \mathrm{~kJ} / \mathrm{gTS}$. Similarly, Kianmehr, (2010) also reported an increase in cCOD of up to $30 \%$ as the sonication duration was increased from 0 to 50 minutes. Kianmehr, (2010) attributed this increase to the solubilisation of EPS, which resulted in an increase in cCOD concentration.

In summary, sonication has been found to lead sludge disintegration, reduction in solids concentration, and increased biodegradability. In addition, it has been reported that sonication accomplishes all of the above without producing any odours and using any additional chemicals (Salsabil et al., 2009 and Pilli et al., 2011). Due to all these reasons, sonication is a popular method of pre-treating WAS. This study will evaluate the effect of sonication on WAS using existing literature sonication durations to determine if existing results can be replicated. 
Table 2.5: Summary of Literature on Sonication Effects on WAS

\begin{tabular}{|c|c|c|c|c|c|c|c|}
\hline \multirow{2}{*}{$\begin{array}{l}\text { Type } \\
\text { of } \\
\text { Feed }\end{array}$} & \multirow{2}{*}{$\begin{array}{c}\text { Sonication } \\
\text { characteristics }\end{array}$} & \multicolumn{2}{|c|}{ Total Solids (g/L) } & \multirow[b]{2}{*}{$\begin{array}{c}\text { Solubilisation } \\
(\%)\end{array}$} & \multirow{2}{*}{$\begin{array}{c}\text { Destruction } \\
\text { Increase }(\%)\end{array}$} & \multirow[b]{2}{*}{$\begin{array}{l}\text { Biogas Volume } \\
\text { Increase }(\%)\end{array}$} & \multirow[b]{2}{*}{ Reference } \\
\hline & & Feed Samples & $\begin{array}{c}\text { Sonicated } \\
\text { Samples }\end{array}$ & & & & \\
\hline WAS & $\begin{array}{l}20-120 \\
\text { minutes } \\
(\text { at } 0.33 \\
\mathrm{W} / \mathrm{mL}) \\
\end{array}$ & 8.2 & - & $3.0-20.0$ & - & - & $\begin{array}{l}\text { Chu et } \\
\text { al., } \\
(2001)\end{array}$ \\
\hline WAS & $\begin{array}{c}0-10 \\
\text { minutes }\end{array}$ & - & - & 577 & - & 151 & $\begin{array}{c}\text { Grönroos } \\
\text { et al., } \\
2004 \\
\end{array}$ \\
\hline WAS & $\begin{array}{l}6250 \mathrm{~kJ} / \mathrm{kgTS} \\
9350 \mathrm{~kJ} / \mathrm{kgTS}\end{array}$ & 20 & 18 & 20 & - & $\begin{array}{l}47 \\
51\end{array}$ & $\begin{array}{c}\text { Bougrier } \\
\text { et al., } \\
(2006)\end{array}$ \\
\hline WAS & 0-30 minutes & 9.95 & $0-24 \%$ & $30.1^{\mathrm{f}}$ & - & - & $\begin{array}{c}\text { Zhang et } \\
\text { al., } \\
(2007)\end{array}$ \\
\hline WAS & $\begin{array}{c}5.0-18.0 \\
W / \mathrm{cm}^{2}\end{array}$ & $5.0-40 \mathrm{~g} / \mathrm{L}$ & - & 20 & $40^{\mathrm{b}}$ & 16 & $\begin{array}{c}\text { Nickel } \\
\text { and Neis, } \\
(2007)\end{array}$ \\
\hline WAS & $\begin{array}{l}2 \text { minutes } \\
4 \text { minutes }\end{array}$ & 23 & - & $\begin{array}{l}4^{\mathrm{g}} \\
8^{\mathrm{h}}\end{array}$ & $\begin{array}{l}5^{c} \\
2^{d}\end{array}$ & $\begin{array}{l}26 \\
29\end{array}$ & $\begin{array}{c}\text { Braguglia } \\
\text { et al., } \\
(2008)\end{array}$ \\
\hline WAS & $\begin{array}{c}0-4 \text { hours } \\
0-108000 \\
\mathrm{~kJ} / \mathrm{kgTS}\end{array}$ & 17.81 & $\begin{array}{c}\text { reduction of } \\
7.1-22.3 \%\end{array}$ & 10 & $2.4-7^{\mathrm{e}}$ & $6.7-83$ & $\begin{array}{c}\text { Salsabil } \\
\text { et al., } \\
(2009)\end{array}$ \\
\hline WAS & $\begin{array}{c}3750-45000 \\
\mathrm{~kJ} / \mathrm{kgTS}\end{array}$ & 37.1 & - & $8.0-50.0$ & - & - & $\begin{array}{l}\text { Kim et } \\
\text { al., } \\
(2010)\end{array}$ \\
\hline WAS & 1 - 30 minutes & - & $\begin{array}{l}\text { reduction of } \\
26 \%^{\mathrm{a}}\end{array}$ & 35.5 & - & - & $\begin{array}{c}\text { Yaqci et } \\
\text { al., } \\
(2011)\end{array}$ \\
\hline
\end{tabular}

${ }^{\mathrm{a}}$ VSS Reduction

b, c, d VSS Destruction

${ }^{\mathrm{e}}$ COD destruction

$\mathrm{f}, \mathrm{g}, \mathrm{h}$ Degree of Disintegration 


\subsection{Chemical Pre-treatment}

Like sonication, chemical treatment has been reported to break down complex organic compounds present in WAS and solubilise them. Chemical pre-treatments that have been evaluated include hydrochloric acid $(\mathrm{HCl})$, sulfuric acid $\left(\mathrm{H}_{2} \mathrm{SO}_{4}\right)$, hydrogen peroxide $\left(\mathrm{H}_{2} \mathrm{O}_{2}\right)$, Sodium Hydroxide $(\mathrm{NaOH})$, potassium hydroxide $(\mathrm{KOH})$, etc. Out of all of the above, $\mathrm{H}_{2} \mathrm{O}_{2}$ is gaining popularity due to its wide range of treatability. Hydrogen peroxide has been found to be able to degrade many kinds of organic compounds including those that are moderately and highly refractory with low biodegradability (Agustina et al., 2005). Moreover it has also been used to treat inorganics and other compounds such as sulfites, nitrites, hypochlorites, aromatics, biphenyls, pesticides, herbicides, etc. Thus, $\mathrm{H}_{2} \mathrm{O}_{2}$ is capable of degrading a wide variety of substances.

In the few studies that have been conducted to determine the effect of peroxide dosing on high solids waste streams it has been concluded that a linear relationship exists between peroxide dose and solids and COD solubilisation. For instance, Wang et al., (2009) reported that an increase in the ratio of $\mathrm{H}_{2} \mathrm{O}_{2} / \mathrm{TCOD}$ from 0 to 4.5 (w/w) resulted in an increase in SCOD concentration by $2000 \mathrm{mg} / \mathrm{L}$. Similarly, they observed a reduction in the VSS/TSS ratio from 0.73 to 0.58 with an increase in the $\mathrm{H}_{2} \mathrm{O}_{2}$ /TCOD ratio, thus demonstrating solubilisation of organics. In another study, Eskicioglu et al., (2008) observed an increase in the solubilisation ratio from 3 to $18 \%$ when the peroxide dose increased 0 to $1 \mathrm{~g} \mathrm{H}_{2} \mathrm{O}_{2} / \mathrm{g}$ TS of thickened WAS. Similarly, Dewil et al., (2007) reported an increase in SCOD concentrations from 787 to 2507 $\mathrm{mg} / \mathrm{L}$ after applying an $\mathrm{H}_{2} \mathrm{O}_{2}$ dose range of 5-50 $\mathrm{gH}_{2} \mathrm{O}_{2} / \mathrm{kgDS}$. Although there has been an increase in SCOD in these studies, none of them reported an increase in cCOD, thus suggesting that the effect of $\mathrm{H}_{2} \mathrm{O}_{2}$ on cCOD was negligible. 
A few studies have reported a loss of organic matter due to oxidation by $\mathrm{H}_{2} \mathrm{O}_{2}$. For instance, Eskicioglu et al., (2008) reported losses of 18, 11, 34, and 16\% of TCOD, proteins, sugars, humic acids and total biopolymer concentrations, respectively after treating a $6.4 \%$ thickened WAS samples with $1 \mathrm{~g} \mathrm{H}_{2} \mathrm{O}_{2}$ /gTS. Similarly, Grönroos et al., (2004) observed a $10 \%$ decrease in COD after treating sludge with $65.8 \mathrm{kgH}_{2} \mathrm{O}_{2} / \mathrm{tDS}$. Therefore, treatment with $\mathrm{H}_{2} \mathrm{O}_{2}$ in both cases led to a loss of resource for methane generation.

In addition to solids and COD solubilisation, some studies have observed an increase in biogas volume when digesting samples after $\mathrm{H}_{2} \mathrm{O}_{2}$ dosing. For instance, Song et al., (2012a) reported that an increase in $\mathrm{H}_{2} \mathrm{O}_{2}$ concentration from $3 \%$ to $4 \%$ improved the biodegradability of rice straw with a $4.5 \%$ TS concentration. The results demonstrated that treatment with $4 \% \mathrm{H}_{2} \mathrm{O}_{2}$ yielded the highest biogas production, with a biogas volume of $327.5 \mathrm{~mL} / \mathrm{gVS}$ removed compared to a control volume of $125 \mathrm{~mL} / \mathrm{gVS}$ removed. In another study, Song et al., (2012b) observed an $88 \%$ increase in methane yield (compared to the control) by applying a $\mathrm{H}_{2} \mathrm{O}_{2}$ dose of $2.68 \%$ (w/w TS). Therefore, peroxidation led to the solubilisation of particulates, which resulted in an improved biodegradability.

In conclusion, pre-treatment of high solids streams with hydrogen peroxide alone has not been widely researched in literature. However, based on available literature, it can be established that peroxidation results in COD and solids solubilisation, and thus improved biodegradability. Peroxidation may also lead to a loss of organic matter, thus diminishing the available resources for methane generation. Therefore, low concentrations of peroxide addition may be necessary to avoid loss of biodegradation potential. 


\subsection{Combined Peroxide-Ultrasonic Pre-treatment}

Although $\mathrm{H}_{2} \mathrm{O}_{2}$ can be used in the treatment of a wide variety of inorganic and organic pollutants, treatment with $\mathrm{H}_{2} \mathrm{O}_{2}$ alone may not be enough to treat high concentrations of some refractory contaminants (Neyens et al., 2003). Combining $\mathrm{H}_{2} \mathrm{O}_{2}$ with other forms of pretreatment such as metals like iron, ozone, microwave, and ultrasound has been found to lead to the generation of strong oxidants in the form of hydroxyl radicals (Eskicioglu et al., 2008). Hydroxyl radicals are known to be a stronger oxidant than $\mathrm{H}_{2} \mathrm{O}_{2}$ itself (Shen and Anastasio, 2012). This combination of pre-treatments known as an advanced oxidation treatment (AOT) may prove to be more efficient in terms of reducing peroxide doses and increasing the extent of solubilisation and biodegradability as compared to the individual treatments.

The use of a combination of peroxide and ultrasound for pre-treatment of WAS has not been widely investigated; however a number of studies with peroxide-microwave, peroxidethermal, peroxide-ozone, and peroxide-iron treatments have been reported. The application of an $\mathrm{H}_{2} \mathrm{O}_{2}$ /US AOP was evaluated by Grönroos et al., (2004). This study compared the increase in SCOD concentrations in sludges that were subjected to three types of PTs - sonication at a specific energy of $6300 \mathrm{~kJ} / \mathrm{kDS}$, treatment with 26.3 and $65.8 \mathrm{kgH}_{2} \mathrm{O}_{2} / \mathrm{tDS}$ for 10 minutes individually, and treatment with a combination of peroxide and US. It was observed that individual treatment with US led to the greatest SCOD increase of about $1000 \mathrm{mg} / \mathrm{L}$. Individual chemical PTs with $26.3 \mathrm{kgH}_{2} \mathrm{O}_{2} / \mathrm{tDS}$ resulted in an insignificant SCOD increase of 150-200 $\mathrm{mg} / \mathrm{L}$, whereas treatment with $65.8 \mathrm{kgH}_{2} \mathrm{O}_{2} / \mathrm{tDS}$ resulted in a decrease in SCOD. Each AOP resulted in a higher SCOD concentration than individual chemical treatments but they were still lower than the US treatment by $11 \%$. This was attributed to the extremely high peroxide doses, 
which led to a loss of organic matter in the sludge, and thus an insignificant or undesirable change in SCOD concentrations.

Although the results from Grönroos et al., (2004) indicated that US PT resulted in improved COD solubilisation as compared to a combined AOP, other AOPs with $\mathrm{H}_{2} \mathrm{O}_{2}$ have shown conflicting results. For instance, Eskicioglu et al., (2008) compared the effects of microwave, chemical and combined microwave -chemical treatment on solubilisation and demonstrated that a $25 \%$ solubilisation was attained with a combined AOP with a $1 \mathrm{gH}_{2} \mathrm{O}_{2} / \mathrm{gTS}$ dose and $120^{\circ} \mathrm{C}$ temperature. The SCOD/TCOD ratio obtained with individual peroxide and microwave PT were 14 and 18\%, respectively. In another study, Yin et al., (2007) compared the use of $\mathrm{H}_{2} \mathrm{O}_{2}$, ozone, MW, $\mathrm{H}_{2} \mathrm{O}_{2}$-ozone, MW- $\mathrm{H}_{2} \mathrm{O}_{2}$, MW-ozone, or MW- $\mathrm{H}_{2} \mathrm{O}_{2}$-ozone for solubilisation of sewage sludge. They subjected $90 \mathrm{~mL}$ of sludge to a MW temperature of $100^{\circ} \mathrm{C}$, peroxide dose of $3 \mathrm{~mL}$, and an ozonation duration of 20 minutes. It was concluded that the MW- $\mathrm{H}_{2} \mathrm{O}_{2}$-ozone combination yielded the greatest COD solubilisation of 37\%. Compared to Grönroos et al., (2004), these AOPs resulted in higher solubilisations than individual PTs. This may have been due to the significantly lower $\mathrm{H}_{2} \mathrm{O}_{2}$ doses as opposed to the ones used by Grönroos et al., (2004).

As with the other pre-treatments discussed in this chapter, an increase in SCOD due to an AOP has been reported to result in an improvement in destruction in subsequent anaerobic digestion. Rivero et al., (2012) observed that thermal PT at $90^{\circ} \mathrm{C}$ did not lead to any increase in solids destruction and peroxide PT at $2 \mathrm{gH}_{2} \mathrm{O}_{2} / \mathrm{gVSS}$ resulted in a maximum VSS destruction increase of $15.2 \%$ via AD. However, a combined AOP resulted in an increase in VSS destruction of $29 \%$. Thus, the combined AOP was more effective in improving the biodegradability of the WAS. 
In conclusion, relatively little research has been done on evaluating the effect of an $\mathrm{H}_{2} \mathrm{O}_{2} /$ US AOP on WAS. However some research has been performed with peroxide-microwave, peroxide-thermal, and peroxide-ozone AOPs. The dose of $\mathrm{H}_{2} \mathrm{O}_{2}$ is a significant factor in an AOP since high doses may lead to loss of organic matter, and thus reduced biodegradability. Using low peroxide doses in combination with other PTs may result in an increased solubilisation and biodegradability than individual treatments.

\subsection{Integration of Pre-treatment and AnMBRs}

As mentioned in Section 2.4, incorporating a membrane into an anaerobic digester can result in an improved biodegradability compared to conventional AD. However, the improvement in biodegradability may be limited due to the reactors inability to completely break down organics and a lengthy and time-consuming digestion process. Moreover, a drawback to using an AnMBR is membrane fouling, which can be challenging when treating high solids waste streams such as WAS (Section 2.5). In addition to the high solids concentrations of the feed, a high SRT/HRT ratio will result in a higher MLSS concentration in the reactor. This may lead to an increase in membrane fouling and thus high costs associated with cleaning and replacement of the membrane.

Integration of PT with AnMBRs may provide a solution to increasing the ultimate biodegradability of WAS. As discussed in section 2.9, it is expected that an AOP using sonication and hydrogen peroxide will result in solubilisation of particulates thus resulting in an increased concentration of SCOD. With a significant amount of particulates broken down, a high sludge age that can be achieved through the use of membranes to prevent biomass washout may result in an enhanced destruction of compounds. Some studies have been performed to determine 
the effect of coupling pre-treatment of WAS with AnMBRs. Pickel, (2010) studied the effect of combining microwave PT of $2 \%$ WAS at $67.5^{\circ} \mathrm{C}$ with AnMBRs and concluded that this combination resulted in greater COD degradation of $48.2 \%$ than a PT + AD (32.8\%) or no PTAD/AnMBR (32.2 and 44.4\%, respectively) combination. The higher destruction of this combination indicated that the pre-treatment, presence of the membrane unit, and the decoupling of the HRT and SRT improved the biodegradation potential of WAS.

Enhanced biodegradability as a result of this combination is expected to result in decreased fouling of the membrane. As mentioned in section 2.6, pre-treatment of WAS is expected to reduce the solids concentration of the WAS. This is a benefit not only because it contributes to high solids reduction but also decreases the solids loading on the membrane in AnMBRs. Decreased loadings may result in reduced membrane fouling. In addition, decreased solids concentrations may also lead to cost savings due to reduced shear rates and reduced requirements for cleaning agents. The literature has established successful operation of membranes with a PT-AnMBR combination. For instance, Pickel, (2010) achieved high destruction rates without any maintenance cleaning or replacement of the membrane, thus demonstrating successful operation of the AnMBR without any major fouling.

As discussed earlier, with pre-treatment, the fraction of colloidal and soluble organic and inorganic materials in WAS is expected to increase. Hence with an increase in the SRT to HRT ratio and a membrane, accumulation of the non-and slowly biodegradable particulates may occur. Therefore it may be possible that an AnMBR treating pre-treated WAS high in cCOD fractions, long SRTs would cause an additional increase in colloidal fractions in the reactor and hence membrane performance would decline. In addition, non-biodegradable and inert fractions may also accumulate in the reactor due to PT and low sludge waste volumes as a result of long 
sludge ages. However due to the lack of studies determining the impact of PT on fouling, the above explanations are uncertain and merely an assumption. Therefore, this study will contribute to filling the void in this area of research, and assess the impact of colloids and other inerts on membrane performance.

\subsection{Summary of Chapter 2}

In conclusion, there are a variety of factors affecting the efficiency of a peroxide-sonic pre-treatment. Most of the studies to date have studies the effect of ultrasound frequency, ultrasound duration, peroxide dose, and TS of sample on WAS solublization. This study will build on the previous studies that have assessed the effect of ultrasound duration and hydrogen peroxide dose on WAS solublization by examining the use of ultrasound durations and peroxide doses that have been reported in the literature. There have been many studies on the individual effect of sonication and a few on the effect of peroxide on WAS; however limited information on the synergistic benefits of peroxide-sonic effect is available. This study aims to determine the effect of a combined hydrogen peroxide and ultrasound PT system on WAS. A major difference between existing chemi-sonic treatments and this study is that this study uses a flow through system to accomplish combined PT of considerably larger volumes of WAS rather than treating WAS individually with each PT for small volumes.

In addition, this study will couple the PT system with a PVDF submerged hollow fibre AnMBR to improve biodegradability, a combination which has not been widely reported in existing literature. In order to determine the effect of PT-AD on WAS biodegradability, a wide range of physical, chemical and biological parameters such as particle size, TS, VS, SCOD, $\mathrm{NH}_{3}$, STKN, heterotrophic count and biogas volume has been reported. This study will focus on COD, 
solids, nitrogen fractions, and membrane performance to assess the process efficiency of PT and AnMBR. Membrane fouling will be assessed by monitoring TMP when operated at constant flux and through critical flux tests that will be conducted at steady state. 


\section{Chapter 3: Pre-treatment of WAS}

\subsection{Introduction}

There are usually two types of waste water sludge that are produced at wastewater treatment plants (WWTPs) - Primary (PS) and Secondary or Waste Activated Sludge (WAS). Primary sludge is the product of a mechanical process while WAS is the product of biological processes such as the activated sludge process. With growing populations the volume of sludge to be processed at WWTPs is generally increasing. This poses a challenge to plant owners and operators since the costs associated with sludge treatment/stabilization and disposal may be as high as $50 \%$ of the total cost of treating wastewater (Zhang et al., 2007).

Anaerobic Digestion (AD) is a common sludge stabilization method employed at WWTPs that not only converts the organic matter into a renewable source of energy i.e. biogas, but also decreases the amount of solids while destroying a majority of the pathogens in the sludge (Abelleira et al., 2012). This complex biochemical process employs facultative and anaerobic microorganisms that work together to achieve stabilization and treatment of sludge in the absence of oxygen. AD decomposes organic matter in 4 stages: Hydrolysis, Acidogenesis, Acetogenesis, and Methanogenesis. The performance of anaerobic digestion of WAS is typically determined by the rate-limiting hydrolysis step since it makes organics available to microorganisms. This slow process thus requires digesters with long retention times, which results in an increase in the volume of the digester and associated costs. Numerous studies have examined methods to increase the rate of hydrolysis and hence reduce the volume needed for digesters in WWTPs.

Pre-treatment (PT) of sludge has been found to be one way of increasing the rate of hydrolysis (Shahriari et al., 2011). Pre-treatment leads to the lysis of cells, which in turn causes 
the release, and thus solubilisation and availability of intracellular matter to microorganisms (Bougrier et al., 2005). Solubilisation of particulate matter has been found to cause changes in the physical and chemical properties of a sludge (such as suspended solids and chemical oxygen demand), thus making it more readily available for microbial growth and metabolic activities (Pham et al., 2007). Since pre-treatment increases the rate of digestion, this may allow treatment plants to reduce the retention time in digesters thereby making operation more economically favourable (Bougrier et al., 2005). A variety of pre-treatments have been proposed for use prior to anaerobic digestion - mechanical such as sonication, chemical such as peroxidation, and thermal treatments. The following provide discussion provides a brief description of all three PTs.

Sonication has been reported to be a promising and effective pre-treatment method to enhance the biodegradability of sludge and has been widely examined at laboratory, pilot and recently at full scale (Tiehm et al., 1997; Chu et al., 2001; Onyeche et al., 2002; Grönroos et al., 2004; Odegaard, 2004; Foladori et al., 2006; Pham et al., 2007; Zhang et al., 2008; Salsabil et al., 2009; Yan et al., 2010; and Braguglia et al., 2011). When an ultrasound (US) wave travels through a media such as water, it generates numerous cavitation bubbles in the water (Suslick 1988). Continuous oscillation of the wave causes the local pressure to drop below the evaporating pressure, which in turn causes these microscopic bubbles to explode (Wandzel et al., 2011). This abrupt and intense collapse of a large number of bubbles produces strong mechanical shear forces that can disintegrate bacterial cells, cells walls, and membranes (Khanal et al., 2007). The disruption of bacterial cells results in the release of intracellular organic substances and solubilisation of particulate organic matter (Takatani et al., 1981). It has been hypothesized that fragmentation of organics due to sonication aids the rate-limiting hydrolysis reaction in 
anaerobic digestion and hence can in turn be reflected by increased methane generation and reduced sludge volume (Show et al., 2007).

Most reports in the literature describe the effect of sonication on WAS through soluble chemical oxygen demand (SCOD) release or the solubilisation ratio. The solubilisation ratio is defined as the fraction of total chemical oxygen demand (COD) that is soluble. Previous studies have demonstrated a linear relationship between sonication duration and the solubilisation ratio or SCOD concentration. For instance, Chu et al., (2001) concluded that as the treatment time was increased from 20 to 120 minutes, the fraction of SCOD/TCOD increased from 3 to $20 \%$. Similarly, Yaqci et al., (2011), reported a 36\% SCOD increase after increasing the sonication duration from 0 to 30 minutes, thus verifying the linear relationship between sonication duration and SCOD concentration.

Most studies have also demonstrated that an increase in SCOD concentration is an indicative of improvement in biodegradability of WAS. For instance, Pham et al., (2007) observed that sonication of $23 \mathrm{~g} / \mathrm{L}$ WAS for 60 minutes yielded the highest solubilisation ratio of $79 \%$ out of a test range of 20-60 minutes. This increase in SCOD/TCOD corresponded to an increase in solids destruction of $36.5 \%$ in aerobic digestion (Pham et al., 2007). In another study, Braguglia et al., (2008) observed a 3\% increase in biogas volume after increasing the sonication duration from 2 to 4 minutes. Overall, sonication as a method of PT has been drawing a lot of attention recently since it can lead to improvements in sludge disintegration and biodegradability, without producing odours, and using chemicals (Salsabil et al., 2009 and Pilli et al., 2011).

Thermal hydrolysis is another widely used technique which has been known to increase the solubilisation ratio, and thus increase destruction rates and biogas volumes (Kepp et al., 
2000). Prior studies on thermal pre-treatment of WAS have examined operation over a broad temperature range of 60 to $270^{\circ} \mathrm{C}$. Thermal PT at temperatures greater than $140^{\circ} \mathrm{C}$ has been reported to be more effective than low temperature thermal PT since higher temperatures are more effective in breaking down cells (Gureiff et al., 2011). However, treatment above $180^{\circ} \mathrm{C}$ has been discouraged due to the formation of non-biodegradable compounds at high temperatures (Donoso-Bravo et al., 2011).

It has been found that treatment duration has less effect on sludge characteristics, when the treatment temperature is between 140 and $180^{\circ} \mathrm{C}$ (Bougrier et al., 2007; Climent et al., 2007; and Donoso-Bravo et al., 2011). Most high temperature pre-treatments use a duration of 30-60 minutes (Burger, 2012). A number of studies have been conducted between 150 and $170^{\circ} \mathrm{C}$ with a treatment duration of 30-60 minutes which have proven to improve the solubilisation and biodegradability or rate of digestion of WAS (Li and Noike., 1992; Bourgrier et al., 2006; Bougrier et al. 2008; Chauzy et al., 2007; Fdz-Polanco et al., 2008; Ramirez el al., 2009; and Burger, 2012). For instance, Burger, (2012) pre-treated WAS at $150^{\circ} \mathrm{C}$ for 30 minutes and observed a 56\% SCOD increase and an increase in the rate of aerobic digestion. In another study, $\mathrm{Li}$ and Noike, (1992) subjected WAS to a heat treatment over a temperature range of $62-175^{\circ} \mathrm{C}$ and a duration of 15-120 minutes. They concluded that pre-treatment of WAS at $170^{\circ} \mathrm{C}$ for 60 minutes resulted in the greatest solubilisation and gas production which was 2 times higher than the control in anaerobic digestion. Similarly, Chauzy et al., (2007) observed an increase in solids destruction from 25 to $45 \%$ via $\mathrm{AD}$ with respect to a control, after pre-treating WAS at $160{ }^{\circ} \mathrm{C}$ for 30 minutes. Therefore, similar to sonication, thermal pre-treatment has been found to result in an increase and improvement in solubilisation and biodegradation or rate of digestion. 
Like sonication and thermal PTs, chemical treatment can also break down complex organic compounds present in WAS, solubilise them and improve WAS biodegradability. Chemical pre-treatments that have been evaluated include hydrochloric acid $(\mathrm{HCl})$, sulfuric acid $\left(\mathrm{H}_{2} \mathrm{SO}_{4}\right)$, hydrogen peroxide $\left(\mathrm{H}_{2} \mathrm{O}_{2}\right)$, sodium hydroxide $(\mathrm{NaOH})$, potassium hydroxide $(\mathrm{KOH})$, etc. Out of these, $\mathrm{H}_{2} \mathrm{O}_{2}$ is gaining popularity due to its wide range of treatability. Hydrogen peroxide has been found to be able to degrade many kinds of organic compounds including those that are moderately and highly refractory with low biodegradability (Agustina et al., 2005). Moreover it has also been used to treat inorganics and other compounds such as sulfites, nitrites, hypochlorites, aromatics, biphenyls, pesticides, herbicides, etc. Thus, $\mathrm{H}_{2} \mathrm{O}_{2}$ is capable of degrading a wide variety of substances.

Literature has shown that a linear relationship exists between peroxide dose and SCOD concentrations and biodegradability of WAS. For instance, Eskicioglu et al., (2008) observed an increase in the solubilisation ratio from 3 to $18 \%$ after applying a peroxide dose range of 0 to 1 $\mathrm{gH}_{2} \mathrm{O}_{2} / \mathrm{gTS}$ to thickened WAS samples. Similarly, Dewil et al., (2007) reported an increase in SCOD release from 787 to $2507 \mathrm{mg} / \mathrm{L}$ after applying an $\mathrm{H}_{2} \mathrm{O}_{2}$ dose range of 5-50 $\mathrm{gH}_{2} \mathrm{O}_{2} / \mathrm{kgDS}$. Song et al., (2012) reported that an increase in $\mathrm{H}_{2} \mathrm{O}_{2}$ concentration from $3 \%$ to $4 \%$ improved the solubilisation and biodegradability of rice straw with $4.5 \% \mathrm{TS}$ concentration. The results demonstrated that treatment with $4 \% \mathrm{H}_{2} \mathrm{O}_{2}$ yielded the highest biogas production, with a biogas volume of $327.5 \mathrm{~mL} / \mathrm{gVS}$ removed compared to a control volume of $125 \mathrm{~mL} / \mathrm{gVS}$ removed.

Although $\mathrm{H}_{2} \mathrm{O}_{2}$ can be used in the treatment of a wide variety of inorganic and organic pollutants, treatment with $\mathrm{H}_{2} \mathrm{O}_{2}$ alone may not be feasible for treating high concentrations of some refractory contaminants (Neyens et al., 2003). Combining $\mathrm{H}_{2} \mathrm{O}_{2}$ with other forms of pretreatment such as metals like iron, ozone, microwave, and ultrasound has been found to lead to 
the generation of strong oxidants in the form of hydroxyl radicals (Eskicioglu et al., 2008). Hydroxyl radicals are known to be stronger oxidants than $\mathrm{H}_{2} \mathrm{O}_{2}$ itself (Shen and Anastasio, 2012). This combination of pre-treatments known as an advanced oxidation process (AOP) may prove to be more efficient in terms of reducing peroxide doses and increasing the extent of solubilisation and biodegradability as compared to the individual treatments.

The use of a combination of peroxide and ultrasound for pre-treatment of WAS has not been widely researched; however a number of studies of peroxide-microwave, peroxide-thermal, peroxide-ozone, and peroxide-iron treatments have been reported. Grönroos et al., (2004) compared the increase in SCOD concentrations among sludge samples that were sonicated at a specific energy of $6300 \mathrm{~kJ} / \mathrm{kgDS}$, treated with 26.3 and $65.8 \mathrm{kgH}_{2} \mathrm{O}_{2} / \mathrm{tDS}$ for 10 minutes individually, and subjected to a combination of both peroxide doses and US. It was observed that individual treatment with US led to the greatest SCOD increase of about $1000 \mathrm{mg} / \mathrm{L}$. Individual chemical PTs with $26.3 \mathrm{kgH}_{2} \mathrm{O}_{2} / \mathrm{tDS}$ resulted in an insignificant SCOD increase of 150-200 $\mathrm{mg} / \mathrm{L}$, whereas treatment with $65.8 \mathrm{kgH}_{2} \mathrm{O}_{2} / \mathrm{tDS}$ resulted in a decrease in SCOD. Each AOP resulted in a higher SCOD concentration than the individual chemical treatments but they were still lower than the US treatment by $11 \%$. This was attributed to the high peroxide doses, which led to a loss of organic matter in the sludge, and thus an insignificant or undesirable change in SCOD concentrations.

Although the results from Grönroos et al., (2004) indicated that US PT resulted in greater COD solubilisation than the combined AOP, other AOPs with $\mathrm{H}_{2} \mathrm{O}_{2}$ have shown differing results. For instance, Eskicioglu et al., (2008) compared microwave, chemical and combined micro-chemical treatment and found $25 \%$ solubilisation was attained with a combined AOP with a $1 \mathrm{gH}_{2} \mathrm{O}_{2} / \mathrm{gTS}$ dose and $120^{\circ} \mathrm{C}$ temperature. The SCOD/TCOD ratios obtained with individual 
peroxide and microwave PT were 14 and 18\%, respectively. In another study, Rivero et al., (2012) observed that thermal PT at $90^{\circ} \mathrm{C}$ did not lead to any solids destruction while peroxide PT at $2 \mathrm{gH}_{2} \mathrm{O}_{2} / \mathrm{gVSS}$ resulted in a maximum VSS destruction of $15.2 \%$ via AD. However, a combined AOP resulted in increased VSS destruction of $29 \%$. Compared to Grönroos et al., (2004), these AOPs resulted in higher solubilisations and destructions than individual PTs. This may have been due to the significantly lower $\mathrm{H}_{2} \mathrm{O}_{2}$ doses as compared to the ones used by Grönroos et al., (2004).

As it can be seen from the literature review, ultrasound, thermal and peroxide treatments have been proven to be successful in improving the biodegradability of WAS. This study will contribute to the knowledge base of WAS pretreatment by comparing the effects of three pretreatments - thermal, sonication, and peroxide-sonic AOP on the physico-chemical characteristics and biodegradability of waste activated sludge. Full-scale installations of thermal PT have been successfully used for more than a decade (Tattersall et al., 2011). Therefore the results with thermal pre-treatment provide a reference point to compare against more innovative pre-treatments such as peroxide-US AOPs. The sonication, thermal and chemical conditions used in this study were adapted from the literature discussed in this chapter. In order to provide a comparison between thermal, sonication, and peroxide-sonic PTs in this study, the change in solubilisation ratios and fractionation of COD of WAS due to each PT was first determined. Based on these preliminary tests involving COD and solubilisation analysis, two pre-treatments were selected to perform detailed COD, SS, nitrogen, and biodegradation analysis to characterize the impact of PT resulted on COD, SS, and nitrogen destruction. The biodegradabilty of WAS was measured over an extended period of operation of an Anaerobic Membrane Bioreactor 
(AnMBR). The methods of sample analysis and the operational conditions for the AnMBR used in this study are described in Section 3.2.

\subsection{Materials and Methods}

\subsubsection{Waste Activated Sludge Characteristics}

Secondary sludge was obtained from the Waterloo WWTP located in Waterloo, ON, Canada, which has a daily operating capacity of $72.73 \mathrm{ML}$. This plant makes use of a conventional wastewater treatment process and consists of preliminary, primary, and secondary treatment. For this study, secondary sludge samples were concentrated by settling at $4^{\circ} \mathrm{C}$ for not more than a day until a desired concentration of about $7.5 \mathrm{gTSS} / \mathrm{L}$ was reached. Table 3.1 presents the characteristics of the thickened WAS that was employed in this study.

Table 3.1: Characteristics of Thickened WAS

\begin{tabular}{|c|c|}
\hline Parameters & Concentration \\
\hline $\mathrm{pH}$ & 7.49 \\
\hline $\mathrm{TS}(\mathrm{g} / \mathrm{L})$ & $7.06 \pm 0.17$ \\
\hline Total COD (g/L) & $7.55 \pm 0.87$ \\
\hline Total TKN (gN/L) & $0.66 \pm 0.05$ \\
\hline Soluble COD (g/L) & $0.08 \pm 0.04$ \\
\hline Soluble TKN (gN/L) & $0.03 \pm 0.01$ \\
\hline Ammonia (gN/L) & $0.02 \pm 0.01$ \\
\hline
\end{tabular}




\subsubsection{Pre-treatment Conditions}

The effects of sonication, peroxide-sonication, and thermal pre-treatments on WAS were compared in this study. As mentioned in Section 3.1, treatment durations for sonication and thermal PT as well as peroxide doses were adapted on the basis of results from prior studies. The following sections describe the conditions, equipment, and processes used for PT of sludge in this study.

\subsubsection{Sonication Pre-treatment}

Pre-treatment of WAS was conducted using a flow through continuous system that incorporated a UIP1000 ultrasonic processor from Hielscher Ultrasonics GmbH, Berlin, Germany. Figure 3.1 displays the flow through ultrasound unit setup used for this study. The apparatus had an operational frequency of $20 \mathrm{kHz}$ and was operated at an amplitude of $250 \mu \mathrm{m}$. To avoid over heating of the apparatus due to continuous operation, tap water was recirculated around the stainless steel flow cell enclosing the sample. The sample was continuously stirred by a magnetic stirrer during the treatment. Sludge was recycled at a flow rate of $15 \mathrm{~mL} / \mathrm{minute}$ and the sample remained in the cell for a retention time of 0.8 seconds. Table 3.2 summarizes the different sonication durations that were used. All sonication experiments were performed in duplicate. 


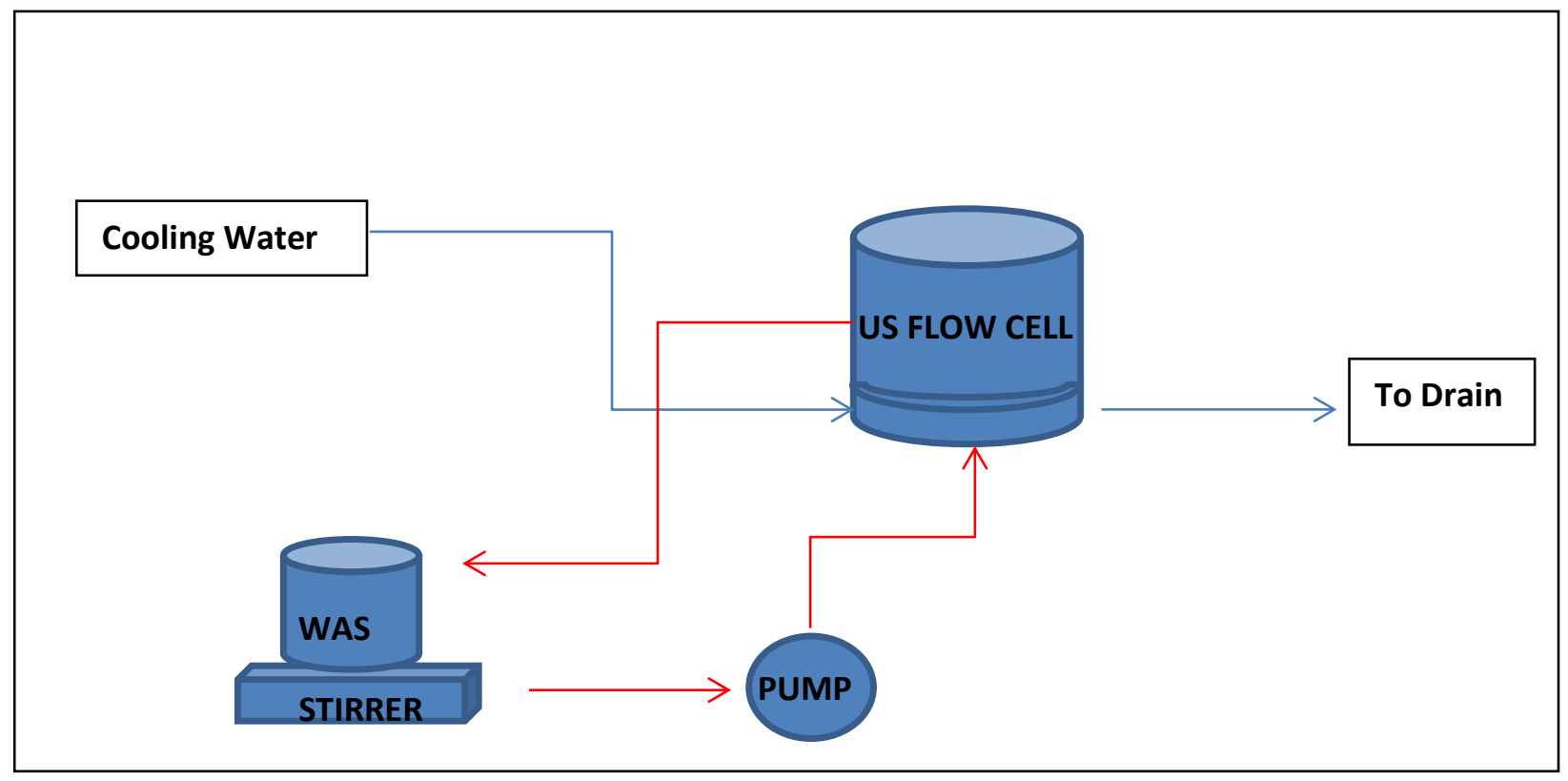

Figure 3.1: Ultrasound Flow Through System Process Flow Diagram

\subsubsection{Pre-treatment with Hydrogen Peroxide/Ultrasound}

Pre-treatment with a combination of hydrogen peroxide and ultrasound was assessed using the ultrasound apparatus described in Section 3.2.2.1. In this approach 1.6 L of WAS was placed in a beaker and a volume of a $35 \%$ solution of $\mathrm{H}_{2} \mathrm{O}_{2}$ was then added. Peroxide was allowed to contact with the sludge for 1 minute before sonication. Table 3.2 summarizes the different peroxide doses that were used in this study. A similar approach was employed for sonication as described in Section 3.2.2.1.

\subsubsection{Thermal Pre-treatment}

Thermal pre-treatment of the WAS was performed using a Parr® Model 4563 Mini Pressure Reactor. Figure 3.2 summarizes the process used for thermal PT in this study. Batch experiments were carried out with $350 \mathrm{~mL}$ of WAS samples for 30 minutes at temperatures of 
either $150^{\circ} \mathrm{C}$ or $170^{\circ} \mathrm{C}$. The sample was continuously stirred by a built in variable speed motor. To avoid over heating of the apparatus due to extended operation, tap water was recirculated around the vessel enclosing the sample.

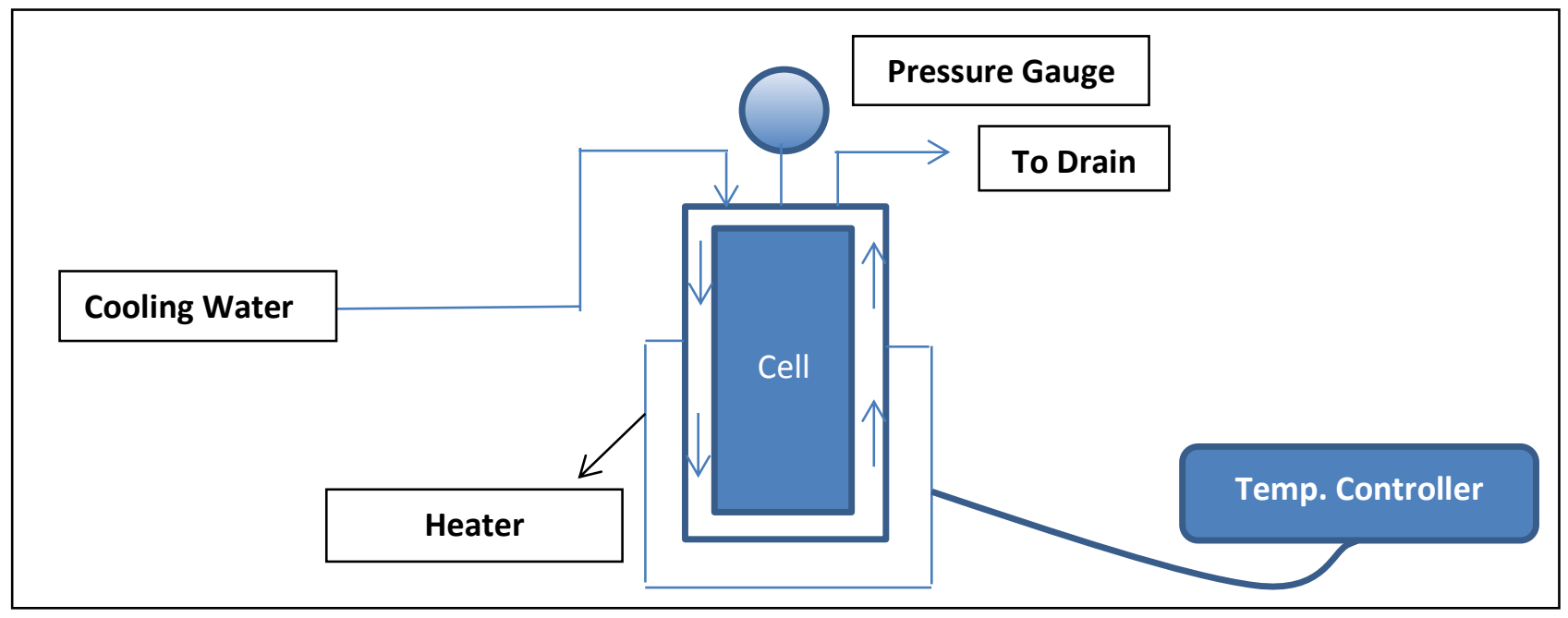

Figure 3.2: Thermal Pre-treatment Process Flow Diagram

Table 3.2: PT Conditions

\begin{tabular}{|c|c|c|c|}
\hline Pre-treatment & $\begin{array}{c}\text { Sonication Duration } \\
(\text { mins })\end{array}$ & $\begin{array}{c}\text { Hydrogen Peroxide } \\
\text { Dose }\left(\mathrm{g} \mathrm{H}_{2} \mathrm{O}_{2} / \mathrm{kg} \text { TS }\right)\end{array}$ & $\begin{array}{c}\text { Thermal PT } \\
\text { Temperature }\left({ }^{\circ} \mathrm{C}\right)\end{array}$ \\
\hline 0 & - & - & - \\
\hline 1 & 10 & - & - \\
\hline 2 & 10 & 5 & - \\
\hline 3 & 10 & 25 & - \\
\hline 4 & 10 & 50 & - \\
\hline 5 & 20 & - & - \\
\hline 6 & 20 & 5 & - \\
\hline 7 & 20 & 25 & - \\
\hline 8 & 20 & 50 & - \\
\hline 9 & 30 & 50 & 150 \\
\hline 10 & 60 & 50 & 170 \\
\hline 11 & - & - & \\
\hline 12 & - & - & - \\
\hline
\end{tabular}




\subsubsection{Anaerobic Membrane Bioreactor (AnMBR) Digestion Operations}

The impact of PT on WAS biodegradability was assessed in long term tests that employed an AnMBR as the bioreactor. A schematic depicting the experimental plan employed for the AnMBR studies is shown in Figure 3.3. As can be seen from the figure, this study was conducted in three phases. Phase 1 utilized raw thickened WAS as feed for the AnMBR while Phases 2 and 3 were carried out with pre-treated WAS. In Phase 2, the AnMBR was fed daily with thickened WAS pre-treated with $50 \mathrm{gH}_{2} \mathrm{O}_{2} / \mathrm{kgTS}$ and 20 minutes US (PT 8) while in Phase

3 the sonication duration was increased to 60 minutes while the peroxide dose was kept constant (PT 10). A 5 L ZeeWeed AnMBR, supplied by General Electric (GE), with a working volume of 4.5 L was operated at an HRT and SRT of 3 and 20 days respectively to accomplish AD for all phases. In Phase 1 (P1) the AnMBR was fed with 1.5 L of thickened WAS daily using a peristaltic pump. The daily permeate volume was $1.275 \mathrm{~L}$ while the waste volume was $225 \mathrm{~mL}$ to maintain the target SRT/HRT values. The operating conditions employed in Phases 2 (P2) and $3(\mathrm{P} 3)$ were the same as that employed in Phase 1. 


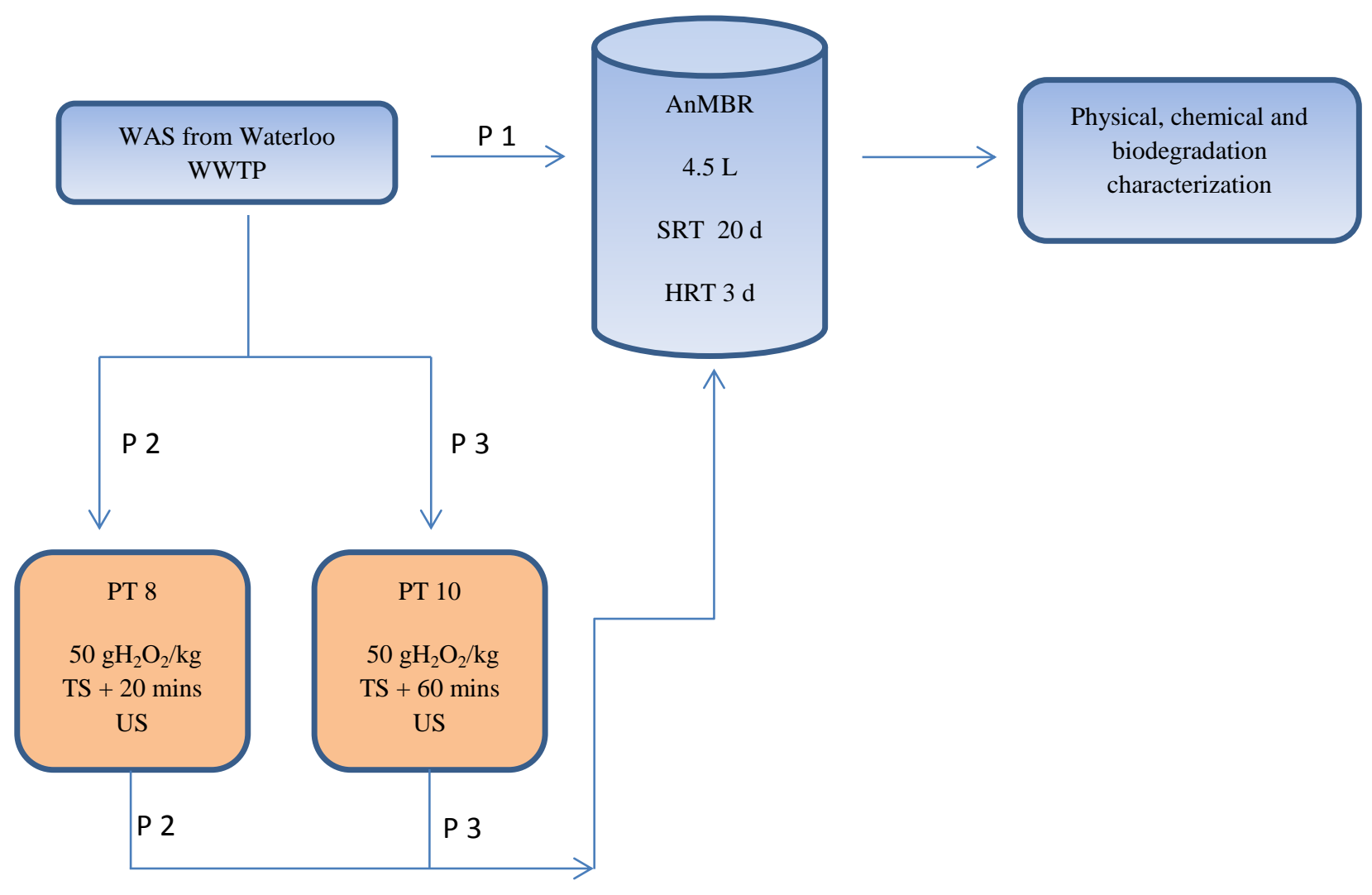

Figure 3.3: Overview of Experimental Plan

Figure 3.4 displays the setup of the reactor used for this study. A flux of $2.75 \mathrm{LMH}$ was used for this study, which corresponded to approximately 3L permeate/day with a membrane surface area of $0.047 \mathrm{~m}^{2}$. Thus, a recirculation point was installed in the permeate collection tank to maintain the HRT at the target value. The recirculation point ensured that only $1.275 \mathrm{~L}$ of permeate was collected every cycle, with the excess recycled back into the reactor.

The AnMBR was maintained at a temperature of $37^{\circ} \mathrm{C}$ using heat tracing cable that was wound around the reactor. The heating cable was controlled by a Dyna-Sense digital temperature controller that was connected to an OMEGA® PR-20 RTD temperature probe which was inserted into the bioreactor through the reactor wall. The reactor and heat trace were wrapped with insulation to help maintain a constant temperature. 
A 3 L Tedlar ${ }^{\circledR}$ gas sampling bag was connected between the gas exit port and the gas meter to buffer pressure changes in the reactor during sludge feeding, wasting, and permeating. The generated biogas for each of the digesters was measured by a gas flow meter that was manufactured at the University of Waterloo and described by Zamanzadeh, (2012). A gas sampling port similar to that described by Zamanzadeh, (2012) was installed into the gas line to facilitate sampling for gas composition. In order to accomplish mixing in the reactor, the generated biogas was recirculated through the reactor at a gas sparging rate of $2 \mathrm{~L} / \mathrm{min}$ with the assistance of a peristaltic pump.

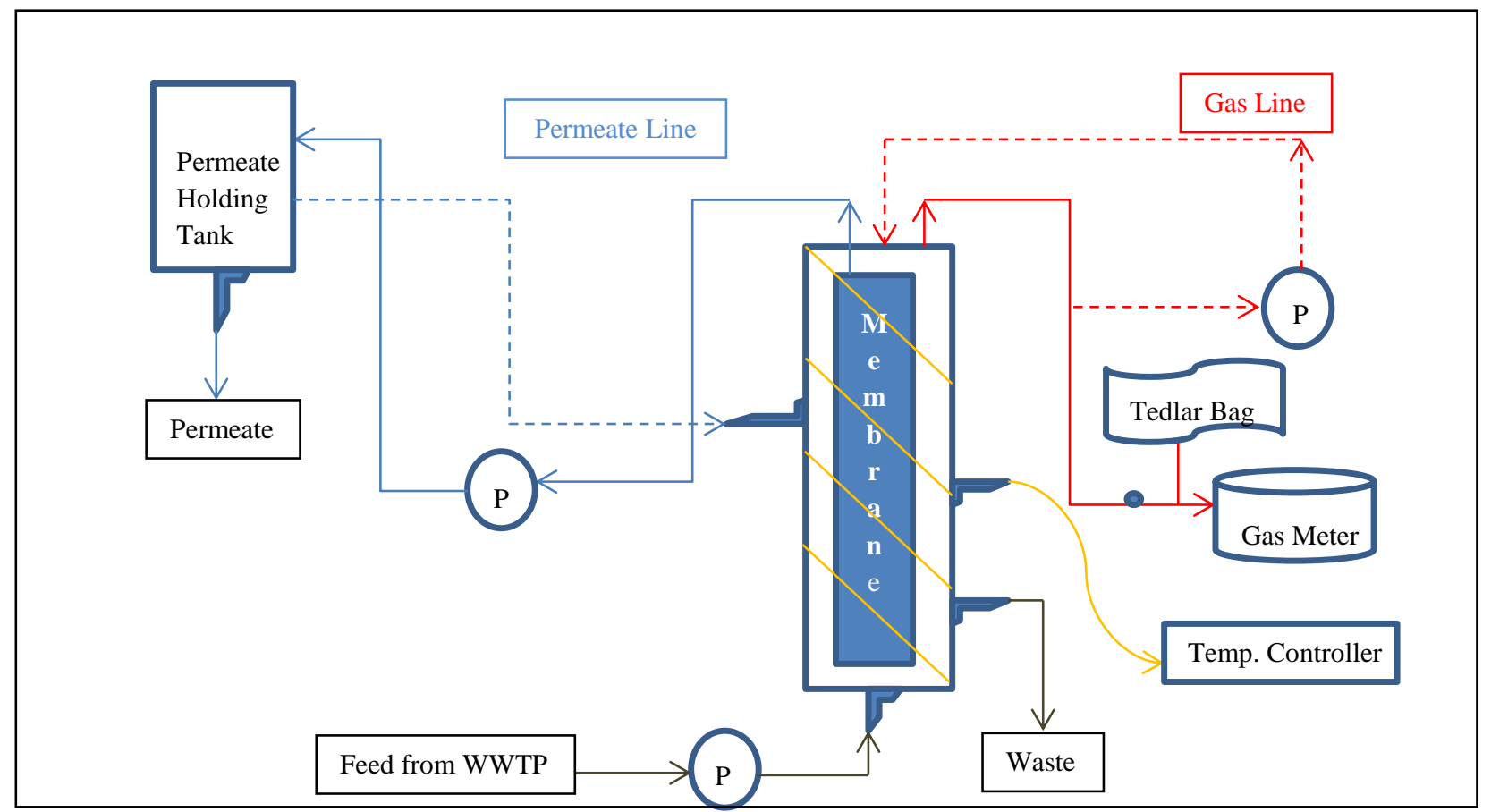

Figure 3.4: AnMBR Process Flow Diagram

\subsubsection{Operation of AnMBR}

The operation of the AnMBR began in October of 2012 and ended in June of 2013. Table 3.3 provides a timeline of the major components of the study with the operation times relative to the starting date. Steady state was reached after 100 days of operation for Phase 1, after which 
the reactor was operated for 35 days during which intensive data collection was conducted according to the sampling plan listed in Section 3.2.5. The reactor was assumed to have reached steady state after it had attained constant COD, SS and nitrogen concentrations. A similar approach was followed with Phase 2 and Phase 3.

Table 3.3: AnMBR Operation Timeline

\begin{tabular}{|c|c|c|}
\hline Operations & Start Date & End Date \\
\hline Sampling of WAS & Day 0 & Day 244 \\
\hline $\begin{array}{c}\text { Physical, Chemical } \\
\text { and Biodegradation } \\
\text { Analysis }\end{array}$ & Day 0 44 \\
\hline $\begin{array}{c}\text { Phase 1 Total } \\
\text { Duration }\end{array}$ & Day 0 & Day 135 \\
\hline $\begin{array}{c}\text { Phase } 1 \text { Steady State } \\
\text { Period }\end{array}$ & Day 100 & Day 135 \\
\hline $\begin{array}{c}\text { Phase } 2 \text { Total } \\
\text { Duration }\end{array}$ & Day 136 & Day 208 \\
\hline $\begin{array}{c}\text { Phase } 2 \text { Steady State } \\
\text { Period }\end{array}$ & Day 167 & Day 208 \\
\hline $\begin{array}{c}\text { Phase } 3 \text { Total } \\
\text { Duration }\end{array}$ & Day 210 & Day 244 \\
\hline $\begin{array}{c}\text { Phase 3 Steady State } \\
\text { Period }\end{array}$ & Day 230 & Day 244 \\
\hline
\end{tabular}

\subsubsection{Sampling Protocol}

The thickened feed, pre-treated feed, and AnMBR samples were analyzed according to the sampling schedule detailed in Table 3.4. All samples were analyzed immediately according to the methods described in Section 3.2.6. Each sample was analyzed in duplicates.

\subsubsection{Feed Collection}

A volume of $40 \mathrm{~L}$ of WAS was sampled from the Waterloo WWTP once per week. Total suspended solids (TSS) measurements were conducted immediately to determine the extent of 
thickening that was required to achieve the desired feed TSS concentration. WAS samples were then thickened accordingly by settling the WAS samples overnight until a TSS concentration of 7.5 g/L was attained. COD, Total Kjeldahl Nitrogen (TKN), ammonia, and SS measurements were performed on the thickened feed $(F)$ samples on the following day.

\subsubsection{PT of WAS}

A volume of $1.6 \mathrm{~L}$ of thickened feed samples was subjected to pre-treatment daily according to the protocol in Section 3.2.2. This ensured that fresh PT feed was fed to the reactor everyday. The pre-treated feed was sampled and analyzed for COD, TKN, ammonia, and SS once per week.

\subsubsection{AnMBR Monitoring}

The waste (W) and permeate (P) streams from the AnMBR were sampled and analyzed for COD, TKN, and ammonia twice a week. The waste stream was sampled and analysed for TSS and VSS once a week. The pH of the waste and permeate was measured daily. The biogas composition and volatile acids to alkalinity ratio (VFA/ALK) were monitored thrice a week. 
Table 3.4: Sampling Schedule

\begin{tabular}{|c|c|c|c|c|c|c|}
\hline Parameter & Mon & Tues & Wed & Thurs & Fri & Sat/Sun \\
\hline TCOD, SCOD, ffCOD & P & W & & P & W, F, PT & \\
\hline TKN, sTKN, Ammonia & $\mathrm{P}$ & $\mathrm{W}$ & & $\mathrm{P}$ & $\mathrm{W}, \mathrm{F}, \mathrm{PT}$ & \\
\hline TSS, VSS & & & $\mathrm{W}, \mathrm{F}, \mathrm{PT}$ & & & \\
\hline pH & $\mathrm{X}$ & $\mathrm{X}$ & $\mathrm{X}$ & $\mathrm{X}$ & $\mathrm{X}$ & $\mathrm{X}$ \\
\hline VFA/ALK & $\mathrm{X}$ & & $\mathrm{X}$ & & $\mathrm{X}$ & \\
\hline Biogas Composition & $\mathrm{X}$ & & $\mathrm{X}$ & & $\mathrm{X}$ & \\
\hline Fresh WAS & & & & $\mathrm{X}$ & & \\
\hline
\end{tabular}

P: Permeate, W: Waste, F: Feed, PT: Pre-treated feed, X: Measured on

\subsubsection{Sample Analysis}

COD analysis was employed to compare thermal, US, and $\mathrm{H}_{2} \mathrm{O}_{2}+\mathrm{US}$ PTs with each other. The fractionation of COD employed in this study is described in Figure 3.5. To evaluate and compare the effect of different PTs on WAS, total COD (TCOD), soluble COD (SCOD), and flocculated and filtered COD (ffCOD) were first measured for all PTs. Once they were determined, particulate COD (pCOD), and colloidal COD (cCOD) were calculated from the measured species for all PTs. Other parameters such as ammonia $\left(\mathrm{NH}_{3}-\mathrm{N}\right)$, TKN, soluble total Kjeldahl nitrogen (STKN), TSS, and volatile suspended solids (VSS) were measured for selected PTs, which were chosen based on the COD analysis. In addition organic nitrogen (ON), soluble organic nitrogen (SON) and fixed/inert suspended solids (FSS/ISS) were calculated from the measured values for these samples. 


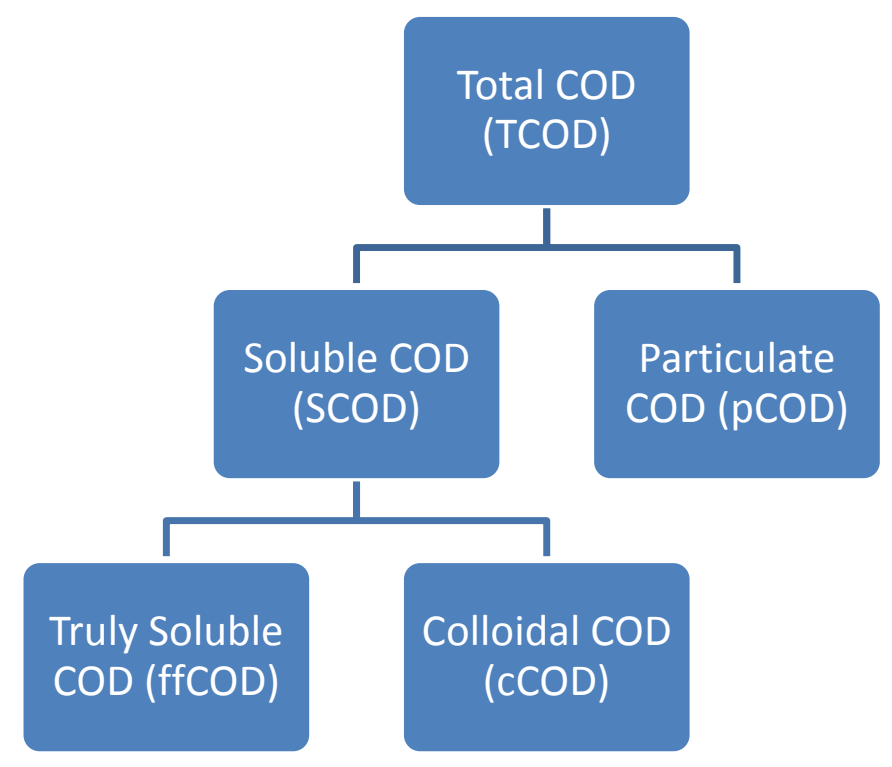

Figure 3.5: Fractionation of COD employed in this study

\subsubsection{Total COD}

COD analysis was conducted according to Standard Method 5220 D (APHA, 1998). To determine the TCOD of a sample, $50 \mathrm{~mL}$ of the sample was first homogenized for 30 seconds. A volume of $2.5 \mathrm{~mL}$ of the blended sample, after applying an appropriate dilution, was added to a COD vial containing $1.5 \mathrm{~mL}$ of COD digestion solution and $3.5 \mathrm{~mL}$ of sulfuric acid reagent. The vial was then mixed by being inverted several times and placed in the preheated HACH COD reactor for 3 hours at $150^{\circ} \mathrm{C}$. Once the total COD samples were cooled to room temperature, they were measured at $600 \mathrm{~nm}$ using a HACH DR/2000 Spectrophotometer. Standards and blanks were also subjected to COD experimental procedures to produce a calibration curve.

\subsubsection{Soluble COD}

In order to determine the SCOD of a sample, $50 \mathrm{~mL}$ of the sample was centrifuged for 30 minutes. The supernatant was then filtered through a Whatman Glass Microfibre filter (934-AH) with a pore size of $1.5 \mu \mathrm{m}$. Once sufficient volume of the filtrate was collected, it was subjected 
to dilution and subsequent measurement as per as the protocol followed with TCOD in Section

\subsubsection{1.}

\subsubsection{Flocculated and Filtered COD}

The flocculated-filtered COD (ffCOD) was considered to represent the truly soluble COD

(Mamais et al., 1993). A volume of $2.5 \mathrm{~mL}$ of $100 \mathrm{mg} / \mathrm{L}$ alum stock solution was added to $25 \mathrm{~mL}$ of the sCOD filtrate and mixed vigorously for 30 seconds. This was followed by allowing the filtrate to settle for 10 minutes, after which it was subjected to 15 minutes of centrifugation. The supernatant obtained from this process was then filtered using a $0.45 \mu \mathrm{m}$ pore size filter. Once sufficient volume of the filtrate was collected, it was subjected to dilution and subsequent measurement as per as the protocol followed with TCOD in Section 3.2.6.1.

\subsubsection{Ammonia}

The analytical method employed for ammonia was conducted according to Standard Method 4500 F (APHA, 1998). A Bran and Luebbe AutoAnalyzer 3 was used to colorimetrically measure the concentration of ammonia in samples. A portion of the sample that was generated for SCOD analysis was used for this purpose after applying an adequate dilution factor. In the AutoAnalyzer the ammonia in a sample was reacted with sodium hypochlorite, a sodium hydroxide buffer solution, and phenol to produced indophenol. Sodium nitroprusside present in the buffer reagent intensified the colour prior to colorimetric analysis at $660 \mathrm{~nm}$.

\subsubsection{Total Kjeldahl Nitrogen}

A portion of the sample that was generated for TCOD analysis was used for TKN analysis. The TKN analysis method employed in this study was developed in the Environment Canada Wastewater Technology Center in Burlington, Ontario. It involved adding $1.5 \mathrm{~mL}$ of a digestion solution to $1 \mathrm{~mL}$ of the homogenized sample in a digestion flask. The digestion 
solution was prepared by first dissolving $40 \mathrm{~g}$ potassium sulfate and $2 \mathrm{~mL}$ selenium oxychloride in $250 \mathrm{~mL}$ sulfuric acid. This solution was then diluted by the addition of deionized water to reach a volume of $500 \mathrm{~mL}$. After addition of the digestion solution the sample was digested in a Bran and Luebbe BD-40 block digester at $220^{\circ} \mathrm{C}$ for 1.5 hours followed by digestion at $380^{\circ} \mathrm{C}$ for 2.5 hours. This digestion converted all the organic nitrogen to ammonia. The samples were allowed to cool down to room temperature overnight, diluted, and analysed the next day using the ammonia analysis described in Section 3.2.6.4.

\subsubsection{Soluble TKN}

A portion of the sample that was generated for measuring SCOD was used for measuring STKN. The same digestion procedure was followed as described in Section 3.2.6.5. The ammonia analyzer was used to measure the concentration of STKN.

\subsubsection{Nitrate}

Nitrate measurements were conducted as per HACH Method 8039 (HACH, 1997). A portion of the sample that was generated for measuring ffCOD was used to measure nitrate. One pouch of HACH NitraVER® 5 Nitrate Reagent power was added to $25 \mathrm{~mL}$ of the sample. The sample was mixed vigorously using a shaker for 1 minute and allowed to rest for 5 minutes. The sample was then analyzed at $400 \mathrm{~nm}$ using the $\mathrm{HACH}$ DR/200 Spectrophotometer.

\subsubsection{Suspended Solids}

The solids analysis in this study was based on Standard Methods 2540 D and E for total suspended solids and volatile suspended solids, respectively (APHA 1998). Total suspended solids were measured by filtering $5 \mathrm{~mL}$ of a sample through a $1.5 \mu \mathrm{m}$ pore size filter that had been previously dried at $550^{\circ} \mathrm{C}$. The filter was then dried at $105^{\circ} \mathrm{C}$ for at least one hour. The increase in mass was then employed to calculate the TSS. The same filter was then combusted at 
$550^{\circ} \mathrm{C}$ for at least 45 minutes. The loss of mass due to ignition was then employed to calculate the VSS. The difference between TSS and VSS employed to estimate the fixed suspended solids (FSS).

\subsubsection{Volatile Fatty Acids to Alkalinity Ratio}

The VFA/Alk ratio was measured to monitor the stability of the AnMBR. A 4-point titration method was adapted from Buchauer, (1998) to determine the ratio for this study. A volume of $50 \mathrm{~mL}$ of permeate sample was titrated with $0.1 \mathrm{~N}$ sulfuric acid solution with constant mixing until pHs of 5, 4.3, and 4 were reached. The volume of titrant used to attain each $\mathrm{pH}$ end point was recorded and the alkalinity and VFA concentration were calculated according to the scheme and formulae provided by Buchauer, (1998).

\subsubsection{0. $\mathrm{pH}$}

The $\mathrm{pH}$ of the permeate and waste samples from the AnMBR was measured daily using an Omega PHB-600R pH Benchtop Meter.

\subsection{Results and Discussion}

\subsubsection{Preliminary Pre-treatment Tests}

Preliminary tests were conducted to compare the effect of thermal, ultrasonic, and peroxide-sonic pre-treatments on WAS. The primary response used in determining the preferred pre-treatment in this preliminary study was the COD solubilisation ratio. As discussed in Section 3.1, the COD solubilisation ratio was defined as the fraction of total COD that was soluble after PT. Although the SCOD/TCOD ratio was the main parameter of interest for determining the preferred PT method, other factors such as loss of TCOD and increase in cCOD and ffCOD fractions were also taken into consideration when making the decision. All preliminary tests were performed in duplicate with fresh WAS from the Waterloo WWTP. 
Figure 3.6 summarizes the COD fractionation that was observed after the various PTs to compare the changes in COD fractions as a result of all PTs. As can be seen from the figure, the ratio of soluble COD to total COD for the untreated thickened WAS was $0.88 \pm 0.11 \%$. This low SCOD/TCOD percentage is typical of fresh WAS. All pre-treatments resulted in an increase in the solubilisation ratio and differing values were obtained for different PTs. Thermal treatment of WAS at $150^{\circ} \mathrm{C}$ resulted in a $27 \pm 2 \%$ increase in the solubilisation ratio whereas treatment at $170^{\circ} \mathrm{C}$ resulted in an additional $8 \%$ (with $2 \%$ deviation) increase. Sonication of WAS for 10 minutes resulted in a $22 \pm 0.1 \%$ increase in solubilisation while 20 minutes of sonication led to an additional 5\% (with 1\% deviation) of solubilisation. Thus, both thermal and sonication pretreatments led to an increase in SCOD concentrations.

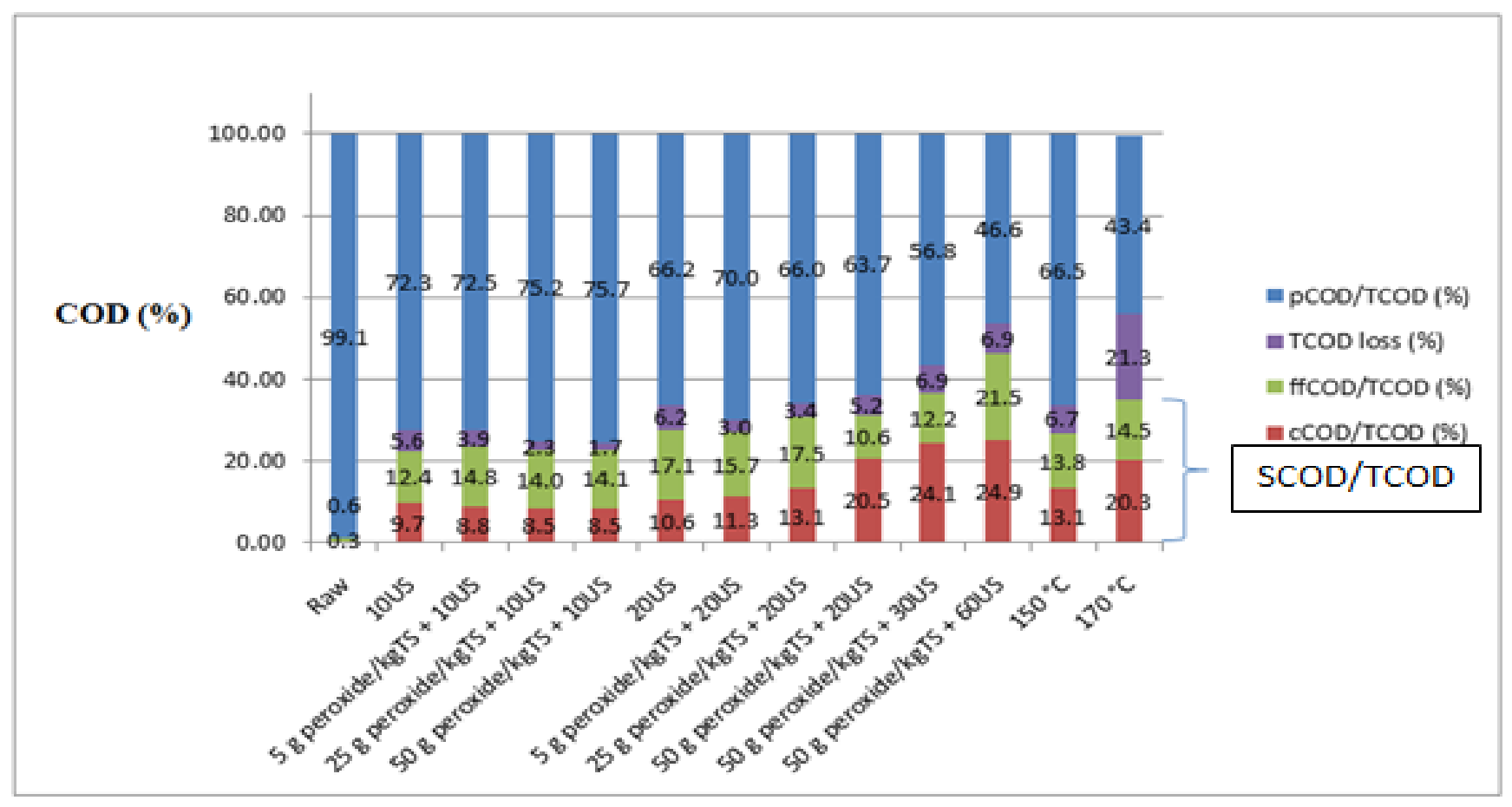

Figure 3.6: Fractionation of COD for all PTs

Solubilisation with the US- $\mathrm{H}_{2} \mathrm{O}_{2}$ combinations was compared to that of PT by sonication alone to determine if the addition of peroxide would improve solubilisation. As can be seen from 
Figure 3.6, the peroxide-sonic PTs resulted in greater solubilisation than sonication alone. For instance, sonication at 20 minutes resulted in a solubilisation ratio of $27 \pm 1 \%$. However the maximum solubilisation that was achieved with addition of peroxide to a sample sonicated for 20 minutes at a maximum dosage of $50 \mathrm{gH}_{2} \mathrm{O}_{2} / \mathrm{kgTS}$ was $32 \%$. By comparison, Grönroos et al., (2004) reported that the COD solubilisation ratio due to a peroxide-sonic PT of excess sludge was $11 \%$ lower than the solubilisation ratio due to sonication alone (Section 3.1). This was attributed to high peroxide doses that were employed in the previous study which led to a loss of organic matter in the sludge, and thus an insignificant or undesirable change in SCOD concentrations. Since the peroxide doses used in this study were much lower than those used by Grönroos et al., (2004), no significant loss of organic matter occurred due to peroxidation (Figure 3.6). The COD solubilisation results from this study thus followed those reported in other studies that used low doses of peroxide (Eskicioglu et al., 2008 and Rivero et al., 2012), i.e. a combined PT resulted in higher solubilisation than individual PT alone.

Treatment with $\mathrm{H}_{2} \mathrm{O}_{2}$ in combination with sonication as an AOP was studied with a $2 \times 4$ factorial design, with two US durations of 10 and 20 minutes and four $\mathrm{H}_{2} \mathrm{O}_{2}$ doses of $0,5,25$, and $50 \mathrm{gH}_{2} \mathrm{O}_{2} / \mathrm{kgTS}$. The resulting solubilisation ratios were assessed using an ANOVA to determine whether peroxide dose and sonication duration had significant impacts on solubilisation (Appendix A1). The statistical analysis revealed that US duration and the interaction term were significant factors affecting solubilisation the $\mathrm{H}_{2} \mathrm{O}_{2}$ dose effects were not statistically significant.

The results from the factorial tests were further examined to quantify the relative contribution of the significant factors to COD solubilisation. As mentioned earlier and as can be seen in Figure 3.6, the peroxide-sonic PTs resulted in greater solubilisations than sonication 
alone. However, the extent of increase in solubilisation varied between sonication durations and thus was dependent on the sonication duration. For instance, PT with 10 minutes of US led to a solubilisation ratio of $22 \pm 0.1 \%$. The combination of peroxide at doses of 5,25 , and 50 $\mathrm{gH}_{2} \mathrm{O}_{2} / \mathrm{kgTS}$ with the same sonication duration led to a solubilisation ratio of $22.5-23 \%$. Hence, a peroxide-sonication AOP at the lower US duration resulted in a minimal increase in solubilisation. On the contrary, combining peroxide additions of upto $50 \mathrm{gH}_{2} \mathrm{O}_{2} / \mathrm{kgTS}$ with WAS pre-treated with 20 minutes of US resulted in an increase in the SCOD/TCOD ratio from $27 \pm 1$ to $32 \pm 1 \%$. Therefore a peroxide-sonication AOP with a higher sonication duration (20 minutes) resulted in a greater and significant increase in solubilisation than the lower sonication duration $\mathrm{AOP}(10$ minutes $)$. An important point to be taken into account is that the peroxidesonication AOP with 10 minutes of sonication still resulted in an improvement in solubilisation, just not as significant as the AOP with 20 minutes of sonication.

As previously discussed, the results of the $\mathrm{US} / \mathrm{H}_{2} \mathrm{O}_{2}$ tests indicated that the duration of sonication affected WAS solubilisation substantially and hence two additional sonication durations were tested to investigate whether increasing the duration beyond 20 minutes would further improve the solubilisation ratio. Hence, durations of 30 and 60 minutes that have been reported in the literature (Section 3.1) were tested with an $\mathrm{H}_{2} \mathrm{O}_{2}$ dosage of $50 \mathrm{gH}_{2} \mathrm{O}_{2} / \mathrm{kgTS}$. The results of these tests (Figure 3.6) revealed SCOD/TCOD ratios of $36 \pm 0.2 \%$ and $46 \pm 0.5 \%$ for US durations of 30 and 60 minutes. Therefore the solubilisation of COD increased with sonication duration over a wide range of treatment conditions.

As mentioned in Section 3.1, most studies have also demonstrated that an increase in SCOD concentration is an indicative of improvement in biodegradability of WAS. As evident from Figure 3.6, combined chemi-sonic PT with $50 \mathrm{gH}_{2} \mathrm{O}_{2} / \mathrm{kgTS}$ and 60 minutes of sonication 
(PT 10) resulted in the largest conversion from pCOD to SCOD (of 46\%). In addition, the TCOD loss due to this PT was small (about $7 \pm 0.5 \%$ ) demonstrating only a modest removal of organic matter. Therefore it was hypothesized that this PT might be effective in achieving the greatest improvement in biodegradability of the WAS.

The impact of thermal PT at $170^{\circ} \mathrm{C}$ was compared with that of chemi-sonic PT using 50 $\mathrm{gH}_{2} \mathrm{O}_{2} / \mathrm{kgTS}$ and 60 minutes of US to provide for a comparison between a well-developed and widely used pre-treatment (thermal) and the AOP (peroxide + US). The results of the testing revealed that the peroxide/US AOP resulted in a higher solubilisation ratio than thermal treatment at $170^{\circ} \mathrm{C}$. The peroxide/US AOP resulted in a $46 \pm 1 \%$ solubilisation ratio whereas thermal PT at $170^{\circ} \mathrm{C}$ resulted in a $35 \pm 2 \%$. In addition, the thermal PT also demonstrated a high TCOD loss of $20 \pm 3 \%$ (Figure 3.6). The average TCOD of raw WAS and the WAS that was pre-treated thermally at $170{ }^{\circ} \mathrm{C}$ was compared using a t-test at $95 \%$ confidence interval (Appendix A2) and the values were found to be significantly different. Therefore, unlike the chemi-sonic AOP, thermal PT at $170^{\circ} \mathrm{C}$ resulted in a significant loss of COD resource.

In addition to SCOD and TCOD, cCOD and ffCOD fractions were assessed when comparing all the pre-treatments to determine the change in truly soluble and colloidal concentrations. cCOD represented the fraction of COD that could pass through a $1.5 \mu \mathrm{m}$ filter, but not a $0.45 \mu \mathrm{m}$ filter. Thus, for this study, cCOD was determined as the difference between the measured SCOD and ffCOD concentrations. As seen from Figure 3.6, thickened untreated WAS contained negligible concentrations of cCOD and ffCOD, which was expected due to the low SCOD concentrations of the raw WAS. However by comparison all PTs resulted in an increase in both colloidal and truly soluble matter, with the 60 minute US AOP resulting in the largest increase in both fractions (Figure 3.6). The 60 minute US AOP resulted in cCOD and 
ffCOD fractions of $25 \pm 1$ and $22 \pm 2 \%$, respectively. This observation was in agreement with Kianmehr, (2010), who proposed that this increase due to pre-treatment may be due to the solubilisation of extra cellular polymeric substances (EPS). Therefore, all PTs resulted in an increase in both cCOD and ffCOD fractions in WAS, with the 60 minute US AOP resulting in the greatest increase of both fractions, as was expected based on the SCOD/TCOD results.

Also evident from Figure 3.6 is that the peroxide-sonication AOP (with 20-60 minutes US and $50 \mathrm{gH}_{2} \mathrm{O}_{2} / \mathrm{kgTS}$ ) resulted in high and similar colloidal matter. The colloidal fractions in WAS pre-treated with 20, 30, and 60 minutes of US (each with $50 \mathrm{gH}_{2} \mathrm{O}_{2} / \mathrm{kgTS}$ ) were 21,24 , and $25 \%$, respectively. If WAS pre-treated with these AOPs were to be subjected to AnMBR digestion, significant membrane fouling may occur due to the high concentration of colloids, which will be discussed in detail in Chapter 4. Conversely, the ffCOD content due to the 3 AOPs were significantly different at $95 \%$ confidence interval. The truly soluble fractions in WAS pretreated with 20, 30, and 60 minutes of US (each with $50 \mathrm{gH}_{2} \mathrm{O}_{2} / \mathrm{kgTS}$ ) were 11,12 , and $22 \%$, respectively. Therefore, WAS PT with $50 \mathrm{gH}_{2} \mathrm{O}_{2} / \mathrm{kgTS}$ and 60 minutes of US was more effective in solubilising particulates into truly soluble COD than the other AOPs. On the basis of these results it was hypothesized that the AOP with 60 minutes of sonication may generate more readily biodegradable COD than the other AOPs as a result of the higher ffCOD concentration.

The pre-treatment resulting in the greatest extent of solubilisation i.e. PT with 50 $\mathrm{gH}_{2} \mathrm{O}_{2} / \mathrm{kgTS}+60$ minutes US was compared with thermal PT at $170^{\circ} \mathrm{C}$ with respect to the production of cCOD and ffCOD fractions to compare a well-developed and widely used pretreatment (thermal) and the AOP (peroxide + US) (Figure 3.6). It can be seen from figure 3.6 that the colloidal concentration as a result of the chemi-sonic AOP was higher than the thermal PT at $170^{\circ} \mathrm{C}$ by an increment of $5 \%$. It can also be seen that the truly soluble content after the 
chemi-sonic PT was higher than the thermal PT by an increment of 7\%. Hence, WAS that was pre-treated with the chemi-sonic AOP resulted in higher concentrations of truly soluble material as well as colloids than thermally PT WAS. Thus, according to the preliminary tests, it was hypothesized that a PT involving peroxidation and sonication, with the highest sonication duration and peroxide dose, may prove to be more effective in improving the biodegradability of WAS than the thermal and other PTs considered in this study.

\subsubsection{Detailed Pre-treatment Tests}

On the basis of the results discussed in Section 3.3.1, an AOP with sonication and $\mathrm{H}_{2} \mathrm{O}_{2}$ was determined to be the preferred PT for this study. In order to assess the effects of sonication duration on the physic-chemico properties and biodegradability of WAS, two AOPs were selected from the preliminary tests for further study- one with a low sonication duration of 20 minutes and another with a considerably higher treatment time of 60 minutes, each with a peroxide dose of $50 \mathrm{gH}_{2} \mathrm{O}_{2} / \mathrm{kgTS}$. In addition to COD analyses, additional responses including nitrogen and solids species were characterized to determine the effect of pre-treatment on the physico-chemical and biodegradation characteristics of WAS. All measurements were performed in duplicates.

\subsubsection{Impact of Peroxide-Sonic PT on Physico-chemical Characteristics of WAS}

\subsection{COD Comparison}

COD fractions before and after each PT were monitored to assess the effect of sonication duration on COD fractions. Figure 3.7 presents the results of the COD analysis for PT conditions of $50 \mathrm{gH}_{2} \mathrm{O}_{2} / \mathrm{kgTS}+20$ minutes US AOP and $50 \mathrm{gH}_{2} \mathrm{O}_{2} / \mathrm{kgTS}+60$ minutes US AOP. As can be seen from the figure, the results of the detailed tests followed a trend similar to that observed in the preliminary tests (Section 3.3.1). The mean TCOD concentrations of the samples pre-treated 
for 20 minutes US (with $50 \mathrm{gH}_{2} \mathrm{O}_{2} / \mathrm{kgTS}$ ) and the raw sludge samples differed by only $6 \%$. A ttest at a 95\% confidence interval (Appendix A2) confirmed that the loss of TCOD due to PT was insignificant. Therefore, no significant loss of organic matter was observed due to the PT with the lower sonication duration. Similarly, the data collected from the PT with the higher sonication duration indicated a $4 \%$ loss of TCOD. A t-test at $95 \%$ confidence interval indicated that this was not a significant difference (Appendix A2). Thus, as was observed in the preliminary results and in $50 \mathrm{gH}_{2} \mathrm{O}_{2} / \mathrm{kgTS}+20$ minutes US PT detailed tests, the $50 \mathrm{gH}_{2} \mathrm{O}_{2} / \mathrm{kgTS}$ + 60 minutes US PT did not significantly affect the TCOD concentration and thus did not result in a loss of the COD resource.

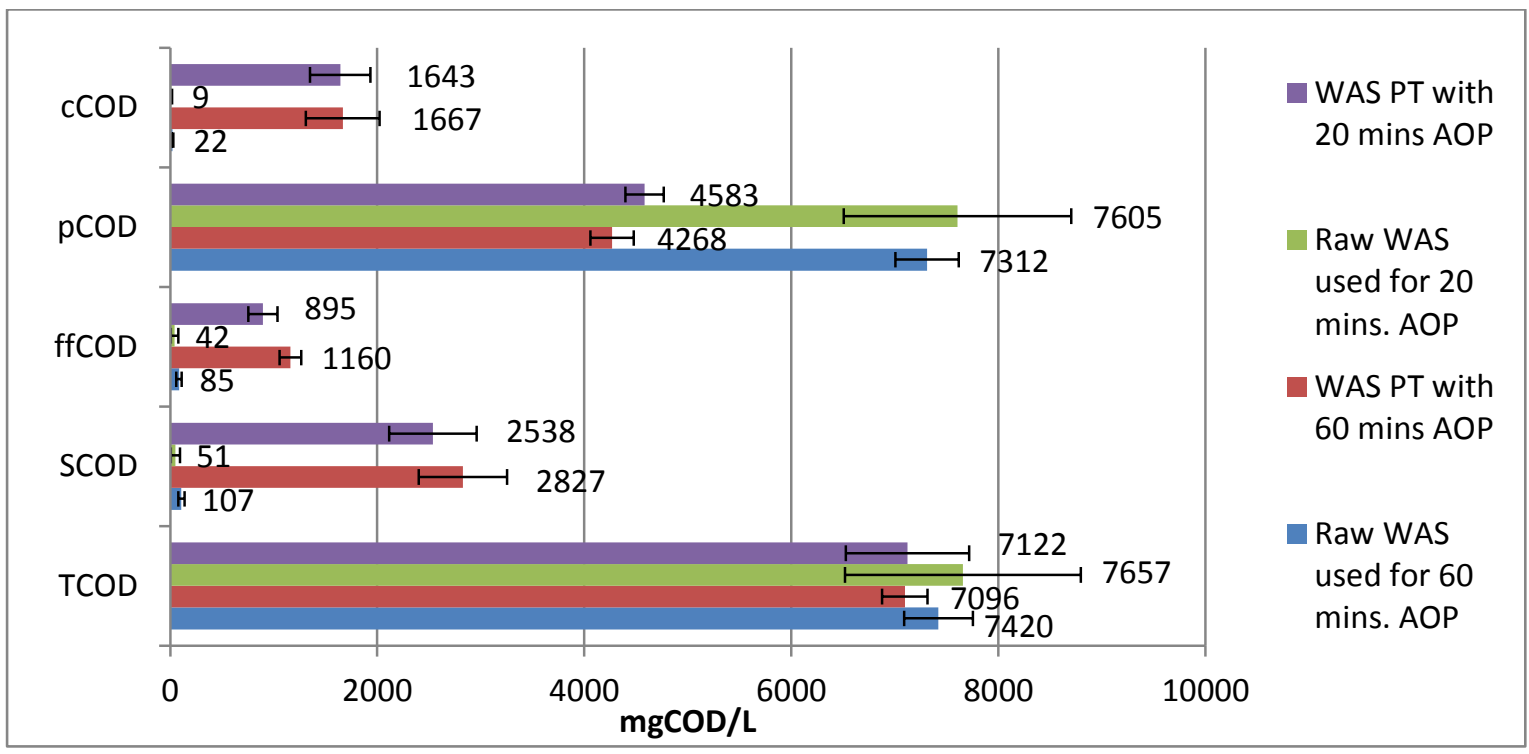

Figure 3.7: Average COD Concentration in Raw and Pre-treated Samples (with error bars)

In addition to TCOD loss, solubilisation ratios were compared between the two PTs to determine if the results of these detailed tests were consistent with the preliminary results discussed in Section 3.3.1. Pre-treatment substantially solubilized COD, with $50 \mathrm{gH}_{2} \mathrm{O}_{2} / \mathrm{kgTS}+$ 60 minutes PT resulting in a higher SCOD/TCOD ratio $(40 \pm 4.5 \%)$ than $50 \mathrm{gH}_{2} \mathrm{O}_{2} / \mathrm{kgTS}+20$ 
minutes PT $(33 \pm 0.60 \%)$. Hence the solubilisation ratios achieved with both PTs were similar to the results obtained in the preliminary tests.

The colloidal and truly soluble COD fractions were also compared between the two PTs to determine if PT resulted in a change in these fractions. From Figure 3.7 it can be seen that both the cCOD and ffCOD concentrations increased due to PT. The cCOD fractions increased by 21 and $24 \%$ for the 20 and 60 minute US AOPs, respectively. The ffCOD fractions increased by 11 and $15 \%$ for the 20 and 60 minutes US AOPs, respectively. A t-test at 95\% confidence interval (Appendix A2) indicated that ffCOD and cCOD concentrations generated in both PTs were significantly different from their respective feeds. This increase was in agreement with Kianmehr, (2010), as discussed in Section 3.3.1. Therefore, both PTs resulted in an increase in colloids and truly soluble materials as was expected based on the SCOD/TCOD results.

Colloidal and truly soluble COD fractions were also compared between the two PTs to assess whether the level of PT affected the distribution of these fractions in WAS (Figure 3.7). From Figure 3.7 it can be seen that the ffCOD and cCOD concentrations resulting from the AOP with 60 minutes of sonication were greater than the AOP with 20 minutes of sonication. The average ffCOD/TCOD fractions for the sludges generated by the 20 minutes and 60 minutes US PT (each with $50 \mathrm{gH}_{2} \mathrm{O}_{2} / \mathrm{kgTS}$ ) were $11.7 \pm 0.7 \%$ and $16.0 \pm 0.7 \%$, respectively whereas the average cCOD/TCOD fractions were $21.4 \pm 0.7 \%$ and $24 \pm 4 \%$, respectively. In addition, the ffCOD/cCOD ratio increased from $55 \pm 4 \%$ to $72 \pm 14 \%$ with an increase in sonication duration. Therefore, the AOP with the 60 minutes of sonication was more effective in solubilising particulates into truly soluble COD. On the basis of these results it was hypothesized that the PT with 60 minutes of sonication may generate more readily biodegradable COD than the PT with 20 minutes of sonication as a result of the higher ffCOD concentration. 
Overall, the results of the detailed COD tests were consistent with the preliminary test results. Pre-treatment resulted in minimal TCOD losses and substantially higher concentrations of ffCOD, cCOD, and thus higher concentrations of truly soluble COD and colloids than the raw samples. In addition, PT with 60 minutes of sonication resulted in higher ffCOD and cCOD fractions than the AOP with 20 minutes of sonication. Finally, due to higher concentrations of

truly soluble COD, PT with $50 \mathrm{gH}_{2} \mathrm{O}_{2} / \mathrm{kgTS}+60$ minutes US may lead to a greater improvement in biodegradation compared to PT with $50 \mathrm{gH}_{2} \mathrm{O}_{2} / \mathrm{kgTS}+20$ minutes US.

\subsection{Suspended Solids}

In order to determine the effect of PT on the physical characteristics of WAS, suspended solids measurements were carried out on the raw and pre-treated WAS for each PT and the results are shown in Figure 3.8. As can be seen in the figure, when PT with a 20 minute US duration was employed the average VSS concentrations before and after the AOP were $5388 \pm$ $94 \mathrm{mg} / \mathrm{L}$ and $4008 \pm 133 \mathrm{mg} / \mathrm{L}$, respectively. By contrast the FSS concentrations before and after the AOP were $1643 \pm 83 \mathrm{mg} / \mathrm{L}$ and $1619 \pm 246 \mathrm{mg} / \mathrm{L}$, respectively. T-tests at a $95 \%$ confidence interval indicated that there was a significant decrease in VSS concentration, but not in FSS concentration. Thus the AOP with 20 minutes of US only solubilised organic solids but did not change the FSS concentration.

When pre-treatment with $50 \mathrm{gH}_{2} \mathrm{O}_{2} / \mathrm{kgTS}$ and 60 minutes of sonication was employed the average VSS concentrations before and after PT were $5258 \pm 131 \mathrm{mg} / \mathrm{L}$ and $2733 \pm 94 \mathrm{mg} / \mathrm{L}$, respectively (Figure 3.8). The corresponding FSS concentrations were $1841 \pm 109 \mathrm{mg} / \mathrm{L}$ and $1364 \pm 101 \mathrm{mg} / \mathrm{L}$, respectively. T-tests at a 95\% confidence interval showed significant differences in both the VSS and FSS concentrations for this AOP. Thus, the PT with 60 minutes of sonication was capable of solubilising inorganic and organic solids, while the PT with 20 
minutes of sonication only solubilized the latter. This reduced mass flow of solids due to both PTs would lower the requirements for downstream sludge processing and disposal when compared against digestion of raw WAS. Since the AOP with 60 minutes of sonication resulted in higher solids solubilisation than the AOP with 20 minutes of sonication, the former AOP should result in higher reductions in mass flow of solids than the latter.

VSS destruction due to PT was calculated for both PTs to compare the destruction of organics by the two AOPs. Equation 3.1 was used to calculate the VSS destruction. The average VSS destruction values achieved by the $50 \mathrm{gH}_{2} \mathrm{O}_{2} / \mathrm{kgTS}+20$ minutes US PT and the 50 $\mathrm{gH}_{2} \mathrm{O}_{2} / \mathrm{kgTS}+60$ minutes PT were $26 \pm 2.6 \%$ and $48 \pm 3 \%$, respectively. Thus, the AOP with 60 minutes of sonication achieved higher VSS destruction than the one with the 20 minutes of sonication. An important observation to be noted is that the VSS destructions were different than the destruction of pCOD by the two AOPs (Figure 3.7). Since pCOD and VSS both provide measurement of organics, this deviation may have been due to an analytical or measurement error in VSS determination.

$$
\text { VSS destruction }(\%)=\frac{[\mathrm{VSS}(\mathrm{raw})-\mathrm{VSS}(\mathrm{PT})]}{\mathrm{VSS}(\mathrm{raw})} * 100 \%
$$

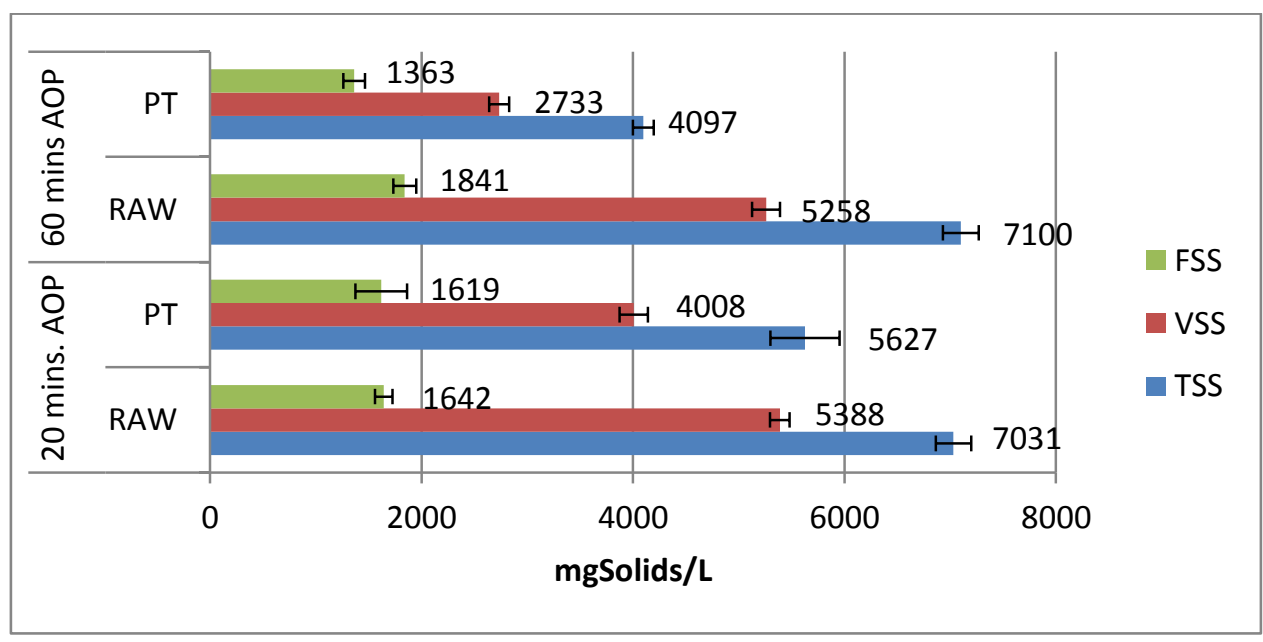

Figure 3.8: Suspended Solids Concentrations for Detailed AOP Testing (with error bars) 
In conclusion, both PTs resulted in solubilisation of organics, however only the AOP with 60 minutes of sonication solubilized inorganics. Both PTs also resulted in high organics degradation, with the AOP with 60 minutes of US duration resulting in a significantly higher VSS destruction than the AOP with 20 minutes of US as a result of high solubilisations.

\subsection{Nitrogen Species}

Nitrogen-bearing compounds such as proteins represent a substantial fraction of the organic matter that is present in sludge. Hence, information on organic nitrogen can provide supporting information on the fate of organic matter through PT. Further, the management of ammonia that is released from organic matter through sludge handling systems is an ongoing challenge. Therefore, information on the fate of ammonia through PT was of interest. Hence, total TKN, soluble TKN, ammonia, total organic nitrogen (tON), soluble organic nitrogen (sON), and particulate organic nitrogen $(\mathrm{pON})$ concentrations were monitored before and after both PTs to determine the impact of PT on the nitrogen-containing species. Total organic nitrogen was calculated as the difference between total TKN and ammonia. Soluble organic nitrogen was calculated as the difference between soluble TKN and ammonia. Particulate organic nitrogen was then calculated as the difference between total and soluble organic nitrogen. The concentrations of these species are summarized in Figure 3.9.

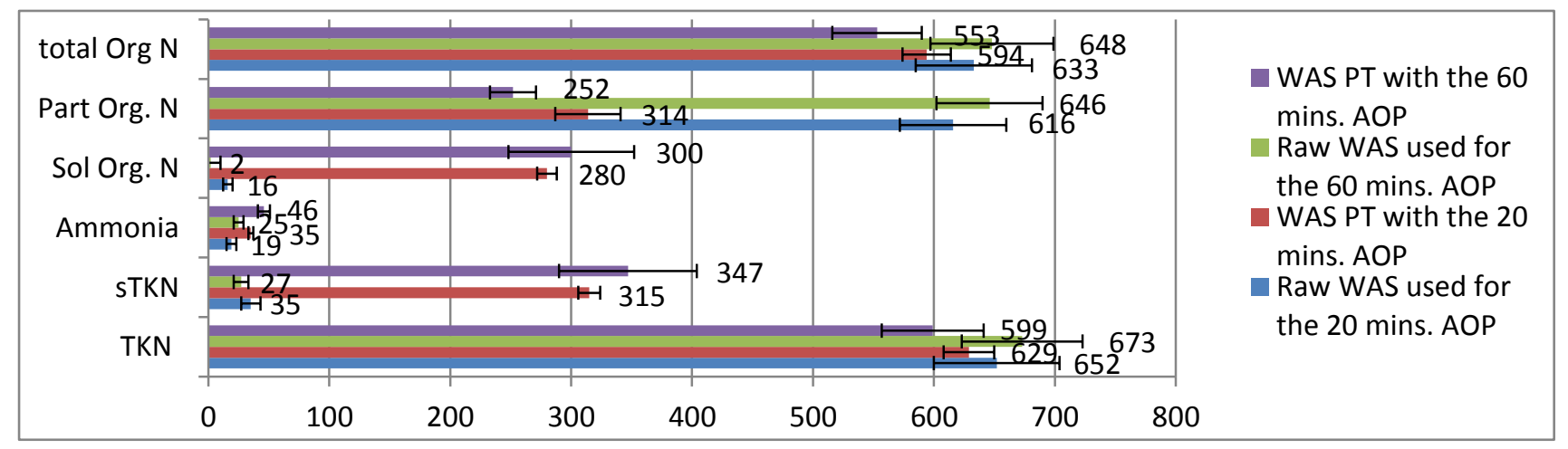

Figure 3.9: Nitrogen Species Concentration in Raw and Pre-treated WAS (with error bars) 
TKN concentrations were compared before and after each PT to determine if PT resulted in any significant removal of TKN. T-tests that were conducted at 95\% confidence interval (Appendix A2) revealed that pre-treatment with 20 minutes sonication and $50 \mathrm{gH}_{2} \mathrm{O}_{2} / \mathrm{kgTS}$ did not significantly change the total TKN concentrations. However, pre-treatment at 60 minutes US and $50 \mathrm{gH}_{2} \mathrm{O}_{2} / \mathrm{kgTS}$ resulted in a significant reduction of $11 \%$ in total TKN concentration. Therefore, unlike PT with the lower sonication duration (20 minutes), PT with 60 minutes of sonication led to a significant TKN removal.

Ammonia concentrations before and after each PT were also monitored to determine if a chemi-sonic AOP was capable of degrading proteins to release ammonia. A t-test that was conducted at a 95\% confidence interval (Appendix A2) revealed that there was a significant increase in ammonia concentrations due to both PTs. The ammonia concentrations increased from $19 \pm 4$ to $35 \pm 2 \mathrm{gN} / \mathrm{L}$ for the 20 minute US AOP whereas the ammonia concentrations increased from $25 \pm 4$ to $46 \pm 5 \mathrm{gN} / \mathrm{L}$ for the 60 minute AOP. Hence, it would appear that there was some mineralization of organic nitrogen to release ammonia. The breakdown of protein could result in the release of amino acids and finally ammonia. Therefore, a chemi-sonic AOP was capable of not only rupturing cell walls and releasing soluble materials but also breaking down compounds at a molecular level.

Nitrate analysis was conducted on raw and 60 minutes US AOP samples in duplicate to determine if ammonia was oxidized to nitrate. The results of this analysis indicated that no increase in nitrate concentrations was detected. Thus, no oxidation of ammonia to nitrate took place during this PT. Hence, nitrate analysis was not conducted with the 20 minute US duration PT samples as it was a less intensive operation. 
Analogous to COD solubilisation, ON solubilisation may be used to assess the impact of pre-treatment on the biodegradability of WAS (Kianmehr, 2010). The solubilisation of organic nitrogen was calculated for both PTs according to equation 3.2. The results revealed that PT with 20 minutes of sonication resulted in a $43 \pm 5 \%$ organic nitrogen solubilisation while PT with 60 minutes of sonication resulted in a $47 \pm 10 \%$ organic nitrogen solubilisation. Thus in addition to COD and VSS solubilisation, both PTs resulted in ON solubilisation and an increase in US duration modestly increased the extent of this response. It was hypothesized that the observed ON solubilisation may result in the increase of biodegradable ON in WAS which may lead to an increase in WAS biodegradability.

$$
\text { ON Solubilisation }(\%)=\frac{(\mathrm{sON}(\mathrm{PT})-\mathrm{sON}(\mathrm{raw}))}{\mathrm{pON}(\mathrm{raw})} * 100 \%
$$

The ratio of nitrogen to COD fractions was monitored to determine the impact of PT on the protein rich compounds in WAS and to support the assessment of the solubilisation result. Figure 3.10 presents the ON/COD ratio and SON/SCOD ratios for WAS pre-treated at 20 minutes US (with $50 \mathrm{gH}_{2} \mathrm{O}_{2} / \mathrm{kgTS}$ ) and 60 minutes US (with $50 \mathrm{gH}_{2} \mathrm{O}_{2} / \mathrm{kgTS}$ ). From the figure it can be seen that the average tON/TCOD ratios for PTs with the 20 and 60 minutes sonication durations were $8.4 \pm 0.9 \%$ and $7.8 \pm 0.3 \%$ respectively. These ratios are comparable with the $7 \%$ nitrogen content of biomass which was reported by Henze et al., (1999). However, the sON/SCOD ratios did not follow the tON/TCOD trend for both PTs. The average ratios for the PTs with 20 and 60 minute sonication durations were $11 \pm 2 \%$ and $11 \pm 0.2 \%$ respectively, which were significantly different from the reported ratio of $7 \%$. These ratios demonstrated that both PTs preferentially solubilised protein-rich compounds over other types of organic matter. 


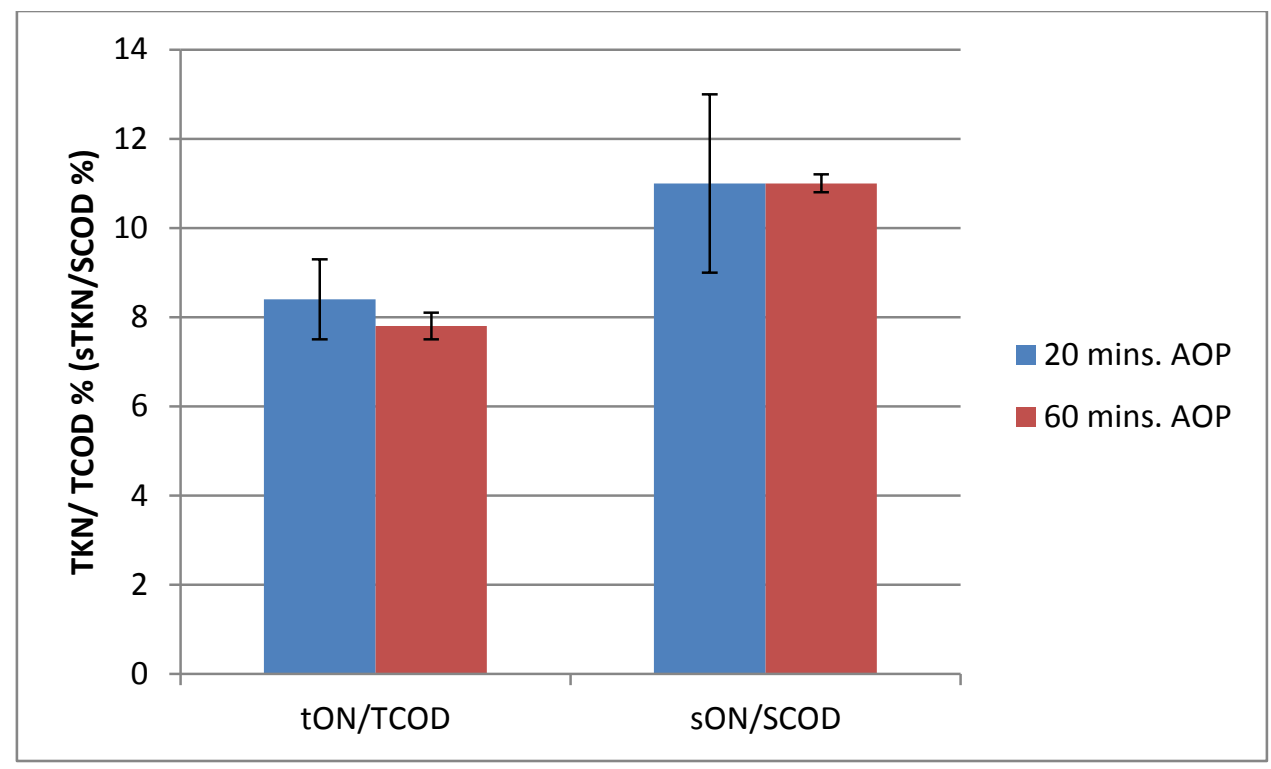

Figure 3.10: Impact of 20 and 60 US minutes AOP on ON/COD ratios (with error bars)

Solubilisation of TKN was compared with solubilisation of COD to determine if chemisonic PT solubilised both species to the same extent. The ratio of sTKN/TKN increased from 5.3 $\pm 0.85 \%$ to $48 \pm 5.3 \%$ for 20 minutes US (with $50 \mathrm{gH}_{2} \mathrm{O}_{2} / \mathrm{kgTS}$ ) whereas 60 minutes of US (with $50 \mathrm{gH}_{2} \mathrm{O}_{2} / \mathrm{kgTS}$ ) resulted in an increase from $4 \pm 0.6 \%$ to $58 \pm 9.8 \%$. The SCOD and sTKN fractions for the AOP with 20 minutes of US were $33 \pm 0.58 \%$ and $48 \pm 5.3 \%$ respectively whereas the SCOD and sTKN fractions for the PT with 60 minutes of US were $40 \pm 4.5 \%$ and 58 $\pm 9.8 \%$ respectively. Hence, the soluble TKN fractions for both PTs were greater than the soluble COD fractions. This demonstrated that chemi-sonic pre-treatment may be more effective in solubilizing materials that consisted of high concentrations of protein and organic nitrogen than other COD components (Dignac et al., 1998).

In conclusion, both PTs resulted in ON solubilisation, with the AOP with 60 minutes of sonication resulting in a higher solubilisation. In addition, the AOP with 60 minutes sonication resulted in some ON destruction and TKN removal, whereas the AOP with 20 minutes of sonication did not lead to any significant removals. The chemi-sonic AOP resulted in protein 
degradation, causing an increase in ammonia concentration. Both PTs were more effective in solubilising TKN particulates than COD particulates.

In summary, all pre-treatments of waste activated sludge examined in this study led to solubilisation of COD. Further, all the AOPs employed in this study resulted in higher solubilisation than the individuals PT. Both AOPs employed in the detailed study significantly solubilised COD while conserving the TCOD, with the 60 minutes AOP resulting in the highest solubilisation. Moreover, the AOP with the lower sonication duration (20 minutes) preferentially solubilized organics while the AOP with the higher US duration (60 minutes) solubilized both organic and inorganic solids. The 60 minute AOP resulted in higher VSS destruction than the 20 minute AOP. T the PT with 60 minutes of US resulted in significant ON destruction, while the PT with 20 minutes of US did not. Both PTs solubilized ON and the solubilisation of this organic matter was greater than that of other types of organic matter.

\subsubsection{Anaerobic Membrane Bioreactor Operation}

This portion of the study is sought to assess the impact of two different levels of the AOP PT on the anaerobic biodegradability of WAS. Biodegradability of WAS was evaluated by treating the WAS in an AnMBR. This section presents the results of anaerobic digestion of raw and PT WAS in the AnMBR. The stability of the AnMBR was measured by monitoring the $\mathrm{pH}$ and the VFA/Alk ratio while the overall performance of the AnMBR was measured in terms of COD, VSS, and ON destruction.

\subsubsection{1. pH and VFA/Alk Ratio for AnMBR}

It was hypothesized that PT of the WAS would increase the biodegradability of the WAS and hence stability with respect to $\mathrm{pH}$ excursions was a potential operational concern. The $\mathrm{pH}$ of the waste and permeate streams was monitored for all phases of AnMBR operation to assess the 
stability of the AnMBR. Figure 3.11 summarizes the $\mathrm{pH}$ of the reactor throughout its operation. The $\mathrm{pH}$ of the waste stream and permeate streams remained relatively constant throughout the operation of the AnMBR. For instance, the average values of the $\mathrm{pH}$ of the waste stream for Phases 1,2 , and 3 were $7.29 \pm 0.11,7.22 \pm 0.02$, and $7.27 \pm 0.04$, respectively. Similarly, the $\mathrm{pH}$ values of the permeate stream for Phases 1,2 , and 3 were $7.28 \pm 0.13,7.22 \pm 0.06$, and $7.18 \pm$ 0.06, respectively. A t-test that was conducted at a $95 \%$ confidence interval revealed there was no significant difference between the $\mathrm{pH}$ of either streams for all phases. Thus the $\mathrm{pH}$ of the waste and permeate streams remained relatively constant in all phases, implying stable operations.

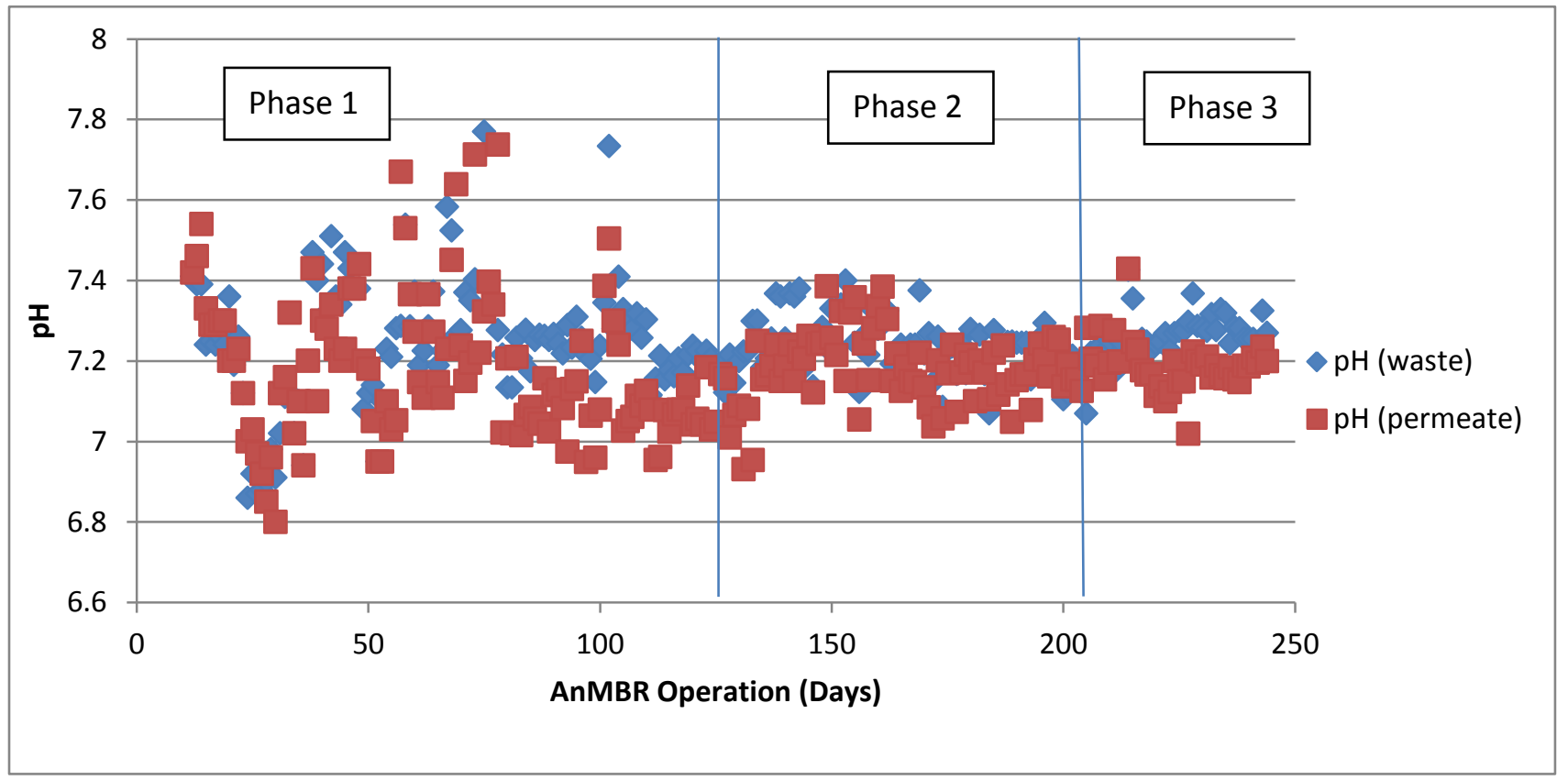

Figure 3.11: $\mathrm{pH}$ in AnMBR throughout all Phases

The ratio of VFA/Alk was also monitored throughout the operation of the AnMBR to monitor reactor stability, and these results are summarized in Figure 3.12. The ratio of VFA/alkalinity is considered a better indicator of the digester health and the buffering capacity 
of the digester than the $\mathrm{pH}$ since $\mathrm{pH}$ may take some time to respond to the accumulation of VFAs in a reactor (Goberna et al., 2010). As can be seen in figure 3.12 most of the VFA/Alk ratios were low $(\leq 0.2)$ with the exception of the periods between Day 12 - Day 45 and Day 146 - Day 151. During these periods, the VFA concentration was high, thus demonstrating an accumulation of acids and a decline of the alkalinity of the system. These results were associated with periods when the reactor was adjusting to a new feed and had not yet attained steady state. The reactor was unsteady between Day 12 - Day 45 since it was adjusting to the Phase 1 feed (Raw WAS), while at Day 146 - Day 151, the reactor was adjusting to the Phase 2 feed (PT 8 feed). During both periods, the acidogens were producing acids that the methanogens were not able to immediately utilize, thus leading to high VFA concentration and unstable operations with respect to the VFA/Alk ratio.

In order to increase the alkalinity of the system and improve the environmental conditions for the microorganisms during both these period, Sodium Bicarbonate $\left(\mathrm{NaHCO}_{3}\right)$ and Potassium Bicarbonate $\left(\mathrm{KHCO}_{3}\right)$ were added in a 1:1 mass ratio. Once steady state was reached for both phases, the VFA/Alk returned to values $\leq 0.2$. After this ratio was attained, no bicarbonate addition was required. Thus the VFA/Alk ratio was in the range $(\leq 0.2)$ suggested by Goberna et al., (2010) for steady AD operation.

An important observation noted during this analysis was that the VFA/Alk ratio did not increase after switching to the Phase 3 feed from the Phase 2 feed. In fact, the ratio declined from the Phase 1 and Phase 2 ratios of $0.076 \pm 0.047$ and $0.076 \pm 0.027$, respectively to $0.053 \pm$ 0.0367 for Phase 3. This may be attributed to the acclimation of the microorganisms to the increased soluble material in the feed in Phase 2. Hence, Phase 3 did not take as much time as Phase 1 and 2 to reach steady state with respect to the VFA/Alk ratio. 


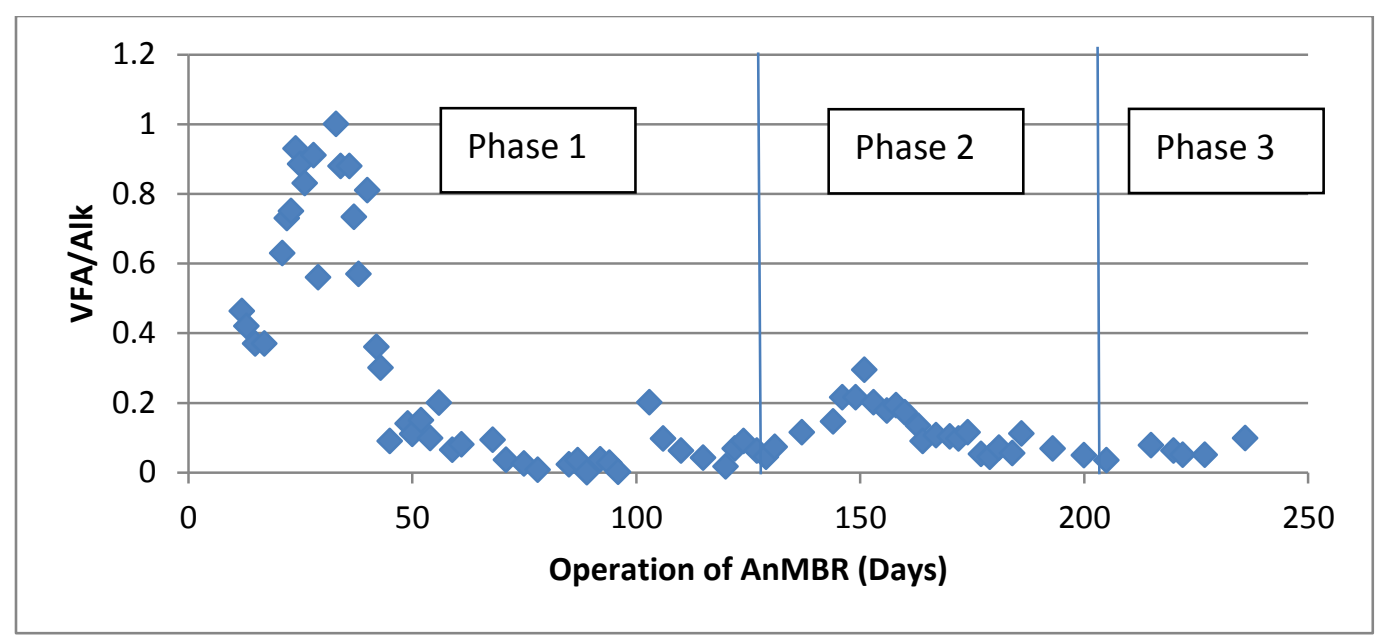

Figure 3.12: $\mathrm{pH}$ in AnMBR throughout all Phases

\subsubsection{COD Destruction and Analysis}

The COD fractions in the reactor were monitored during all phases of operation to compare the biodegradability of the raw and PT WAS streams. As mentioned in Section 3.2, the AnMBR was operated at the same operational conditions for all phases, thus ensuring identical conditions for comparing WAS biodegradability. For each phase, COD destruction was calculated by comparing the cumulative mass of COD in the feed and outgoing streams during the steady state period of each phase (Table 3.3). The cumulative COD mass loadings in each stream were calculated and then graphed and the percent loss between the incoming and outgoing stream slopes yielded the COD destruction efficiency. Figure 3.13 provides a sample COD destruction graph along with corresponding calculations for Phase 1. From this plot it can be seen that the cumulative responses were linear in nature and this confirmed the assumption that the concentrations of COD in the various streams were not varying with time. Similar plots for the other phases can be found in Appendix A6. 


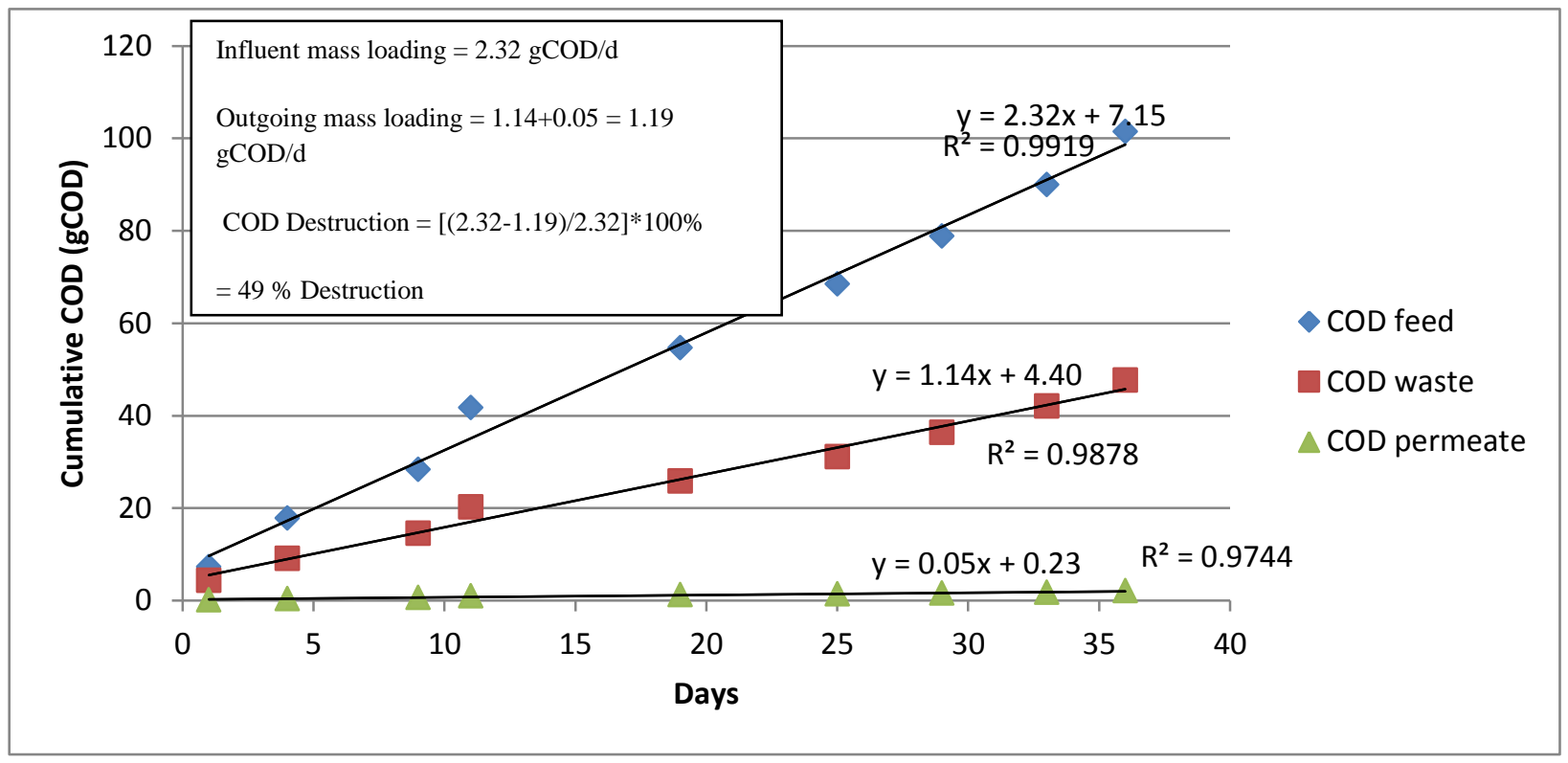

Figure 3.13: Total COD Destruction for Phase 1 Steady State

COD destruction values were determined for each phase of the study to allow for a comparison of the biodegradability of the raw and PT WAS. Figure 3.14 summarizes the extent of COD destruction observed in each phase of this study. As discussed in Section 3.3.2., in Phases 2 and 3, COD was also destroyed during pre-treatment. Although minimal, the TCOD losses that occurred during both PTs contributed to the overall COD destruction in each phase.

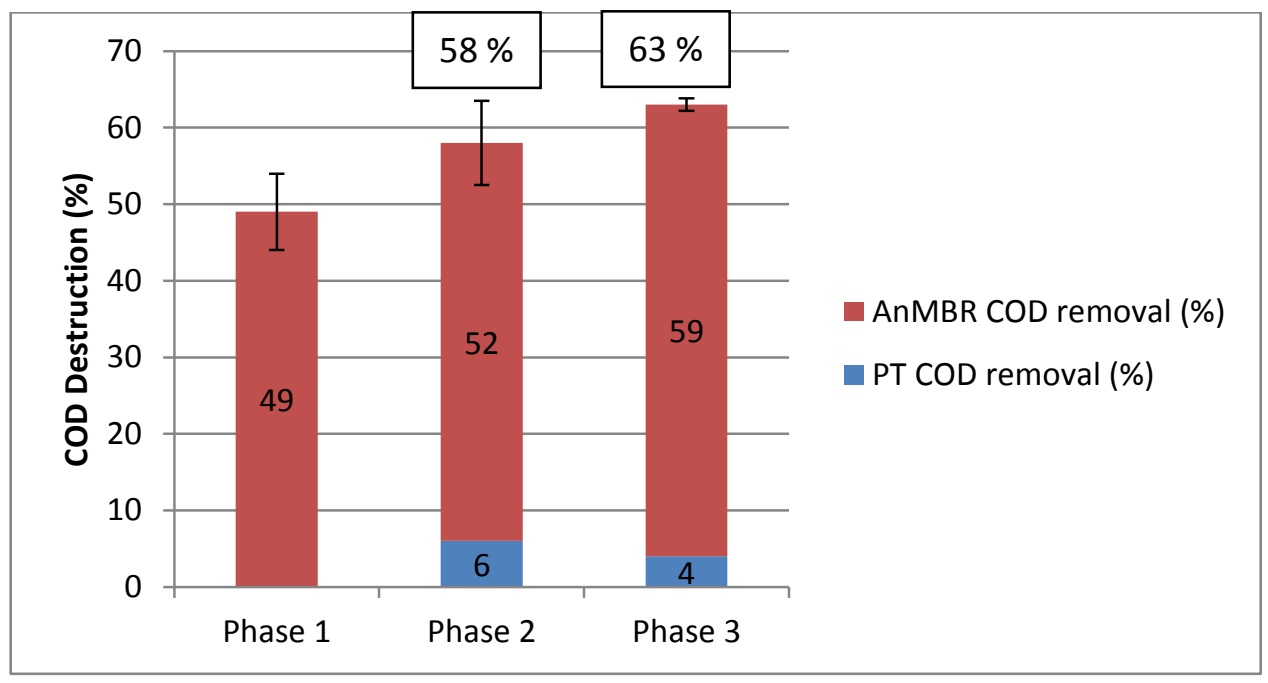

Figure 3.14: COD Destructions Rates for Phase 1, 2, and 3 (with error bars) 
As it can be seen from Figure 3.14, Phase 1 resulted in 49\% COD destruction, while Phases 2 and 3 resulted in increased overall COD destruction values of 58 and 63\%, respectively. Hence, when compared to operation without PT the overall performance improved from Phase 1 to Phase 2 by an increment of $9 \%$ while Phase 3 resulted in an increase by $14 \%$ with respect to Phase 1. In terms of digester performance, it is seen that the COD destruction increased from 49 to $52 \%$ after switching the feed from raw to Phase 2 PT WAS. The COD destruction in the digester further improved by an increment of $7 \%$ after changing the PT conditions from Phase 2 to Phase 3. It has been previously shown that anaerobic digestion at an SRT of 20 days will result in the destruction of the majority of the biodegradable fraction of sludge (Szeinbaum, 2009). Hence, it appears that both PTs were able to convert some non-biodegradable COD to biodegradable COD, which resulted in an improvement in the ultimate biodegradability of WAS. Therefore pre-treatment of WAS by the AOPs increased the biodegradation of WAS, with the highest destruction observed with the AOP involving the greatest sonication duration and peroxide dose.

The concentrations of pCOD, SCOD, ffCOD, and cCOD were monitored during the steady state operation of the AnMBR to obtain insight into the fate of these materials in the digester. It was hypothesized that an improved understanding of the behaviour of these materials would provide insight into the biodegradability of the soluble and colloidal fractions that were generated in PT. Figure 3.15 presents the concentrations of these COD species in the AnMBR waste stream for each phase. From Figure 3.15 it can be seen that the concentrations of all COD species decreased as the level of PT intensity increased (i.e. Phase $3<$ Phase $2<$ Phase 1 ). The average pCOD and SCOD concentrations were 15 and 23\% lower in Phase 2 than Phase 1. These values were further decreased by $5 \%$ and $26 \%$ in Phase 3. ANOVA tests revealed that there was 
significant difference between the Phase 1 and Phase 2 COD concentrations. The changing COD concentrations in each phase suggested differing biodegradabilities and hence a cumulative mass balance was conducted on each species assuming that there was no production of a species in the digester.

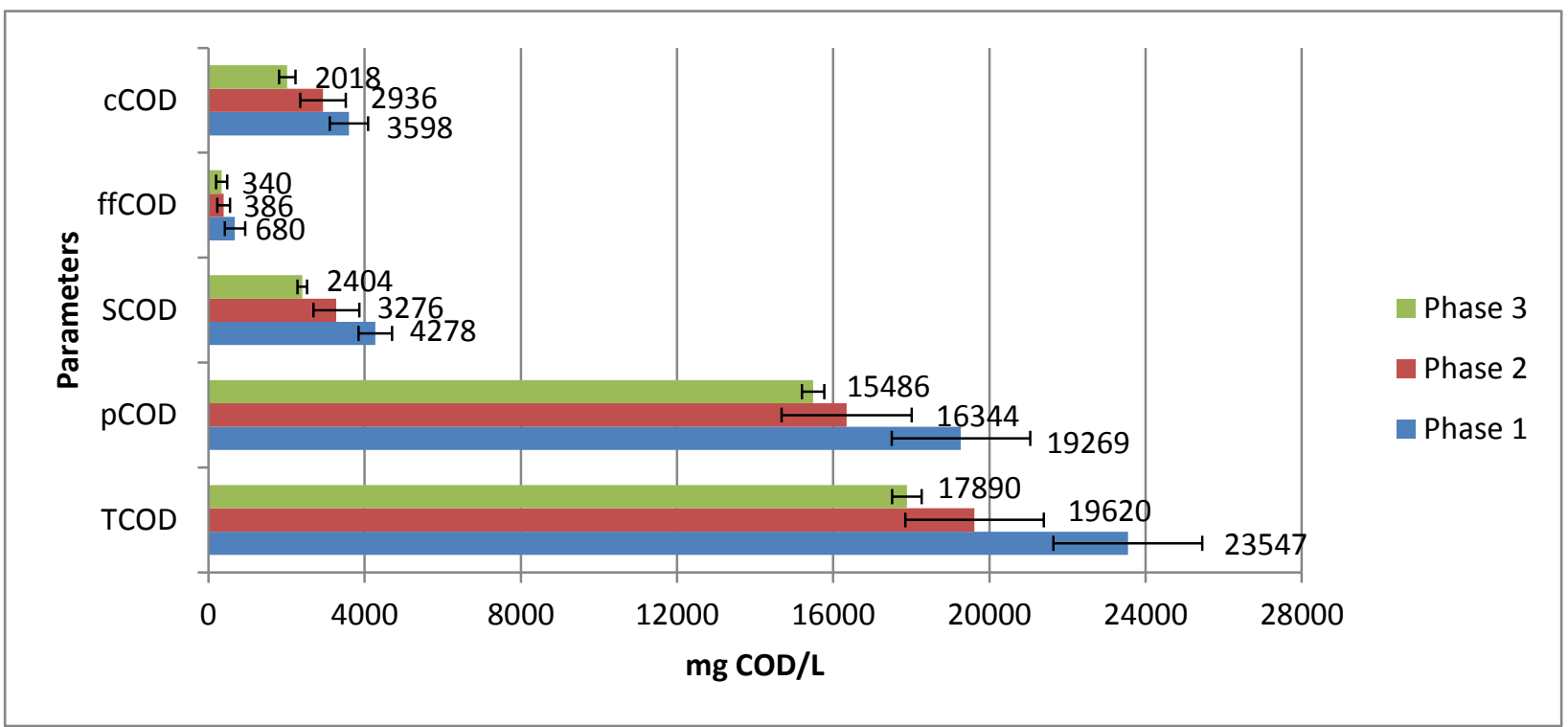

Figure 3.15: Average COD Concentrations in Phase 1, 2, and 3 AnMBR WAS (with error bars)

Figure 3.16 presents the results of a steady state cumulative mass balance of COD species that occurred during all three phases and provides insights into COD fractionation, transformation and removal in each phase. This figure summarizes the cumulative COD masses in raw WAS, PT streams and the AnMBR streams (waste and permeate streams). As previously discussed (Section 3.3.2) and as can be seen in Figure 3.16, ffCOD and cCOD contributed relatively little to the cumulative TCOD of the raw WAS (5.1 and $0.9 \mathrm{~g}$ COD or feed TCOD fractions of 2.3 and $0.4 \%$ in Phase 1). However, the cumulative masses of ffCOD and cCOD in the AnMBR streams in Phase 1 were 8.2 and $18.8 \mathrm{~g}$ COD or feed TCOD fractions of 3.6 and $8.44 \%$, respectively. The cumulative masses of ffCOD and CCOD increased by 60 and over 100 $\%$, respectively after digestion when compared to the feed. The increased ffCOD and cCOD 
cumulative masses in the Phase 1 AnMBR streams were attributed to hydrolysis that resulted in the degradation of particulate COD (from 217.5 to 86.6 gCOD or 68 to $38 \%$ of feed COD) (Figure 3.16) to produce non-biodegradable soluble and colloidal COD species. Therefore, the remaining COD masses in the AnMBR streams represented the non-biodegradable fractions.

Conversely, the pre-treated feeds contained high concentrations of ffCOD and hence Phase 2 PT and Phase 3 PT resulted in cumulative ffCOD feed masses of 14.1 and $31.9 \mathrm{~g} \mathrm{COD}$ or feed TCOD fractions of 8 and 16\%, respectively (Figure 3.16). The pre-treated feeds also had high cumulative masses of cCOD in Phase 2 and 3 and the cumulative cCOD masses were 45.9 and 45.0 gCOD or feed COD fractions of 24 and 23\%, respectively. (Figure 3.16) However the cumulative ffCOD masses in the AnMBR streams in Phases 2 and 3 after digestion were 6.4 and 5.5 gCOD or feed COD fractions of 3.4 and $2.8 \%$, respectively. Similarly the cumulative cCOD masses in the AnMBR streams in Phase 2 and Phase 3 were 12.6 and 8.6 gCOD or feed COD fractions of 6.7 and $4.3 \%$, respectively. Thus, after digestion of PT WAS in Phase 2 and Phase 3, the ffCOD fractions decreased by 4.1 and $13.2 \%$, respectively and the cCOD fractions decreased by 17.3 and $18.7 \%$, respectively with respect to the feed. Hence, a significant fraction of the feed ffCOD and cCOD was consumed during digestion in both PT phases, with Phase 3 resulting in the highest removal. In addition the decrease of the cumulative mass of pCOD from 127 to $71 \mathrm{gCOD}$ (or feed COD fractions of 68 to 38\%) for Phase 2 and from 120 to $66 \mathrm{gCOD}$ (or feed COD fractions of 61 to $33 \%$ ) for Phase 3 suggested degradation and transformation of pCOD into cCOD and ffCOD for substrate consumption during digestion.

From Figure 3.16 it can be seen that although the pre-treated feed contained significantly higher cumulative ffCOD masses than the Phase 1 feed, Phase 2 and Phase 3 AnMBR streams contained lower ffCOD masses than the Phase 1 AnMBR streams. In addition, despite the higher 
cumulative colloidal COD masses of both pre-treated feeds, the cumulative masses of cCOD in the PT AnMBR streams were lower than Phase 1. As mentioned earlier Phase 1 resulted in an increase in ffCOD and cCOD masses by 60 and over $100 \%$ with respect to the Phase 1 feed. However, in the case of Phase 2, the ffCOD and cCOD masses in the AnMBR streams decreased by 55 and $72 \%$, respectively with respect to the feed. Similarly, the mass of ffCOD and cCOD in the AnMBR streams decreased by 83 and $81 \%$, respectively in Phase 3 when compared to the feed. Therefore, compared to Phase 1, Phases 2 and 3 resulted in higher fragmentation of fines and colloids and consumption of truly soluble material, with Phase 3 resulting in the highest consumption. This suggests that PT improved the biodegradation of WAS by converting nonbiodegradable COD to biodegradable COD and reduced the mass of non-biodegradable soluble and colloidal COD remaining in the AnMBR streams. It is hypothesized that this reduction in mass of colloids with each phase due to improved biodegradability may result in reduction in membrane fouling, a concern that will be addressed in detail in Chapter 4.

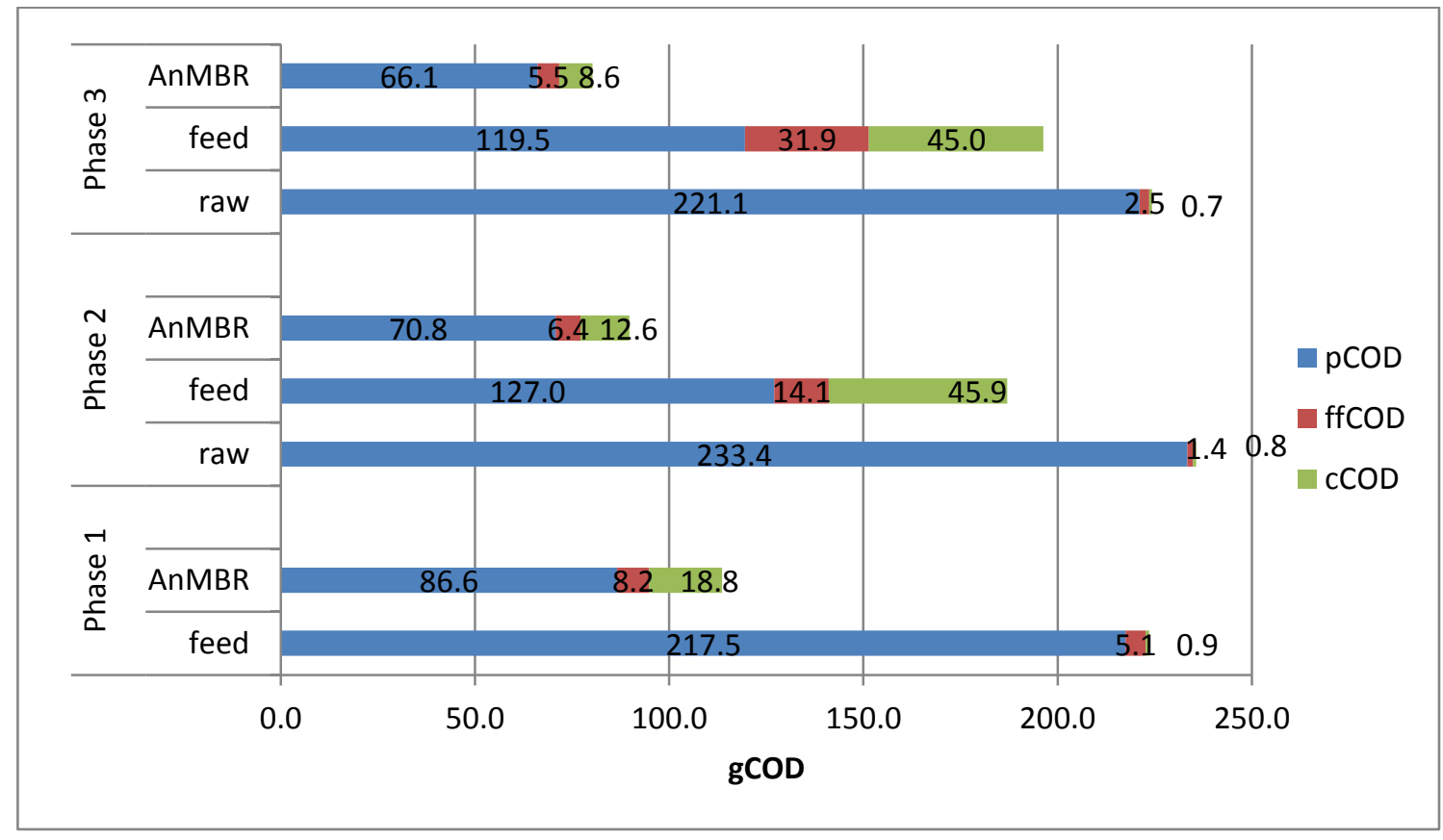

Figure 3.16: Cumulative Mass Balance of COD Species through PT and AD 
Permeate ffCOD concentrations were also monitored during the operation of the AnMBR to determine permeate quality that might impact upon downstream operations in a wastewater treatment plant. Figure 3.17 summarizes the permeate ffCOD concentrations for Phases 1, 2, and 3. From this figure it can be seen that low and comparable ffCOD concentrations of 151-166 $\mathrm{mg} / \mathrm{L}$ were observed for all phases. The permeate concentrations were compared and found to be not statistically indifferent. Therefore PT did not result in any significant change in permeate quality.

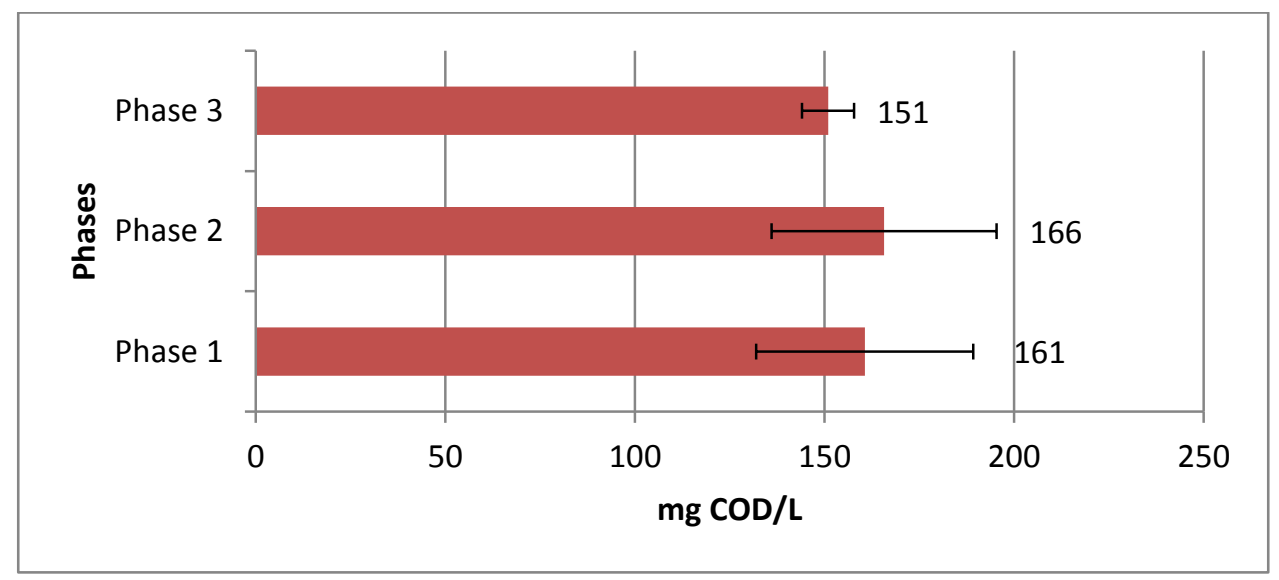

Figure 3.17: Average Permeate ffCOD Concentrations for all Phases (with error bars)

\subsubsection{Solids Destruction}

The behaviour of suspended solids was examined as an additional indicator of the performance of the AnMBR. For each phase, VSS destruction was calculated by comparing the cumulative mass of VSS in the feed and outgoing streams. Since the permeate was solids-free, only the waste stream was used in the cumulative analysis. Once the cumulative VSS mass loading in the streams were calculated, they were plotted versus time and the difference between the incoming and outgoing stream slopes was employed to calculate the VSS destruction efficiency. Figure 3.18 provides a sample VSS mass loading graph along with corresponding calculations for Phase 1. VSS data for all other phases can be found in Appendix A7. From 
Figure 3.18 it can be seen that the cumulative responses were linear in nature and this confirmed the assumption that the concentrations of solids in the various streams were not varying with

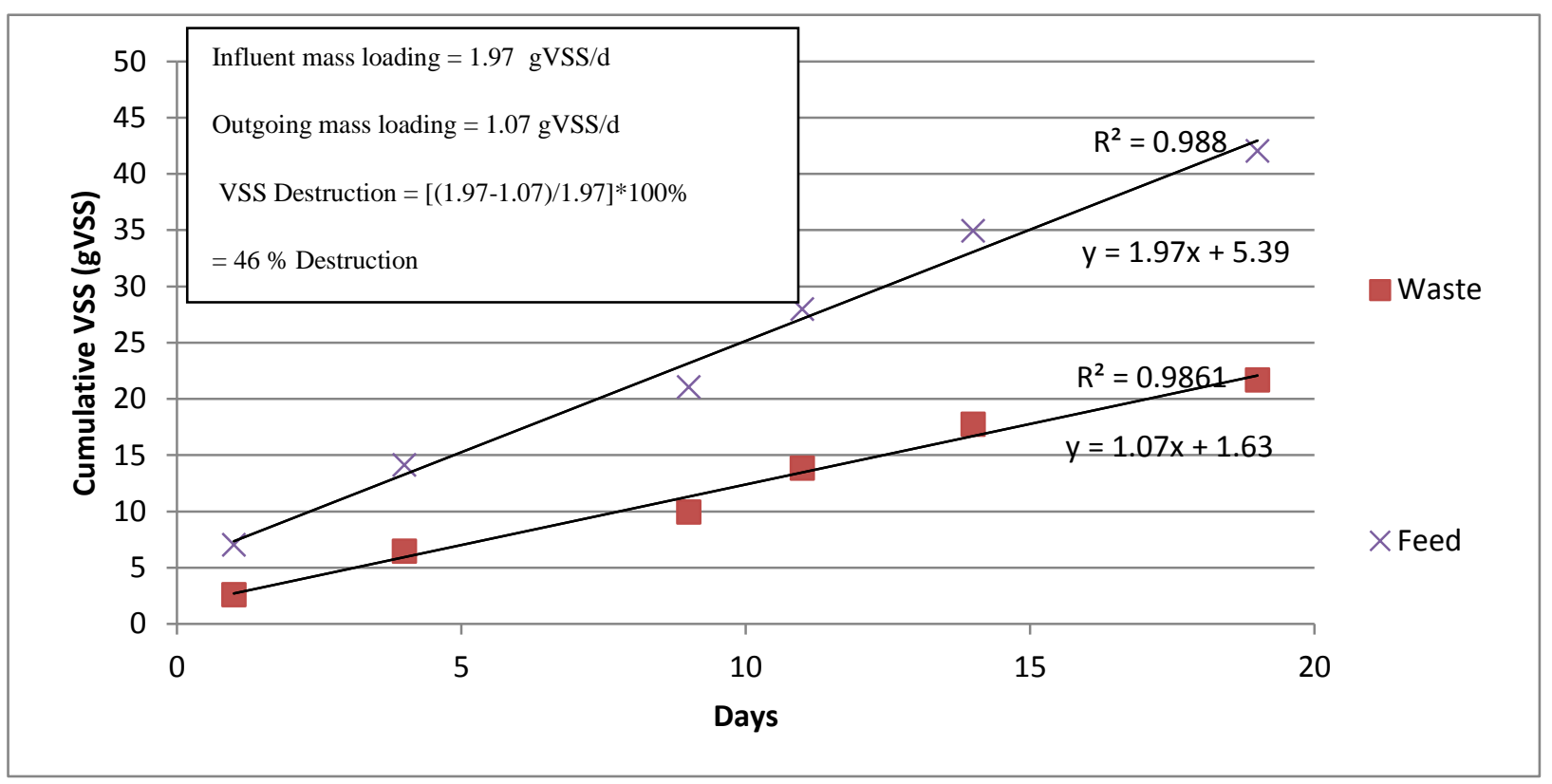

Figure 3.18: Total VSS Destruction for Phase 1 Steady State

The VSS destruction values observed in each phase were compared to determine if PT resulted in higher VSS removal. Figure 3.19 summarizes the VSS destruction efficiencies observed in all phases of the study. As discussed in Section 3.3.2., in Phases 2 and 3 VSS destruction occurred during the pre-treatment stage, and this contributed to the overall VSS destruction in each phase. As can be seen in figure 3.19, Phase 1 resulted in a $46 \%$ VSS destruction, while Phases 2 and 3 resulted in overall VSS destructions of 71 and $77 \%$, respectively. Therefore, the results of this study were consistent with the results of Pham et al. (2007) and Braguglia et al. |(2008) that demonstrated AOPs can result in high solubilisation ratios, and thus greater destructions. When only the AnMBR was examined, the VSS removals in Phase 2 and 3 were observed to be lower than in Phase 1. The lower VSS removals in Phase 2 and Phase 3 were likely due to the fact that the PT substantially destroyed VSS in these Phases. 
However when PT and digestion were considered collectively the overall VSS destruction improved, suggesting that PT improved overall VSS degradation.

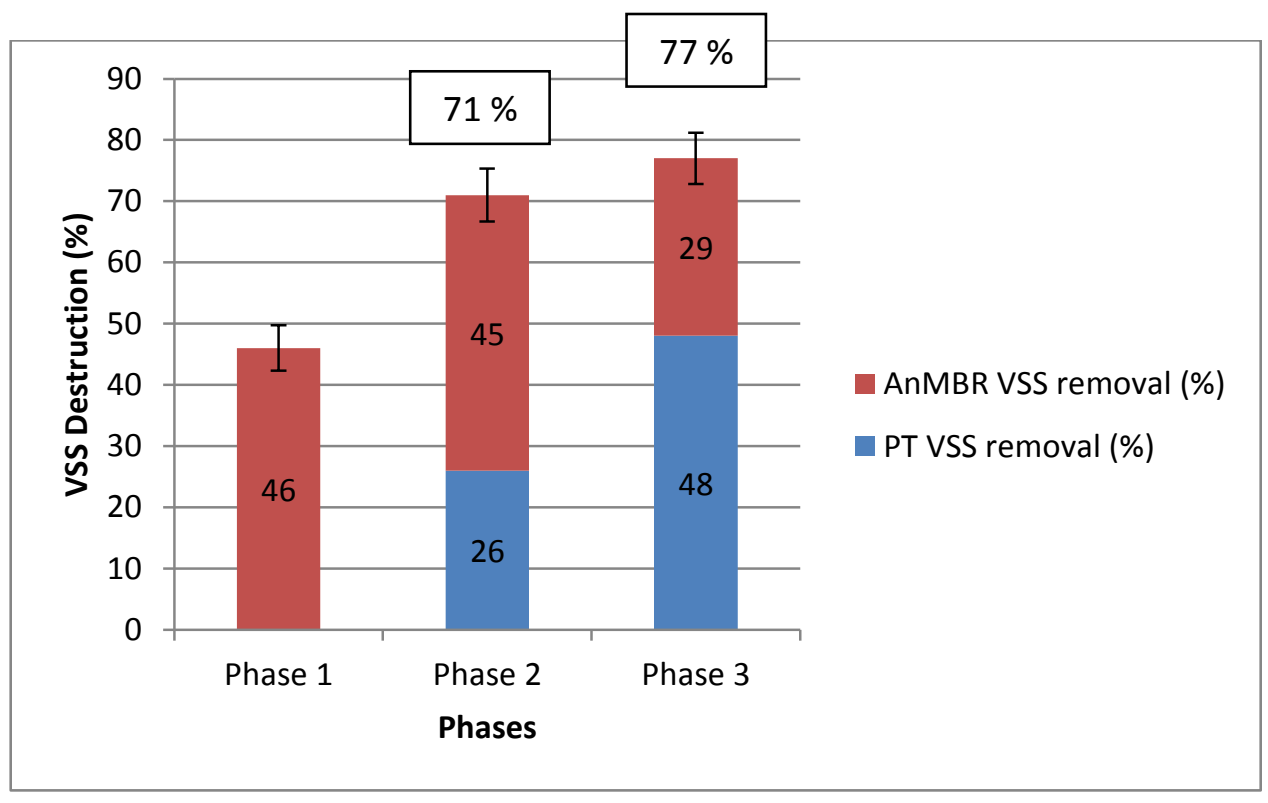

Figure 3.19: VSS Destruction Rates for Phase 1, 2, and 3 (with error bars)

TSS, VSS, and FSS concentrations were monitored during the steady state operation of the AnMBR to provide insight into the properties of the waste stream that would have to be handled after digestion. In addition this analysis would help with characterizing membrane fouling as a result of PT (Chapter 4). Figure 3.20 summarizes the solids concentrations observed during all phases. As can be seen in this figure, all solids decreased in concentration as the level of PT increased. The average TSS concentration in the AnMBR waste was 7\% less in Phase 2 than Phase 1 and an additional 12\% less in Phase 3. Similarly the average AnMBR VSS concentrations was less in Phase 2 than Phase 1 by $10 \%$ and the VSS concentration further decreased by $12 \%$ in Phase 3 . ANOVA tests revealed that there was a significant difference in TSS and VSS concentrations between all phases. The reduced concentration of solids would lower the requirements for downstream sludge processing and disposal when compared against digestion of untreated raw WAS. In addition, reduction in membrane fouling might be 
anticipated as a result of reduced mass loading on the membrane, a concern that will be addressed in detail in Chapter 4 .

In addition to TSS and VSS, FSS concentrations were monitored throughout the operation of the AnMBR to determine if PT impacted on the fate of inorganic particulates through the system. In Figure 3.20 it can be observed that changing the AnMBR feed from raw WAS to PT WAS in the Phase 2 feed did not alter the FSS concentration in the AnMBR. The average FSS concentrations in Phase 1 and Phase 2 AnMBR WAS were $8623 \pm 552$ and $8550 \pm$ $584 \mathrm{mg} / \mathrm{L}$, respectively. Statistical analysis at 95\% confidence level revealed no significant difference between the two concentrations. However, a significant FSS decrease of $13 \%$ was observed between Phase 1 and Phase 3. This was in agreement with the previously discussed PT results that demonstrated no solubilisation of FSS with a PT duration of 20 minutes but partial solubilisation with 60 minutes of PT. The reduction in the concentration of these solids will lower the requirements for downstream sludge processing and disposal when compared against digestion of untreated raw WAS.

Furthermore, the FSS concentrations in the feed and the AnMBR waste were compared for all phases to determine if accumulation of inerts took place in the AnMBR. It was observed that the FSS concentrations in the digester were significantly higher than that present in the feed for all phases, which suggested accumulation of inerts. The ratios of AnMBR to feed FSS concentrations were determined to be somewhat less (5.3-5.6) than the SRT/HRT ratio (6) for all phases. This indicated that some of the feed FSS was dissolved during digestion and the FSS in the AnMBR did not accumulate at the same ratio as that of the SRT/HRT. 


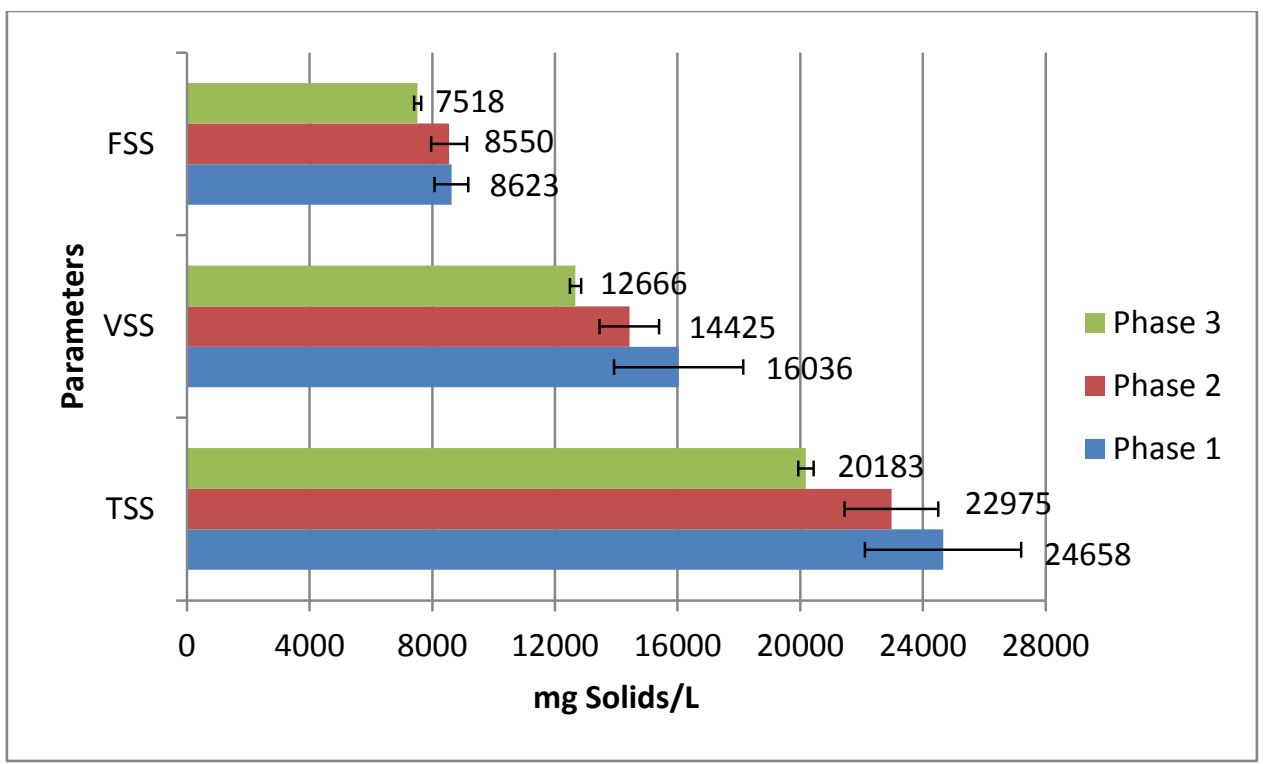

Figure 3.20: Average SS Concentrations in Phase 1, 2, and 3 AnMBR WAS (with error bars)

\subsubsection{Organic Nitrogen Destruction and Analysis}

Organic Nitrogen $(\mathrm{ON})$ destruction can be employed as an alternative indication of the performance of the AnMBR and thus was monitored throughout the AnMBR operation. Organic nitrogen was calculated as the difference between TKN and Ammonia. For each phase, ON destruction was calculated by comparing the cumulative mass of $\mathrm{ON}$ in the feed and outgoing streams. Once the cumulative ON mass loadings in each stream was calculated, they were graphed and the percent loss between the incoming and outgoing stream slopes yielded the ON destruction rate. Figure 3.21 provides a sample $\mathrm{ON}$ destruction graph along with corresponding calculations for Phase 1. From Figure 3.21 it can be seen that cumulative mass lines followed a linear pattern and hence this demonstrates that steady state had been achieved during this analysis. ON data for all other phases can be found in Appendix A8. 


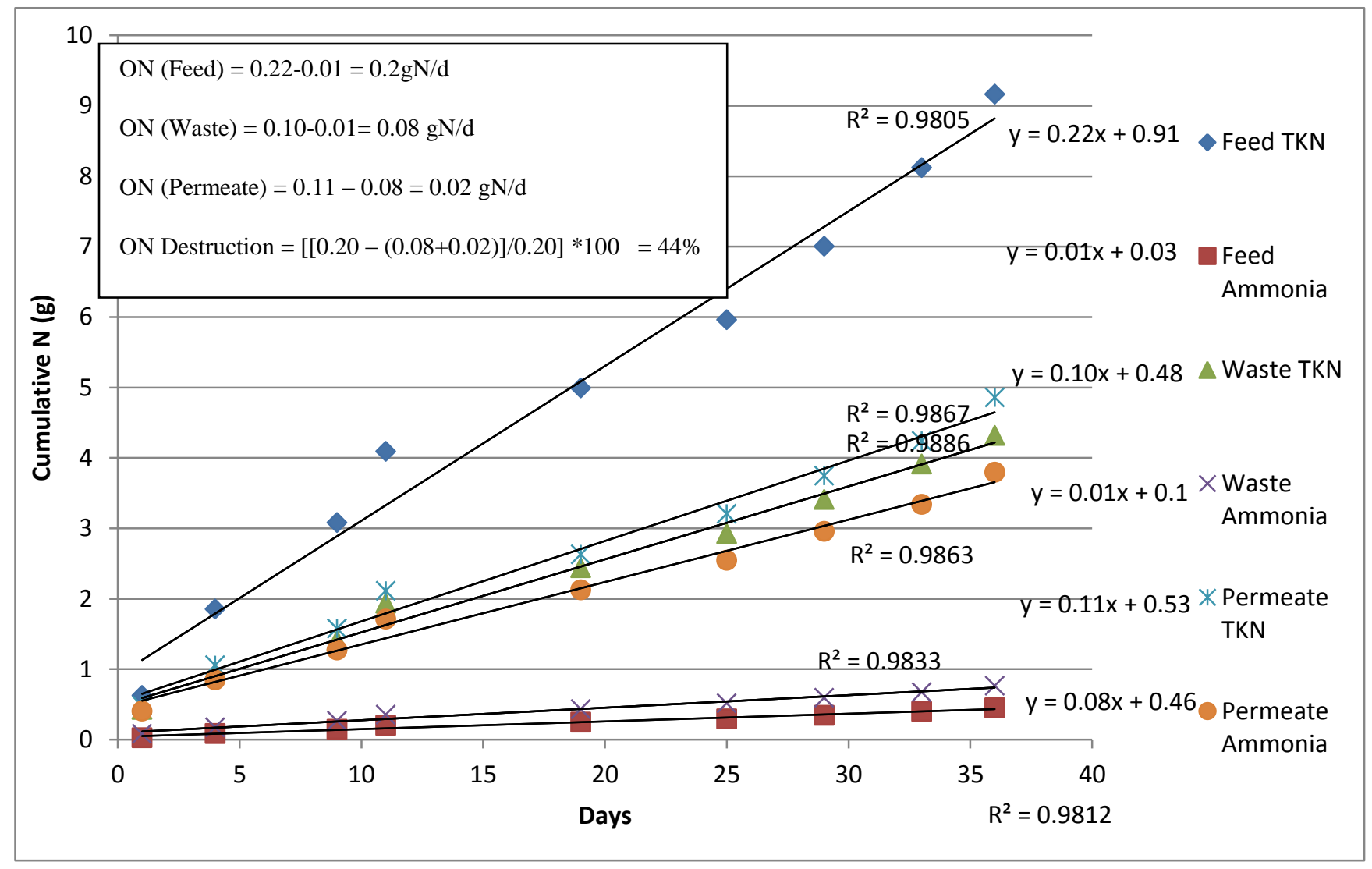

Figure 3.21: Total ON destruction for Phase 1 Steady State

The calculated ON destruction values were compared between phases to determine if PT impacted on the biodegradability of ON compounds. Figure 3.22 summarizes the ON destruction that was observed in each phase of this study. As discussed in Section 3.3.2., in Phases 2 and 3, ON destruction occurred during the pre-treatment stage, which contributed to the overall ON destruction in each phase. As can be seen from Figure 3.22, Phase 1 resulted in a 44\% ON destruction, while Phases 2 and 3 resulted in increased overall ON destruction values of 52 and $70 \%$, respectively. When ON removal in the AnMBR was considered by itself, it was observed to increase by $2 \%$ in Phase 2 when compared to Phase 1 while Phase 3 resulted in an additional 10\% improvement over that observed in Phase 2. Overall, Phase 3 achieved the greatest degradation of ON, indicating that pre-treatment of WAS improved the biodegradation in the 
AnMBR. This was expected as PT solubilized organic nitrogen (with Phase 3 PT resulting in the highest solubilisation), thus making organics biodegradable and available for microorganisms to consume and degrade.

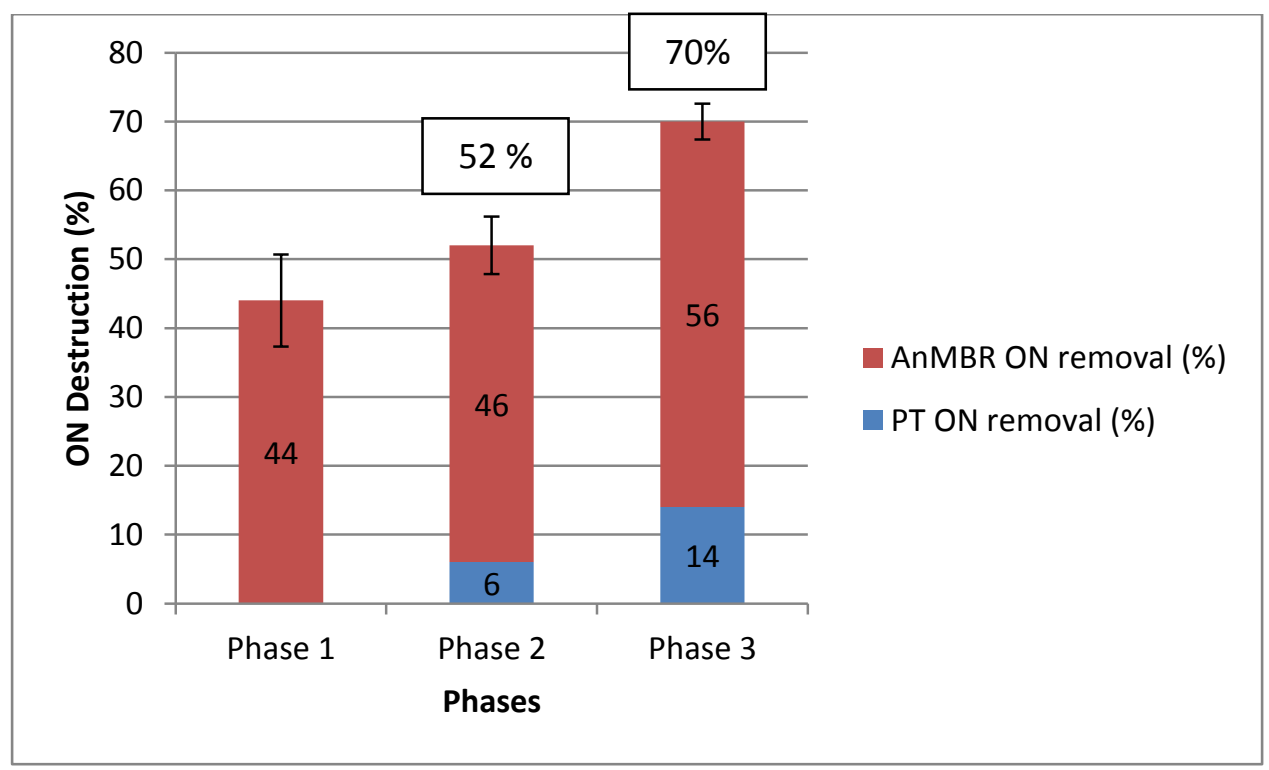

Figure 3.22: ON Destruction Rates for Phase 1, 2, and 3 (with error bars)

The ON destruction was compared with the COD destruction in each phase to determine if $\mathrm{PT}$ resulted in greater ON destruction than COD destruction. The COD destruction in Phases 1,2 , and 3 were $49 \pm 5,58 \pm 5$, and $63 \pm 1 \%$ while the $\mathrm{ON}$ destruction in these phases were $44 \pm$ 7, $52 \pm 4$, and $70 \pm 3 \%$, respectively. Therefore, similar ON and COD destruction was accomplished for Phases 1 and 2 when variability was considered. This result was contrary to the result obtained in Section 3.3.2.1.3 that Phase 2 PT solubilised nitrogen containing species to a greater extent than COD species. A potential explanation for this observed ON destruction in Phase 2 despite higher ON solubilisation may have been due to the formation of nonbiodegradable nitrogen species due to Phase 2 PT. In the case of Phase 3, however, it is seen that a higher ON destruction was obtained than COD destruction. Therefore, PT with 60 minutes of US and $50 \mathrm{gH}_{2} \mathrm{O}_{2} / \mathrm{kgTS}$ was more effective in destroying organics comprising nitrogen species 
than COD species, which is in agreement with the result obtained in Section 3.3.2.1.3. Thus it appears that Phase 3 PT generated higher nitrogen containing biodegradable species, which resulted in higher ON destructions.

The average concentrations of TKN, sTKN, $\mathrm{NH}_{3}, \mathrm{sON}$, and pON were monitored during the steady state operation of the AnMBR as their presence in the permeate and waste streams may impact upon downstream operations in a wastewater treatment plant. Figure 3.23 presents a plot of the nitrogen species in the AnMBR WAS throughout its operation. From this figure it can be observed that with the exception of pON the concentrations of the nitrogen species decreased as the level of pre-treatment increased. This decrease with each phase may reduce the requirements for downstream processing when compared against digestion of untreated raw WAS.

The ammonia fractions were monitored in the feed and AnMBR streams to monitor protein degradation as a result of hydrolysis in the AnMBR and to determine if ammonia concentrations in the AnMBR may be inhibitory to the activity of microorganisms. Although the feed contained low concentrations of ammonia in all phases, the AnMBR WAS had elevated concentrations of ammonia. The feed ammonia concentrations for Phases 1, 2, and 3 were $36 \pm$ 5, $35 \pm 2$, and $47 \pm 5 \mathrm{mg} / \mathrm{L}$, respectively while the corresponding AnMBR WAS ammonia concentrations for the three phases were $378 \pm 30,306 \pm 34$, and $252 \pm 14 \mathrm{mg} / \mathrm{L}$, respectively. This increase was as a result of the long SRT and digestion, which lead to the de-amination of proteins and the subsequent release of ammonia. In addition, although AnMBR WAS ammonia concentrations were higher than the feed, they were considerably lower than the inhibitory concentration of $3000 \mathrm{mg} / \mathrm{L}$ proposed by Rittmann and McCarty, (2000). Thus it is hypothesized that the ammonia concentrations in the AnMBR did not inhibit the activity of microorganisms. 
Also observed from this discussion is that the PT phases had lower ammonia concentrations than the control reactor. This observation will be discussed in the upcoming paragraphs.

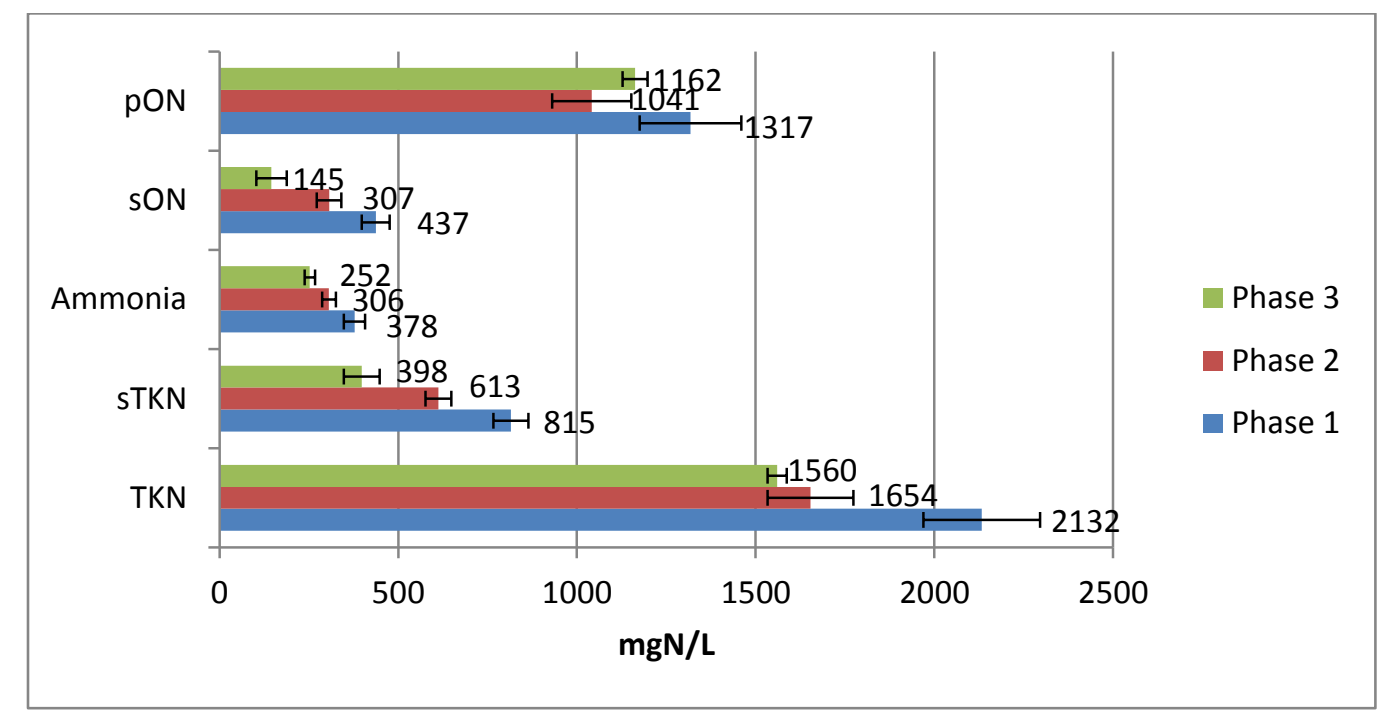

Figure 3.23: Average Nitrogen Concentrations in Phase 1, 2, and 3 AnMBR WAS (with error bars)

A cumulative mass balance was conducted on TKN in all three phases to monitor the conservation of nitrogen species in this study. Figure 3.24 presents a cumulative mass balance of TKN observed throughout this study. As can be seen from the figure, TKN masses remained essentially constant in Phase 1 feed and AnMBR (waste and permeate streams). The cumulative mass of TKN in the Phase 1 feed was $20.3 \mathrm{~g} \mathrm{~N}$ while the cumulative mass of TKN in the Phase 1 AnMBR (waste and permeate streams) was $19.5 \mathrm{gN}$. The small difference of $4 \%$ between the Phase 1 TKN masses demonstrated that there was no significant lack of mass balance closure, and thus was indicate of good data quality. In Phase 2 and Phase 3 differences of 12\% and 18\% respectively were observed between the feed and AnMBR (permeate and waste streams) masses . These differences were significantly different than the Phase 1 difference and thus there was a lack of mass balance closure in Phases 2 and 3. 
As established earlier that a lack of mass balance closure was encountered with both the PT phases. This can be explained by the fact that ammonia concentrations decreased with each phase despite the higher destructions, as observed earlier. Since PT solubilizes organic nitrogen and higher ON destructions were observed with both PT reactors than the control phase, it was expected that the ammonia concentration would be greater in the pre-treated reactors than the control reactor. These low ammonia concentrations in the PT phases may be a result of struvite precipitation during anaerobic digestion of PT WAS, which resulted in a high deviation in mass balance closure. As stated earlier, PT solubilises species and increases the rate of hydrolysis. This increase in the rate of hydrolysis is expected to result in a greater degradation of complex molecules into magnesium, ammonium and phosphate (Ariyanto et al., 2013) than the control reactor. In addition, the $\mathrm{pH}$ remained around 7.2 during the operation of the AnMBR in this study, which falls within the $\mathrm{pH}$ conditions (7-11) required for struvite precipitation (Nelson et al., 2003). Under these conditions, an increase in magnesium, ammonium and phosphate concentrations due to PT may have led to an increase in struvite precipitation. Since Phase 3 PT resulted in higher solubilisations then Phase $2 \mathrm{PT}$, it is expected that struvite precipitation in Phase 3 would be higher than Phase 2, which led to lower ammonia concentrations. It is recommended for future work to measure struvite concentrations in the AnMBR to determine the definite cause of ammonia loss in the AnMBR. 


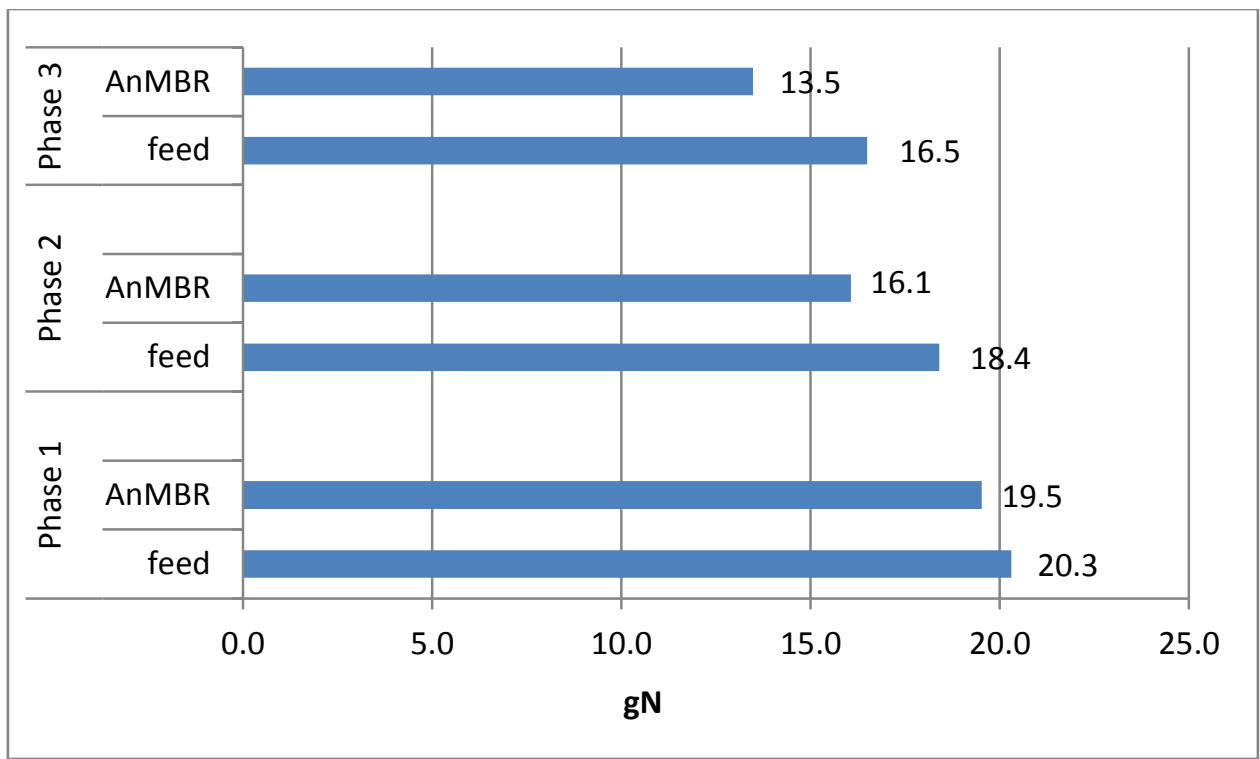

Figure 3.24: Cumulative TKN Mass Balance in Phases 1, 2, and 3

The concentrations of ammonia in the permeate was also monitored to determine the quality of the permeate that might impact upon downstream operations in a wastewater treatment plant. Figure 3.25 summarizes the permeate ammonia species concentrations. As expected permeate ammonia concentrations for all phases were higher than the feed and consistent with the AnMBR WAS ammonia concentrations. To reduce the concentrations of ammonia and further improve the permeate quality, the permeate could be subjected to nutrient recovery process before it is discharged.

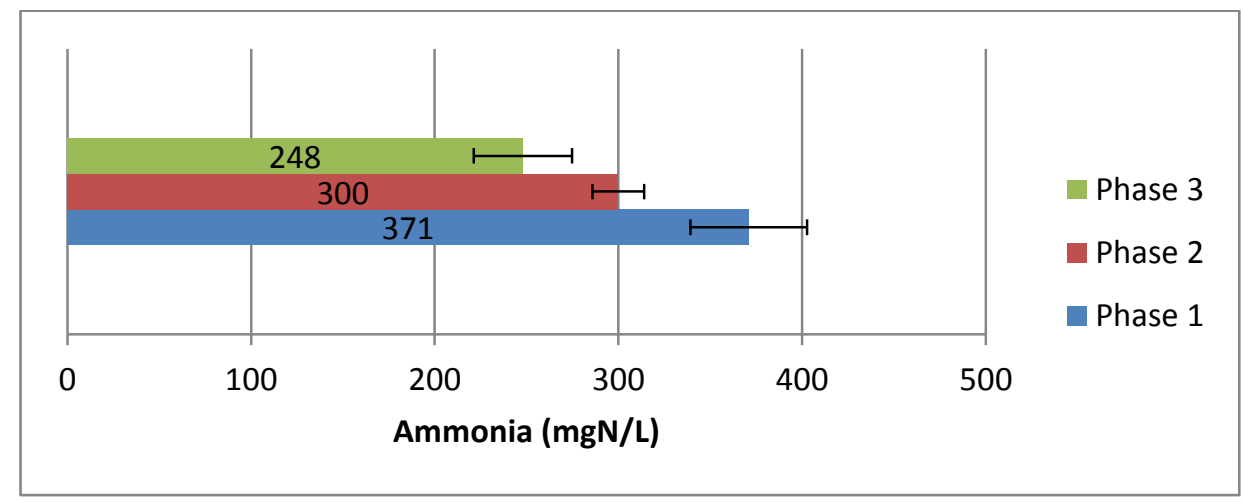

Figure 3.25: Average Ammonia Concentrations in Phase 1, 2, and 3 Permeate (with error bars) 


\subsubsection{COD Decay Tests - Estimation of Biodegradable COD}

COD decays tests were performed to determine the impact of pre-treatment on the readily biodegradable fraction of COD in the WAS. It was hypothesized that PT would increase the readily biodegradable fraction and that this fraction could be quantified by monitoring COD removal during the period between feed cycles. These tests were performed for Phases 2 and 3, once both phases had reached steady state. These tests were duplicated for both phases and the procedure outlined below was followed.

In these tests, the concentrations of TCOD and SCOD in the system (AnMBR + permeate holding tank) were measured every 5 hours by withdrawing $37.5 \mathrm{~mL}$ of AnMBR WAS. To avoid complications with permeate withdrawal, the COD of the permeate was estimated by measuring the SCOD of the AnMBR. The mass of TCOD and SCOD in the system was then calculated by multiplying the volumes in the reactor and the permeate holding tank by their respective COD concentrations at each sampling time. In order to determine the volume of sludge remaining in the reactor, the volume of permeate collected at every withdrawal period was subtracted from the working volume of the reactor. The masses of COD in the reactor and the permeate holding tank were then added to determine the mass of COD in the system, which was then plotted against time to produce a mass decay plot.

The COD decay plots for both phases are summarized in Figure 3.26 to compare the COD consumption in the two PT phases. As mentioned earlier, this test was duplicated for each phase and the error bars represent the variation between the duplicated tests. Each plot corresponded to one reaction cycle, which was 24 hours for this study. As can be seen from the figure, the highest COD concentration in the system was observed at the beginning of each cycle, following WAS addition to the AnMBR. It can also be seen in the plot that the mass of COD in 
the system became effectively constant at the end of each reaction period (except for $\mathrm{t}=10$ hours in Phase 2), thus demonstrating that the biodegradable COD had been consumed by the end of the cycle. The mass of COD in the system at $t=10$ hours in Phase 2 was lower than expected and may have been a result of analytical error, thus resulting in a deviation from the true mass of COD in the reactor at that time. Therefore, an estimated decay curve was generated for Phase 2 (Figure 3.26).

To compare the change in biodegradability between the two phases, the difference between the mass of COD in reactor at the beginning and the end of the cycle in each phase was assessed using Equation 3.3.

$$
\text { COD change }(\%)=\frac{\mathrm{TCOD}_{\text {start }}-\mathrm{TCOD}_{\mathrm{end}}}{\mathrm{TCOD}_{\text {start }}} * 100 \%
$$

The average COD changes for Phase 2 and Phase 3 were $18 \pm 1.3 \%$ and $24 \pm 0.1 \%$, respectively. A t-test at $95 \%$ confidence interval revealed that the extent of COD reduction was significant different between the two phases. Therefore, PT in Phase 3 increased the fraction of COD that could be degraded in the AnMBR as compared to Phase 2. The results from these tests were thus in agreement with the COD destruction results in the previous section.

The rate of COD decline in the reactor was also monitored to estimate the amount of readily biodegradable in both PT phases. As can be seen from Figure 3.26, the mass of COD in the reactor declined more rapidly with Phase 3 compared to the Phase 2 pre-treated feed. In Phase 2 the mass of COD declined from 85 to 70 gCOD after 10 hours of digestion, after which the mass of COD in the system remained constant. By contrast In Phase 3 the mass of COD was reduced from 81 to $61 \mathrm{~g} \mathrm{COD}$ in 5 hours, after which the mass of COD in the system remained constant. Hence, the results indicate that the Phase 3 pre-treated feed had a greater readily biodegradable COD content than the Phase 2 pre-treated feed. Therefore PT of WAS with a 
higher sonication duration (60 minutes) resulted in a greater improvement in readily biodegradable content, thus resulting in higher COD destruction as summarized in Section 3.3.3.3.

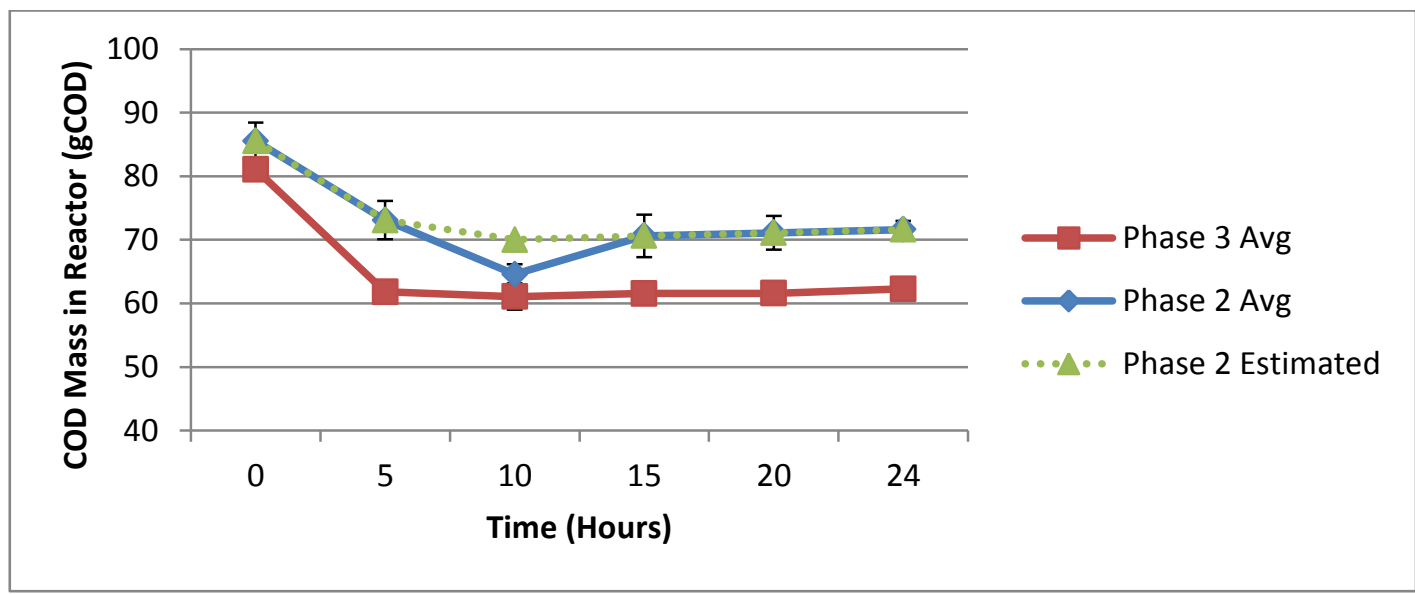

Figure 3.26: COD Decay Results for Phase 2 and Phase 3 (with error bars)

\subsubsection{Comparison of Phases}

This section provides a brief summary of all the responses characterized in each phase to provide an overall assessment of the effect of PT on WAS biodegradability. Compared to the control AnMBR, both pre-treatments resulted in an overall increase in COD, VSS, and ON destruction. Figure 3.27 summarizes the destructions observed throughout the operation of the AnMBR. As can be seen from the figure, Phase 1 resulted in 49\%, 44\%, and 46\% COD, ON and VSS destruction. Operation with PT in Phase 2 resulted in an increase in overall destruction for all parameters. The COD, ON, and VSS destruction in Phase 2 were 58, 52 and 71\% respectively. Increasing the sonication duration from 20 to 60 minutes further improved COD, ON and VSS destruction. The COD, ON, and VSS destruction in Phase 3 were 63, 70 and 77\% respectively. Thus, solubilisation of COD, ON, and VSS as a result of PT led to the increase in availability of substrate to microorganisms and conversion of non-biodegradable into biodegradable materials, thus resulting in greater COD, ON, and VSS destructions. 


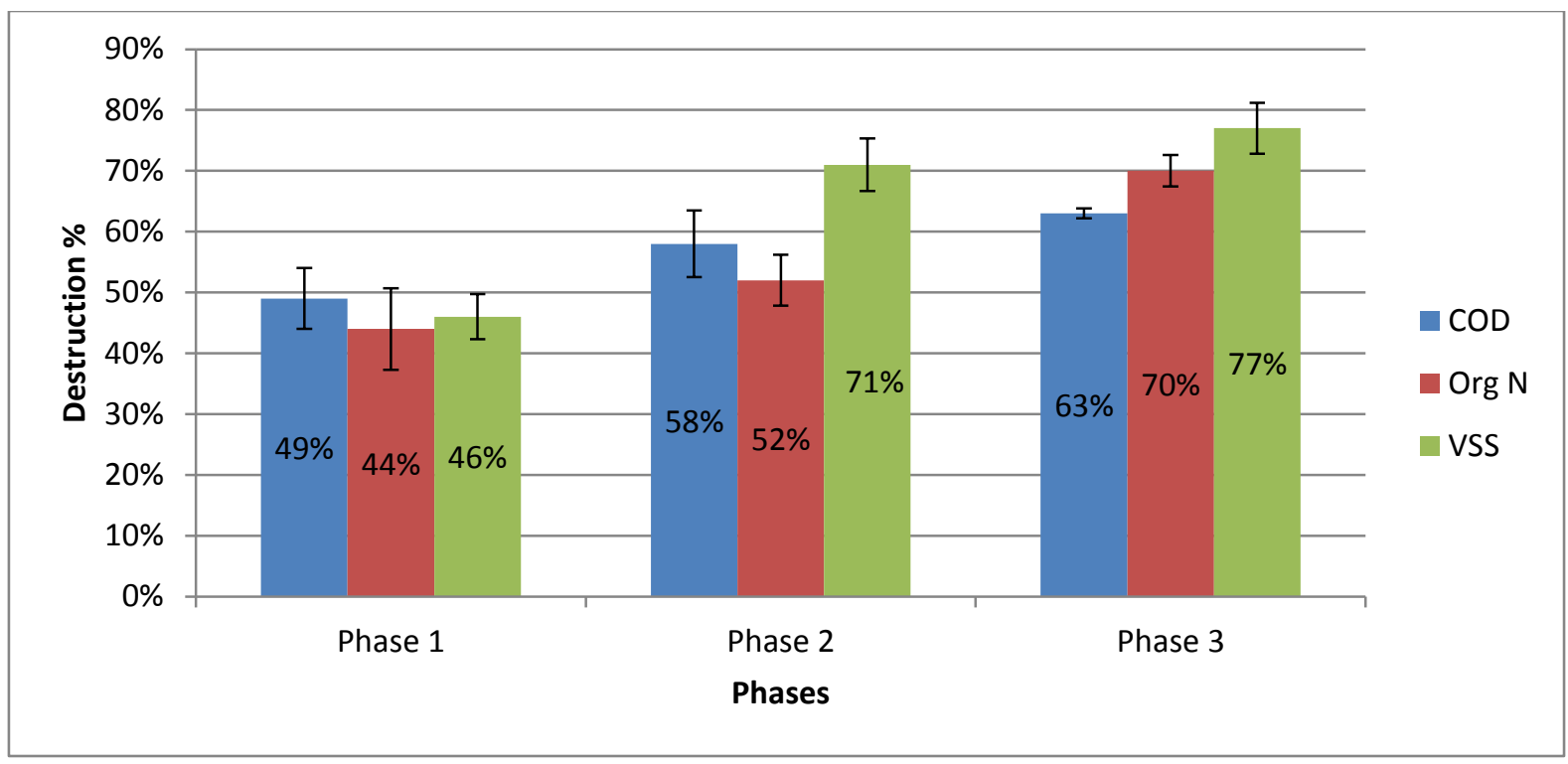

Figure 3.27: Total COD, VSS, and ON Destruction Rates for all Phases (with error bars)

\subsection{Conclusion}

In conclusion, all pre-treatments of waste activated sludge involving thermal, sonication and peroxide addition led to solubilisation of COD, with the peroxide-sonic PT with 50 $\mathrm{gH}_{2} \mathrm{O}_{2} / \mathrm{kgTS}$ and 60 minutes of US resulting in the greatest SCOD/TCOD ratio. All the AOPs employed in this study resulted in higher solubilisation than the individuals PT. Both the AOPs employed in the detailed study (20 and 60 minutes US each with $50 \mathrm{gH}_{2} \mathrm{O}_{2} / \mathrm{kgTS}$ ) significantly solubilised COD while conserving the TCOD, with the 60 minutes AOP resulting in the highest solubilisation. Moreover, the AOP with the lower sonication duration (20 minutes) preferentially solubilized organics while the AOP with the higher US duration (60 minutes) solubilized both organic and inorganic solids. The 60 minute AOP resulted in higher VSS destruction than the 20 minutes AOP. Both PTs solubilised ON and the PT with 60 minutes of US resulting in significant ON destruction, while the PT with 20 minutes of US did not.

Pre-treatment with both AOPs enhanced the biodegradation of WAS used in this study. Pre-treatment with $50 \mathrm{gH}_{2} \mathrm{O}_{2} / \mathrm{kgTS}$ followed by 60 minutes of US resulted in higher COD, VSS, 
and $\mathrm{ON}$ destructions than pre-treatment with $50 \mathrm{gH}_{2} \mathrm{O}_{2} / \mathrm{kgTS}$ followed by 20 minutes of US.

This was attributed to solubilisation and an increase in the biodegradable fraction in the Phase 3

PT. Some accumulation of colloids and inerts was observed in the AnMBR reactor. PT resulted in a reduction in the mass flow of solids and organics. Thus a PT-AnMBR system may reduce the requirements for downstream processing when compared with digestion of untreated raw WAS. 


\section{Chapter 4: Membrane Performance of AnMBR treating Raw and Pre-treated WAS}

\subsection{Introduction}

Anaerobic digestion (AD) is a common sludge stabilization method employed in wastewater treatment plants that not only converts the organic matter into a renewable source of energy i.e. biogas, but also decreases the amount of solids while destroying a majority of the pathogens in the sludge (Abelleira et al., 2012). However conventional anaerobic processes typically need to be operated at long hydraulic residence times and require large bioreactor volumes to accommodate the rate limiting hydrolysis process and the slow growth rates of methanogens (Bougrier et al., 2006). The incorporation of membranes into the design of anaerobic digesters has the potential to considerably reduce bioreactor volumes by decoupling the HRT from the SRT (Dagnew, 2010). The operation of the bioreactors at relatively shorter HRTs and longer SRTs can reduce the bioreactor volume, while accomplishing higher organic loading and destruction rates.

Although AnMBRs appear to provide considerable advantages over conventional digesters when bioreactor performance is considered, a potential challenge is the fouling of membranes due to the accumulation of microorganisms, colloids, solutes, and cell debris in or on membrane surfaces (Meng el al., 2009). Membrane fouling results in an increased filtration resistance, thus reducing the permeate flux (Judd, 2008) or conversely, the TMP increases if operated in constant flux mode. The inefficient operation of membranes due to fouling will require elevated maintenance and energy costs and may require frequent replacement of membranes, which in turn increases costs. Therefore, characterization of fouling is desirable as it will facilitate the development of strategies that might be employed to reduce these costs. 
The potential for membrane fouling is elevated when treating high solids waste streams such as WAS. In this application, the high solids concentrations of the feed stream, and the amplification of non-biodegradable suspended solids concentrations in the MLSS due to the ratio of SRT/HRT can lead to high MLSS concentrations that may lead to membrane fouling. The MLSS concentrations may be reduced through the use of sludge pretreatment (PT) technologies. PT technologies are growing in popularity as they promise to increase WAS biodegradability. However, PT has been shown to produce colloidal solids that may accumulate in AnMBRs if they are not biodegraded. The presence of colloids has been identified as a significant factor in membrane fouling when treating sludge (Wu et al., 2009 and Fan et al., 2006). Operation at extended SRTs has also been found to result in colloid generation due to hydrolysis of particulates. Hence, operation at long SRTs in combination with pre-treatment (PT) may lead to a higher concentration of colloids than untreated WAS due to the solubilising effect of PT. There is however little evidence in the literature to indicate whether the increase in colloid concentrations with PT would offset the benefits that might be achieved with lower MLSS.

While PT may reduce fouling when digesting WAS it is prudent to ensure that membrane flux is maximized through implementation of strategies that are known to minimize fouling. A number of strategies to minimize and control fouling have been reported in prior studies. For instance, operating the membrane below the critical flux has been reported to result in minimal fouling (Jeison and van Lier, 2006a). Another method to control fouling is to integrate a period of relaxation into the membrane operation rather than operating with continuous permeation (Jude, 2006). For instance, Dagnew et al., (2012) compared the performance of a tubular membrane with continuous permeation at a flux of 30 litres per $\mathrm{m}^{2}$ per hour (LMH) with that of a membrane operating on a cycle with 5 minutes of permeation followed by 1 minute of relaxation. 
They observed that relaxation extended the operation of the membrane by limiting the maximum transmembrane pressure (TMP) to 30 kilopascals $(\mathrm{kPa})$ while continuous operation led to a TMP of $80 \mathrm{kPa}$, thus demonstrating increased fouling of the membrane.

In addition to a relaxed mode of operation and operation below critical flux, regular maintenance cleaning can also ensure reduced fouling and long term operation of membranes despite high solids concentrations and operating flux. For instance, Pierkiel and Lanting, (2005) attributed the long term successful performance of an AnMBR treating a combination of PS and WAS with an MLSS of 5-20 g/L and flux of 146 and 66.7-83 LMH to daily and monthly maintenance cleaning with a combination of phosphoric acid and sodium hydroxide. In addition to a phosphoric acid and sodium hydroxide combination, a variety of chemical agents have been successfully used to perform maintenance cleaning of membranes. For instance, Lee et al., (2001) achieved a flux recovery of up to $86 \%$ of the initial membrane flux for an AnMBR treating swine manure by subjecting the membrane to a cleaning by an alkaline solution followed by an acidic agent. In another study, Kang et al., (2002) observed that the permeate flux increased by two times after performing acidic cleaning. The cleaning efficiency has also been observed to be dependent on the sequence of cleaning. For instance, Dagnew, (2010) observed that cleaning with $\mathrm{NaOH}$ followed by citric acid caused further fouling of the membrane due to the precipitation of inorganic materials that were present on the cake layer as a result of the increase in $\mathrm{pH}$. However when the cleaning order was reversed, almost $100 \%$ of the flux was recovered. Therefore, in addition to regular maintenance cleaning, it is essential to determine the ideal cleaning sequence when using a combination of chemicals to maintain membrane performance. 
Operation with high MLSS concentration does not necessarily translate to a need for frequent cleaning. In some cases, membrane performance can be maintained by applying gas sparging or cross flow velocities to scour foulants that are deposited on or in the membrane. For instance, Padmasiri et al., (2007) operated a side stream AnMBR with MLSS concentrations of 27 and $49 \mathrm{~g} / \mathrm{L}$ to treat swine manure with no cleaning employed during its operation. The long term performance of the membrane was attributed to the use of high cross-flow velocities that prevented deposition of foulants on or in the membrane. However, a decline in the biological activity of the micro-organisms was also reported, which may be attributed to an interruption of the syntrophic interaction of acetogenic and methanogenic organisms as a result of high velocities (Brockmann and Seyfried, 1997 and Hernandez et al., 2002). Hence strategies to minimize the decline in flux without excessive shear rates need to be explored.

In conclusion, relatively few studies have evaluated membrane fouling in the digestion of high solids streams in AnMBRs. In addition, there is little information available on the impact of an integrated PT-AnMBR system on membrane fouling. This study aimed to determine the feasibility of anaerobic digestion of WAS that was pre-treated with a peroxide+sonic AOP in an AnMBR. In order to determine if such a system can be successfully applied, this study monitored the effect of changing biomass characteristics due to PT on membrane fouling and critical flux. In addition, this study examined if operation of a hollow fibre membrane with a fouling minimizing strategy that involved maintenance cleaning, gas sparging, a relaxed mode of operation, and an operational flux below the critical flux is feasible. 


\subsection{Materials and Methods}

This portion of the study examined the impact of WAS PT on membrane performance in a bench scale AnMBR system. Relaxed operation, maintenance cleaning, and operation below critical flux were implemented to maintain the performance of the hollow fibre membrane. The following sections present, in detail, the experimental set-up and operational parameters as well as the approaches used for determining critical flux, maintenance cleaning and sample analysis.

\subsubsection{Experimental Set-up}

A submerged 5 L AnMBR was operated for nearly 250 days as per the set-up discussed in Section 3.2.3. A ZeeWeed hollow fibre PVDF membrane with a nominal pore size of 0.04 $\mu \mathrm{m}$ and a nominal membrane surface area of $0.047 \mathrm{~m}^{2}$ was employed in the apparatus (supplied by GE, Canada). The operational temperature was controlled at $37^{\circ} \mathrm{C}$ by a Dyna-Sense digital temperature controller linked to an OMEGA® PR-20 RTD probe that was inserted in the bioreactor. TMP was monitored via a mechanical pressure gauge for the first 70 days of operation. The mechanical gauge did not provide continuous monitoring and accurate data, and hence an OMEGA® DPG4000 digital pressure gauge and logger was integrated into the permeate line after 70 days of operation. The operating flux was maintained at $2.75 \mathrm{LMH}$ using a peristaltic pump. Mixing and membrane sparging was achieved by recycling biogas at $2 \mathrm{~L} / \mathrm{min}$ using a peristaltic pump. The membrane was operated in a relaxed mode of operation with 8 minutes of permeation followed by 2 minutes of relaxation. The temperature, flux, relaxation and permeation duration were maintained throughout the operation of the AnMBR to ensure constant conditions. 


\subsubsection{Operational Conditions}

Table 4.1 summarizes the steady state operating conditions that were relevant to membrane operation throughout this study. As described in Chapter 3, the AnMBR was operated in 3 phases to facilitate an assessment of the bioreactor and membrane performance when digesting raw and pre-treated WAS. Phase 1 was operated with raw thickened WAS while in Phases 2 and 3 the reactor was fed PT WAS. All phases were operated at an SRT of 20 days and an HRT of 3 days and made use of WAS that was collected from the Waterloo WWTP which was adjusted through settling to a TSS of approximately $7.5 \mathrm{~g} / \mathrm{L}$ as discussed in Section 3.2.1.

Table 4.1: Steady State Operational Conditions Relevant for Membrane Performance

\begin{tabular}{|c|c|c|c|c|c|c|}
\hline Phase & Feed & $\begin{array}{c}\text { SRT/HRT } \\
(\text { days })\end{array}$ & $\begin{array}{c}\text { Reactor } \\
\text { TSS }(\mathrm{g} / \mathrm{L})\end{array}$ & $\begin{array}{c}\text { Reactor } \\
\text { SCOD } \\
(\mathrm{g} / \mathrm{L})\end{array}$ & $\begin{array}{c}\text { Reactor } \\
\text { ffCOD } \\
(\mathrm{g} / \mathrm{L})\end{array}$ & $\begin{array}{c}\text { Reactor } \\
\text { cCOD } \\
(\mathrm{g} / \mathrm{L})\end{array}$ \\
\hline 1 & WAS & $20 / 3$ & $25 \pm 2.5$ & $4.2 \pm 0.4$ & $0.7 \pm 0.2$ & $3.6 \pm 0.5$ \\
\hline 2 & $\begin{array}{c}\text { WAS pre-treated with } \\
50 \mathrm{gH}_{2} \mathrm{O}_{2} / \mathrm{kgTS}+20 \\
\text { minutes US }\end{array}$ & $20 / 3$ & $23 \pm 1.5$ & $3.3 \pm 0.6$ & $0.3 \pm 0.1$ & $2.9 \pm 0.6$ \\
\hline 3 & $\begin{array}{c}\text { WAS pre-treated with } \\
50 \mathrm{gH}_{2} \mathrm{O}_{2} / \mathrm{kgTS}+60 \\
\text { minutes US }\end{array}$ & $20 / 3$ & $20 \pm 0.2$ & $2.4 \pm 0.1$ & $0.4 \pm 0.1$ & $2.0 \pm 0.2$ \\
\hline
\end{tabular}

\subsubsection{Maintenance Cleaning Procedure}

Maintenance cleaning was performed three times a week. A combination of $50 \mathrm{~mL}$ of $2 \mathrm{~g} / \mathrm{L}$ citric acid and $50 \mathrm{~mL}$ of $0.2 \mathrm{~g} / \mathrm{L}$ sodium hypochlorite was used to clean the membrane. The cleaning process was initiated by switching off the permeation pump with continuous gas sparging for 10 minutes, after which gas sparging was stopped for 1 minute. This was followed 
by backwashing with each chemical for 40 seconds of backpulse and 4 minutes of relaxation. This cleaning cycle was repeated until $50 \mathrm{~mL}$ of each chemical was used. After backwashing, the gas sparging pump was switched on for 5 minutes, after which regular permeation of the membrane was commenced.

\subsubsection{Critical Flux Determination}

Critical flux tests were conducted using the method introduced by Field et al., (1995). The critical flux test involved increasing the permeate flux in fixed increments for constant time periods and monitoring the TMP at each flux. A plot of this data reveals a linear relation between the TMP and flux within the sub-critical flux range and an exponential relation beyond the critical flux range. The exponential increase in TMP indicates rapid accumulation of foulants. Critical flux tests were conducted at steady state in Phase 2 and Phase 3. For each flux step, the increment in flux was $6 \mathrm{LMH}$. The duration of each step was $10 \mathrm{~min}$ and this was followed by a 2 min relaxation time to prevent accumulation of foulants before the next flux value was implemented. Critical flux tests were duplicated in each phase to determine if this test was reproducible.

\subsubsection{Sample Analysis}

Sample analyses were performed according to the methods described in Section 3.2.6. COD and solids analyses were conducted to characterize the biomass and determine its effect on membrane fouling. All measurements were carried out in duplicate. 


\subsection{Results}

The following sections will discuss the impact of operating the bench scale AnMBR with raw and PT WAS as a feed on the performance of the hollow fibre membrane. Apart from monitoring the overall performance and fouling rate of the membrane throughout AnMBR operation, this study examined trends between solids and colloidal concentrations and membrane fouling. Lastly, the results of critical flux tests that were conducted to attain additional insight into the potential operating flux under differing PT conditions will be assessed. Throughout these analyses, the efficiency of the fouling minimizing strategy adopted for this study was monitored.

\subsubsection{Overall Membrane Performance}

As mentioned in Chapter 3, the AnMBR was manually fed with WAS once a day and was then operated with continuous permeation for the remainder of the daily cycle. In this operation, the volume of sludge in the reactor was at its highest level immediately after feeding and then decreased until the daily permeate volume was collected. Since the TMP was affected by the head pressure between the TMP gauge and the liquid level, this fluctuation in liquid level in the reactor resulted in a daily fluctuation in TMP. Hence, two TMP patterns were observed in each cycle; one when the liquid level in the reactor was descending (daily permeate volume of 1.275 L not collected) and the other when the daily permeate volume had already been collected. For the purposes of this study, the TMP values for the period spanning from the beginning of the daily AnMBR operation cycle until the daily permeate volume was collected will be referred to as the low range TMPs, while the TMPs after the permeate volume has been collected will be referred to as high range TMPs. 
The high and low range TMPs were monitored to obtain insight into membrane performance over the range of feed compositions to the AnMBR. Figure 4.1 summarizes the TMP observed throughout the operation of the AnMBR. From the figure it is seen that the operation of the membrane was steady over the length of the study until the membrane was replaced during Phase 2 operation. The membrane was replaced because the TMP rose to $60 \mathrm{kPa}$ after feeding the reactor for 2 consecutive days. The increase in TMP was later found to be due to a fault in the head of the gas sparging pump, which led to a decline in the sparging rate. This result was consistent with that of Padmasiri et al., (2007), where the long term performance of the membrane was attributed to the use of high cross-flow velocities that prevented deposition of foulants on or in the membrane. Therefore, an effective sparging rate was required to minimize membrane fouling and maintain the performance of the membrane.

The TMP values that were recorded prior to and after membrane replacement were compared to determine if any fouling had occurred before the replacement of the membrane. As can be seen in Figure 4.1, both ranges of TMP reduced slightly after replacing the membrane. The higher TMP range decreased from approximately 4.2 to $3.6 \mathrm{kPa}$ and the lower TMP range decreased from 3.3 to $3.2 \mathrm{kPa}$ when the membrane was replaced (Day 140). This decrease suggested that some fouling had occurred in Phase 1 and Phase 2 before the replacement of the membrane.

The initial TMP observed with the second membrane was compared with the early Phase 1 TMP values to determine if both the membranes exhibited similar initial TMPs after start-up. From Figure 4.1, it can be seen that the high range TMP after 1 month of start-up was low (3.6 $\mathrm{kPa}$ ) and similar to the initial TMP of the second membrane (3.7 kPa). Since TMP was only monitored from Day 30 of AnMBR operation, the behaviour of the first membrane during the 
first month of operation was not available. However from the TMP around Day 35, it can be assumed that the initial behaviour of the first membrane was the same as the second membrane.

The increase in TMP during operation with the first membrane was monitored to determine the time period over which fouling might take place. From Figure 4.1 it can be seen that the high range TMP values increased to approximately $4.4 \mathrm{kPa}$ after 30 days of operation. Therefore it appears that some fouling of the first membrane took place when the reactor was adjusting to the Phase 1 feed. This may have been due to fouling that resulted from the accumulation of solids and inerts as evidenced by the elevated reactor solids concentrations of 36 $\mathrm{g} / \mathrm{L}$ (Figure 4.3) that was observed during this transient period.

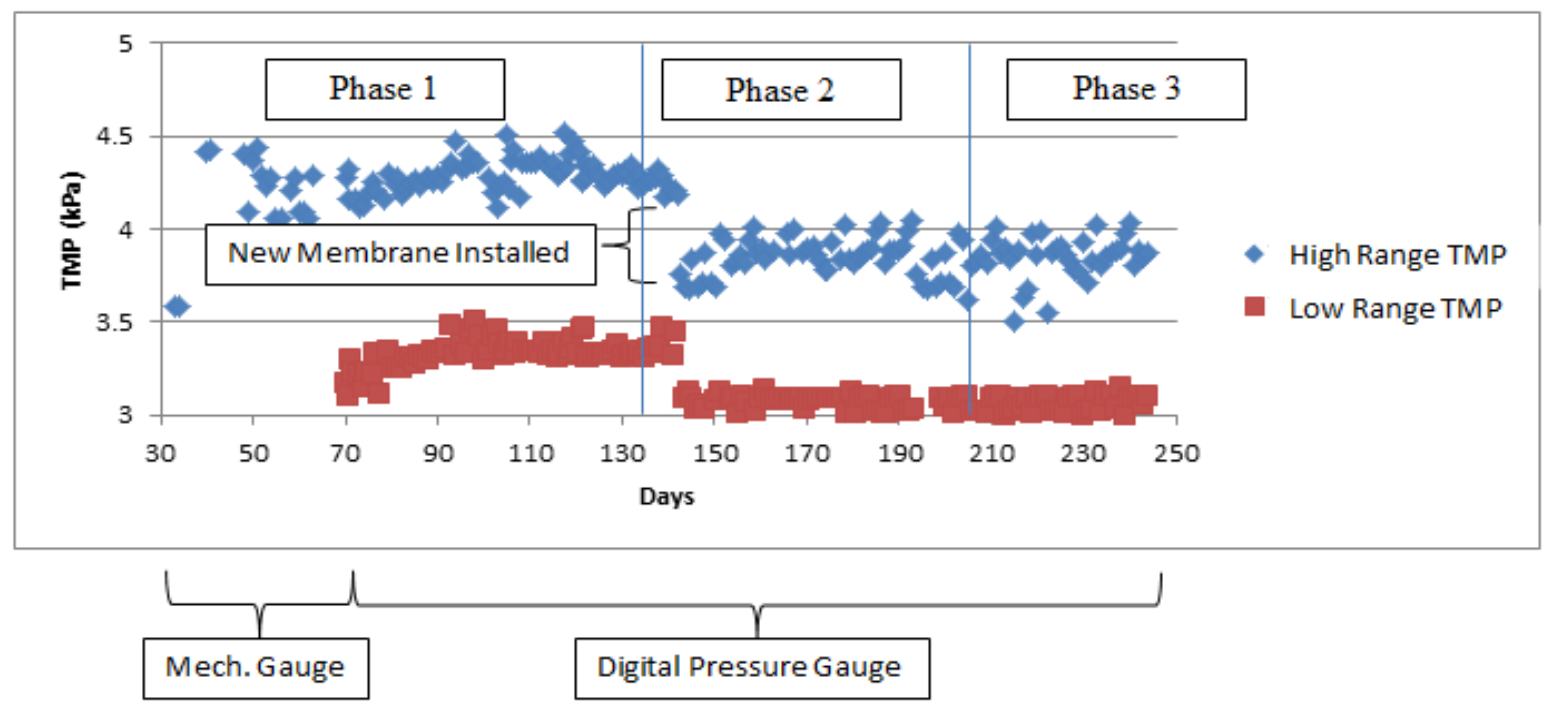

Figure 4.1: Overall Membrane Performance of Digested Sludge

The membrane performance was assessed in terms of the fouling rate (Equation 4.1) as this was believed to provide a more well-defined evaluation of membrane fouling. The replacement of the membrane made it difficult to compare fouling between phases on the basis of absolute TMP. The fouling rate values were considered to be more independent of the 
membrane replacement and hence could be used to compare the fouling between phases. Since calculation of the fouling rate required two values of TMP for each day only the data collected using the data logger was used to calculate the fouling rates (after Day 70). Fouling rates were calculated using Equation 4.1 for the high and low range TMP values, from Day 70 until Day 244 , to determine the effect of fresh feed and digester WAS on membrane fouling.

$$
\text { Fouling Rate }=\frac{\mathrm{TMP}_{\text {end }}-\mathrm{TMP}_{\text {start }}}{\text { time }_{\text {start }}-\text { time }_{\text {end }}} \quad \text { Eq. } 4.1
$$

Where $\mathrm{TMP}_{\text {start }}=$ initial high/low range $\mathrm{TMP}(\mathrm{kPa}), \mathrm{TMP}_{\text {end }}=$ final high/low range $\mathrm{TMP}(\mathrm{kPa})$, Time $_{\text {start }}=$ time which corresponds to the initial low/high range TMP (hour), Time $e_{\text {end }}=$ time which corresponds to the final low/high range TMP (hour).

Fouling rates were determined for each phase to evaluate if the change in feed characteristics affected membrane fouling in each phase. Since maintenance cleaning was performed 3 times a week throughout AnMBR operation, it was difficult to compare the effect of changing feed characteristics on membrane fouling based on the overall fouling rate due to the day-to-day variability in the fouling rate. Therefore the fouling rates that were determined for the days without maintenance cleaning were compared between phases. Figure 4.2 summarizes these fouling rates for both TMP ranges throughout the operation of the AnMBR. As can be seen from the figure, the low range average steady state fouling rates in Phases 1, 2, and 3 were $0.006 \pm$ $0.001,0.006 \pm 0.001$, and $0.005 \pm 0.002 \mathrm{kPa} /$ hour, respectively. Similarly, the high range average steady state fouling rates in Phases 1,2 , and 3 were $0.012 \pm 0.003,0.012 \pm 0.004$, and $0.012 \pm 0.005 \mathrm{kPa} /$ hour, respectively. An ANOVA test that compared these values indicated that there was no significant difference between the steady state fouling rates. Therefore the installation of a fresh membrane and the reduction in solids loading on the membrane in Phase 2 
(from Phase 1) did not significantly reduce the fouling rate. Hence, the results suggest that the changing biomass characteristics due to PT (i.e. solids and colloid concentrations) in Phase 2 did Phase 3 did not affect membrane fouling. However, the membrane was operated at a very low flux of $2.75 \mathrm{LMH}$, and hence it is likely that this low operational flux did not induce significant deposition of foulants on or in the membrane. The relatively consistent fouling rate over the course of the operation indicated good membrane operations at this low flux.

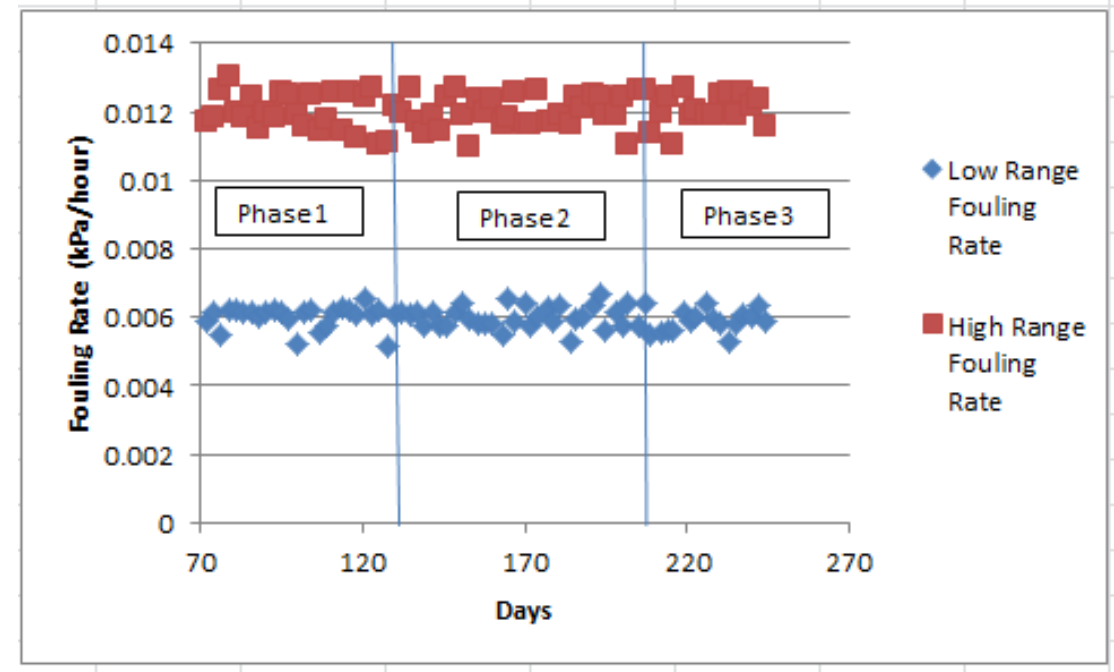

Figure 4.2: Fouling Rates Observed Throughout Membrane Operation

\subsubsection{Impact of Solids Fractions on Membrane Performance}

The relationship between solids concentrations and membrane fouling was evaluated to determine if the changes in the feed composition due to PT affected membrane performance. Figure 4.3 summarizes the TSS, VSS, and FSS concentrations observed in the AnMBR throughout the study along with the corresponding high and low range fouling rates associated with the TMPs. As can be seen in Figure 4.3, no apparent relationship existed between the fouling rate and solids concentration throughout the operation of the AnMBR. Therefore the 
decrease in solids loading on the membrane did not result in any significant reduction in membrane fouling. In addition, accumulation of inerts in all three phases (Chapter 3) did not significantly affect the fouling rate. Overall there appeared to be little relationship between these solids concentration and membrane fouling. This may have been due to the combination of the high cleaning frequency of 3 times a week, the high gas sparging rate of $2 \mathrm{~L} / \mathrm{min}$, the low operational flux of 2.75 LMH and a relaxed permeation cycle. Therefore, the operational design was successful in minimizing the likelihood of excessive fouling despite high solids concentrations.

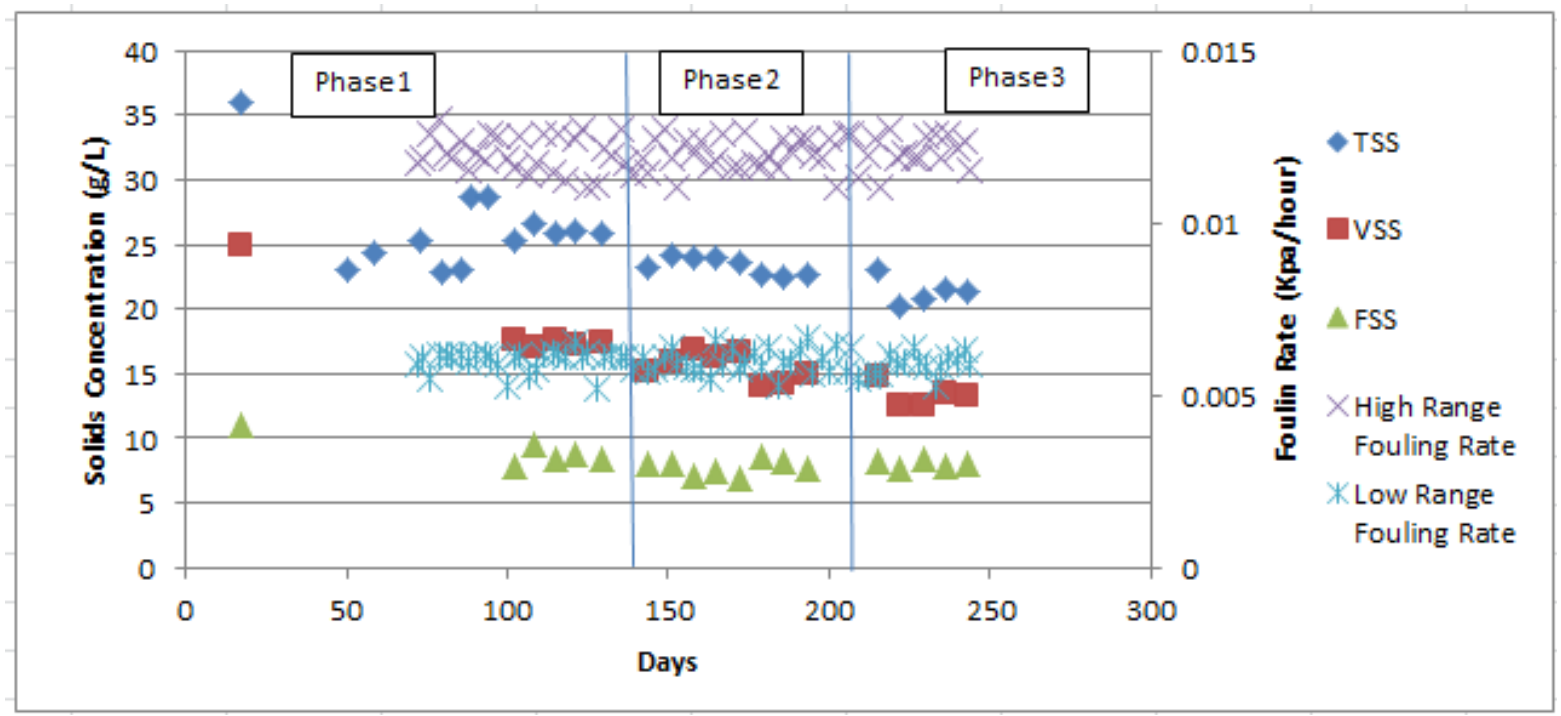

Figure 4.3: Effect of Solids Loading on Membrane Fouling

\subsubsection{Impact of COD Fractions on Membrane Performance}

The impact of colloid concentrations on membrane performance was assessed since colloids have been identified as a significant foulant in AnMBRs in other studies (Wu et al., 2009 and Fan et al., 2006). For this study, colloidal COD (cCOD) was determined as the difference between the SCOD and ffCOD filtrate values. Figure 4.4 summarizes the average 
TCOD and cCOD concentrations along with the low and high range fouling rates. As seen in Figure 4.4, no apparent relationship existed between COD and the fouling rate. Therefore, analogous to solids concentration, the reduction in total and colloidal COD loading on the membrane with PT did not result in any significant reduction in membrane fouling. Overall there was little relationship between either TCOD or cCOD concentrations and membrane fouling.

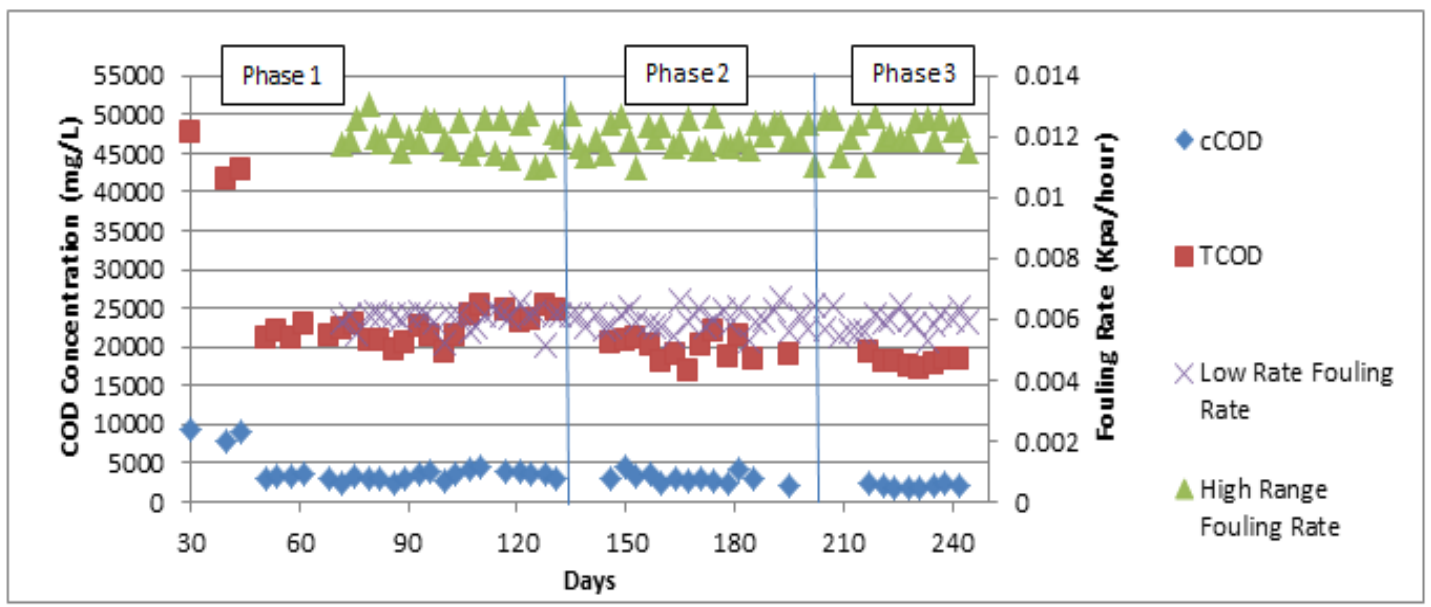

Figure 4.4: Effect of Colloidal COD on Membrane Fouling

\subsubsection{Critical Flux Tests}

Critical flux tests were conducted during Phase 2 and Phase 3 steady state operation to determine the effect of PTs on potential fouling over a larger range of flux values. Figure 4.5 presents the flux steps employed and the average TMP responses at each step for the duplicated tests in both phases. Duplicate tests were carried out on two consecutive days for each phase without employing any maintenance cleaning of the membrane during these two days to determine if exposure of the membrane to high fluxes led to significant membrane fouling. As evident from Figure 4.5, the duplicate experiments in each phase did not show much variation in 
the results. The deviations between the TMPs of each flux step in the duplicated tests for both phases were below $1 \mathrm{kPa}$ (Figure 4.5), thus demonstrating that the results were reproducible. From Figure 4.5, it can be seen that with the exception of the flux step from 12 to $6 \mathrm{LMH}$ there was little difference in the TMP responses between phases. Even in this step the difference between the TMP responses was modest (approx. 10\% of absolute value). Hence, the results of the critical flux tests indicated that the differences in the AnMBR contents (TSS, VSS, COD species) between Phases 2 and 3 that were previously documented (Section 3.3.2.1) did not significantly impact on membrane fouling over a wider range of flux values.

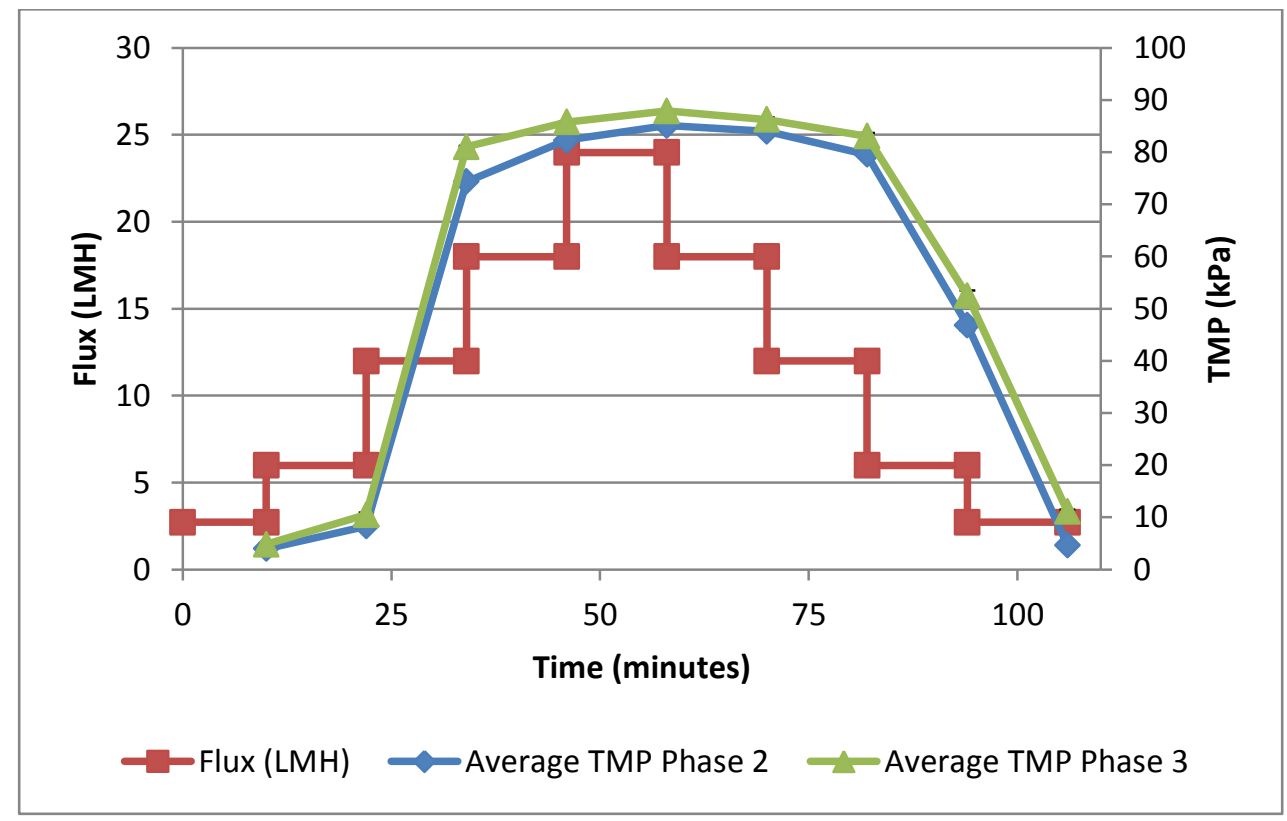

Figure 4.5: Critical Flux Test Results (with error bars)

The critical flux range for both phases was determined to establish the optimal operational flux range where minimal fouling takes place. As seen in Figure 4.6, the relationship between TMP and flux was essentially linear up to a flux of $6 \mathrm{LMH}$ for duplicate trials for both phases, indicating no significant fouling in this flux range. This relationship increased rapidly from 6 to 
12 LMH for both phases, thus demonstrating that the critical flux was within a flux range of 6-12 LMH for both phases. At fluxes higher than $6 \mathrm{LMH}$, the resistance due to cake layer formation likely increased, thus resulting in the high TMPs. In order to minimize fouling, operation below the critical flux range is recommended. Operation at fluxes higher than $6 \mathrm{LMH}$ may result in significant membrane fouling.

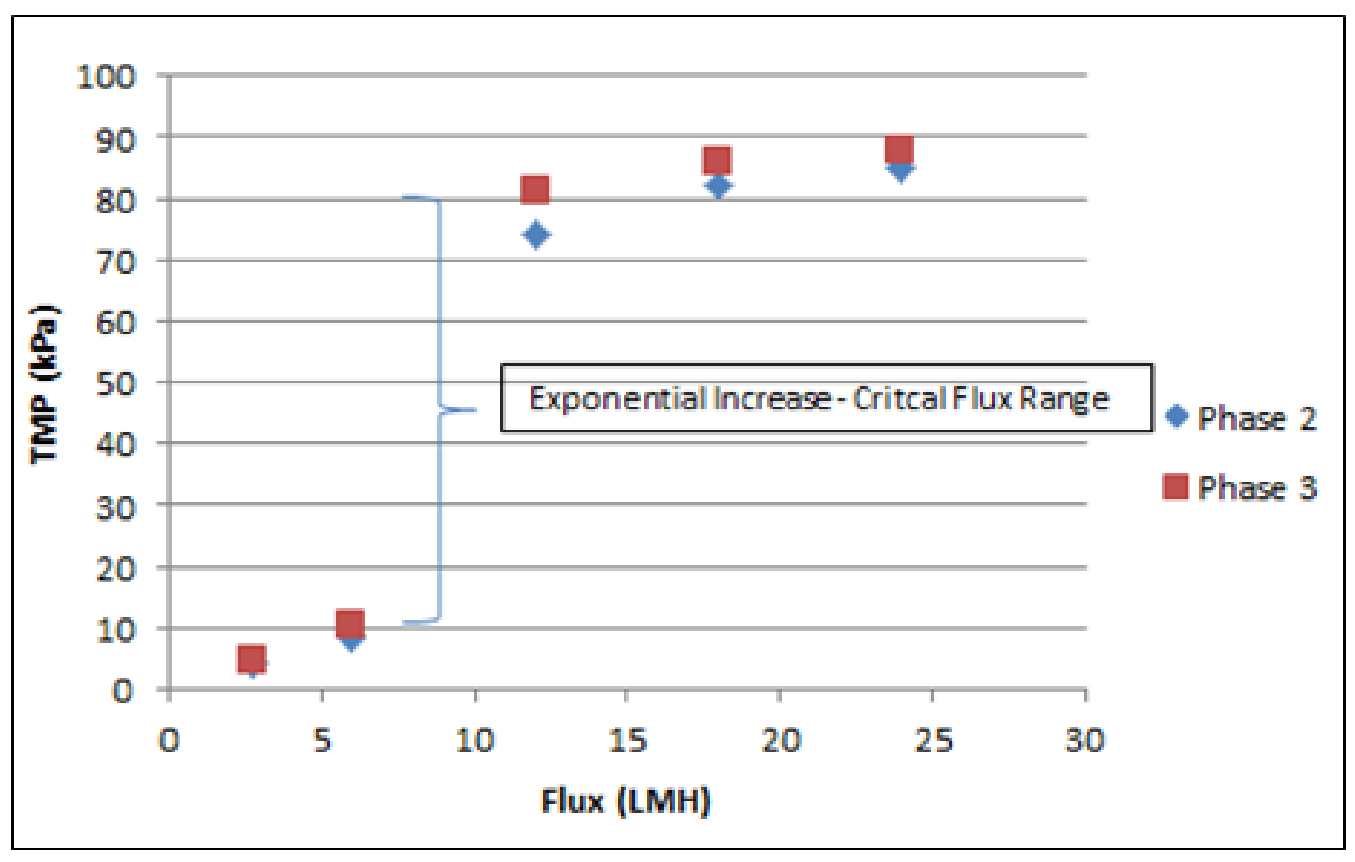

Figure 4.6: Critical Flux Range for Phase 2 and Phase 3

\subsection{Conclusion}

In conclusion, successful membrane performance was observed in AnMBR operation with raw and PT WAS. Fouling did not increase over the period of operation of the hollow fibre membrane despite high solids and colloidal concentrations in the AnMBR. The minimal fouling was attributed to the use of a relaxed mode of operation, an operational flux below the critical flux, a cleaning frequency of 3 times a week, and a gas sparging rate of $2 \mathrm{~L} / \mathrm{min}$. The implementation of PT did not affect membrane fouling as evidenced by insignificant impacts on 
the fouling rates and through the critical flux tests. The critical flux range for Phase 2 and 3 was determined to be 6 to $12 \mathrm{LMH}$ and these values appeared to be independent of the biomass concentrations in the AnMBR. Thus the results of this study demonstrate that a hollow fibre membrane can be applied to filter anaerobically digested sludges that have undergone PT which generates high concentrations of colloids and inerts. 


\section{Chapter 5: Conclusions}

This chapter provides a summary of significant conclusions related to this study. The chapter commences with conclusions that were drawn from a comparison of thermal, sonication, and peroxide-sonic PT that was based on COD analyses. This study compared thermal PT at 150 and $170^{\circ} \mathrm{C}$ for 30 minutes, sonication at 10 and 20 minutes and a peroxide-sonic AOP with hydrogen peroxide doses of 5, 25, and $50 \mathrm{gH}_{2} \mathrm{O}_{2} / \mathrm{kgTS}$ and US durations of 10, 20, 30, and 60 minutes. This section is followed by conclusions that were derived from a detailed study that examined COD, nitrogen, and solids responses in PT and subsequent AnMBR digestion when PTs that consisted of $50 \mathrm{gH}_{2} \mathrm{O}_{2} / \mathrm{kgTS}$ followed by 20 minutes of US and $50 \mathrm{gH}_{2} \mathrm{O}_{2} / \mathrm{kgTS}$ followed by 60 minutes of US were examined. Finally, this chapter provides conclusions related to membrane performance that were developed after observing operation during digestion of raw and PT WAS with an AnMBR.

\subsection{Comparison of Pre-treatments - Preliminary Tests}

- All PTs resulted in an increase in the solubilisation ratio, thus resulting in high colloidal and soluble COD concentrations.

- Pre-treatment with $50 \mathrm{gH}_{2} \mathrm{O}_{2} / \mathrm{kgTS}$ and 60 minutes of US resulted in the highest fraction of soluble COD of $46 \%$ and in an insignificant loss in TCOD (about 7\%), implying no loss in substrate for potential biogas production.

- The $50 \mathrm{gH}_{2} \mathrm{O}_{2} / \mathrm{kgTS}+60$ minutes US AOP and the other AOPs (with 20-30 minutes US and $50 \mathrm{gH}_{2} \mathrm{O}_{2} / \mathrm{kgTS}$ ) resulted in similar fractions of cCOD 25 and $21-24 \%$, respectively. However the ffCOD fraction of the 60 minute US AOP (22\%) was higher than the other AOPs (11-12\%), thus implying that the 60 minutes US AOP was more effective in solubilising particulates into soluble COD than the other AOPs. 
- The results from this study demonstrated that a sonication + peroxide AOP resulted in higher solubilisation than individual sonication PT.

- In terms of the hydrogen peroxide and sonication AOP, sonication duration and the interaction term (sonication + peroxide) were determined to have a greater impact on sludge solubilisation than hydrogen peroxide dose. This was attributed to the low doses of peroxide.

\subsection{Comparison of the 20 and 60 minutes US AOP-Detailed Tests}

In order to assess the effects of sonication duration on the physico-chemical properties and biodegradability of WAS, two AOPs were selected from the preliminary tests for further study- one with a low sonication duration of 20 minutes and another with a considerably higher treatment time of 60 minutes, each with a peroxide dose of $50 \mathrm{gH}_{2} \mathrm{O}_{2} / \mathrm{kgTS}$.

\subsubsection{Physico-chemical Comparison of the 20 and 60 minutes US AOP}

- Both pre-treatments resulted in minimal TCOD losses (of 4-6\%) and substantially higher ratios of SCOD/TCOD (33\% for the 20 minutes AOP and $40 \%$ for the 60 minutes AOP), and thus higher concentrations of truly soluble COD and colloids than the raw samples.

- PT with 60 minutes of sonication resulted in higher ffCOD and cCOD fractions (16 and $24 \%$ ) than the AOP with 20 minutes of sonication (12 and 21\%).

- The 60 minute AOP solubilised both VSS and FSS but the 20 minutes AOP solubilised only VSS.

- Both PTs resulted in VSS solids degradation, with the AOP with 60 minutes of US duration resulting in a significantly higher VSS destruction (46\%) than the AOP with 20 minutes of US (26\%) as a result of high solubilisations. 
- Both PTs resulted in ON solubilisation, with the AOP with 60 minutes of sonication resulting in a higher solubilisation (47\%). In addition, the AOP with 60 minutes sonication resulted in some TKN removal (11\%), whereas the AOP with 20 minutes of sonication did not lead to any significant removal.

- The chemi-sonic AOPs resulted in protein degradation, causing an increase in ammonia concentration thereby indicating not only rupture of cell walls to release soluble materials but also breaking down of compounds at the molecular level

\subsubsection{Biodegradability Comparison of the 20 and 60 minutes US AOP}

- Pre-treatment of WAS resulted in higher COD, solids, and ON destruction than raw WAS in anaerobic digestion. Using raw WAS as the feed to an AnMBR (Phase 1) resulted in COD, ON, and VSS destructions of 49,44 , and $46 \%$, respectively. The COD, ON, and VSS destructions achieved in with the 20 minute AOP were 58, 52, and 71\%, while the destructions with the 60 minute AOP were 63,70 , and $77 \%$, respectively.

- COD decay tests demonstrated that the 60 minute US AOP resulted in a greater readily biodegradable content then the 20 minute US AOP,.

- A cumulative COD mass balance demonstrated an improvement in the biodegradability of WAS with an increase in sonication duration

- Ammonia concentrations were observed to decrease as PT intensity increased despite higher ON solubilisations and destruction with PT. It was hypothesized that this was due to an increase in struvite precipitation with PT as it was likely that magnesium, and phosphate release would also have increased with PT.

- Analysis of the fixed suspended solids revealed an accumulation of inerts within the AnMBR in all three phases. The ratios of AnMBR to feed FSS concentrations were 
determined to be somewhat less (5.3-5.6) than the SRT/HRT ratio (6) for all phases. This indicated that some of the feed FSS was dissolved during digestion and the FSS in the AnMBR did not accumulate at the same ratio as that of the SRT/HRT.

\subsection{Membrane Performance of AnMBR}

- Successful membrane performance was observed in AnMBR operation with raw and PT WAS.

- Fouling did not increase over the period of operation of the hollow fibre membrane despite high solids and colloidal concentrations in the AnMBR. The minimal fouling was attributed to the use of a relaxed mode of operation (with 8 minutes permeation and 2 minutes relaxation), an operational flux below the critical flux (2.75 LMH), a cleaning frequency of 3 times a week, and a gas sparging rate of $2 \mathrm{~L} / \mathrm{min}$.

- The critical flux range for Phase 2 and 3 was determined to be 6 to $12 \mathrm{LMH}$ and these values appeared to be independent of the biomass concentrations in the AnMBR. In conclusion, PT enhanced the biodegradability of WAS. The application of a long SRT, membrane installation, and an effective fouling minimizing system allowed for a high loading rate while maintaining improved biodegradation. Due to a reduced mass flow of solids and organics, a PT-AnMBR system may reduce the requirements for downstream processing when compared with digestion of untreated raw WAS. Therefore, a PT-AnMBR system can be successfully used to treat high solids waste streams. 


\section{Chapter 6: Recommendations}

This chapter provides recommendations for future work involving a PT-AnMBR system. This section will focus on suggestions on pre-treatment, AnMBR biodegradation, and membrane operations.

\subsection{Pre-treatment and AnMBR Biodegradation Operations}

- In order to avoid solubilisation of particulates due to storage of WAS for extended durations, it is recommended to sample fresh WAS from the WWTP every day rather than on a weekly basis. This will ensure that the AnMBR is being fed with WAS of similar concentrations every day.

- Operation of the AnMBR at further reduced HRTs and increased SRTs and the application of more rigorous PT is recommended to determine if biodegradability of WAS and operational costs can be further improved.

- The hypothesized struvite precipitation mechanism should be examined in more detail.

- Biogas production and pathogen concentrations may be monitored in the future to provide a comprehensive characterization of the effect of a PT-AnMBR system on biodegradability and quality of WAS.

\subsection{Membrane Operations}

The following are some recommendations to further improve the approach and characterization of the impact of the physico-chemical characteristics of raw and PT WAS on membrane performance.

- In addition to solids and colloids measurements, analysis of inorganic foulants such as struvite should be performed in future studies to better characterize membrane fouling. 
- To avoid a broad range of TMPs (and fouling rates), continuous feeding instead of manual feeding is recommended for future studies. 


\section{References}

1. APHA, AWWA, and WEF, (2005). "Standard Methods for the Examination of Water and

Wastewater.” $21^{\text {st }}$ ed. American Public Health Association, Washington, D.C.

2. Abelleira, J., Elvira, S.I.P., Oneto, J.S., Portela, J.R., and Nebot, E. (2012). “Advanced

Thermal Hydrolysis of Secondary Sewage Sludge: A Novel Process Combining Thermal

Hydrolysis and Hydrogen Peroxide Addition.” Resources, Conservation and Recycling, $59,52-57$.

3. Agustina, T.E., and Vareek, H.M. (2005). “A Review of Synergistic Effect of Photocatalysis and Ozonation on Wastewater Treatment." J. Photochem. Photobio C., 264-273.

4. Appels, L., Baeyens,J., Degrève, J., and Dewil, R. (2008). "Principles and Potential of the Anaerobic Digestion of Waste-Activated Sludge.” Prog. Energy Combust. Sci., 34, 755781.

5. Ariyanto, E., Sen, T.K., and Ang, H.M. (2013). "The Influence of Various PhysicoChemical Process Parameters on Kinetics and Growth Mechanism of Struvite Crystallisation." Advanced Powder Tech.

6. Bougrier, C., Carr`ere, H., and Delgen`es, J.P. (2005). "Solubilisaiton of Waste Activated Sludge by Ultrasonic Treatment", Chem. Eng. J, 106 (2), 163-169.

7. Bougrier, C., Albasi, C., Delgen`es, J.P., and Carr`ere, H. (2006). "Effect of Ultrasonic, Thermal and Ozone Pre-Treatments on Waste Activated Sludge Solubilisation and Anaerobic Biodegradability.” Chemical Engineering and Processing, 45 (2006), 711718. 
8. Bougrier, C., Delgen `es, J.P., and Carr`ere, H. (2006b). "Impacts of Thermal PreTreatments on the Semi-Continuous Anaerobic Digestion of Waste Activated Sludge.” Biochemical Engineering Journal, 34 (2007), 20-27.

9. Bougrier, C., Carr`ere, H., and Delgen`es, J.P. (2008). "Effect of Thermal Pretreatments on Five Different Waste Activated Sludge Samples Solubilisaiton, Physical Properties and Anaerobic Digestion.", Chem. Eng. J, 139, 236-244.

10. Bowen, W. R., Calvo, J. I., and Hernández, A. (1995). "Steps of membrane blocking in flux decline during protein microfiltration." Journal of Membrane Science, 101, 153165.

11. Braguglia, C.M., Mininni, G., and Gianico, A. (2008). "Is Sonication Effective to Improve Biogas Production and Solids Reduction in Excess Sludge Digestion?" Water Science and Technology, 54 (4), 479-483.

12. Braguglia, C.M., Gianico, A., and Mininni, G. (2011). "Laboratory-Scale Ultrasound Pre-Treated Digestion of Sludge: Heat and Energy Balance.” Bioresource Technology, 102 (2011), 7567-7573.

13. Brockmann, M., and Seyfried, C. F. (1997). "Sludge activity under the conditions of crossflow microfiltration.” Water Science and Technology, 35(10), 173-181.

14. Burger, G.S. (2012). "Investigation of the Impacts of Thermal Activated Sludge Pretreatment and Development of a Pretreatment Model." Masters Thesis, University of Waterloo, Canada.

15. Buchauer, K. (1998). “A Comparison of Two Simple Titration Procedues to Determine Volatile Fatty Acids in Influents to Waste-Water and Sludge Treatment Processes." Water SA, 24(1), 49-56. 
16. Chang, I.S., Clech, P.L., Jefferson, B., and Judd, S. (2002). "Membrane Fouling in Membrane Bioreactors for Wastewater Treatment." Journal of Env. Eng., 1018-1029.

17. Charfi, A., Amar, N.B., Harmand, J. (2012). "Analysis of Fouling Mechanisms in Anaerobic Membrane Bioreactors.” Water Research, 46, 2637-2650.

18. Chauzy, J., Cretenot, D., Bausseon, A., D.S. (2007). “Anaerobic Digestion Enahnced by Thermal Hydrolysis: First Reference BIOTHELYS ${ }^{\circledR}$ at Saumur, France. Facing Sludge Diversities: Challenges, Risks and Opportunities.” Antalya, Turkey.

19. Choi, Y.J. (2003). "Critical Flux, Resistance, and Removal of Contaminants in Ultrafiltration (UF) of Natural Organic Materials.” PhD Thesis, The Pennsylvania State University, USA.

20. Chu, C.P., Chang, B.V., Liao, G.S., Jean, D.S., and Lee, D.J. (2001). “Observations on Changes in Ultrasonically Treated Waste-Activated Sludge.” Water Research, 35 (4), 1038-1046.

21. Climent, M., I. Ferrer, M. del Mar Baeza, A. Artola, F. Vazquez, and X. Font. (2007). "Effects of Thermal and Mechanical Pretreatments of Secondary Sludge on Biogas Production Under Thermophilic Conditions. Chem. Eng. J., 133, 335-345.

22. Dagnew, M. (2010). "Characterization of Anaerobic Membrane Digesters for Stabilization of Waste Activated Sludge." PhD Thesis, University of Waterloo, Canada. 23. Dagnew, M., Parker, W., and Seto, P. (2012). “Anaerobic Membrane Bioreactors for Treating Waste Activated Sludge: Short Term Membrane Fouling Characterization and Control Tests.” Journal of Membrane Science. Volumes 421-422, 103-110.

24. Defrance, L. and Jaffrin, M.Y. (1999). "Comparison between Filtrations at Fixed Transmembrane Pressre and Fixed Permeate Flux: Application to a Membrane 
Bioreactor used for Wastewater Treatment.” Journal of Membrane Science, 152 (2), 203-210.

25. Dereli, R.K., Ersahin, M.E., Ozgun, H., Ozturk, I., Jeison, D., Zee, F., and van Lier, J. (2012). "Potential of Anaerobic Membrane Bioreactors to Overcome Treatment Limitations Induced by Industrial Wastewaters.” Bioresource Tech., 122, 160-170.

26. Dewil, R., Appels, L., Baeyens, J., and Degreve, J. (2007). "Peroxidation Enhances the Biogas Production in the Anaerobic Digestion of Biosolids." Journal of Hazardous Materials, 146 (3), 577-581.

27. Dignac, M.F., Urbain, V. Rybacki, D., Bruchet, A., Snidaro, D. and Scribe, P. (1998). "Chemical description of extracellular polymers: implication on activated sludge floc structure.” Water Sci Technol, 38, pp. 45-53.

28. Donoso-Bravo, A. S., Perez-Elvira, E. Aymerich, and F. Fdz-Polanco. (2011). "Assessment of the Influence of Thermal Pretreatment Time on the Macromolecular Composition and Anaerobic Biodegradability of Sewage Sludge.” Biores. Tech., 102, 660-666

29. Eskicioglu, C., Prorot, A., Marin, J., Droste, R.L., and Kennedy, K.J. (2008). "Synergetic Pretreatment of Sewage Sludge by Microwave Irradiation in Presence of $\mathrm{H}_{2} \mathrm{O}_{2}$ for Enhanced Anaerobic Digestion.” Water Research, 42 (18), 4674-4682.

30. Fan, F., Zhou, H., \& Husain, H. (2006). "Identification of Wastewater Sludge Characteristics to Predict Critical Flux for Membrane Bioreactor Processes.” Water Research, 40 (2), 205-212.

31. Fernandez-Polanco, F., Velazquez, R., Perez-Elvira, S.I., Casas, C., Del, B. D., Cantero, F.J., Fernandez-Polanco, M.; Rodriguez, P.; Panizo, L.; Serrat, J. and Rouge, P. (2008). 
"Continuous thermal hydrolysis and energy integration in sludge anaerobic digestion plants." Water Science and Technology, 57 (8), 1221-1226.

32. Field, R. W., Wu, D., Howell, J. A., and Gupta, B. B. (1995). "Critical Flux Concept for Microfiltration Fouling." Journal of Membrane Science, 100, 259-272.

33. Foladori, P., Laura, B., Gianni, A., and Giuliano, Z. (2006). "Effects of Sonication on Bacteria Viability in Wastewater Treament Plants Evaluated by Flow Cytometry - Fecal Indicators, Wastewater and Activated Sludge.” Water Research, 41 (2007), 235-243.

34. Fuchs, W., Binder, H., Mavrias, G., Braun, R. (2003). "Anaerobic Treatment of Wastewater with High Organic Content using a Stirred Tank Reactor Coupled with a Membrane Filtration Unit." Water Res., 37(4), 902-908.

35. Goberna, M., Schoen, M.A., Sperl, D., Wett, W., and Insam, H. (2010). "Mesophilic and thermophilic co-fermentation of cattle excreta and olive mill wastes in pilot anaerobic digesters." Biomass Bioenergy, 34, 340-346.

36. Grönroos, A., Kyllönen, H., Korpijärvi, K., Pirkonen, P., Paavola, T., Jokela, J., and Rintala, J.(2005). "Ultrasound Assisted Method to Increase Soluble Chemical Oxygen Demand (SCOD) of Sewage Sludge for Digestion." Ultrasonics Sonochemistry, 12 (2005), 115-120.

37. Gujer, W. and Zehnder, A.J.B. (1983). "Conversion processes in anaerobic digestion.” Water Sci. Technol., 15 (8/9), 127-167.

38. Gurieff, N., J. Bruss, S. Hoejsgaard, J. Boyd, and M. Kline. (2011). "Maximizing Energy Efficiency and Biogas Production: EXELYS-Continuous Thermal Hydrolysis." Proceedings of the WEFTEC Conference, Los Angeles, California, October. 
39. Ghyoot, W. R., and Verstraete, W. H. (1997). "Coupling membrane filtration to anaerobic primary sludge digestion." Environmental Technology, 18, 569-580.

40. HACH Water Analysis Handbook. (1997). $3^{\text {rd }}$ edition.

41. Henze, M., Gujer, W., Mino, T., Matsuo, T., Wentzel, M.C., Marais, G.V.R. and van Loosdrecht, M. C. M. (1999). Activated sludge model No. 2D, ASM2D, Water Sci. Technol. 39 (1), 165-182.

42. Hermia, J., (1982). “Constant Pressure Blocking Filtration Laws-Application to Power Law Non-Newtonian Fluids.” Trans IChemE60, 183-187.

43. Ho, C.C., and Zydney, A.L., (2006). “A combined pore blockage and cake filtration model for Protein fouling during micro filtration." Journal of Colloid and Interface Science, 232, 389-399.

44. Hong, S.P., Bae, T.H., Tak, T.M., Hong, S., and Randall, A. (2002). "Fouling Control in Activated Sludge Submerged Hollow Fiber Membrane Bioreactors.” Desalination, 143 (3), 219-228.

45. Hernandez, A.E., Belalcazar, L.C., Rodriquez, M.S., and Giroldo, E. (2002). "Retention of Granular Sludge at High Hydraulic Loading Rates in an Anaerobic Membrane Bioreactor with Immersed Filtration. Wat. Sci. Technol., 45 (10), 169-174.

46. Hulse, C.A., Singh, K.S. and Grant, S.R. (2009). “An innovative submerged anaerobic membrane bioreactor treatment for potato solids and bioenergy production." WEFTEC 2009, 2216-2230

47. Hwang, K., and Lin, T. (2002). "Effect of morphology of polymeric membrane on the performance of cross-flow microfiltration.” Journal of Membrane Science, 199, 41-52. 
48. Jaffrin, M. Y., Ding, L. H., Couvreur, C., and Khari, P. (1997). "Effect of ethanol on ultrafiltration of bovine albumin solutions with organic membranes.” Journal of Membrane Science, 124, 233-241.

49. Jeison, D. and van Lier, J.B. (2006a). "Bio-Layer Management in Anaerobic Membrane Bioreactors for Wastewater Treatment.” Water Sci. Technol., 54 (4), 81-86.

50. Jeison, D., and van Lier, J.B. (2006b). "Cake Layer Formation in Anaerobic Submerged Membrane Bioreactors (AnSMBR) for Wastewater Treatment.” Journal of Membrane Science. 284 (1-2), 227-236.

51. Jeison, D., van Lier, J.B., (2007). “Cake formation and consolidation: main factors governing the applicable flux in anaerobic submerged membrane bioreactors (AnSMBR) treating acidified wastewaters." Sep. Purif. Technol. 56 (1), 71-78.

52. Jeison, D., Kremer, B., and Lier, J.B.V. (2008). “Application of Membrane Enhanced Biomass Retention to the Anaerobic Treatment of Acidified Wastewaters under Extreme Saline Conditions.” Separation and Purification Technology, 64 (2), 198-205.

53. Judd, S. J., Robinson, T., Holdner, J., Alvarez-Vazquez, H., and Jefferson, B. (2004)."Impact of membrane material on membrane bioreactor permeability." WaterEnvironment-Membrane Technology Conference, Seoul, Korea.

54. Kianmehr, P. (2010). “Characterization of Pretreatment Impacts Properties of Waste Avtivated Sludge and Digestibility." PhD Thesis, University of Waterloo, Canada.

55. Kim, J.O., and Jung, J.T. (2007). "Performance of membrane-coupled organic acid fermentor for the resources recovery form municipal sewage sludge." Water Sci. Technol., 55, 245-252 
56. Kepp U., Machenbach I., Weisz N. and Solheim O.E. (2000). "Enhanced stabilization of sewage sludge through thermal hydrolysis - three years of experience with full scale plant.” Water Sci. Techn., 42(9), 89-96.

57. Kang, I.J., Yoon, S.H., and Lee, C.H. (2002). "Comparison of the Filtration Characteristics of Organic and Inorganic Membrane in a Membrane-Coupled Anaerobic Bioreactor.” Water Research, 36 (7), 1803-1813.

58. Kim, J., Park, C., Kim, T.H., Lee, M., Kin, S., Kim, S.W., and Lee, J. (2003). "Effects of Various Pretreatments for Enhanced Anaerobic Digestion with Waste Activated Sludge." Journal of Bioscience and Bioeng., 95(3), 271-275.

59. Kim, T.H., Lee, S.R., Nam, Y.K., Kong, J., Park, C., and Lee, M. (2009). "Disintegration of Excess Activated Sludge by Hydrogen Peroxide Oxidation." Desalination, 246 (1-3), 275-284.

60. Kim, D.H., Joeng, E., Oh, S.E., and Shin, H.S. (2010). “Combined (Alkaline + Ultrasonic) Pretreatment Effect on Sewage Sludge Disintegration.” Water Research, 44 (2010), 3093-3100.

61. Khanal, S.K., Grewell, D., Sung, S. and Leeuwen, J.V. (2007). “Ultrasound Application in Wastewater Sludge Pre-treatment: A Review." Critical Reviews in Environmental Science and Technology, 37, 277-313.

62. Lafitte-Trouqué, S., and Forster, C.F. (2002). "The Use of Ultrasound and $\gamma$-irradiation as Pre-Treatment for the Anaerobic Digestion of Waste Activated Sludge at Mesophilic and Thermophilic Temperatures.” Biores. Technol., 84 (2002), 113-118. 
63. Lee, S., Jung, J., and Chung, Y. (2001). "Novel Method for Enhancing Permeate Flux of Submerged Membrane System in Two-Phase Anaerobic Reactor.” Water Research, 35(2), 471-477.

64. Lew, B., Tarre, S., Beliavski, M., Dosoretz, C., and Green, M. (2009). “Anaerobic Membrane Bioreactor (AnMBR) for Domestic Wastewater Treatment.” Desalination, $243,251-257$.

65. Liu H. and Fang, H. H. P. (2002). "Extraction of extracellular polymeric substances (EPS) of sludges.” J.Biotecinol., 95(3), 249-256.

66. Li-Y, Y. and Noike, T. (1992). "Upgrading of Anaerobic Digestion of Waste Activated Sludge by Thermal Pretreatment." Water Sci. and Tech.,26, 857-866.

67. Maier, R.M., Pepper, I.L., and Gerba, C.P. (2008). A Textbook of Environmental Microbiology, $2^{\text {nd }}$ Edition. Elsevier Science, San Diego, CA.

68. Mamais, D., Jenkins, D. and Pitt, P. (1993). “A rapid physical-chemical method for the determination of readily biodegradable soluble COD in municipal wastewater.", Water Research, 27 (1), 195-197.

69. Metcalf and Eddy Inc. (2003). Wastewater engineering: treatment and reuse, $4^{\text {th }}$ edition. McGraw-Hill, New York.

70. Meng, F.G., Chae, S.R., Drews, A., Kraume, M., Shin, H.S., and Yang, F.L. (2009). "Recent Advances in Membrane Bioreactors (MBRs): Membrane Fouling and Membrane material Water Res., 43, 1489-1512.

71. Musser, J. (2010). "Integration of Ozone and Ultrasound Activated Sludge PreTreatments into a Wastewater Treatment Whole-Plant Simulator.” Masters' Thesis, University of Waterloo, Canada. 
72. Nelson, N.O., Mikkelsen, R.K., and Hesterberg, D.L. (2003). "Struvite Precipitation in Anaerobic Swine Lagoon Liquid: Effect of $\mathrm{pH}$ and Mg:P Ratio and Determination of Rate Constant." Bioresource Tech., 89, 229-236.

73. Neyens, E., and Baeyens, J. (2003). “A Review of Classic Fenton`s Peroxidation as an Advances Oxidation Technique.” J Hazard Mater, 98 (1-3), 33-50.

74. Nickel, K., and Neis, U. (2007). "Ultrasonic Disintegration of Biosolids for Improved Biodegradation." Ultrasonics Sonochemistry, 14 (2007), 450-455.

75. Odegaard, H. (2004). "sludge Minimization Technologies - An Overview." Water Science and Technol.,49 (10), 31-40.

76. Onyeche, T.I., Schläfer, O., Bormann, H., Schröder, C., and Sievers, M. (2002). "Ultrasonic Cell Disruption of Stabilised Sludge with Subsequent Anaerobic Digestion." Ultrasonics, 40, 31-35.

77. Padmasiri, S. I., Zhang, J., Fitch, M., Norddahl, B., Morgenroth, E., Raskin, L. (2007). "Methanogenic Population Dynamics and Performance of an Anaerobic Membrane Bioreactor (AnMBR) Treating Swine Manure Under High Shear Conditions." Water Res., 41(1), 134-144.

78. Pierkiel, A. and Lanting, J. (2005). "Membrane-coupled anaerobic digestion of municipal sewage sludge." Water Science and Technology, 52(1-2), 253-258.

79. Pham, T.T.H., Barnabé, S., Verma, M., and Tyagi, R.D. (2007). “Optimization of Ultrasonication Treatment Process for Improvement of Wastewater Sludge Biodegradability using Response Surface Methodology.” 759-766.

80. Pickel, J. (2010). “An Evaluation of Alternative for Enhancing Anaerobic Digestion of Waste Activated Sludge.” Masters Thesis, University of Waterloo, Waterloo. 
81. Pilli, S., Bhunia, P., Yan, S., LeBlanc, R.J., Tyagi, R.D., and Surampalli, R.Y. (2011). "Ultrasonic Pretreatment of Sludge: A Review, Ultrason. Sonochem. In press.

82. Puchajda, B. and Oleszkiewicz, J. (2008). "Impact of sludge thickening on energy recovery from anaerobic digestion." Water Science and Technology, 57-3, 395-401.

83. Ramirez, I., Mottet, A., Carrere, H., Deleris, S., Vedrenne, F., and Stayer, J.P. (2009). “Modified ADM1 Disintegration/Hydrolysis Structures for Modeling Batch Thermophilic Anaerobic Digestion of Thermally Pretreatment Waste Activated Sludge.” Water Research, 43, 3479-3492.

84. Rittmann and McCarty. (2000). Environmental Microbiology: Principles and Applications. McGraw Hill.

85. Rivero, J.A., Madhavan, N., Suidan, M.T., Ginestet, P., Audic, J, M. (2006). "Enhancement of Anaerobic Digestion of Excess Municipal Sludge with Thermal and/or Oxidative Treatment." Journal of Env. Eng., 132 (6), 638-644.

86. Ruiz-Hernando, M., Martinez-Elorza, G., Labanda, J., and Llorens, J. (2013). "Dewaterability of Sewage Sludge by Ultrasonic, Thermal, and Chemical Treatments." Chemical Eng. Jour., 230, 102-110.

87. Salsabil, M. R., Prorot, A., Casellas, M., and Dagot, C. (2009). "Pre-Treatment of Activated Sludge: Effect of Sonication on Aerobic and Anaerobic Digestibility." Chem. Eng. J., 148 (2-3), 327-335.

88. Saddoud, A., Hassaïri, L., and Sayadi, S. (2007). “Anaerobic Membrane Reactor with Phase Separation for the Treatment of Cheese Whey." Bioresource Technology, 98(11), 2102-2108. 
89. Sahinkaya, S., and Sevimla, M.F. (2013). "Sono-Thermal Pre-Treatment of Waste Activated Sludge Before Anaerobic Digestion." Ultrasonics Sonochemistry, 20 (1), $587-$ 594.

90. Shahriari, H., Warith, M., Hamoda, M., and Kennedy, K, J. (2011). “Anaerobic Digestion of Organic Fraction of Municipal Solid Waste Combining Two Pretreatment Modalities, High Temperature Microwave and Hydrogen Peroxide.” Waste Management, 32 (2012), 41-52.

91. Shen, H. and Anastasio C.. (2012). "A comparison of hydroxyl radical and hydrogen peroxide generation in ambient particle extracts and laboratory metal solutions." Atmospheric Environment, 46, 665- 668.

92. Show, K.Y., Mao, T., and Lee, D.J. (2007). “Optimisation of Sludge Disruption by Sonication." Water Research, 41, 4741-4747.

93. Song, Z., Yang, G., Gua, Y., and Zhang, T. (2012). “Comparison of Two Chemical Pretreatments of Rice Straw for Biogas Production by Anaerobic Digestion.” BioResources, 7(3), 3223-3236.

94. Song, Z.L., Yag, .H.,Feng, Y.Z., Ren, G.X., and Han, X.H. (2012b). "Pretreatment of Rice Straw by Hydrogen Peroxide for Enahnced MethaneYield.” Journal of Integrative Agriculture, 12 (7), 1258-1266.

95. Suslick, K. S. "Homogeneous Sonochemistry" in Ultrasound: Its Chemical, Physical and Biological Effects; Suslick, K. S., ed.; VCH Publishers: New York, 1988; pp. 123164.

96. Szeinbaum, N. (2009). “Assessment of Anaerobic Treatment of Select Waste Streams in Paper Manufacturing Operations.” Masters Thesis, Georgia Institute of Technology. 
97. Takashima, M., Sugawara, Y., Ohkawa, T., Ohkubo, Y. (1991). "Effects of Heat Treatment on the High -Rate Anaerobic Digestion of Human Wastes Concentrates." Water Science and Technology, 23 (7-9), 1137-1145.

98. Takatani,S., Takayama, S., Yamauchi. T.(1981). A study of anaerobic digestion for sewage sludge. Mitsubishi Juko Giho (Japan) 18:1-7.

99. Trzcinski, A.P., and Stuckey, D.C. (2009). "Continuous treatment of the organic fraction of municipal solid waste in an anaerobic two-stage membrane process with liquid recycle." Water Res., 43, 2449-2462.

100. Trzcinski, A.P., and Stuckey, D.C. (2010). "Treatment of municipal solid waste leachate using a submerged anaerobic membrane bioreactor at mesophilic and psychrophilic temperatures: analysis of recalcitrants in the permeate using GC-MS." Water Res., 44, 671-680.

101. Tiehm, A., Nickel, K., Zellhorn, M. and Neis, U. (2001). "Ultrasonic Waste Activated Sludge Disintegration for Improving Anaerobic Stabilisation.” Water Research, 35(8). 102. Verstraete, W. and Vandevivere, P. (1999). "New and broader applications of anaerobic digestion.” Crit. Rev. Environ. Sci. Technol., 28, 151.

103. Wang, Q. H., Chen, J. C., Kakimoto, K., Ogawa, H. I., and Kato, Y. (1995).

"Pretreatment of Waste Activated Sludge Results in Enhancement of its Anaerobic Digestion Efficiency.” Journal of the society of water environment (Japan), 18, 857-882.

104. Wang, Y., Wei, Y., and Liu, J. (2009). “Effect of H2O2 Dosing Strategy on Sludge Pretreatment by Microwave-H2O2 Advanced Oxidation Process.” J Hazard Mater, 169 $(1-3), 680-684$. 
105. Wandzel, R.T., Ofverstrom, S., Dauknys, R., and Medrzycka, K. (2011) "Effect of Disintegration Pretreatment of Sewage Sludge for Enhanced Anaerobic Digestion." The $8^{\text {th }}$ International Conference, Vilnius,Lithuania,(2-3), 679-683

106. Wu, Z., Wang, X., Wang, Z., \& Du, X. (2009). "Identification of sustainable flux in the process of using flat-sheet membrane for simultaneous thickening and digestion of waste activated sludge.” Journal of Hazardous Materials, 162 (2-3), 1397 -1403.

107. Xu, M., Wen, X., Huang, X., and Li, Y. (2010). "Membrane fouling control in an anaerobic membrane bioreactor coupled with online ultrasound equipment for digestion of waste activated sludge.” Sep. Sci. Technol., 45, 941-947.

108. Yan, Y., Feng, L., Zhang, C., Wisniewski, C., and Zhou, Q. (2010). “Ultrasonic Enhancement of Waste Activated Sludge Hydrolysis and Volatile Fatty Acids Accumulation at pH 10.0.” Water Research, 44 (2010), 3329-3336.

109. Yaqci, N., and Akpinar, I. (2011). "The Investigation and Assessment of Characteristics of Waste Activated Sludge after Ultrasound Pretreatment." Environ. Technol., 32 (1-2), 221-30.

110. Yin, G., Liao, P.H., Lo, K.V. (2007). “An Ozone/Hydrogen Peroxde/MicrowaveEnhanced Advanced Oxidation Process for Sewage Treatment." J Envrion. Sci. Health A Tox. Hazard Subst. Environ. Eng., 42 (8), 1177-1181.

111. Zamanzadeh, M. (2012). "Enhancement of Modeling Phased Anaerobic Digestion Systems through Investigation of Their Microbial Ecology and Biological Activity." PhD Thesis, University of Waterloo, Canada. 
112. Zhang, P., Zhang, G., and Wang, W. (2007). "Ultrasonic Treatment of Biological Sludge: Floc Disintegration, Cell Lysis and Inactivation.” Bioresource Technology, 98 (2007) 207-210.

113. Zhang, G., Zhang, P., Yang, J., and Liu, H. (2008). “Energy-Efficient Sludge Sonication: Power and Sludge Characteristics.” Bioresource Technology, 99, 9029-9031. 


\section{Appendix A: Physio-Chemical, Biodegradation and Membrane Operations Data}

\section{A1: Factorial Design for US $+\mathrm{H}_{2} \mathrm{O}_{2}$ AOP}

Table A1.1: 2 x 4 Factorial Design for US $+\mathrm{H}_{2} \mathrm{O}_{2}$ PT

\begin{tabular}{|c|c|c|c|c|c|}
\hline \multirow{2}{*}{$\begin{array}{c}\text { US Duration } \\
\text { (minutes) }\end{array}$} & \multicolumn{4}{|c|}{$\mathrm{H} 2 \mathrm{O} 2$ Dose $(\mathrm{gH} 2 \mathrm{O} 2 / \mathrm{kg} \mathrm{TS})$} & \multirow{2}{*}{ Row Sum } \\
\cline { 2 - 5 } & 0 & 5 & 25 & 50 & \\
\hline \multirow{3}{*}{10} & 0.2207 & 0.2243 & 0.21558 & 0.2313 & \\
\cline { 2 - 5 } & 0.2221 & 0.2261 & 0.23626 & 0.22138 & \\
\cline { 2 - 5 } & $\mathbf{0 . 4 4 2 8}$ & $\mathbf{0 . 4 5 0 4}$ & $\mathbf{0 . 4 5 1 8 3}$ & $\mathbf{0 . 4 5 2 6 8}$ & \multirow{2}{*}{$\mathbf{1 . 7 9 7 7 1}$} \\
\hline \multirow{3}{*}{20} & 0.2832 & 0.24836 & 0.29125 & 0.30527 & \\
\cline { 2 - 5 } & 0.26982 & 0.3047 & 0.32123 & 0.31642 & \\
\cline { 2 - 5 } & $\mathbf{0 . 5 5 3 0 2}$ & $\mathbf{0 . 5 5 3 0 6}$ & $\mathbf{0 . 6 1 2 4 9}$ & $\mathbf{0 . 6 2 1 6 8}$ & \multirow{2}{*}{$\mathbf{2 . 3 4 0 2 5}$} \\
\hline \multirow{2}{*}{ Column Sum } & $\mathbf{0 . 9 9 5 8 2}$ & $\mathbf{1 . 0 0 3 4 6}$ & $\mathbf{1 . 0 6 4 3 2}$ & $\mathbf{1 . 0 7 4 3 6}$ & \multirow{2}{*}{$\mathbf{8 . 2 7 5 9 1}$} \\
\hline
\end{tabular}

$\mathrm{S}_{\mathrm{C}}=4.28066$

$\mathrm{S}_{\mathrm{D}}=3.18753$

$\mathrm{S}_{\mathrm{H} 2 \mathrm{O} 2}=1.47624$

$\mathrm{S}_{\mathrm{US}}=3.19209$

$\mathrm{S}_{\mathrm{T}}=3.18999$

$\mathrm{S}_{\mathrm{I}}=3.21135$

ANOVA:

\begin{tabular}{|c|c|c|c|c|}
\hline Source & SS & $\boldsymbol{d f}$ & MS & F \\
\hline H2O2 & 1.47624 & 3 & 0.49208 & 200.032 \\
\hline US & 3.19209 & 1 & 3.19209 & 4297.597 \\
\hline Interaction & 3.21135 & 3 & 1.07045 & 43.142 \\
\hline Treatment & 3.18999 & 7 & 0.00246 & \\
\hline Error & 0.00246 & 1 & & \\
\hline
\end{tabular}

$\mathrm{F}_{1,3,0.05}=215.71$

$\mathrm{F}_{1,1,0.05}=161.45$

$\mathrm{F}_{\mathrm{obs}}>\mathrm{F}_{\text {critical }}$ for US and interaction term $\rightarrow$ US and interaction factors are significant. 


\section{A2: Statistical Analysis t-tests}

T-test for Thermal PT at $170^{\circ} \mathrm{C}$

$\mathrm{X}_{1}=14735 \mathrm{mg} / \mathrm{L}$

$X_{2}=11602.5$

$\mathrm{n}_{1}=2$

$\mathrm{n}_{2}=2$

$\mathrm{v}=2, \mathrm{t}_{\mathrm{obs}}=15.533$

$\mathrm{t}_{\text {critical }}=\mathrm{t}_{0.025,2}=4.30$

$\mathrm{t}_{\mathrm{obs}}>\mathrm{t}_{\text {critical }} \rightarrow$ There is significant difference between the two means.

T-test for PT 8 TCOD loss

$X_{1}=7657.083, S_{1}=1139.612$

$X_{2}=7122.5, S_{2}=595.643$

$\mathrm{n}_{1}=6$

$\mathrm{n}_{2}=6$

$\mathrm{v}=8, \mathrm{t}_{\mathrm{obs}}=1.0183$

$\mathrm{t}_{\text {critical }}=\mathrm{t}_{0.025,8}=2.31$

$\mathrm{t}_{\mathrm{obs}}<\mathrm{t}_{\text {critical }} \rightarrow$ There is no significant difference between the two means.

\section{T-test for PT 10 TCOD loss}

$\mathrm{X}_{1}=7420 \mathrm{mg} / \mathrm{L}, \mathrm{S}_{1}=332.27 \mathrm{mg} / \mathrm{L}$

$\mathrm{X}_{2}=7096 \mathrm{mg} / \mathrm{L}, \mathrm{S}_{2}=218.96 \mathrm{mg} / \mathrm{L}$

$\mathrm{n}_{1}=6$

$\mathrm{n}_{2}=6$

$\mathrm{v}=9, \mathrm{t}_{\mathrm{obs}}=1.99$

$\mathrm{t}_{\text {critical }}=\mathrm{t}_{0.025,9}=2.26$

$t_{\text {obs }}<t_{\text {critical }} \rightarrow$ There is no significant difference between the two means.

T-test for PT 8 ffCOD increase

$\mathrm{X}_{1}=42.08 \mathrm{mg} / \mathrm{L}, \mathrm{S}_{1}=36.2 \mathrm{mg} / \mathrm{L}$

$\mathrm{X}_{2}=895.83 \mathrm{mg} / \mathrm{L}, \mathrm{S}_{2}=140.15 \mathrm{mg} / \mathrm{L}$

$\mathrm{n}_{1}=6$

$\mathrm{n}_{2}=6$

$\mathrm{v}=6, \mathrm{t}_{\mathrm{obs}}=14.45$ 
$\mathrm{t}_{\text {critical }}=\mathrm{t}_{0.025,6}=2.45$

$\mathrm{t}_{\mathrm{obs}}>\mathrm{t}_{\text {critical }} \rightarrow$ There is a significant difference between the two means.

\section{T-test for PT 10 ffCOD increase}

$\mathrm{X}_{1}=85 \mathrm{mg} / \mathrm{L}, \mathrm{S}_{1}=25.06 \mathrm{mg} / \mathrm{L}$

$$
\mathrm{X}_{2}=1160.42 \mathrm{mg} / \mathrm{L}, \mathrm{S}_{2}=104.62 \mathrm{mg} / \mathrm{L}
$$

$\mathrm{n}_{1}=6$

$$
\mathrm{n}_{2}=6
$$

$\mathrm{v}=6, \mathrm{t}_{\mathrm{obs}}=24.5$

$\mathrm{t}_{\text {critical }}=\mathrm{t}_{0.025,6}=2.45$

$\mathrm{t}_{\mathrm{obs}}>\mathrm{t}_{\text {critical }} \rightarrow$ There is a significant difference between the two means.

\section{T-test for PT 8 cCOD increase}

$\mathrm{X}_{1}=9.16 \mathrm{mg} / \mathrm{L}, \mathrm{S}_{1}=8.55 \mathrm{mg} / \mathrm{L}$

$\mathrm{X}_{2}=1642.92 \mathrm{mg} / \mathrm{L}, \mathrm{S}_{2}=292.21 \mathrm{mg} / \mathrm{L}$

$\mathrm{n}_{1}=6$ $\mathrm{n}_{2}=6$

$\mathrm{v}=5, \mathrm{t}_{\mathrm{obs}}=13.7$

$\mathrm{t}_{\text {critical }}=\mathrm{t}_{0.025,5}=2.57$

$\mathrm{t}_{\mathrm{obs}}>\mathrm{t}_{\text {critical }} \rightarrow$ There is a significant difference between the two means.

\section{T-test for PT 10 cCOD increase}

$\mathrm{X}_{1}=22.92 \mathrm{mg} / \mathrm{L}, \mathrm{S}_{1}=9.26 \mathrm{mg} / \mathrm{L}$

$$
\mathrm{X}_{2}=1667.5 \mathrm{mg} / \mathrm{L}, \mathrm{S}_{2}=356.83 \mathrm{mg} / \mathrm{L}
$$

$\mathrm{n}_{1}=6$

$\mathrm{n}_{2}=6$

$\mathrm{v}=5, \mathrm{t}_{\mathrm{obs}}=11.3$

$\mathrm{t}_{\text {critical }}=\mathrm{t}_{0.025,5}=2.57$

$\mathrm{t}_{\mathrm{obs}}>\mathrm{t}_{\text {critical }} \rightarrow$ There is a significant difference between the two means.

\section{T-test for PT 8 VSS decrease}

$\mathrm{X}_{1}=5388.33 \mathrm{mg} / \mathrm{L}, \mathrm{S}_{1}=93.86 \mathrm{mg} / \mathrm{L}$

$\mathrm{X}_{2}=4008.33 \mathrm{mg} / \mathrm{L}, \mathrm{S}_{2}=133.33 \mathrm{mg} / \mathrm{L}$

$\mathrm{n}_{1}=9$

$\mathrm{n}_{2}=9$ 
$\mathrm{v}=14, \mathrm{t}_{\mathrm{obs}}=25.4$

$\mathrm{t}_{\text {critical }}=\mathrm{t}_{0.025,14}=2.14$

$\mathrm{t}_{\mathrm{obs}}>\mathrm{t}_{\text {critical }} \rightarrow$ There is a significant difference between the two means.

\section{T-test for PT 8 FSS decrease}

$\mathrm{X}_{1}=1642.78 \mathrm{mg} / \mathrm{L}, \mathrm{S}_{1}=83.83 \mathrm{mg} / \mathrm{L}$

$$
\mathrm{X}_{2}=1619.44 \mathrm{mg} / \mathrm{L}, \mathrm{S}_{2}=246.02 \mathrm{mg} / \mathrm{L}
$$

$\mathrm{n}_{1}=9$ $\mathrm{n}_{2}=9$

$\mathrm{v}=10, \mathrm{t}_{\mathrm{obs}}=0.27$

$\mathrm{t}_{\text {critical }}=\mathrm{t}_{0.025,10}=2.23$

$\mathrm{t}_{\mathrm{obs}}<\mathrm{t}_{\text {critical }} \rightarrow$ There is no significant difference between the two means.

\section{T-test for PT 10 VSS decrease}

$\mathrm{X}_{1}=5258.33 \mathrm{mg} / \mathrm{L}, \mathrm{S}_{1}=131.23 \mathrm{mg} / \mathrm{L}$

$$
\mathrm{X}_{2}=2733.33 \mathrm{mg} / \mathrm{L}, \mathrm{S}_{2}=94.29 \mathrm{mg} / \mathrm{L}
$$

$\mathrm{n}_{1}=9$

$$
\mathrm{n}_{2}=9
$$

$\mathrm{v}=14, \mathrm{t}_{\mathrm{obs}}=46.88$

$\mathrm{t}_{\text {critical }}=\mathrm{t}_{0.025,14}=2.14$

$\mathrm{t}_{\mathrm{obs}}>\mathrm{t}_{\text {critical }} \rightarrow$ There is a significant difference between the two means.

\section{T-test for PT 10 FSS decrease}

$\mathrm{X}_{1}=1841.67 \mathrm{mg} / \mathrm{L}, \mathrm{S}_{1}=108.65 \mathrm{mg} / \mathrm{L}$

$\mathrm{n}_{1}=9$

$\mathrm{v}=16, \mathrm{t}_{\mathrm{obs}}=9.67$

$\mathrm{t}_{\text {critical }}=\mathrm{t}_{0.025,16}=2.12$

$\mathrm{t}_{\mathrm{obs}}>\mathrm{t}_{\text {critical }} \rightarrow$ There is a significant difference between the two means. 


\section{T-test for PT 8 VSS/TSS decrease}

$\mathrm{X}_{1}=77 \%, \mathrm{~S}_{1}=0.71 \%$

$\mathrm{X}_{2}=71 \%, \mathrm{~S}_{2}=2.6 \%$

$\mathrm{n}_{1}=9$

$\mathrm{n}_{2}=9$

$\mathrm{v}=9, \mathrm{t}_{\mathrm{obs}}=6.68$

$\mathrm{t}_{\text {critical }}=\mathrm{t}_{0.025,9}=2.26$

$\mathrm{t}_{\mathrm{obs}}>\mathrm{t}_{\text {critical }} \rightarrow$ There is a significant difference between the two means.

T-test for PT 10 VSS/TSS decrease

$\mathrm{X}_{1}=74 \%, \mathrm{~S}_{1}=1.2 \%$

$\mathrm{X}_{2}=67 \%, \mathrm{~S}_{2}=2.1 \%$

$\mathrm{n}_{1}=9$

$\mathrm{n}_{2}=9$

$\mathrm{v}=13, \mathrm{t}_{\mathrm{obs}}=8.68$

$\mathrm{t}_{\text {critical }}=\mathrm{t}_{0.025,13}=2.16$

$\mathrm{t}_{\mathrm{obs}}>\mathrm{t}_{\text {critical }} \rightarrow$ There is a significant difference between the two means.

\section{T-test for PT 8 TKN decrease}

$\mathrm{X}_{1}=651.98 \mathrm{mg} / \mathrm{L}, \mathrm{S}_{1}=51.91 \mathrm{mg} / \mathrm{L}$

$\mathrm{X}_{2}=629 \mathrm{mg} / \mathrm{L}, \mathrm{S}_{2}=20.8 \mathrm{mg} / \mathrm{L}$

$\mathrm{n}_{1}=6$

$\mathrm{n}_{2}=6$

$\mathrm{v}=6, \mathrm{t}_{\mathrm{obs}}=1.00$

$\mathrm{t}_{\text {critical }}=\mathrm{t}_{0.025,6}=2.45$

$\mathrm{t}_{\mathrm{obs}}<\mathrm{t}_{\text {critical }} \rightarrow$ There is no significant difference between the two means.

T-test for PT 10 TKN decrease

$\mathrm{X}_{1}=673.8 \mathrm{mg} / \mathrm{L}, \mathrm{S}_{1}=50.52 \mathrm{mg} / \mathrm{L}$

$\mathrm{n}_{1}=6$

$\mathrm{v}=10, \mathrm{t}_{\mathrm{obs}}=2.76$

$\mathrm{t}_{\text {critical }}=\mathrm{t}_{0.025,10}=2.23$
$\mathrm{X}_{2}=599.71 \mathrm{mg} / \mathrm{L}, \mathrm{S}_{2}=42.17 \mathrm{mg} / \mathrm{L}$

$\mathrm{n}_{2}=6$ 
$\mathrm{t}_{\mathrm{obs}}>\mathrm{t}_{\text {critical }} \rightarrow$ There is a significant difference between the two means.

\section{T-test for PT 8 Ammonia Increase}

$\mathrm{X}_{1}=18.93 \mathrm{mg} / \mathrm{L}, \mathrm{S}_{1}=3.94 \mathrm{mg} / \mathrm{L}$

$\mathrm{n}_{1}=6$

$\mathrm{v}=7, \mathrm{t}_{\mathrm{obs}}=8.88$

$\mathrm{t}_{\text {critical }}=\mathrm{t}_{0.025,7}=2.36$

$\mathrm{t}_{\mathrm{obs}}>\mathrm{t}_{\text {critical }} \rightarrow$ There is a significant difference between the two means.

\section{T-test for PT 10 Ammonia increase}

$\mathrm{X}_{1}=25.10 \mathrm{mg} / \mathrm{L}, \mathrm{S}_{1}=3.96 \mathrm{mg} / \mathrm{L}$

$\mathrm{n}_{1}=6$

$\mathrm{v}=9, \mathrm{t}_{\mathrm{obs}}=8.09$

$\mathrm{t}_{\text {critical }}=\mathrm{t}_{0.025,9}=2.26$

$\mathrm{t}_{\mathrm{obs}}>\mathrm{t}_{\text {critical }} \rightarrow$ There is a significant difference between the two means.

\section{T-test for PT 8 ON decrease}

$\mathrm{X}_{1}=633.06 \mathrm{mg} / \mathrm{L}, \mathrm{S}_{1}=35.76 \mathrm{mg} / \mathrm{L}$

$$
\mathrm{X}_{2}=594.31 \mathrm{mg} / \mathrm{L}, \mathrm{S}_{2}=19.72 \mathrm{mg} / \mathrm{L}
$$

$\mathrm{n}_{1}=6$

$$
\mathrm{n}_{2}=6
$$

$\mathrm{v}=7, \mathrm{t}_{\mathrm{obs}}=1.81$

$\mathrm{t}_{\text {critical }}=\mathrm{t}_{0.025,7}=2.36$

$\mathrm{t}_{\mathrm{obs}}<\mathrm{t}_{\text {critical }} \rightarrow$ There is no significant difference between the two means.

\section{T-test for PT 10 ON decrease}

$\mathrm{X}_{1}=648.69 \mathrm{mg} / \mathrm{L}, \mathrm{S}_{1}=52.935 \mathrm{mg} / \mathrm{L}$

$$
\mathrm{X}_{2}=552.96 \mathrm{mg} / \mathrm{L}, \mathrm{S}_{2}=34.918 \mathrm{mg} / \mathrm{L}
$$

$\mathrm{n}_{1}=6$

$\mathrm{n}_{2}=6$

$\mathrm{v}=9, \mathrm{t}_{\mathrm{obs}}=3.69$ 
$\mathrm{t}_{\text {critical }}=\mathrm{t}_{0.025,9}=2.26$

$\mathrm{t}_{\mathrm{obs}}>\mathrm{t}_{\text {critical }} \rightarrow$ There is a significant difference between the two means. 


\section{A3: Preliminary PT Tests}

Table A3.1: Preliminary PT Results

\begin{tabular}{|c|c|c|c|c|c|c|c|c|c|c|c|}
\hline \multirow{2}{*}{$\begin{array}{c}\text { Pre- } \\
\text { treatment }\end{array}$} & \multicolumn{2}{|c|}{ cCOD/TCOD $(\%)$} & \multicolumn{2}{|c|}{$\begin{array}{c}\text { ffCOD/TCOD } \\
(\%)\end{array}$} & \multicolumn{2}{|c|}{$\begin{array}{c}\text { pCOD/TCOD } \\
(\%)\end{array}$} & \multicolumn{2}{|c|}{$\begin{array}{c}\text { sCOD/TCOD } \\
(\%)\end{array}$} & \multicolumn{2}{|c|}{ TCOD loss $(\%)$} & \multirow[b]{2}{*}{ SUM } \\
\hline & Average & SD (\%) & Average & $\begin{array}{l}\text { SD } \\
(\%)\end{array}$ & Average & $\begin{array}{l}\text { SD } \\
(\%)\end{array}$ & Average & $\begin{array}{l}\text { SD } \\
(\%)\end{array}$ & Average & $\begin{array}{l}\text { SD } \\
(\%)\end{array}$ & \\
\hline 0 & 0.32 & 1.12 & 0.57 & 1.94 & 99.11 & 0.11 & 0.89 & 0.11 & 0.00 & 0.00 & 100.00 \\
\hline 1 & 9.75 & 0.41 & 12.39 & 2.27 & 72.31 & 0.92 & 22.14 & 0.10 & 5.55 & 0.18 & 100.00 \\
\hline 2 & 8.81 & 0.17 & 14.81 & 0.13 & 72.51 & 3.19 & 22.52 & 0.13 & 3.86 & 0.70 & 98.89 \\
\hline 3 & 8.51 & 1.31 & 14.01 & 0.34 & 75.20 & 0.80 & 22.59 & 1.46 & 2.29 & 0.80 & 100.07 \\
\hline 4 & 8.52 & 2.15 & 14.08 & 0.49 & 75.67 & 1.20 & 23.63 & 0.70 & 1.74 & 0.46 & 101.04 \\
\hline 5 & 10.57 & 0.38 & 17.08 & 1.33 & 66.19 & 1.44 & 27.65 & 0.95 & 6.15 & 0.21 & 100.00 \\
\hline 6 & 11.30 & 0.51 & 15.68 & 0.51 & 70.02 & 0.94 & 26.98 & 3.98 & 2.99 & 1.43 & 100.00 \\
\hline 7 & 13.09 & 0.20 & 17.52 & 0.72 & 66.01 & 2.28 & 30.61 & 2.12 & 3.38 & 0.43 & 100.00 \\
\hline 8 & 20.53 & 0.34 & 10.55 & 0.70 & 63.75 & 2.06 & 31.08 & 0.78 & 5.17 & 1.17 & 100.00 \\
\hline 9 & 24.13 & 2.11 & 12.17 & 2.44 & 56.80 & 0.38 & 36.30 & 0.16 & 6.90 & 1.31 & 100.00 \\
\hline 10 & 24.91 & 0.95 & 21.53 & 1.84 & 46.62 & 1.63 & 46.44 & 0.49 & 6.94 & 0.44 & 100.00 \\
\hline 11 & 13.07 & 0.72 & 13.81 & 1.05 & 66.47 & 0.05 & 26.88 & 1.51 & 6.65 & 0.13 & 100.00 \\
\hline 12 & 20.28 & 1.94 & 14.50 & 0.10 & 43.39 & 0.71 & 34.35 & 1.53 & 21.26 & 2.45 & 98.99 \\
\hline
\end{tabular}




\section{A4: Detailed PT 8 Tests}

Table A4.1: Detailed Tests for PT 8 RAW

\begin{tabular}{|c|c|c|c|c|c|c|}
\hline \multirow{2}{*}{ DAYS } & \multicolumn{7}{|c|}{ RAW } \\
\cline { 2 - 7 } & $\begin{array}{c}\text { TCOD } \\
(\mathbf{m g} / \mathbf{L})\end{array}$ & $\begin{array}{c}\text { SCOD } \\
(\mathbf{m g} / \mathbf{L})\end{array}$ & $\begin{array}{c}\text { ffCOD } \\
(\mathbf{m g} / \mathbf{L})\end{array}$ & $\begin{array}{c}\text { tTKN } \\
(\mathbf{m g} / \mathbf{L})\end{array}$ & $\begin{array}{c}\text { sTKN } \\
(\mathbf{m g} / \mathbf{L})\end{array}$ & $\begin{array}{c}\text { NH3 } \\
(\mathbf{m g} / \mathbf{L})\end{array}$ \\
\hline 1 & 9266.25 & 111.25 & 90.00 & 579.74 & 24.31 & 13.54 \\
\hline 5 & 9266.25 & 111.25 & 90.00 & 579.74 & 24.31 & 13.54 \\
\hline 8 & 6772.50 & 33.75 & 37.50 & 699.36 & 40.20 & 20.41 \\
\hline 12 & 6777.50 & 33.75 & 37.50 & 699.36 & 40.20 & 20.41 \\
\hline 16 & 6930.00 & 5.00 & 2.50 & 676.87 & 41.82 & 22.86 \\
\hline 19 & 6930.00 & 5.00 & 2.50 & 676.87 & 41.82 & 22.86 \\
\hline Average & 7657.08 & 50.00 & 43.33 & 651.99 & 35.44 & 18.93 \\
\hline SD & 1139.61 & 44.87 & 35.96 & 51.91 & 7.90 & 3.94 \\
\hline
\end{tabular}

Table A4.2: Detailed Tests for PT 8 WAS

\begin{tabular}{|c|c|c|c|c|c|c|}
\hline \multirow{2}{*}{ DAYS } & \multicolumn{7}{|c|}{ PT 8 WAS } \\
\cline { 2 - 7 } & $\begin{array}{c}\text { TCOD } \\
(\mathbf{m g} / \mathbf{L})\end{array}$ & $\begin{array}{c}\text { SCOD } \\
(\mathbf{m g} / \mathbf{L})\end{array}$ & $\begin{array}{c}\text { ffCOD } \\
(\mathbf{m g} / \mathbf{L})\end{array}$ & $\begin{array}{c}\text { tTKN } \\
(\mathbf{m g} / \mathbf{L})\end{array}$ & $\begin{array}{c}\text { sTKN } \\
(\mathbf{m g} / \mathbf{L})\end{array}$ & $\begin{array}{c}\text { NH3 } \\
(\mathbf{m g} / \mathbf{L})\end{array}$ \\
\hline 1 & 7953.75 & 3138.75 & 1087.5 & 600.0001 & 322.2557 & 32.931 \\
\hline 5 & 7953.75 & 3138.75 & 1087.5 & 600.0001 & 322.2557 & 32.931 \\
\hline 8 & 6588.75 & 2227.5 & 843.75 & 647.2137 & 302.6608 & 34.083 \\
\hline 12 & 6588.75 & 2227.5 & 843.75 & 647.2137 & 302.6608 & 34.083 \\
\hline 16 & 6825 & 2250 & 756.25 & 640.192 & 320.0949 & 37.4445 \\
\hline 19 & 6825 & 2250 & 756.25 & 640.192 & 320.0949 & 37.4445 \\
\hline Average & 7122.50 & 2538.75 & 895.83 & 629.14 & 315.00 & 34.82 \\
\hline SD & 595.64 & 424.36 & 140.16 & 20.80 & 8.77 & 1.91 \\
\hline
\end{tabular}


Table A4.3: Detailed Solids Tests for PT 8 WAS

\begin{tabular}{|c|c|c|c|c|c|c|c|c|c|}
\hline \multirow[b]{2}{*}{ Date } & \multirow[b]{2}{*}{ DAYS } & \multicolumn{4}{|c|}{$\mathbf{R A W}$} & \multicolumn{4}{|c|}{ PT 8} \\
\hline & & $\begin{array}{c}\text { TSS } \\
(\mathrm{mg} / \mathrm{L})\end{array}$ & $\begin{array}{c}\text { VSS } \\
(\mathrm{mg} / \mathrm{L})\end{array}$ & $\begin{array}{c}\text { FSS } \\
(\mathrm{mg} / \mathrm{L})\end{array}$ & VSS/TSS & $\begin{array}{c}\text { TSS } \\
(\mathrm{mg} / \mathrm{L})\end{array}$ & $\begin{array}{c}\text { VSS } \\
(\mathrm{mg} / \mathrm{L})\end{array}$ & $\begin{array}{c}\text { FSS } \\
(\mathrm{mg} / \mathrm{L})\end{array}$ & VSS/TSS \\
\hline Apr-12 & 1 & 6850 & 5300 & 1550 & 0.773723 & 5525 & 4075 & 1450 & 0.737557 \\
\hline Apr-14 & 3 & 6850 & 5300 & 1550 & 0.773723 & 5525 & 4075 & 1450 & 0.737557 \\
\hline Apr-16 & 5 & 6850 & 5300 & 1550 & 0.773723 & 5525 & 4075 & 1450 & 0.737557 \\
\hline Apr-18 & 7 & 6850 & 5300 & 1550 & 0.773723 & 5525 & 4075 & 1450 & 0.737557 \\
\hline Apr-19 & 8 & 7150 & 5425 & 1725 & 0.758741 & 5500 & 3875 & 1625 & 0.704545 \\
\hline Apr-21 & 10 & 7150 & 5425 & 1725 & 0.758741 & 5500 & 3875 & 1625 & 0.704545 \\
\hline Apr-23 & 12 & 7150 & 5425 & 1725 & 0.758741 & 5500 & 3875 & 1625 & 0.704545 \\
\hline Apr-25 & 14 & 7150 & 5425 & 1725 & 0.758741 & 5500 & 3875 & 1625 & 0.704545 \\
\hline Apr-26 & 15 & 7280 & 5595 & 1685 & 0.768544 & 6550 & 4275 & 2275 & 0.652672 \\
\hline \multicolumn{2}{|c|}{ Average } & 7031.1111 & 5388.333 & 1642.778 & 0.766489 & 5627.778 & 4008.333 & 1619.444 & 0.713453 \\
\hline \multicolumn{2}{|c|}{ SD } & 166.56293 & 93.86752 & 83.83552 & 0.0071 & 326.2677 & 133.3333 & 246.0177 & 0.026532 \\
\hline
\end{tabular}




\section{A5: Detailed PT 10 Tests}

Table A5.1: Detailed Tests for PT 10 RAW

\begin{tabular}{|c|c|c|c|c|c|c|}
\hline \multirow{2}{*}{ DAYS } & \multicolumn{7}{|c|}{ RAW } \\
\cline { 2 - 7 } & $\begin{array}{c}\text { TCOD } \\
(\mathbf{m g} / \mathbf{L})\end{array}$ & $\begin{array}{c}\text { SCOD } \\
(\mathbf{m g} / \mathbf{L})\end{array}$ & $\begin{array}{c}\text { ffCOD } \\
(\mathbf{m g} / \mathbf{L})\end{array}$ & $\begin{array}{c}\text { tTKN } \\
(\mathbf{m g} / \mathbf{L})\end{array}$ & $\begin{array}{c}\text { sTKN } \\
(\mathbf{m g} / \mathbf{L})\end{array}$ & $\begin{array}{c}\text { NH3 } \\
(\mathbf{m g} / \mathbf{L})\end{array}$ \\
\hline 1 & 7428.75 & 86.25 & 58.75 & 741.32 & 35.80 & 22.82 \\
\hline 6 & 7428.75 & 86.25 & 58.75 & 741.32 & 35.80 & 22.82 \\
\hline 8 & 7008.75 & 87.50 & 77.50 & 619.82 & 21.11 & 21.81 \\
\hline 12 & 7008.75 & 87.50 & 77.50 & 619.82 & 21.11 & 21.81 \\
\hline 15 & 7822.50 & 150.00 & 118.75 & 660.27 & 24.17 & 30.68 \\
\hline 19 & 7822.50 & 150.00 & 118.75 & 660.27 & 24.17 & 30.68 \\
\hline Average & 7420.00 & 107.92 & 85.00 & 673.80 & 27.03 & 25.10 \\
\hline SD & 332.27 & 29.76 & 25.06 & 50.52 & 6.33 & 3.96 \\
\hline
\end{tabular}

Table A5.2: Detailed Tests for PT 10 WAS

\begin{tabular}{|c|c|c|c|c|c|c|}
\hline \multirow{2}{*}{ DAYS } & \multicolumn{7}{|c|}{ PT 10 WAS } \\
\cline { 2 - 7 } & $\begin{array}{c}\text { TCOD } \\
(\mathbf{m g} / \mathbf{L})\end{array}$ & $\begin{array}{c}\text { SCOD } \\
(\mathbf{m g} / \mathbf{L})\end{array}$ & $\begin{array}{c}\text { ffCOD } \\
(\mathbf{m g} / \mathbf{L})\end{array}$ & $\begin{array}{c}\text { tTKN } \\
(\mathbf{m g} / \mathbf{L})\end{array}$ & $\begin{array}{c}\text { sTKN } \\
(\mathbf{m g} / \mathbf{L})\end{array}$ & $\begin{array}{c}\text { NH3 } \\
(\mathbf{m g} / \mathbf{L})\end{array}$ \\
\hline 1 & 6903.75 & 2433.75 & 1162.50 & 571.19 & 293.39 & 42.80 \\
\hline 6 & 6903.75 & 2433.75 & 1162.50 & 571.19 & 293.39 & 42.80 \\
\hline 8 & 6982.50 & 2626.25 & 1031.25 & 568.61 & 322.32 & 43.30 \\
\hline 12 & 6982.50 & 2626.25 & 1031.25 & 568.61 & 322.32 & 43.30 \\
\hline 15 & 7402.50 & 3423.75 & 1287.50 & 659.33 & 425.84 & 54.13 \\
\hline 19 & 7402.50 & 3423.75 & 1287.50 & 659.33 & 425.84 & 54.13 \\
\hline Average & 7096.25 & 2827.92 & 1160.42 & 599.71 & 347.19 & 46.74 \\
\hline SD & 218.92 & 428.58 & 104.62 & 42.17 & 56.86 & 5.22 \\
\hline
\end{tabular}


Table A5.3: Detailed Solids Tests for PT 10

\begin{tabular}{|c|c|c|c|c|c|c|c|c|c|}
\hline \multirow[b]{2}{*}{ Date } & \multirow[b]{2}{*}{ DAYS } & \multicolumn{4}{|c|}{$\mathbf{R A W}$} & \multicolumn{4}{|c|}{ PT 10} \\
\hline & & $\begin{array}{c}\text { TSS } \\
(\mathrm{mg} / \mathrm{L})\end{array}$ & $\begin{array}{c}\text { VSS } \\
(\mathrm{mg} / \mathrm{L})\end{array}$ & $\begin{array}{c}\text { FSS } \\
(\mathrm{mg} / \mathrm{L})\end{array}$ & VSS/TSS & $\begin{array}{c}\text { TSS } \\
(\mathrm{mg} / \mathrm{L})\end{array}$ & $\begin{array}{c}\text { VSS } \\
(\mathrm{mg} / \mathrm{L})\end{array}$ & $\begin{array}{c}\text { FSS } \\
(\mathrm{mg} / \mathrm{L})\end{array}$ & VSS/TSS \\
\hline Jun-07 & 1 & 7025 & 5100 & 1925 & 0.725979 & 4225 & 2825 & 1400 & 0.668639 \\
\hline Jun-09 & 3 & 7025 & 5100 & 1925 & 0.725979 & 4225 & 2825 & 1400 & 0.668639 \\
\hline Jun-12 & 6 & 7025 & 5100 & 1925 & 0.725979 & 4225 & 2825 & 1400 & 0.668639 \\
\hline Jun-13 & 7 & 7050 & 5300 & 1750 & 0.751773 & 4000 & 2725 & 1275 & 0.68125 \\
\hline Jun-14 & 8 & 7050 & 5300 & 1750 & 0.751773 & 4000 & 2725 & 1275 & 0.68125 \\
\hline Jun-16 & 10 & 7050 & 5300 & 1750 & 0.751773 & 4000 & 2725 & 1275 & 0.68125 \\
\hline Jun-18 & 12 & 7050 & 5300 & 1750 & 0.751773 & 4000 & 2725 & 1275 & 0.68125 \\
\hline Jun-19 & 13 & 7050 & 5300 & 1750 & 0.751773 & 4100 & 2500 & 1600 & 0.609756 \\
\hline Jun-21 & 15 & 7575 & 5525 & 2050 & 0.729373 & 4100 & 2500 & 1600 & 0.609756 \\
\hline \multicolumn{2}{|c|}{ Average } & 7100 & 5258.333 & 1841.667 & 0.740686 & 4097.222 & 2708.333 & 1388.889 & 0.661159 \\
\hline \multicolumn{2}{|c|}{ SD } & 168.32508 & 131.2335 & 108.6534 & 0.012434 & 98.20928 & 119.6058 & 125.339 & 0.028022 \\
\hline
\end{tabular}




\section{A6: COD Destruction Results}

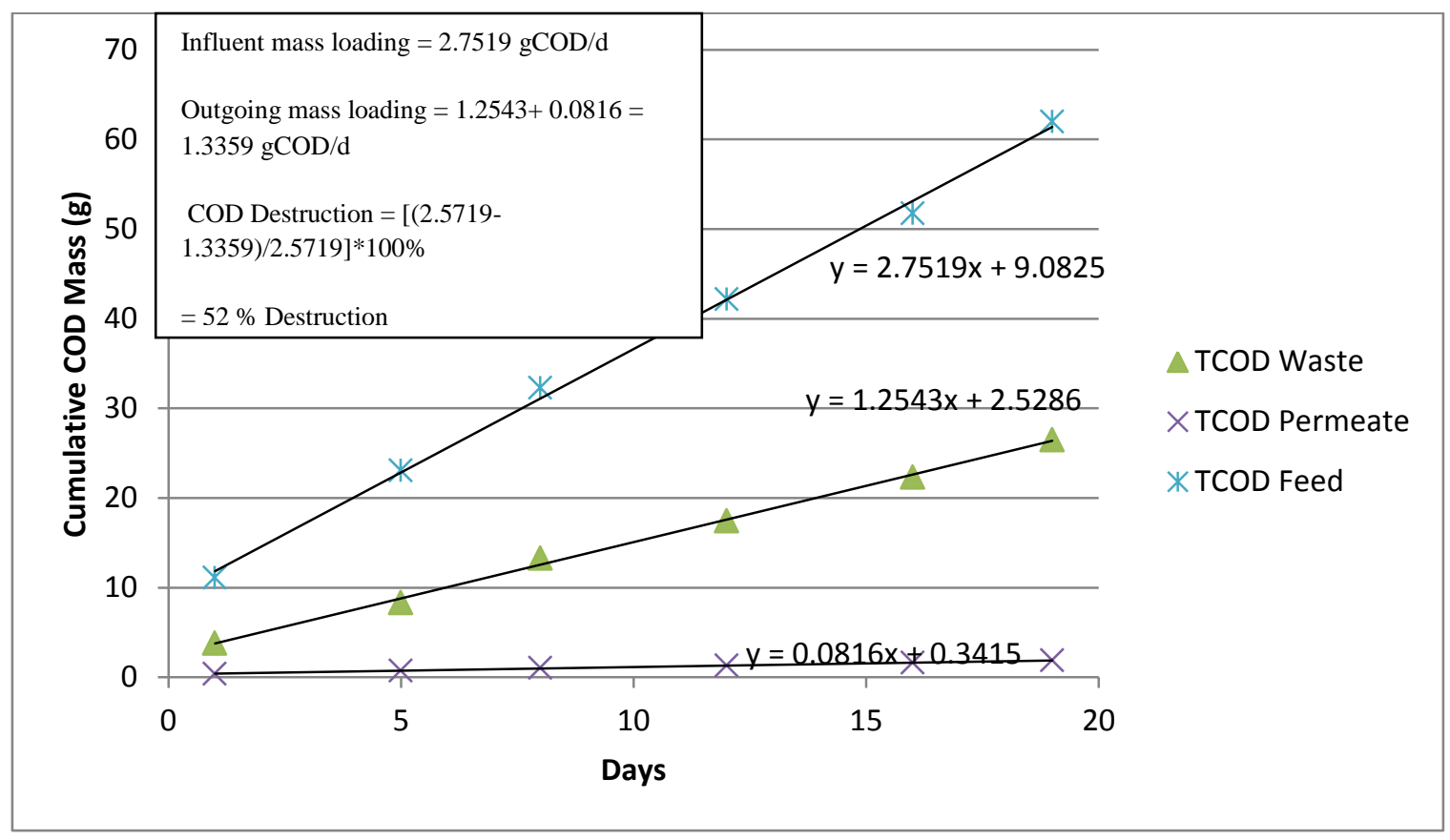

Figure A6.1: Phase 2 COD Destruction

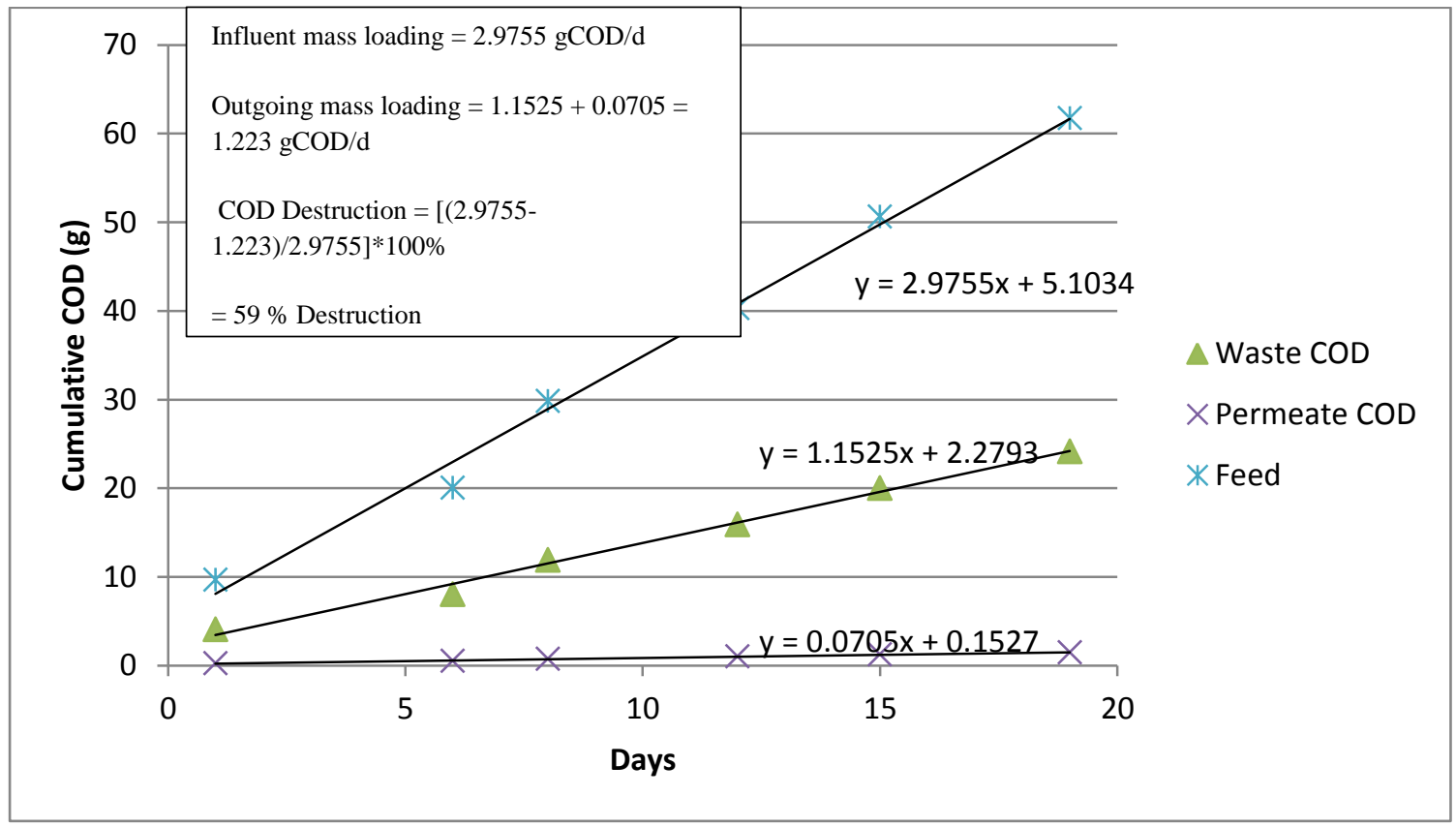

Figure A6.2: Phase 3 COD Destruction 


\section{A7: Solids Destruction Results}

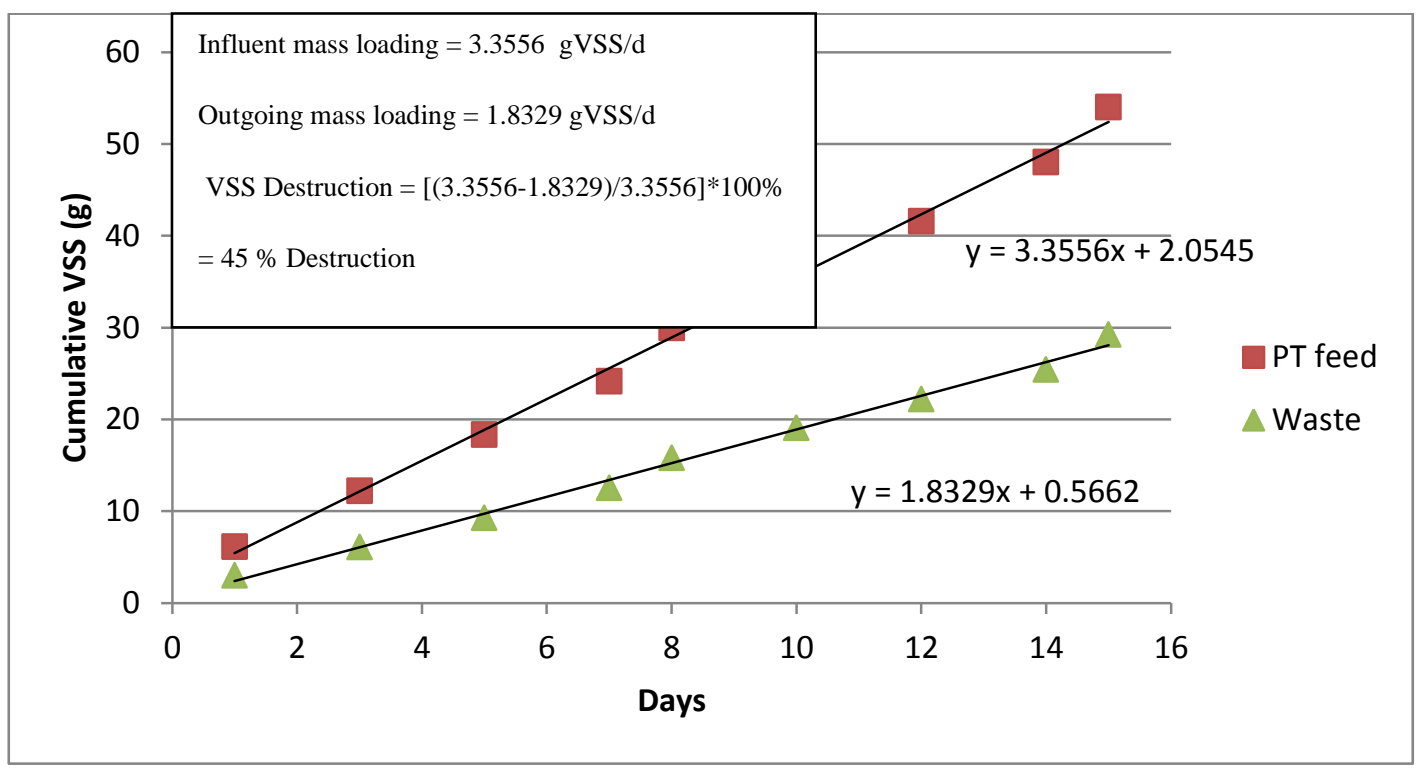

Figure A7.1: Phase 2 Solids Destruction

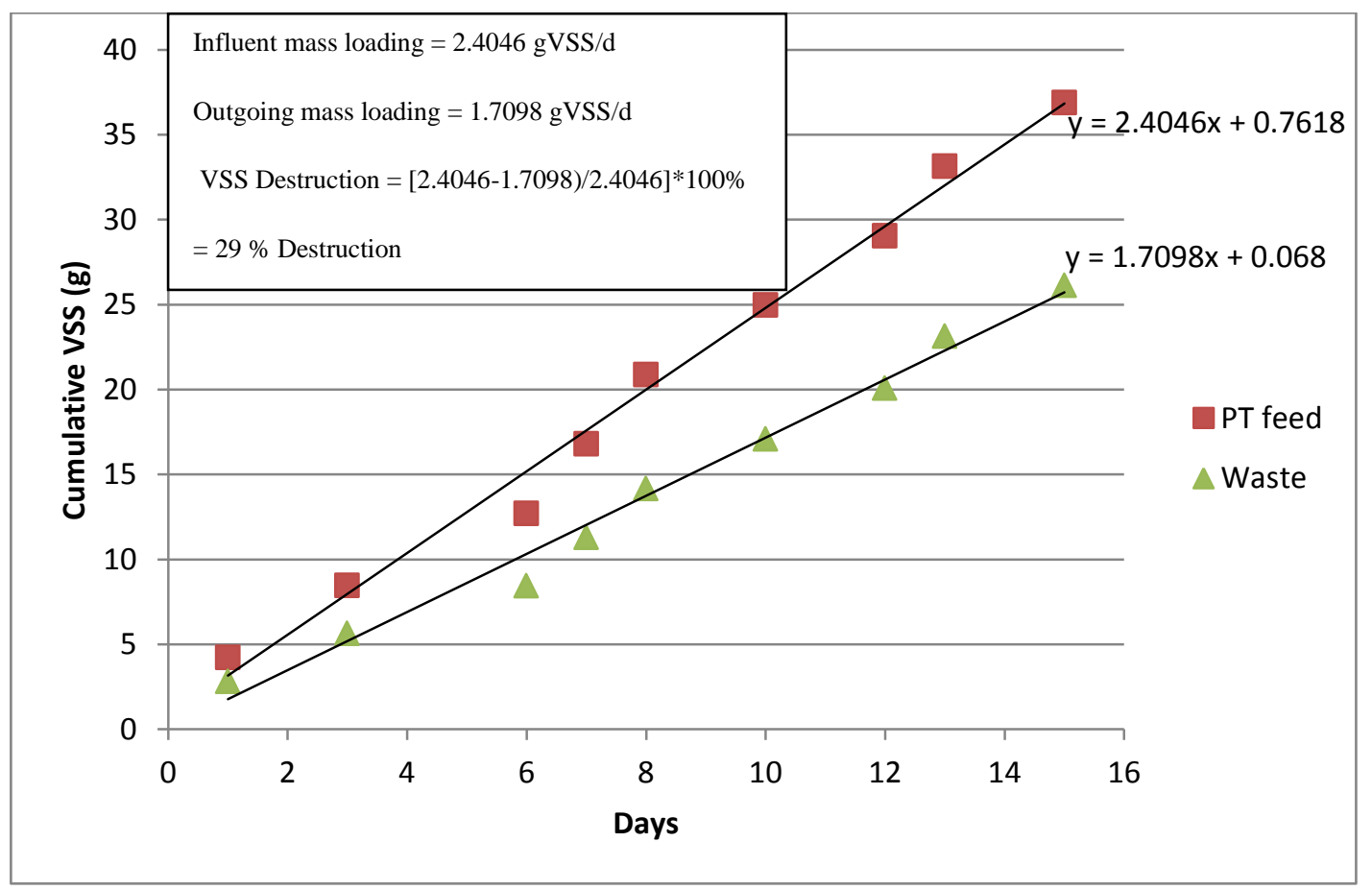

Figure A7.2: Phase 2 Solids Destruction 


\section{A8: ON Destruction Results}

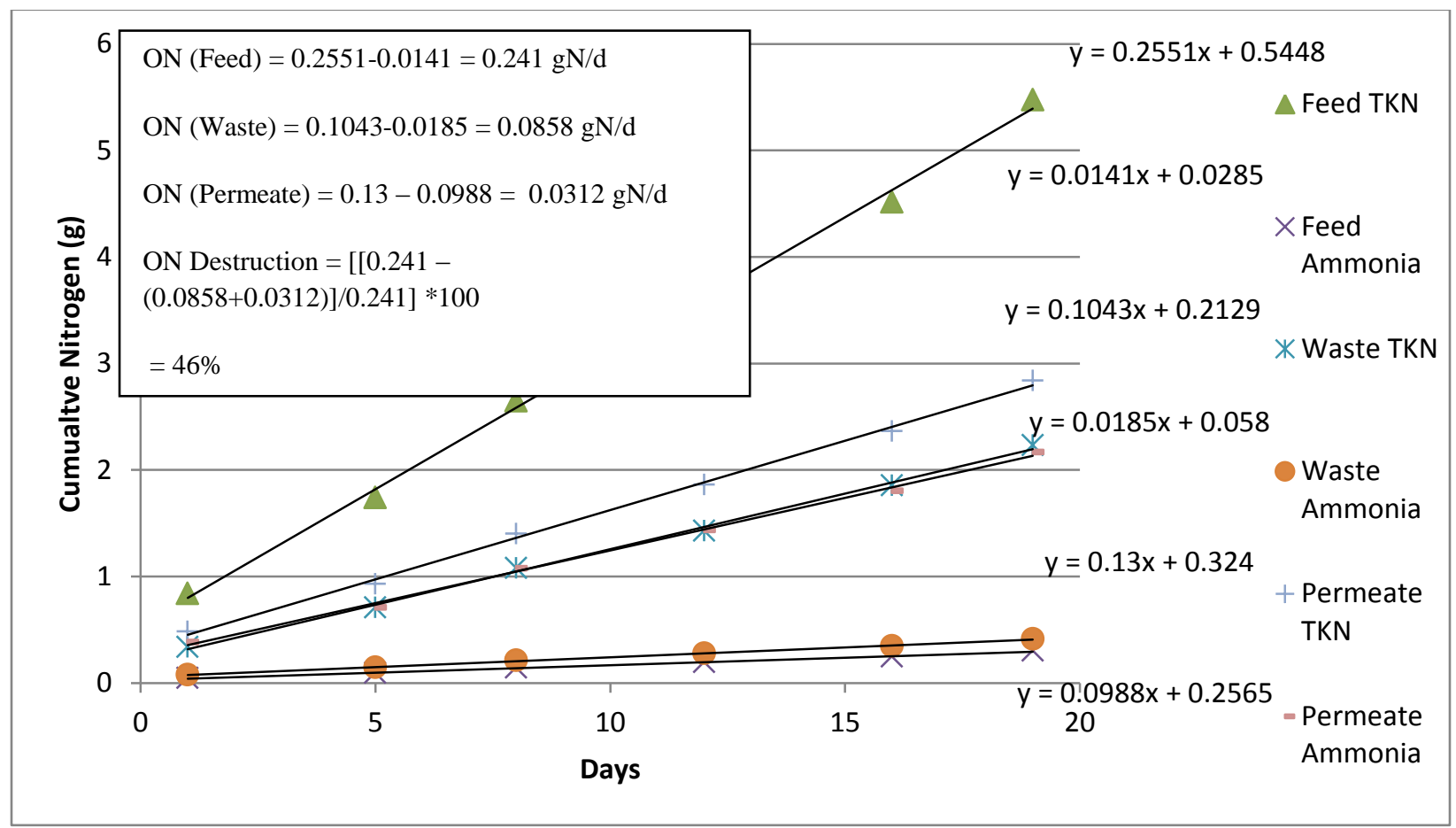

Figure A8.1: ON Destruction for Phase 2

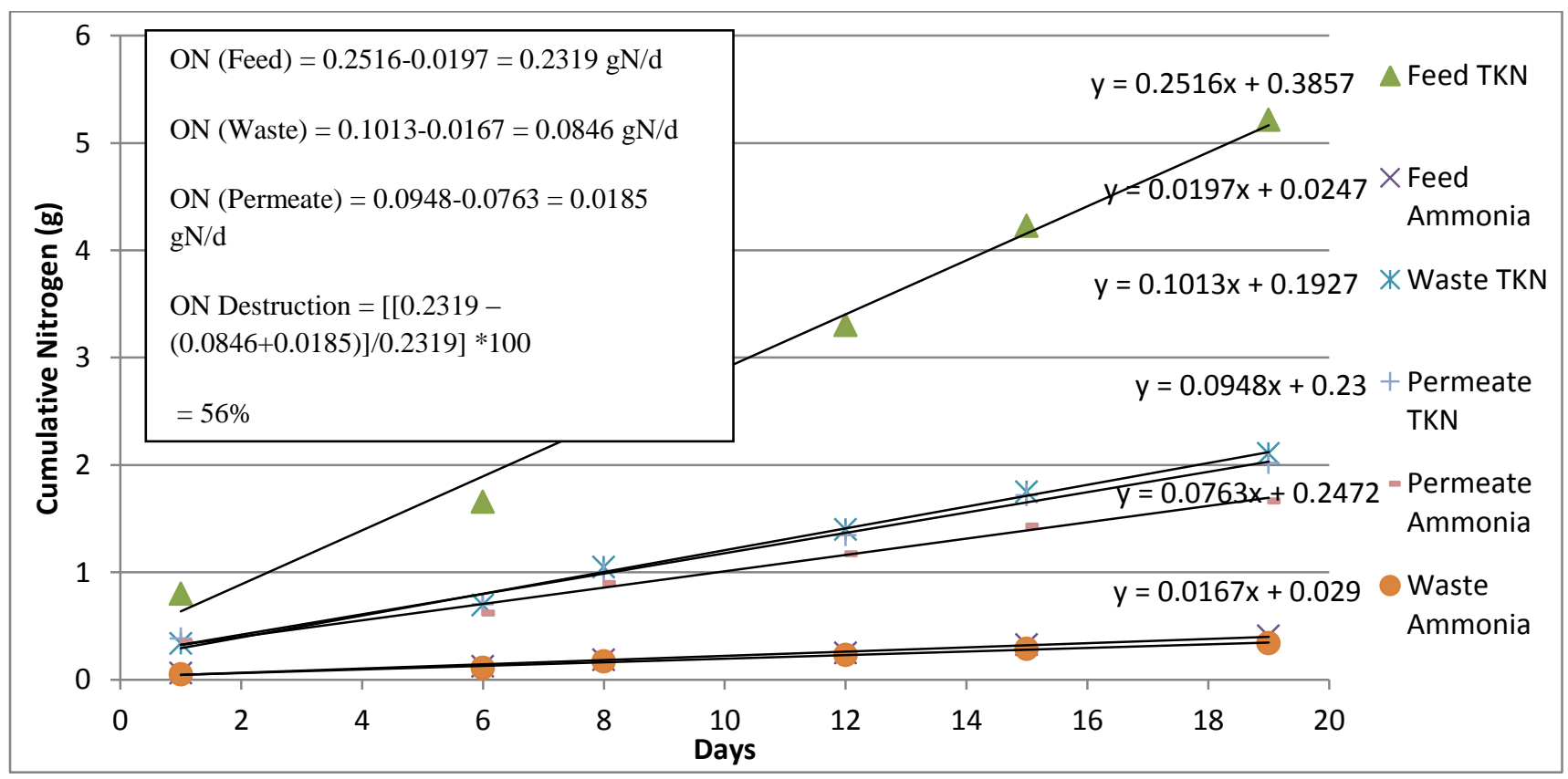

Figure A8.2: ON Destruction for Phase 3 


\section{A9: COD Decay Tests for Phase 2 and Phase 3}

Table A9.1: COD Decay Data for Phase 2

\begin{tabular}{|c|c|c|c|c|}
\hline Time (hr) & T1 & T2 & Phase 3 Avg & SD \\
\hline 0 & 82.305 & 79.863 & 81.084 & 1.221 \\
\hline 5 & 65.305 & 62.324 & 63.8145 & 1.4905 \\
\hline 10 & 63.163 & 58.992 & 61.0775 & 2.0855 \\
\hline 15 & 62.945 & 60.196 & 61.5705 & 1.3745 \\
\hline 20 & 62.566 & 60.59 & 61.578 & 0.988 \\
\hline 24 & 64.131 & 62.441 & 63.286 & 0.845 \\
\hline COD Change & 0.2208128 & 0.2181486 & 0.219480705 & 0.0013321 \\
\hline
\end{tabular}

Table A9.2: COD Decay Data for Phase 3

\begin{tabular}{|c|c|c|c|c|}
\hline Time (hr) & T1 & T2 & Phase 2 Avg & SD \\
\hline 0 & 88.408 & 82.653 & 85.5305 & 2.8775 \\
\hline 5 & 76.105 & 70.07 & 73.0875 & 3.0175 \\
\hline 10 & 66.171 & 63 & 64.5855 & 1.5855 \\
\hline 15 & 73.989 & 67.26 & 70.6245 & 3.3645 \\
\hline 20 & 73.732 & 68.44 & 71.086 & 2.646 \\
\hline 24 & 72.954 & 70.283 & 71.6185 & 1.3355 \\
\hline COD Change & 0.1748032 & 0.1496618 & 0.162232512 & 0.0125707 \\
\hline
\end{tabular}


A10: Critical Flux Tests for Phase 2 and Phase 3

Table A10.1: Critical Flux Test for Phase 2

\begin{tabular}{|c|c|c|c|}
\hline Time (mins) & $\begin{array}{c}\text { Flux } \\
(\text { LMH) }\end{array}$ & $\begin{array}{c}\text { Average } \\
\text { TMP }\end{array}$ & SD \\
\hline 10 & 2.75 & 3.979 & 0.089 \\
\hline 22 & 5.99 & 8.315 & 0.115 \\
\hline 34 & 11.99 & 74.3535 & 0.3665 \\
\hline 46 & 17.99 & 82.29 & 0.06 \\
\hline 58 & 23.98 & 85.0885 & 0.2285 \\
\hline 70 & 17.99 & 83.9625 & 0.3625 \\
\hline 82 & 11.99 & 79.555 & 0.055 \\
\hline 94 & 5.99 & 46.85 & 1 \\
\hline 106 & 2.75 & 4.675 & 0.075 \\
\hline
\end{tabular}

Table A10.2: Critical Flux Test for Phase 3

\begin{tabular}{|c|c|c|c|}
\hline Time (mins) & Flux (LMH) & Average TMP & SD \\
\hline 10 & 2.75 & 4.84 & 0.08 \\
\hline 22 & 5.99 & 10.495 & 0.395 \\
\hline 34 & 11.99 & 81 & 0.2 \\
\hline 46 & 17.99 & 85.75 & 0.15 \\
\hline 58 & 23.98 & 87.88 & 0.19 \\
\hline 70 & 17.99 & 86.25 & 0.35 \\
\hline 82 & 11.99 & 83.05 & 0.65 \\
\hline 94 & 5.99 & 52.5 & 1 \\
\hline 106 & 2.75 & 11.15 & 0.35 \\
\hline
\end{tabular}

